\title{
CONTRIBUIÇÕES À MODELAGEM NUMÉRICA DE ALVENARIA ESTRUTURAL
}

\section{SUZANA CAMPANA PELETEIRO}

Tese apresentada à Escola de Engenharia de São Carlos, da Universidade de São Paulo, como parte dos requisitos para a obtenção de título de Doutor em Engenharia de Estruturas.

ORIENTADOR: Prof. Dr. Márcio Roberto Silva Corrêa

São Carlos

2002 
Aos meus pais -

Alcibei e Maria Ozilia -, irmãos -

Ubiratan e Guilherme e sobrinho -

Guilherme. 


\section{AGRADECIMENTOS}

A Deus, por tudo.

Ao Prof. Dr. Márcio Roberto Silva Corrêa, muito mais do que pela orientação, mas pela amizade, empenho, dedicação, paciência e incentivo, não só durante a realização deste trabalho, mas por todos esses anos de convivência.

Ao amigo Rivelli da Silva Pinto, não só pela amizade, mas pelo incentivo e apoio imprescindíveis para a realização desse trabalho.

Ao Prof. Dr. Marcio Antonio Ramalho, pela amizade e incentivo.

Aos amigos da TECSOF - Engenharia de Estruturas, em especial à amiga Valéria Perassoli, pelo apoio e amizade inestimáveis.

Aos amigos Fabiana Lopes e Edgard, pela amizade e constante incentivo desde o mestrado.

A Kristiane, Osvaldo e Vanessa, que sempre estiveram presentes com sua amizade nos momentos que necessitei.

Ao Valentim e à Andréa Juste, pelo auxílio e informações concedidas durante a realização do trabalho e pela amizade.

Aos amigos que fiz durante o mestrado e o doutorado: Aline, Ana C., Anamaria, Ana Rita, Andréa, Ângela, Crés, Cristina Vidigal, Daniel, Fabiana Mamede, Felício, Joel, Juliana, Luciana, Mônica, Rejane, Richard, Tatiana Almeida, Tatiana Dumet.

Aos professores, colegas e funcionários do Departamento de Engenharia de Estruturas da Escola de Engenharia de São Carlos, pela colaboração. Especialmente a Rosi e a Nadir.

Ao Conselho Nacional de Desenvolvimento Científico e Tecnológico CNPq, pela bolsa concedida. 


\section{SUMÁRIO}

Lista de figuras......................................................................... i

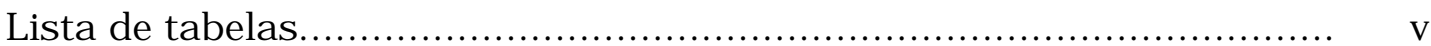

Lista de abreviaturas e siglas........................................................ vi

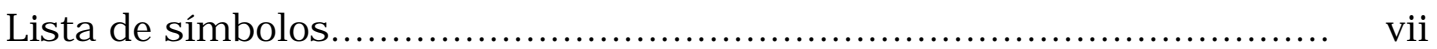

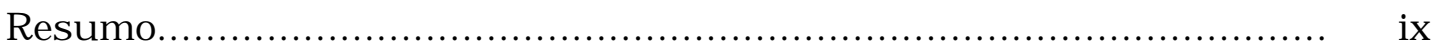

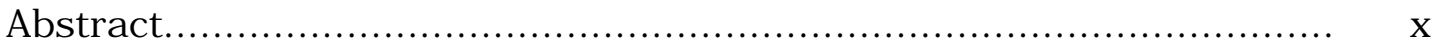

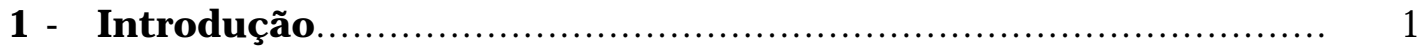

1.1 - Considerações preliminares.............................................. 1

1.2 - Objetivos e metodologia.................................................... 3

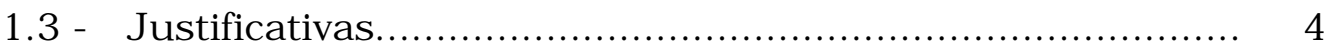

1.4 - Resumo dos capítulos..................................................... 5

2 - Revisão dos critérios de resistência utilizados na alvenaria estrutural

2.1 - Propriedades do material.....................................................

2.1.1 - Micro e macro modelagem.............................................. 7

2.1.2 -Mecanismos de ruptura................................................ 10

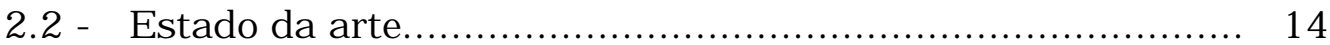

2.2.1 - Modelos discretos.................................................... 14

2.2.2 - Modelos homogeneizados......................................... 25

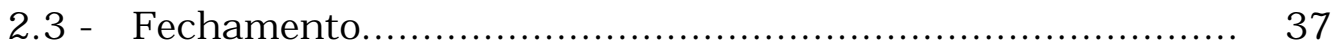

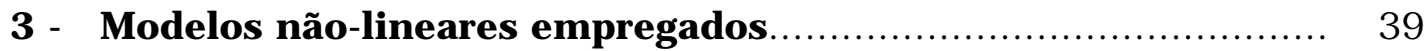

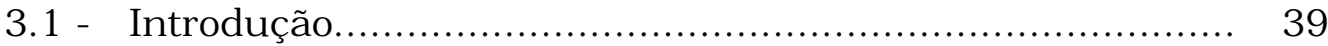

3.1.1 - Modelos para materiais frágeis (ANSYS)......................... 39

3.1.2 - Modelo elastoplástico clássico (ABAQUS/Standard)......... 43

3.1.3 - Modelo elastoplástico para o concreto

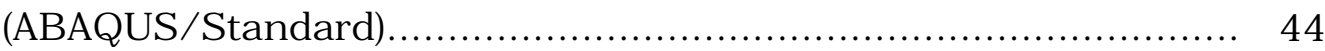

3.1.4 - Modelo para materiais frágeis (ABAQUS/Explicit)............ 47 
4 - Modelagem do volume padrão de parede

4.1 - Generalidades......................................................... 53

4.2 - Determinação das características elásticas da alvenaria..... 54

4.3 - Estudo linear do material ortotrópico equivalente............. 58

4.3.1 - Exemplo 1 - Força horizontal uniformemente distribuída 58

4.3.2 - Exemplo 2 - Força vertical uniformemente distribuída.... 65

4.4 - Fechamento........................................................... 69

5 - Aferição dos modelos não lineares para alvenaria submetida à

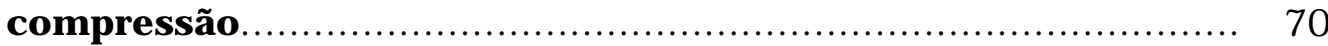

5.1 - Considerações preliminares......................................... 70

5.2 - Exemplo................................................................... 70

5.3 - Fechamento......................................................... 81

6 - Estudo de interação de paredes........................................ 82

6.1 - Introdução........................................................... 82

6.2 - Análise de interação de paredes................................... 82

6.2.1 - Análise experimental e análise numérica.................... 82

6.2 .2 - Deslocamentos verticais....................................... 86

6.2 .3 - Tensões normais verticais..................................... 91

6.2.4 - Deformação........................................................ 94

6.3 - Fechamento.................................................... 99

7 - Modelagem de paredinhas comprimidas............................ 100

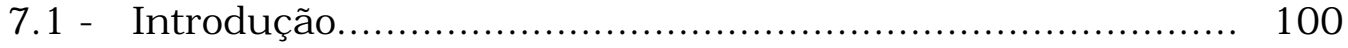

7.2 - Trabalho experimental............................................... 101

7.3 - Análise numérica.................................................... 104

7.4 - Comparação entre as análises numéricas e experimentais.. 108

7.4.1 - Parede PAB1A2.................................................. 108

7.4.2 - Parede PAB1A1 ................................................... 113 
7.4.3 - Parede PAB2A1 ..................................................... 117

7.4 .4 - Parede PAB2A2 .................................................. 122

7.5 - Fechamento......................................................... 126

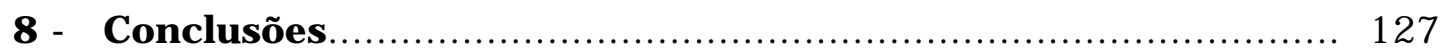

Referências Bibliográficas.............................................. 136 
Figura 2.1 - Técnicas de modelagem da alvenaria: (a) Exemplar da alvenaria; (b) Micromodelagem; (c) Micromodelagem simplificada; (d) Macromodelagem

Figura 2.2 - Mecanismos de ruptura: (a) Fissuras nas juntas;

(b) Escorregamento; (c) Fissuração das unidades;

(d) Fissura diagonal; (e) Fendilhamento

Figura 2.3 - Comportamento típico de materiais frágeis submetidos à carregamento uniaxial e definição da energia de fratura:

(a) tração; (b) compressão.

Figura 2.4 - Homogeneização em duas etapas

Figura 2.5 - Critério de resistência proposto. Diferentes valores de resistência à tração e compressão são adotados em cada um dos eixos dos materiais.

Figura 3.1 - Comportamento uniaxial do modelo

Figura 3.2 - Superfície de ruptura em três dimensões

Figura 3.3 - Superficie de ruptura em duas dimensões

Figura 3.4 - Superfície de ruptura no plano $p-q$

Figura 3.5 - Comportamento uniaxial do modelo

Figura 3.6 - Superfície de ruptura no estado plano de tensões

Figura 3.7 - Critério de Rankine no plano desviador 50

Figura 3.8 - Critério de Rankine no plano $p-q \quad 51$

Figura 3.9 - Critério de Rankine no estado plano de tensões 51

Figura 4.1 - Célula típica da alvenaria 54

Figura 4.2 - Discretização da célula 55

Figura 4.3 - Gráfico da relação $\mathrm{E}_{\mathrm{x}} / \mathrm{E}_{\mathrm{b}} \mathrm{x}$ Espessura da Argamassa 56

Figura 4.4 - Gráfico da relação $\mathrm{E}_{\mathrm{y}} / \mathrm{E}_{\mathrm{b}} \mathrm{x}$ Espessura da Argamassa $\quad 57$

Figura 4.5 - Gráfico da relação $\mathrm{E}_{\mathrm{x}} / \mathrm{E}_{\mathrm{y}} \mathrm{x}$ Espessura da Argamassa $\quad 57$

Figura 4.6 - Caso de Carregamento $1 \quad 59$

Figura 4.7 - Deslocamentos: (a) micromodelo; (b) homogeneização numérica; (c) homogeneização PANDE et al. 60

Figura 4.8 - Tensões $\sigma_{\mathrm{x}}$ : (a) micromodelo; (b) homogeneização numérica; (c) homogeneização PANDE et al.

Figura 4.9 - Tensões $\sigma_{y}$ : (a) micromodelo; (b) homogeneização numérica;(c) homogeneização PANDE et al. 
Figura 4.10 - Tensões $\tau_{\mathrm{xy}}$ : (a) micromodelo; (b) homogeneização numérica; (c) homogeneização PANDE et al.

Figura 4.11 - Tensão $\sigma_{\mathrm{y}}$ próxima ao ponto de aplicação da força (micromodelo)

Figura 4.12 - Tensão Vertical na Parede $(y=274) \quad 64$

Figura 4.13 - Tensão Vertical na Parede $(y=305)$

Figura 4.14 - Caso de Carregamento $2 \quad 65$

Figura 4.15 - Deslocamentos: (a) micromodelo plano; (b) micromodelo sólido; $\quad$ (c) homogeneização numérica; (d) homogeneização PANDE et al.

Figura 4.16 - Tensão Vertical na Parede $(y=274) \quad 67$

Figura 4.17 - Tensão Vertical na Parede $(y=305) \quad 68$

Figura 4.18 - Tensão de Cisalhamento na Parede $(\mathrm{y}=274)$

Figura 4.19 - Tensão de Cisalhamento na Parede (y=305) 69

$\begin{array}{lll}\text { Figura 5.1 - Tensão x Deformação do artefato bloco } & 71\end{array}$

Figura 5.2 - Tensão x Deformação da argamassa 72

$\begin{array}{ll}\text { Figura } 5.3 \text { - Superfície de ruptura } & 72\end{array}$

Figura 5.4 - Representação do amolecimento à tração 73

$\begin{array}{ll}\text { Figura } 5.5 \text { - Prisma ensaiado } & 74\end{array}$

Figura 5.6 - Gráfico Força x Deformação 75

Figura 5.7 - Detalhe do gráfico Força x Deformação 76

$\begin{array}{ll}\text { Figura } 5.8 \text { - Parede ensaiada } & 77\end{array}$

$\begin{array}{ll}\text { Figura } 5.9 \text { - Gráfico Força de ruptura x Área carregada } & 77\end{array}$

Figura 5.10 - Tensões transversais em uma parede sólida submetida a $\begin{array}{ll}\text { uma força concentrada } & 78\end{array}$

$\begin{array}{ll}\text { Figura 5.11 - Padrão de ruptura } & 79\end{array}$

Figura 5.12 - Gráfico da tensão vertical $\left(\sigma_{\mathrm{y}}\right)$ ao longo da altura da 80 parede

Figura 5.13 - Gráfico tensão transversal $\left(\sigma_{\mathrm{x}}\right)$ ao longo da altura da $\begin{array}{ll}\text { parede } & 80\end{array}$

Figura 6.1 - Esquema de amarração das paredes 83

Figura 6.2 - Painel de alvenaria 83

Figura 6.3 - Instrumentação dos Painéis 84

Figura 6.4 - Discretização do painel 85

Figura 6.5 - Deslocamentos verticais na direção $2(\mathrm{~cm}) \quad 89$

Figura 6.6 - Deslocamentos verticais ao longo da altura da parede $(\mathrm{F}=280 \mathrm{kN}) \quad 90$ 
Figura 6.7 - Deslocamentos verticais ao longo da altura da parede $(\mathrm{F}=400 \mathrm{kN})$

Figura 6.8 - Deslocamentos verticais ao longo da altura da parede $(\mathrm{F}=425 \mathrm{kN})$

Figura 6.9 - Tensões normais verticais $-\sigma_{22}\left(\mathrm{kN} / \mathrm{cm}^{2}\right)$

Figura 6.10 - Tensões normais verticais ao longo da altura da parede $(\mathrm{F}=280 \mathrm{kN})$

Figura 6.11 - Tensões normais verticais ao longo da altura da parede $(\mathrm{F}=400 \mathrm{kN})$

Figura 6.12 - Tensões normais verticais ao longo da altura da parede $(\mathrm{F}=425 \mathrm{kN})$

Figura 6.13 - Comportamento típico do trecho inferior da alma

Figura 6.14 - Comportamento típico do trecho inferior da flange 95

Figura 6.15 - Comportamento típico do trecho superior da alma 96

Figura 6.16 - Comportamento típico do trecho superior da flange $\quad 97$

Figura 6.17 - Diagrama tensão x deformação típico do trecho superior 97

Figura 6.18 - Diagrama tensão x deformação típico do trecho inferior 98

Figura 6.19 - Deformações plásticas verticais $\left(\varepsilon_{\mathrm{p} 22}\right) \quad 99$

Figura 7.1 - Posição dos transdutores na paredinha (medidas em $\mathrm{mm})$

103

Figura 7.2 - Discretização da paredinha 105

$\begin{array}{ll}\text { Figura } 7.3 \text { - Forma de ruptura típica (PAB1A2) } & 109\end{array}$

Figura 7.4 - Tensão principal máxima (PAB1A2) 110

Figura 7.5 - Tensão normal horizontal $\sigma_{11}$ (PAB1A2) 110

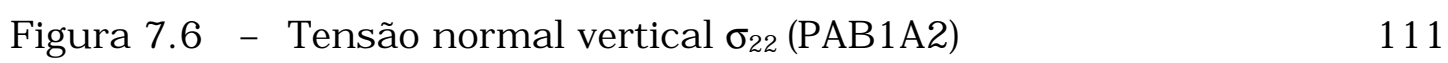

Figura 7.7 - Tensão equivalente de von Mises (PAB1A2) 111

Figura 7.8 - Gráfico Tensão x Deformação (PAB1A2) 112

$\begin{array}{lr}\text { Figura } 7.9 \text { - Forma de ruptura típica (PAB1A1) } & 113\end{array}$

$\begin{array}{ll}\text { Figura 7.10 - Tensão principal máxima (PAB1A1) } & 114\end{array}$

Figura 7.11 - Tensão normal horizontal $\sigma_{11}$ (PAB1A1) 115

Figura 7.12 - Tensão normal vertical $\sigma_{22}$ (PAB1A1) 115

Figura 7.13 - Tensão equivalente de von Mises (PAB1A1) 116

$\begin{array}{ll}\text { Figura 7.14 - Gráfico Tensão x Deformação (PAB1A1) } & 117\end{array}$

$\begin{array}{ll}\text { Figura 7.15 - Forma de ruptura típica (PAB2A1) } & 118\end{array}$

Figura 7.16 - Tensão principal máxima (PAB2A1) 119

Figura 7.17 - Tensão normal horizontal $\sigma_{11}$ (PAB2A1) 119

$\begin{array}{ll}\text { Figura } 7.18 \text { - Tensão normal vertical } \sigma_{22}(\mathrm{PAB} 2 \mathrm{~A} 1) & 120\end{array}$ 
Figura 7.19 - Tensão equivalente de von Mises (PAB2A1) 120

Figura 7.20 - Gráfico Tensão x Deformação (PAB2A1) 121

Figura 7.21 - Forma de ruptura típica (PAB2A2) 122

$\begin{array}{ll}\text { Figura } 7.22 \text { - Tensão principal máxima (PAB2A2) } & 123\end{array}$

Figura 7.23 - Tensão normal horizontal $\sigma_{11}$ (PAB2A2) 123

$\begin{array}{ll}\text { Figura } 7.24 \text { - Tensão normal vertical } \sigma_{22} \text { (PAB2A2) } & 124\end{array}$

Figura 7.25 - Tensão equivalente de von Mises (PAB2A2) 124

Figura 7.26 - Gráfico Tensão x Deformação (PAB2A2) 125 
Tabela 4.1 - Propriedades Ortotrópicas $\quad 59$

Tabela 4.2 - Porcentagem de erro em relação ao micro-modelo 63

Tabela 5.1 - Propriedades dos componentes dos materiais 71

Tabela 6.1 - Propriedades dos componentes 85

Tabela 6.2 - Deslocamentos relativos verticais numéricos e experimentais $(\mathrm{F}=280 \mathrm{kN}) \quad 87$

Tabela 6.3 - Deslocamentos relativos verticais numéricos e experimentais $(\mathrm{F}=400 \mathrm{kN}) \quad 88$

Tabela 6.4 - Deslocamentos relativos verticais numéricos e experimentais $(\mathrm{F}=425 \mathrm{kN}) \quad 88$

Tabela 7.1 - Valores médios de resistência à compressão dos blocos 101

Tabela 7.2 - Valores médios dos módulos de elasticidade dos blocos 102

Tabela 7.3 - Valores médios de resistência à compressão das $\begin{array}{ll}\text { argamassas } & 102\end{array}$

Tabela 7.4 - Valores dos módulos de elasticidade das argamassas 103

Tabela 7.5 - Resistência à compressão das paredinhas 104

$\begin{array}{ll}\text { Tabela } 7.6 \text { - Propriedades dos componentes } & 107\end{array}$

Tabela 7.7 - Resistência à compressão parede PAB1A2 109

Tabela 7.8 - Resistência à compressão parede PAB1A1 113

Tabela 7.9 - Resistência à compressão parede PAB2A1 118

Tabela 7.10 - Resistência à compressão parede PAB2A2 122 


\section{LISTA DE ABREVIATURAS E SIGLAS}

$\begin{array}{ll}\mathrm{A}_{b} & \text { Área bruta } \\ \mathrm{A}_{1} & \text { Área líquida } \\ \mathrm{A} 1 & \text { Argamassa com traço 1:0,5:4,5 } \\ \mathrm{A} 2 & \text { Argamassa com traço } 1: 1: 6 \\ \mathrm{ABNT} & \text { Associação Brasileira de Normas Técnicas } \\ \mathrm{CP} & \text { Corpo de prova } \\ \mathrm{BS} & \text { British Standards Institution } \\ \text { B1 } & \text { Bloco de concreto com resistência à compressão nominal de } \\ & 4,5 \text { MPa } \\ \text { B2 } & \text { Bloco de concreto com resistência à compressão nominal de } \\ & \text { 12 MPa } \\ \text { EPUSP } & \text { Escola Politécnica da Universidade de São Paulo } \\ \text { EESC } & \text { Escola de Engenharia de São Carlos } \\ \text { EF } & \text { Ensaios finais } \\ \text { NBR } & \text { Norma Brasileira Registrada } \\ \text { SET } & \text { Departamento de Engenharia de Estruturas } \\ \text { USP } & \text { Universidade de São Paulo } \\ 2 D & \text { Bidimensional } \\ \text { 3D } & \text { Tridimensional }\end{array}$




\section{LISTA DE SÍMBOLOS}

$\mathrm{a}_{0} \quad$ Razão entre a resistência à compressão biaxial e a uniaxial

$\mathrm{cm}$ Centímetros

$\mathrm{cm}^{2} \quad$ Centímetros quadrados

E Módulo de elasticidade

$\mathrm{E}_{\mathrm{a}} \quad$ Módulo de elasticidade da argamassa

$\mathrm{E}_{\mathrm{b}} \quad$ Módulo de elasticidade do bloco

$\mathrm{E}_{\mathrm{x}} \quad$ Módulo de elasticidade na direção $\mathrm{x}$

$\mathrm{E}_{\mathrm{y}} \quad$ Módulo de elasticidade na direção y

$\mathrm{f}_{\mathrm{a}} \quad$ Resistência à compressão da argamassa

$\mathrm{f}_{\mathrm{am}} \quad$ Resistência à compressão média da argamassa

$\mathrm{f}_{\mathrm{b}} \quad$ Resistência à compressão do bloco

$\mathrm{f}_{\mathrm{c}} \quad$ Resistência uniaxial ao esmagamento

$\mathrm{F}_{\mathrm{c}} \quad$ Equação da superfície de compressão do critério (ABAQUS)

$\mathrm{f}_{\mathrm{bm}} \quad$ Resistência média à compressão do bloco

$\mathrm{f}_{\text {cpa }}$ Resistência à compressão d parede

$\mathrm{f}_{\mathrm{pa}} \quad$ Resistência à compressão da paredinha

$\mathrm{f}_{\mathrm{pam}}$ Resistência à compressão média da paredinha

$\mathrm{F}_{\text {rup }}$ Força de ruptura à compressão

$\mathrm{f}_{\mathrm{t}} \quad$ Resistência uniaxial à tração

$\mathrm{H}_{\mathrm{b}} \quad$ Altura do bloco

$\mathrm{J}_{2} \quad$ Segundo invariante da parte deviatórica do tensor de tensões

$\mathrm{kN}$ Quilonewton

$\mathrm{L}_{\mathrm{b}} \quad$ Largura do bloco

m Metro

$\mathrm{m}^{3} \quad$ Metro cúbico

p Tensão média

q Tensão equivalente de von Mises

MPa Megapascal

S Superficie de ruptura

$v_{\mathrm{a}} \quad$ Coeficiente de Poisson da argamassa

$v_{\mathrm{b}} \quad$ Coeficiente de Poisson da unidade 
$v_{\mathrm{xy}} \quad$ Coeficiente de Poisson

$\varepsilon_{\mathrm{cu}} \quad$ Deformação última à compressão

$\varepsilon_{\mathrm{e}} \quad$ Deformação elástica

$\sigma_{1}, \sigma_{2}, \sigma_{3} \quad$ Tensões principais

$\sigma_{11}$ Tensão na direção $1^{*}$

$\sigma_{22}$ Tensão na direção $2^{*}$

$\sigma_{33}$ Tensão na direção $3^{*}$

$\sigma_{\mathrm{c}}$ Tensão de resistência à compressão

$\sigma_{\mathrm{t}} \quad$ Tensão de resistência à tração

$\sigma \quad$ Tensão

$\sigma_{\mathrm{x}}$ Tensão na direção $\mathrm{x}$

$\sigma_{\mathrm{y}} \quad$ Tensão na direção y

$\sigma_{z} \quad$ Tensão na direção $z$

$\tau_{\mathrm{C}} \quad$ Tensão de resistência num estado de cisalhamento puro

$\tau_{\mathrm{xy}} \quad$ Tensão de cisalhamento no plano xy

* Direções 1,2 e 3 não são necessariamente principais. 
PELETEIRO, SUZANA C. (2002). Contribuições à modelagem numérica de alvenaria estrutural. São Carlos, 2002. 143p. Tese (Doutorado) - Escola de Engenharia de São Carlos, Universidade de São Paulo.

Uma das áreas da engenharia civil que têm apresentado maior potencial de crescimento é a execução de edifícios em alvenaria estrutural. Usualmente são utilizados procedimentos puramente experimentais para o desenvolvimento dos processos construtivos e de projeto. Entretanto, a experimentação sem uma modelagem teórica prévia pode ser muito dispendiosa. A modelagem numérica, desde que confiável, pode ser de grande ajuda na redução do número de corpos-de-prova a serem ensaiados e do número de pontos a serem instrumentados, bem como o seu devido posicionamento. Isso significa diminuição de custos e maior eficiência na obtenção de resultados.

No presente trabalho apresentam-se as ferramentas computacionais mais adequadas para a análise de alvenaria estrutural submetida a compressão, objetivando o suporte teórico a pesquisas experimentais. Elabora-se um estudo comparativo sobre os vários recursos de modelagem numérica, linear e não-linear, disponíveis em softwares comerciais baseados no Método dos Elementos Finitos.

Inicialmente, após a apresentação do estado da arte, investiga-se a modelagem numérica do volume elementar representativo da alvenaria. Modelos não-lineares são, então, escolhidos, aferindo-os com resultados disponíveis na literatura técnica. São realizadas simulações de casos específicos de paredes de alvenaria submetidas à compressão, assim como a interação de paredes sujeitas a carregamentos verticais. Resultados experimentais são comparados com os produzidos por modelos lineares e não-lineares, focando a análise na sua representatividade e no seu grau de precisão.

Palavras-chave: Alvenaria estrutural, modelagem numérica, análise não-linear, resistência à compressão. 


\section{ABSTRACT}

PELETEIRO, SUZANA C. (2002). Contributions to the numerical analysis of masonry. São Carlos, 2002. 143p. Tese (Doutorado) - Escola de Engenharia de São Carlos, Universidade de São Paulo.

The construction of structural masonry buildings has been one of the most increasing civil engineering areas. The development of building and design methods usually is based only on experiments. However, testing without previous numerical analysis can be very expensive. Numerical modeling, since reliable, can be greatly helpful for reducing the number of experimental tests and the number of instrumented points, including the improvement of their positions. That enables smaller costs and higher efficiency in obtaining the results.

The present work deals with the most appropriate computational strategies for the analysis of masonry walls subjected to compression, focusing the theoretical support for experimental research programs. A comparative study is elaborated on the several capabilities of linear and nonlinear numerical models, which are available in commercial computer programs based on the Finite Element Method.

Initially, after the presentation of the state-of-the-art, the numerical analysis of the representative volume masonry element is investigated. Nonlinear models are chosen and confronted with available results in the technical literature. Specific cases of masonry walls submitted to compression are numerical simulated, including the interaction of intersecting walls under vertical loads. Experimental results are compared to those produced by linear and nonlinear numerical modeling, emphasizing their effectiveness and precision.

Keywords: Structural masonry, numerical analysis, nonlinear analysis, compressive strength. 


\section{INTRODUÇÃO}

\subsection{Considerações preliminares}

Desde a Antigüidade a alvenaria tem sido utilizada largamente pelo ser humano em suas habitações, monumentos e templos religiosos. Como exemplos famosos podem ser citados: a pirâmide de Queóps, em que foram utilizados mais de dois milhões de blocos de pedra, o farol de Alexandria, com altura próxima a $190 \mathrm{~m}$ e as grandes catedrais góticas, construídas na Idade Média, com vãos expressivos e arquitetura belíssima realizada com a utilização de arcos e abóbadas.

Apesar do uso intenso da alvenaria, apenas no início do século passado, por volta de 1920, passou-se a estudá-la com base em princípios científicos e experimentação laboratorial, segundo DICKEY \& SCHNEIDER (1994). Esta postura possibilitou o desenvolvimento de teorias racionais que fundamentam a arte de se projetar alvenaria estrutural.

A partir daí, segundo OLIVEIRA JR. (1992), edifícios cujas paredes tinham espessuras exorbitantes $(\sim 1,80 \mathrm{~m})$, como o Monadnock Building construído em Chicago no final do século XIX, cederam lugar a edifícios com paredes mais esbeltas.

Com a utilização do concreto armado e do aço estrutural, que possibilitaram a construção de edifícios com peças de reduzidas dimensões, a utilização da alvenaria dirigiu-se, prioritariamente, às edificações de pequeno porte. 
Na década de 50, a utilização da alvenaria ganhou novo impulso, após a realização de uma série de experimentações na Europa. Em 1951, Paul Haller dimensionou e construiu na Suíça edifício de 13 pavimentos em alvenaria não armada, com paredes internas de $15 \mathrm{~cm}$ de espessura e externas com 37,5 cm, conforme pode ser visto em AMRHEIN (1978). Muitos edifícios foram construídos na Inglaterra, Alemanha e Suíça, e também nos Estados Unidos, em que a alvenaria estrutural passou a ser empregada mesmo em zonas sujeitas a abalos sísmicos, sendo neste caso utilizada a alvenaria armada.

Segundo SABBATINI, no Brasil, após a sua implantação em 1966, quando em São Paulo foram construídos alguns prédios de quatro pavimentos, o desenvolvimento da alvenaria estrutural tem se dado de maneira lenta e reservada. Isso tem ocorrido não obstante o seu caráter econômico, especialmente associado ao fato de se utilizarem as paredes não apenas como elementos de vedação, mas, também, como elementos portantes. Por muitos anos a alvenaria estrutural foi pouco utilizada devido a muitos fatores tais como: preconceito, maior domínio da tecnologia do concreto armado por parte de construtores e projetistas e pouca divulgação do assunto nas universidades durante o processo de formação do profissional. Muitos projetistas são leigos no que diz respeito a este sistema construtivo e acabam, assim, optando pelo concreto armado. Isto é também influenciado pelo reduzido número de publicações sobre o assunto em português, pois a maior parte da bibliografia é estrangeira e voltada para as peculiaridades do país de origem.

Se o projeto de edifícios de alvenaria não obteve um avanço que possa ser comparado ao das estruturas de concreto armado, o mesmo podese dizer de itens isolados do processo construtivo. A verdade é que será necessário um avanço mais significativo, não só de procedimentos de projeto, mas também da própria pesquisa básica em alvenaria. Essa pesquisa é de suma importância inclusive para que se possam melhorar os procedimentos de projeto. Existem sérias lacunas quando se fala do comportamento da alvenaria quanto a alguns aspectos que podem ser considerados básicos, como por exemplo o cisalhamento dos painéis.

Usualmente são utilizados procedimentos puramente experimentais para o estudo desses tópicos. Entretanto, considera-se que a 
experimentação, sem uma modelagem teórica prévia, pode ser muito dispendiosa. A modelagem numérica, desde que confiável, pode ser de grande ajuda na redução do número dos corpos-de-prova a serem ensaiados e no número de pontos a serem instrumentados. Isso significa redução de custos e prazos e maior eficiência na obtenção de resultados.

No Brasil, a pesquisa sobre modelagem matemática de painéis de alvenaria é muito incipiente, na verdade quase inexistente. Alguns poucos trabalhos como LA ROVERRE (1994), CORRÊA \& RAMALHO (1994a) e CORRÊA \& RAMALHO (1994b) representam uma breve introdução ao tema. Entretanto essa linha de pesquisa precisa ser muito desenvolvida, pois é básica para a experimentação que, por sua vez, é fundamental para o desenvolvimento do processo construtivo como um todo.

Com este trabalho, que constitui mais uma etapa de uma série de pesquisas que vêm se encadeando há alguns anos, procurar-se-á contribuir para o aumento do acervo técnico em alvenaria estrutural.

\subsection{Objetivos e metodologia}

O objetivo principal deste trabalho é apresentar as ferramentas computacionais mais adequadas para a análise de alvenaria estrutural a serem utilizadas no suporte teórico a pesquisas experimentais desenvolvidas, de maneira a reduzir os custos e aumentar a eficiência nos ensaios. O trabalho será desenvolvido elaborando-se um estudo sobre os vários recursos de modelagem numérica, linear e não-linear, disponíveis em softwares comerciais.

A metodologia empregada para realização do trabalho pode ser descrita como:

a) Pesquisa bibliográfica para verificar o estado da arte, com análise dos critérios de resistência mais adequados à alvenaria.

b) Modelagem numérica, em elementos finitos, do volume elementar representativo (VER) da alvenaria.

c) Estudo da influência de consideração de modelos utilizando-se elementos planos e tridimensionais. 
d) Estudo da interação de paredes de alvenaria, análise da amarração direta, com utilização de modelos lineares e não lineares.

e) Modelagens de casos específicos de paredes de alvenaria submetidas à compressão. Comparação dos resultados numéricos com resultados obtidos experimentalmente, utilizando-se modelos lineares e não lineares.

\subsection{Justificativas}

Umas das áreas da engenharia civil que tem apresentado maior potencial de crescimento é, sem sombra de dúvida, a execução de edifícios em alvenaria estrutural. Isso se deve principalmente à economia obtida por esse processo construtivo em relação ao concreto convencional, por propiciar uma maior racionalização na execução da obra, reduzindo-se o consumo e o desperdício dos materiais. Essa economia pode chegar a 30\% do valor da estrutura, em casos de edifícios em alvenaria não armada de até oito pavimentos. Dessa forma, as edificações tornam-se mais baratas para o comprador final, havendo uma melhor penetração no mercado, em especial junto às classes média e baixa. Portanto, é evidente o grande benefício social que pode advir do desenvolvimento desse processo construtivo.

Deve-se considerar, entretanto, que conforme foi mencionado em item anterior, o projeto de edifícios de alvenaria estrutural ainda é feito de uma maneira quase empírica, não se tendo verificado para esse campo o desenvolvimento que se observa para as estruturas convencionais em concreto armado. A própria normalização nacional é pobre e um grande esforço precisa ser feito nessa direção para que se possa projetar e executar edifícios mais baratos e seguros. Esse esforço traduz-se em pesquisas voltadas para a realidade brasileira, sem o que se tornará praticamente impossivel desenvolver de forma satisfatória os procedimentos normativos nessa área. É importante ressaltar que, quanto às pesquisas mencionadas, uma dificuldade adicional deve ser considerada: na Europa e nos Estados Unidos, nossos tradicionais "fornecedores" de pesquisas em engenharia civil, os sistemas construtivos adotados são ligeiramente diferentes do ideal 
para o Brasil. Na Europa praticamente só se constrói com tijolos cerâmicos e nos Estados Unidos, devido à ocorrência de sismos, predomina amplamente a alvenaria armada. Já no caso brasileiro, o sistema mais utilizado é a alvenaria parcialmente armada de blocos de concreto ou cerâmicos.

Assim sendo, é imprescindível e urgente que haja uma concentração de esforços na direção de se implementar um conjunto de pesquisas que possam embasar a reformulação das normas nacionais, tornando-as mais adequadas à elaboração de projetos cada vez mais econômicos e seguros. Exatamente por se encaixar nesse objetivo bastante amplo é que se justifica a importância da elaboração do presente trabalho. Ele será, com certeza, uma contribuição importante nesse esforço de elucidação de detalhes significativos sobre um processo construtivo de grande viabilidade econômica e interesse social.

\subsection{Resumo dos capítulos}

No capítulo 2 apresenta-se um panorama geral sobre o comportamento do material alvenaria e sobre o estado da arte dos estudos científicos realizados nessa área.

No capítulo 3 analisam-se os modelos não lineares dos softwares comerciais ANSYS e ABAQUS utilizados no desenvolvimento do presente trabalho.

No capítulo 4 faz-se a modelagem do volume padrão representativo do material alvenaria. Apresentando-se um material linear ortotrópico equivalente.

No capítulo 5 realiza-se a aferição dos modelos não lineares apresentados no capítulo 3, comparando-se resultados teóricos com experimentais encontrados na literatura.

O capítulo 6 apresenta a análise de um painel $\mathrm{H}$, ensaiado no laboratório do Departamento de Engenharia de Estruturas da Escola de Engenharia de São Carlos (SET-EESC-USP), fazendo-se comparações entre 
os valores numéricos, lineares e não-lineares, e os resultados experimentais.

No capítulo 7 apresenta-se a análise numérica de paredinhas, submetidas à compressão, também ensaiadas no SET-EESC-USP.

No capítulo 8 apresentam-se as conclusões do trabalho. 


\section{REVISÃO DOS \\ CRITÉRIOS DE RESISTÊNCIA \\ UTILIZADOS NA ALVENARIA ESTRUTURAL}

\subsection{Propriedades do material}

\subsubsection{Micro e macro modelagem}

A alvenaria é um material estrutural composto, formado de unidades (blocos ou tijolos) de concreto ou cerâmicos, e argamassa. Pode-se afirmar, então, que se trata de um material heterogêneo e anisotrópico que apresenta, por natureza, uma resistência à compressão elevada, dependente principalmente da resistência da unidade. Por outro lado a resistência à tração é baixa e está determinada principalmente pela adesão da unidade com a argamassa.

Segundo GALLEGOS (1991) a alvenaria tem uma resistência a compressão elevada, dependente principalmente da resistência da própria unidade, mas a resistência a tração é reduzida e definida principalmente pela adesão entre a argamassa e a unidade. Segundo o autor, nos casos em que a alvenaria é construída com unidades de baixa resistência, a adesão pode apresentar resistência à tração igual ou superior à da própria unidade. Para esses casos pode-se falar da homogeneidade e isotropia do material com alguma segurança, por outro lado a resistência da alvenaria será reduzida. 
Os fatores que influenciam as propriedades da alvenaria são muitos, tais como: anisotropia e dimensão das unidades, espessura das juntas, propriedades das unidades e da argamassa, arranjo das juntas horizontais e verticais e qualidade da mão-de-obra. Devido a essa grande diversidade, a simulação numérica da alvenaria se torna extremamente trabalhosa. Apenas recentemente a pesquisa em alvenaria começou a mostrar interesse em modelos mais refinados, tornando o cálculo de estruturas em alvenaria menos empírico e mais sofisticado.

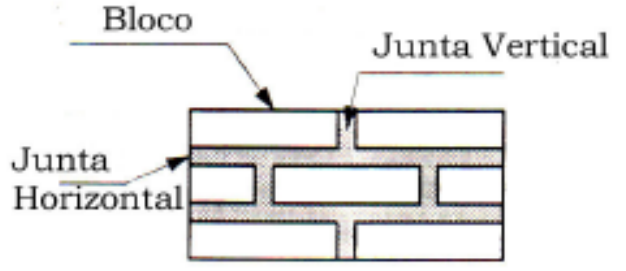

(a)

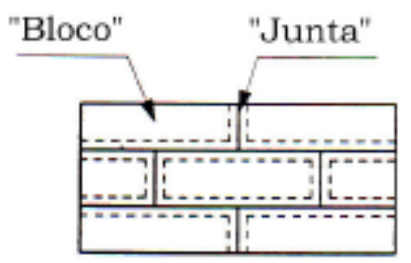

(c)

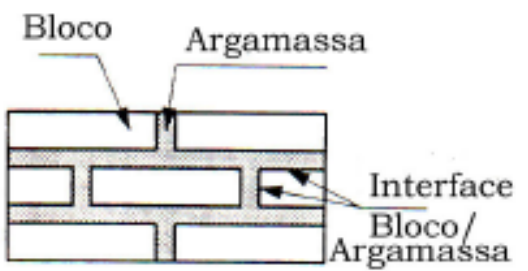

(b)

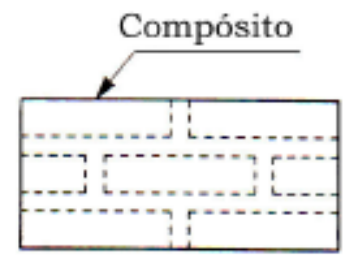

(d)

Figura 2.1 - Técnicas de modelagem da alvenaria: (a) Exemplar da alvenaria; (b) Micromodelagem; (c) Micromodelagem simplificada; (d) Macromodelagem Adaptada de LOURENÇO (1996)

Em geral, para se fazer uma modelagem numérica são utilizados dois modelos aproximados: a micromodelagem ou a macromodelagem. Na micromodelagem os seus componentes são discretizados individualmente, separando-se unidade e argamassa. A macromodelagem considera a alvenaria como um compósito. Segundo LOURENÇO (1996), dependendo do nível de precisão e da simplicidade desejada, é possivel utilizar as seguintes estratégias para a modelagem, conforme figura 2.1.

- Micromodelagem detalhada (fig. 2.1b): as unidades e a argamassa são representadas por elementos contínuos, e a interface entre eles é representada por elementos descontínuos; 
- Micromodelagem simplificada (fig. 2.1c): as unidades são representadas por elementos contínuos e suas dimensões são expandidas, enquanto o comportamento das juntas de argamassa e da interface é considerado nos elementos descontínuos;

- Macromodelagem (fig. 2.1d): unidade, argamassa e interface são consideradas dispersas no meio contínuo. Considera-se a alvenaria como um meio contínuo, com propriedades homogêneas.

Na primeira aproximação, o módulo de elasticidade, o coeficiente de Poisson e, opcionalmente, as propriedades não-lineares da unidade e da argamassa são levadas em consideração. A interface da unidade com a argamassa representa um plano potencial de fissuração/deslizamento, com rigidez inicial pequena para evitar a interpenetração do meio contínuo. Isto possibilita que se estude a ação combinada da unidade, da argamassa e da interface de forma mais minuciosa.

$\mathrm{Na}$ segunda aproximação, cada junta é simulada como uma interface média, e as unidades têm suas dimensões expandidas, com o intuito de manter inalteradas as características geométricas da alvenaria. Essa alvenaria é então considerada como um conjunto de unidades elásticas unidas por linhas potenciais de fratura e deslizamento nas juntas. Perde-se precisão porque nesse tipo de modelagem o efeito de Poisson na argamassa é desprezado.

A terceira aproximação não faz distinção entre a unidade e a argamassa, mas trata a alvenaria como um meio homogêneo, contínuo e anisotrópico.

Não é possível afirmar qual das formas de modelagem é mais vantajosa em relação às outras, porque cada uma delas apresenta vantagens e desvantagens para estudos específicos.

A escolha deve ser feita de acordo com o objetivo a ser alcançado. $\mathrm{O}$ estudo da micromodelagem é necessário para fornecer um bom entendimento sobre o comportamento local das estruturas em alvenaria. Esta forma de modelagem apresenta-se muito importante para a análise de detalhes estruturais. Por exemplo, análise de distribuição e concentração de 
tensões junto a vãos de portas e janelas. A macromodelagem é mais adequada para análises mais gerais da estrutura, principalmente quando se está estudando paredes sólidas com dimensões grandes o suficiente para garantir distribuições de tensões bastante uniformes. Claramente a macromodelagem é mais prática, apresenta um tempo de processamento reduzido, uma economia de memória dos computadores e uma geração de rede mais simples. Este tipo de modelagem é mais valiosa quando existe um compromisso entre precisão e eficiência.

\subsubsection{Mecanismos de ruptura}

A fissuração é a causa mais freqüente da ruptura no comportamento da alvenaria; impedi-la torna-se então uma preocupação constante. Ela é produzida por deformações excessivas induzidas por esforços à tração muito grandes. A deformação pode ser causada por forças aplicadas ou por restrição à variação volumétrica do material. A aplicação do método dos elementos finitos para a análise de estruturas em alvenaria requer um modelo apropriado para o material.

De acordo com LOURENÇO \& ROTS (1997a) um modelo preciso para análise de estruturas em alvenaria precisa incluir os mecanismos básicos de ruptura que caracterizam o material, figura 2.2:

a) Fissura nas juntas;

b) Escorregamento ao longo de uma junta horizontal ou vertical com valores baixos de tensão normal;

c) Fissuração das unidades de alvenaria na direção da tração;

d) Fissura diagonal à tração nas unidades de alvenaria com valores de tensão normal suficientes para desenvolver atrito nas juntas;

e) Fendilhamento das unidades à tração como resultado da dilatação da argamassa, com valores altos de tensão normal de compressão. 


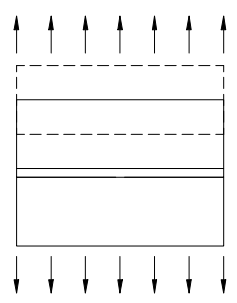

(a)

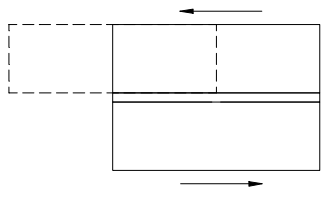

(b)

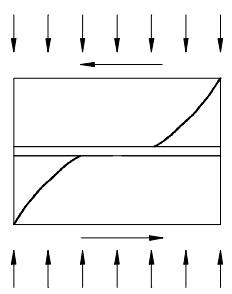

(d)

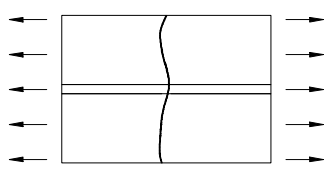

(c)

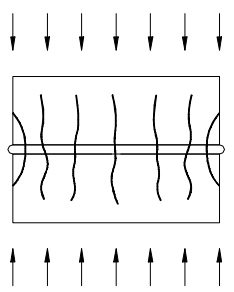

(e)

Figura 2.2 - Mecanismos de ruptura: (a) Fissuras nas juntas; (b) Escorregamento; (c) Fissuração das unidades; (d) Fissura diagonal; (e) Fendilhamento

Adaptada de LOURENÇO(1996)

Pela descrição dos fenômenos torna-se claro que: (a,b) são mecanismos das juntas, (c) é um mecanismo da unidade, e (d,e) são mecanismos combinados de ambos os materiais.

O mecanismo de ruptura dos componentes submetidos a esforços de tração e compressão é essencialmente o mesmo, ou seja, crescimento das fissuras a nível micro do material. Neste caso, deformações inelásticas resultam de um processo dissipativo, no qual a energia de fratura é liberada durante a ocorrência de fratura interna. O material composto apresenta, no entanto, outro tipo de ruptura: o escorregamento que resulta em um atrito seco entre os componentes, uma vez que o amolecimento é completado. Se uma micromodelagem é utilizada, todos esses fenômenos podem ser incorporados no modelo porque as juntas e as unidades são representadas 
separadamente. Numa macromodelagem, as juntas são dispersas num meio contínuo homogêneo anisotrópico e a interação dos componentes não pode ser incorporada no modelo. Dessa forma, uma relação de tensões e deformações médias é estabelecida.

Independentemente do tipo de modelagem adotada, modelos precisos de alvenaria só podem ser usados se for realizada uma descrição completa dos materiais. Geralmente este não é o caso, porque resultados experimentais adequados para a modelagem numérica são escassos, especialmente no regime de amolecimento. $O$ amolecimento é um decréscimo gradual da resistência mecânica do material sob um acréscimo contínuo da deformação. É uma característica importante dos materiais semifrágeis, como blocos cerâmicos, argamassa, rocha e concreto, que rompem devido ao processo progressivo de crescimento interno de fissuras. Este comportamento mecânico é comumente atribuído à heterogeneidade do material, devido à presença de fases diferentes e defeitos dos materiais, como fendas e vazios. Mesmo antes da aplicação das forças, a argamassa contém microfissuras devidas à retração durante a cura e à presença de agregados. As tensões iniciais e as microfissuras, assim como a variação da rigidez e da resistência, provoca o crescimento das fissuras quando o material é submetido a uma deformação progressiva. Inicialmente as microfissuras são estáveis, o que significa que elas crescem apenas quando as forças aplicadas aumentam. Em torno da carga de pico, ocorre uma aceleração na formação das fissuras e início da formação de macrofissuras. As macrofissuras são instáveis, o que significa que a carga tem que diminuir para evitar um crescimento incontrolável.

Num ensaio com deformação controlada, o crescimento das macrofissuras resulta no amolecimento e a concentração das fissuras em uma zona pequena, enquanto o resto do espécime se descarrega. Para ruptura à tração, este processo foi bem identificado, HORDIJK (1991) apud LOURENÇO (1996). Para ruptura por cisalhamento, um processo de amolecimento também é observado, com degradação da coesão no modelo de Coulomb. Para ruptura à compressão, o comportamento de amolecimento é altamente dependente da condição de contorno nos ensaios e da dimensão do corpo ensaiado, van MIER (1984) e VONK (1992) apud LOURENÇO (1996). A figura 2.3 mostra características dos diagramas 
tensão/deformação para materiais frágeis submetidos à tração e à compressão uniaxial.
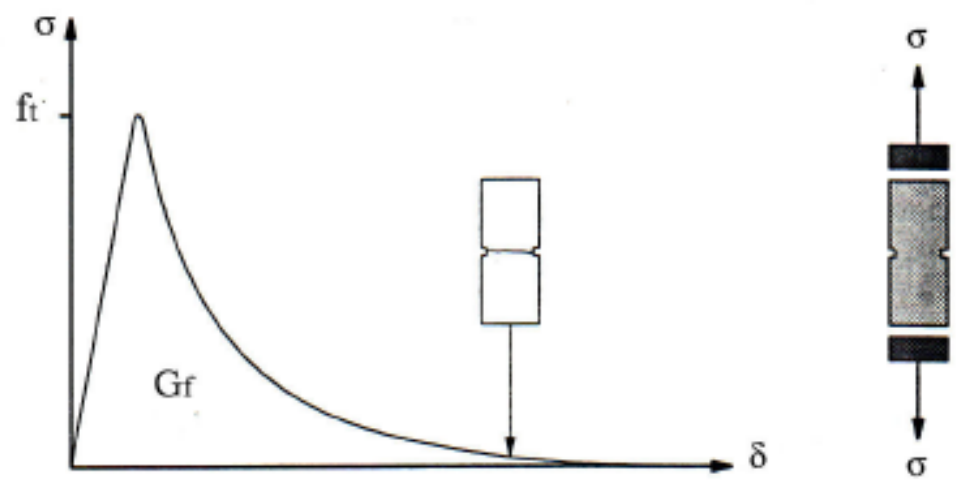

(a)
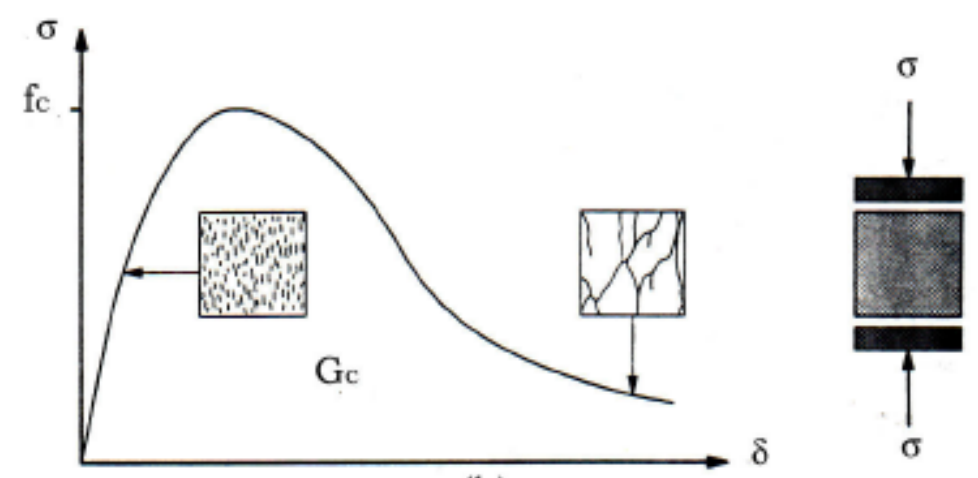

(b)

Figura 2.3 - Comportamento típico de materiais frágeis submetidos à carregamento uniaxial e definição da energia de fratura: (a) tração; (b) compressão.

Adaptada de LOURENÇO (1996)

A argamassa constituinte da alvenaria é usualmente muito mais deformável do que a unidade e geralmente começa a apresentar deformações plásticas muito antes do que as unidades. A maior parte da deformação não-linear da alvenaria, até antes da ruptura, ocorre apenas nas juntas. 


\subsection{Estado da arte}

O constante crescimento da utilização da alvenaria em obras de construção civil proporciona um grande interesse na análise mais detalhada do comportamento destas estruturas por parte da comunidade científica. Com o objetivo de suprir o meio técnico com informações mais precisas e confiáveis, muitos pesquisadores se dedicam ao estudo da alvenaria, apresentando novos modelos e critérios para uma modelagem mais adequada do seu comportamento.

Dois modelos diferentes, o modelo homogeneizado e o modelo discreto (ou micromodelo), têm sido utilizados para simular as respostas lineares e não-lineares da alvenaria. Conforme LUCIANO \& SACCO (1997) um dos micromodelos mais utilizados é o denominado material "sem tração" (no-tension). Neste tipo de modelagem a alvenaria é considerada elástica na compressão e sem capacidade para suportar tensões de tração. O material “sem tração” foi proposto por HEYMAN (1966) que apresentou uma teoria para a análise limite das estruturas em alvenaria. A principal hipótese é o desprezo da resistência à tração da alvenaria, sendo que, com isso, o colapso geralmente ocorre devido às aberturas de fissuras nas regiões tracionadas.

\subsubsection{Modelos Discretos}

Em 1978, PAGE publicou um estudo que trata da análise de paredes de alvenaria cerâmica sujeitas a um carregamento no seu próprio plano, um problema comumente encontrado em projetos de estruturas de alvenaria. Ele apresentou um método que considerava o comportamento não- da alvenaria. Até então a abordagem do estudo da alvenaria mais comum era a consideração de um material elástico linear isotrópico, ignorando-se a influência das juntas de argamassa como planos de fraqueza ("plane of weakness”). De acordo com esse trabalho, hipóteses dessa natureza apresentam resultados satisfatórios nos casos em que a estrutura analisada está submetida a níveis baixos de tensão, mas não são 
adequadas para casos em que as tensões aplicadas são altas e onde é necessária uma análise da redistribuição de tensões. A redistribuição acontece devido ao comportamento não-linear (predominante na argamassa) e à ruptura localizada nas áreas onde ocorre um descolamento entre a unidade e a argamassa. PAGE utilizou uma modelagem discreta, considerando a alvenaria como um material bifásico consistindo de unidades elásticas submersas numa matriz inelástica que seria a argamassa. A ruptura ocorre nas juntas, se o critério de resistência à tração ou ao cisalhamento for violado. Estas características foram incorporadas em um programa de elementos finitos incremental que modela a propriedade não-linear das juntas e considera a sua ruptura progressiva. As propriedades do material, necessárias para definir o modelo, foram determinadas experimentalmente através de testes em painéis de alvenaria e em unidades individuais. As juntas são modeladas com um elemento de ligação que limita: a tensão de tração; altas tensões de compressão (com características de deformações não-lineares); e a tensão de resistência ao cisalhamento, variável dependente do valor da tensão de compressão apresentada.

A utilização do conceito de elemento de ligação possibilita uma modelagem bastante apropriada das propriedades não-lineares da alvenaria, com a vantagem de se conseguir caracterizar o material através de ensaios uniaxiais. Com isso elimina-se a necessidade da realização de ensaios biaxiais, que são bem mais complexos. Para a análise de um painel de alvenaria, a distribuição de tensões, obtida numericamente, apresentou uma razoável precisão quando comparada com a análise experimental. Mesmo para altos níveis de carga, onde uma redistribuição de tensões bastante significativa já havia ocorrido, foram obtidos resultados bastante coerentes. A ênfase do trabalho está na determinação da redistribuição das tensões na alvenaria, e não na obtenção da força de ruptura, que ocorre por ruptura progressiva ou deslizamento, ou ambos em um determinado número de elementos.

ALI \& PAGE (1987) apresentaram um programa em elementos finitos para analisar o comportamento não-linear da alvenaria de unidades sólidas de concreto sujeita a forças concentradas. As juntas e as unidades são modeladas separadamente, com previsão de características não-lineares 
de deformação dos materiais, ruptura da unidade e da argamassa, e ruptura da junta de argamassa. A fissuração e a conseqüente perda da resistência à tração são as maiores causas da não-linearidade. As características de deformação e o critério de ruptura dos materiais constituintes são determinados em ensaios individuais das unidades, de exemplares de argamassa e amostras de paredes de alvenaria. $O$ comportamento não-linear da alvenaria é causado principalmente por dois efeitos: ruptura progressiva e características não-lineares dos materiais constituintes. Para que o modelo do material represente adequadamente o comportamento da alvenaria, ambos os efeitos devem ser incluídos. A ruptura pode ocorrer por esmagamento ou fissuração dos materiais constituintes, ou por ruptura da junta na interface argamassa/unidade. $\mathrm{O}$ método de análise proposto é uma ferramenta válida e eficiente para a análise não-linear de painéis de alvenaria submetidos a carregamentos em seu próprio plano. A idealização do material proposta é capaz de representar o comportamento predominante nas estruturas de alvenaria submetidas a cargas monotonicamente crescentes. O método é capaz de predizer a carga inicial de fissuração, a carga última e o padrão de ruptura com razoável precisão.

ALI \& PAGE (1988a) apresentaram um modelo em elementos finitos para a análise de painéis de alvenaria de unidades sólidas de concreto com forças concentradas atuando em seu próprio plano. No estudo a alvenaria é considerada no estado plano de tensões, uma hipótese razoável para a maioria dos casos de carregamento atuante no plano. O modelo proposto reproduz as características não-lineares da alvenaria causadas pela nãolinearidade do material e falha local progressiva. As unidades e a argamassa são modeladas separadamente, considerando-se as características de deformação não-lineares dos dois materiais, assim como a ruptura da unidade, da argamassa ou da junta unidade/argamassa. Devido à habilidade do modelo em considerar efeitos locais, o modelo é capaz de reproduzir o comportamento das paredes de alvenaria nas quais altas tensões locais e altos gradientes de tensão estão presentes. As propriedades dos materiais para o modelo são determinadas a partir de ensaios em painéis reduzidos e em seus materiais constituintes. Ensaios com cargas concentradas em paredes de alvenaria foram utilizados como base de 
comparação entre os valores teóricos obtidos e os valores experimentais e apresentaram uma boa concordância.

Conforme ALI \& PAGE (1989) a ruptura em paredes de alvenaria de unidades sólidas de concreto submetidas a cargas concentradas usualmente ocorre como uma fissura, ou fissuras, que se propagam ao longo do painel logo abaixo do ponto de aplicação da carga. Os autores apresentaram um estudo que simula essa fissuração local, utilizando dois modelos de fissuras diferentes. Um dos modelos espalha o efeito da fissuração através do domínio do elemento (modelo de fissuras dispersas), e o outro desconecta progressivamente os nós apropriados de elementos adjacentes (modelo de fissuras discretas). Estas técnicas de modelar a fissuração foram incorporadas em programa de elementos finitos para estados planos de tensões. Elementos quadrilaterais com quatro nós, com uma rede mais refinada próxima ao local de aplicação da carga, foram utilizados com sucesso para simular a fissuração progressiva que aparece próxima à região em que é aplicada a força concentrada.

Nos modelos, as juntas e as unidades são consideradas separadamente com propriedades de deformação não-lineares dos materiais para caracterizar os diferentes modos de ruptura. As características necessárias para se definir os modelos não-lineares em elementos finitos foram determinadas a partir de ensaios em modelos reduzidos de paredes de alvenaria e seus componentes. O modelo dos materiais inclui características de deformação não-lineares para a unidade e a argamassa e critérios de ruptura para a unidade e a junta. A ruptura pode ocorrer por esmagamento ou fissuração dos materiais constituintes, ou por ruptura nas juntas da interface unidade-argamassa.

Os autores escolheram os ensaios com forças concentradas em painéis de alvenaria para averiguar a precisão e a diferença entre os dois modelos de fissuras adotados. A escolha foi feita em função do estado de concentração de tensões que aparece logo abaixo do ponto de aplicação das forças. Comparando-se os dois modelos de fissuras adotados, foram verificadas algumas diferenças na determinação da força última e no padrão de ruptura dos painéis. No modelo de fissuras espalhadas, a fissura se propaga ao longo de um ou mais elementos como um todo. No modelo de 
fissuras discretas, a propagação acontece na forma de linhas retas ao longo da separação dos nós dos elementos. No primeiro caso, a fissura pode se propagar em qualquer direção, enquanto no segundo caso a fissura só pode se propagar em linhas horizontais e verticais.

O critério de resistência proposto apresentou resultados coerentes com referência à propagação das fissuras, padrão de fissuração e força de ruptura. Os modelos são aplicáveis a qualquer conjunto unidadeargamassa e qualquer padrão de juntas. Verificou-se, porém, que o modelo de fissuras discretas é mais apropriado na análise do problema de cargas concentradas, apresentando a desvantagem de gerar um custo computacional quatro vezes maior do que o modelo de fissuras dispersas.

PAGE \& SHRIVE (1990) publicaram um artigo analisando a aplicação de forças concentradas em paredes de alvenaria e os seus mecanismos de ruptura. Segundo os autores, quando uma força concentrada é aplicada em uma parede de alvenaria, altas tensões locais são desenvolvidas na região logo abaixo desta. Nessa região um estado de compressão triaxial é desenvolvido, enquanto um pouco mais abaixo o estado de tensões muda para uma compressão vertical e uma tração biaxial. Como a alvenaria resiste pouco à tração, esta região é crítica, e as fissuras vão aparecer nesse ponto, se a força se tornar excessiva. Ensaios realizados comprovaram que na região logo abaixo do ponto de aplicação da carga, devido ao estado de compressão triaxial, a resistência da parede de alvenaria aumenta.

Os autores realizaram uma série de ensaios experimentais, aplicando forças concentradas em paredes de blocos vazados de concreto e tijolos maciços cerâmicos, com o intuito de avaliar a diferença de comportamento dos mesmos. Concluíram que, no caso dos tijolos maciços, a consideração do aumento de resistência da parede, devido ao estado triaxial de tensões, é bastante coerente e esse aumento de resistência pode ser considerado. No caso dos blocos vazados o comportamento é bastante diferente e novos estudos precisam ser realizados para que o mecanismo seja melhor compreendido e, então, considerado.

ROTS (1991a) apresentou uma breve avaliação de um projeto de pesquisa em mecânica computacional de alvenaria estrutural. Segundo o autor, dependendo do grau de precisão necessária e da simplicidade 
desejada, pode-se adotar diferentes modelos para a análise da alvenaria. Em um primeiro caso, as juntas da alvenaria podem ser representadas por elementos contínuos, considerando-se ou não o comportamento não-linear. As juntas podem ser representadas por elementos descontínuos, sendo possivel considerar a alvenaria como um conjunto de unidades com comportamento elástico linear unidos por linhas potenciais de fratura nas juntas. Nesse caso há uma perda de precisão porque o efeito Poisson nas juntas é desprezado. No terceiro caso as juntas são consideradas espalhadas na alvenaria, não havendo distinção entre unidades e argamassa; a alvenaria é considerada como um meio compósito anisotrópico. Esta aproximação é mais adequada na análise global de grandes estruturas em alvenaria.

Uma aproximação detalhada que representa a alvenaria como um conjunto de unidades ligadas por elementos de interface não-lineares, mostrou-se capaz de simular a propagação da fratura ao longo das juntas horizontais e verticais e ao longo das unidades. Finalmente, com uma visão para a análise global de alvenaria estrutural como um meio composto anisotrópico, foi demonstrado que um modelo de fissuras espalhadas baseado na decomposição da deformação (em duas partes: uma $\Delta \varepsilon^{a}$ da fissura e outra $\Delta \varepsilon^{\text {na }}$ do material sólido entre fissuras) pode ser facilmente estendido para incluir os efeitos da ortotropia inicial e o ângulo de inclinação entre a fissura e a junta.

ROTS (1991b) estudou as possibilidades de se utilizarem os modelos de fissuras espalhadas ou discretas para simular a fratura localizada em materiais com amolecimento. São feitas comparações entre fissuras fixas, multidirecionais e fissuras espalhadas rotacionadas, onde a orientação das fissuras é mantida constante, atualizada em um passo inteligente ou atualizada constantemente. Depois as aproximações com fissuras espalhadas são comparadas com sistemas onde tem-se fissuras discretas potencialmente definidas.

Guando se utilizou a aproximação de fissuras espalhadas, o conceito de fissura rotacionada (coaxial) e o conceito de fissura fixa com desconsideração da retenção do cisalhamento obtiveram os melhores resultados. Fissuras fixas com significativa retenção do cisalhamento 
levaram a tensões muito grandes após a fissuração e a uma resposta muito rígida. Uma deficiência da aproximação espalhada é o perigo de aparecerem tensões de travamento. Isto é devido ao fato de que as descontinuidades geométricas são modeladas utilizando-se o conceito de deslocamentos contínuos. O conceito de fissuras discretas envolve uma descontinuidade e não sofre o risco de aparecerem tensões de travamento. O uso de elementos de interface como locais potenciais para o aparecimento de fissuras é versátil para o caso onde o caminho provável da fratura pode ser prédefinido, e em casos onde certos caminhos de fissuração prevalecem.

LOFTI \& SHING (1991) apresentaram um trabalho com o objetivo de avaliar a capacidade dos modelos de fissuras espalhadas em analisar a resistência e os vários mecanismos de ruptura para paredes de alvenaria de unidades de concreto sujeitas ao cisalhamento. Com esta finalidade foi desenvolvida uma formulação em elementos finitos com um modelo de fissuras espalhadas adotando o modelo da plasticidade $\mathrm{J}_{2}$ para a alvenaria íntegra e um modelo constitutivo não-linear ortotrópico para a alvenaria fissurada. O desempenho do modelo é avaliado com resultados experimentais obtidos de painéis de alvenaria. A objetividade dos resultados numéricos com respeito à dimensão da rede é considerada. Apesar do modelo ter produzido excelentes resultados com respeito ao comportamento predominante de flexão, ele apresenta uma desvantagem principal em capturar o comportamento frágil ao cisalhamento de painéis pouco armados. A capacidade da aproximação das fissuras espalhadas em capturar a resistência e o mecanismo de ruptura para paredes de alvenaria armadas, sujeitas ao cisalhamento, é examinada. Foi demonstrado que enquanto a resposta à flexão do painel de alvenaria armada pode ser reproduzido com precisão utilizando-se o modelo de fissuras espalhadas, o comportamento frágil, quando o painel está submetido ao cisalhamento, caracterizado por fissuras diagonais, não pode ser determinado com precisão. Este fato é devido à inerente limitação da aproximação por fissuras espalhadas, na qual as fissuras abertas são modeladas adotandose um campo de deslocamentos contínuos, o que leva a uma restrição cinemática irreal da fissura aberta. Em virtude dessas limitações, assim como de outros problemas tais como: dependência da dimensão da malha e dificuldades de se calibrar o modelo, os modelos de fissuras espalhadas 
devem ser utilizados com muito cuidado, por usuários experientes e bem informados que estejam atentos às suas limitações. Caso contrário, poderá conduzir a conclusões errôneas como foi demonstrado nos exemplos numéricos apresentados pelos autores.

ULM \& PIAU (1993) apresentaram um trabalho onde aplicam a teoria de contato nas juntas da alvenaria para simular o comportamento não-linear. Baseado na hipótese de continuidade do campo de deslocamento e/ou deformação, um elemento finito plano é deduzido para a análise não-linear de estruturas de alvenaria sujeitas a cargas monotônicas, cíclicas e carregamento dinâmico, assim como para análise de estados limites. O elemento possui seis graus de liberdade e considera um mecanismo de abertura e fechamento das juntas de alvenaria com ou sem material para simular a junta. O colapso de um templo devido a cargas sísmicas é utilizada para ilustrar a eficiência do modelo aplicado para a análise de estruturas, apresentando uma boa precisão.

Segundo LOTFI \& SHING (1994) a ruptura de estruturas de alvenaria de unidades de concreto não armadas sujeitas a um carregamento lateral horizontal é predominantemente devida à fissuração das juntas de argamassa, assim como da fissuração e esmagamento das unidades. Estes fenômenos podem ser simulados utilizando-se uma aproximação do método dos elementos finitos no qual as juntas de argamassa são modeladas com elementos de interface e as unidades de alvenaria são modeladas com elementos planos com fissuras dispersas. No estudo apresentado, esta aproximação foi adotada para simular o comportamento e os mecanismos de ruptura do material alvenaria, baseados no comportamento de seus materiais constituintes. Para se efetuar essa simulação foi desenvolvido um modelo constitutivo de interface capaz de simular o início e a propagação da fissura. A eficiência do modelo proposto em representar o comportamento das juntas de argamassa da alvenaria é avaliada confrontando-se os resultados com valores experimentais. Os resultados das análises demonstraram que o modelo numérico é capaz não só de predizer a capacidade de carga da alvenaria, mas também fornecer informações detalhadas do modo de ruptura, ductilidade e padrão de fissuração. 
RIDDINGTON \& NAOM (1994) apresentaram um programa em elementos finitos com o propósito de determinar a resistência última à compressão da alvenaria. O critério de ruptura local incluído no programa é a resistência à tração da unidade, a resistência à tração da argamassa, a resistência à tração e ao cisalhamento na junta unidade/argamassa. Considera-se, também, o comportamento elástico não-linear da argamassa. O programa é estruturado de forma que todos os critérios de ruptura e a não-linearidade da argamassa são considerados em cada uma das iterações. O programa foi capaz de determinar a capacidade última de compressão da alvenaria com razoável precisão, comparando-se com paredes ensaiadas experimentalmente. Quando a não-linearidade física da argamassa não foi incluída na análise, a resistência última à compressão da alvenaria foi superestimada. O trabalho demonstrou que a capacidade de carga da alvenaria decresce com o aumento da espessura da argamassa. Observou-se, também, que um acréscimo na resistência à tração da unidade resulta em um acréscimo da resistência à compressão da parede.

FUSCHI et al. (1995) apresentaram uma aproximação numérica para a análise de paredes de alvenaria estrutural submetidas a um estado plano de tensões. Adota-se um modelo constitutivo para o material perfeitamente não resistente à tração. As equações são expressas na forma clássica incremental com lei de fluxo associativa para material elastoplástico. A eficiência do modelo proposto foi examinado e aprovado por uma análise de precisão. Dois exemplos de painéis de alvenaria, cujo comportamento é assumido como descrito pelo modelo, foram analisados pelo método dos elementos finitos. A grande desvantagem do modelo é o fato da alvenaria ser admitida como indefinidamente linear na compressão. Os valores de deslocamento obtidos no colapso iminente podem ser maiores comparando-se com os valores que a estrutura real apresenta. Este fato pode estar violando a hipótese de pequenas deformações. Essa desvantagem pode ser eliminada pela introdução de limites apropriados na tensão de compressão máxima admitida, de uma forma consistente com o modelo apresentado. Finalmente, comparações dos resultados obtidos com dados da literatura disponíveis parecem comprovar a eficiência do procedimento empregado, respeitando-se suas limitações. 
SAYED-AHMED \& SHRIVE (1996) apresentaram um modelo elastoplástico não-linear em elementos finitos para alvenaria de unidades vazadas de concreto utilizando-se elementos de casca isoparamétricos. O comportamento não-linear da alvenaria devido à fissuração progressiva, e as não-linearidades física e geométrica são consideradas no modelo. Foram realizadas análises numéricas de prismas com três unidades de altura e os resultados em termos de tensão, deformação e deslocamento foram comparados com resultados experimentais. Os resultados apresentaram boa concordância. Segundo os autores a ruptura das paredes de alvenaria de unidades vazadas se inicia pela fissuração dos septos verticais no plano da parede. Uma análise 3D é essencial para predizer o estágio inicial de ruptura. Análises utilizando-se elementos tridimensionais (sólidos), mesmo com uma rede bastante refinada, não pode oferecer uma solução para o problema, porque não é capaz de modelar o mecanismo de ruptura global. Utilizou-se um elemento de casca que incorpora os modelos de fendilhamento dos septos, comportamento não-linear da argamassa e o início da instabilidade final da alvenaria fissurada. Assim o modelo tem condições de acompanhar o comportamento da alvenaria vazada, desde o aparecimento da primeira fissura até próximo à ruptura total, incluindo comportamento não-linear físico e geométrico.

De acordo com ANDREAUS (1996) a ruptura de painéis de alvenaria submetidos a carregamentos em seu próprio plano pode ser atribuída a três mecanismos básicos: deslizamento das juntas de argamassa, fissuração das unidades e fendilhamento da junta de argamassa, e fissuração do plano médio. No artigo, Andreaus emprega três critérios de ruptura conhecidos para determinar os estados de tensão de colapso de painéis de alvenaria sob carregamento no seu próprio plano. Estes critérios são expressos em termos de constantes elásticas e parâmetros de resistência, que são identificados através de dados experimentais da literatura. O modo de colapso que exibe o deslizamento das juntas de argamassa, o fendilhamento das juntas horizontais, e o deslizamento e fendilhamento das juntas horizontais, pode ser compreendido com suficiente precisão pelo modelo de Mohr-Coulomb, que tem uma modificação com o intuito de considerar a dependência nãolinear da tensão de cisalhamento com a tensão normal. O critério da 
máxima deformação de tração (critério de Saint-Venant) foi associado com o modo de colapso caracterizado pela fissuração das unidades e fendilhamento da argamassa, fissuração das unidades e juntas verticais, deslizamento das juntas horizontais e fendilhamento das juntas verticais, fendilhamento das juntas horizontais, fendilhamento e deslizamento das juntas e deformação biaxial. Por fim a fissuração do plano médio pode ser avaliada quando o critério de máxima tensão de compressão é cumprido (Navier). Alguns resultados experimentais encontrados na literatura foram coletados com o intuito de definir aproximadamente, de uma forma adimensional, o intervalo de tensões onde os diferentes mecanismos ocorrem, o deslizamento, o fendilhamento e a fissuração. O critério de ruptura proposto parece estar em boa concordância com os resultados experimentais, com as seguintes limitações: painéis reduzidos, paredes simples, unidades sólidas, juntas de argamassa regulares e carregamento em seu próprio plano.

LOURENÇO, ROTS \& BLAAUWENDRAAD (1997) publicaram um artigo onde apresentam possíveis aplicações de modelagens numéricas de estruturas de alvenaria. Os exemplos apresentam os problemas de normas de projeto e sua relação com os modelos numéricos, a análise de estruturas complexas existentes sujeitas a novas condições de carregamento e a segurança de estruturas antigas. Os exemplos apresentam uma indicação, em três diferentes categorias, de possíveis regras para a análise não-linear de estruturas de alvenaria. O primeiro exemplo trata de normas de projeto e como elas podem ser realçadas e racionalizadas com o auxilio de modelos numéricos. Com este propósito, as especificações de juntas de dilatação em paredes de alvenaria são discutidas. O segundo exemplo trata da análise de estruturas complexas existentes, sujeitas a novas condições de carregamento. Com este propósito, os modelos são utilizados para predizer a quantidade de dano, associado com a fissuração, para prédios em Amsterdã, Holanda, devido aos recalques provocados pela abertura de túneis. O último exemplo trata da segurança de estruturas antigas. Com este propósito, a resistência residual de um prédio de 350 anos danificado por um terremoto, em Salvitelle, Itália, é calculada e comparada com resultados experimentais. Os exemplos demonstram o nível de elaboração do modelo numérico para a alvenaria. 


\subsubsection{Modelos Homogeneizados}

DHANASEKAR et al. (1985) apresentaram um trabalho que descreve o desenvolvimento de um critério de ruptura, no estado plano, para paredes de alvenaria. O critério pode ser programado utilizando-se o método dos elementos finitos, e utilizado para se determinar a ruptura em regiões localizadas de uma parede, permitindo assim uma análise mais verossímil da alvenaria. Utilizando resultados experimentais, os autores determinaram uma superfície de ruptura completa para a análise de paredes de alvenaria. A superfície de ruptura obtida é fechada e pode ser representada pela intersecção de três cones elípticos. Os fatores que influenciam a superfície de ruptura são discutidos e os ensaios mecânicos necessários para se definir uma superfície de ruptura conservativa são descritos. Uma série de ensaios em painéis de alvenaria publicados anteriormente foram analisados e novos ensaios foram realizados. Os ensaios biaxiais de compressãocompressão e compressão-tração foram realizados em painéis quadrados com uma variação do ângulo formado entre as juntas horizontais e o lado carregado. Verificou-se que a carga e o padrão de ruptura da alvenaria são fortemente influenciados pelas juntas de argamassa que atuam como planos de fraqueza. O artigo apresenta a superficie de ruptura em dois sistemas de referência: no sistema de tensões principais e sua orientação em relação à junta horizontal $\left(\sigma_{1}, \sigma_{2}, \theta\right)$; e em termos do sistema de tensões relacionados com a direção das juntas $\left(\sigma_{\mathrm{n}}, \sigma_{\mathrm{p}}, \tau\right)$.

PAGE et al. (1985) apresentaram um modelo em elementos finitos para paredes de alvenaria de tijolos cerâmicos sólidos, que incorpora características realistas do material deduzidas de um grande número de ensaios em painéis de alvenaria. Utiliza-se um modelo contínuo macroscópico para a relação tensão-deformação, consideram-se deformações não-lineares e um critério de ruptura progressiva que leva em consideração a orientação das juntas. A ruptura pode ocorrer apenas nas juntas ou em um modelo envolvendo a unidade e as juntas. O programa de elementos finitos, para estado plano de tensões, é baseado em um elemento isoparamétrico de oito nós e é utilizado para simular um carregamento incremental e a ruptura progressiva das paredes de alvenaria sujeitas a um 
carregamento no seu plano. A eficiência do programa é demonstrada comparando-se o comportamento nos resultados numéricos com os valores obtidos nos ensaios experimentais obtidos em cinco pórticos de aço preenchidos com unidades de alvenaria. A grande vantagem do modelo apresentado é que as propriedades médias, que incluem a influência tanto da unidade quanto das juntas, foram determinadas em ensaios de laboratório. Isto significa que uma rede de elementos relativamente pobre pode ser utilizada, não havendo necessidade de se discretizar a unidade e a argamassa separadamente. Isto é uma grande vantagem computacional na análise de grandes painéis de alvenaria, devido à simplificação na geração da rede e economia no tempo de processamento.

Em 1989, PANDE et al. apresentaram um artigo onde utilizam um "material aproximado equivalente” para a determinação das propriedades elásticas da parede de alvenaria. É introduzido um sistema composto de duas camadas paralelas de materiais, formado de bloco e argamassa, e determinam-se as propriedades médias para este sistema. Estende-se, então, a aplicação para a alvenaria, com dois conjuntos de juntas de argamassa (horizontal e vertical) que pode ser representado por um material equivalente elástico ortotrópico. O processo consiste em duas etapas: na primeira é realizada uma homogeneização horizontal, incluindo-se as unidades e as juntas verticais. Na segunda etapa, a homogeneização vertical é realizada, unindo-se o material homogeneizado anteriormente com as juntas horizontais (Figura 2.4). Expressões para as propriedades elásticas do material equivalente são determinadas em termos das propriedades elásticas da unidade e da argamassa, considerando-se a espessura relativa da argamassa. 


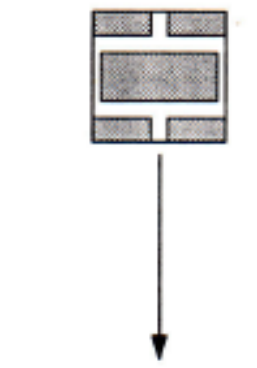

Homogeneização

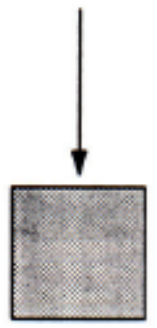

(a)

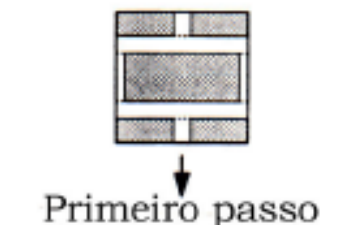
(ao longo do eixo $\mathrm{x}$ )

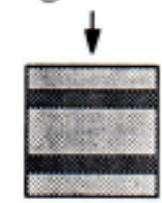

Segundo passo (ao longo do eixo y)

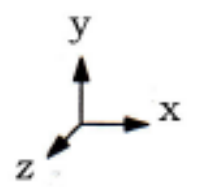

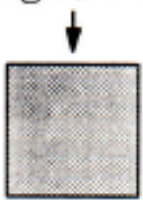

(b)

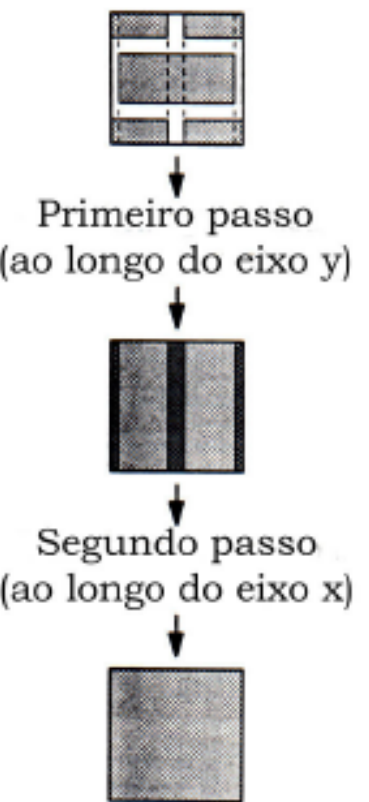

(c)

Figura 2.4 - Homogeneização em duas etapas

Adaptada de LOURENÇO(1996)

Os referidos autores concluem que o módulo de elasticidade longitudinal $(\mathrm{E})$ normal às juntas verticais do material equivalente é menor do que aquele na direção paralela à junta. Também foi determinado que a rigidez ao cisalhamento do material equivalente no plano paralelo às juntas horizontais é, em geral, maior que a rigidez ao cisalhamento perpendicular às juntas horizontais. Verificou-se que para o caso mais comum, em que $\mathrm{E}_{\mathrm{a}}<\mathrm{E}_{\mathrm{b}}$ (módulo de elasticidade da argamassa<módulo de elasticidade do bloco), o acréscimo da espessura da argamassa resulta numa redução do E da alvenaria e um acréscimo do $\mathrm{E}$ da argamassa provoca um aumento do $\mathrm{E}$ da alvenaria.

EL-METWALLY, ASHOUR \& CHEN (1991) descreveram um método de análise para predizer a capacidade de resistência de paredes de alvenaria de concreto com a consideração das não-linearidades física e geométrica. Utilizaram a técnica de integração de Newmark, que já havia sido utilizada anteriormente para paredes de concreto. No trabalho, essa técnica foi aprimorada para levar em consideração o amolecimento do material. Neste estudo, a relação tensão-deformação real da alvenaria é implementada num 
programa para a análise estrutural. Uma faixa de parede, de comprimento unitário, é tratada como uma viga-coluna em estado plano de deformações. A relação tensão-deformação da alvenaria é considerada não-linear na compressão e desprezada na tração. O comportamento e a resistência das paredes são estudados utilizando-se o método computacional desenvolvido. São consideradas apenas paredes submetidas a carregamento uniforme excêntrico em relação ao plano médio em ambas as extremidades. A capacidade de carregamento das paredes foi considerada muito sensivel a pequenas variações do valor da excentricidade. Os tipos de colapso, instabilidade ou ruptura do material, são influenciados principalmente pela esbeltez e pelo valor da excentricidade. Uma pequena variação da força axial acarreta uma grande mudança na capacidade portante da alvenaria.

Em 1992, PIETRUSZCZAK \& NIU apresentaram uma formulação matemática para a descrição das propriedades mecânicas médias da alvenaria estrutural de unidades de concreto. Um elemento típico de alvenaria é considerado como um meio composto para a qual as propriedades macroscópicas médias podem ser unicamente identificadas. Assim, um volume elementar representativo do material considerado é adotado como consistindo de um número de unidades interceptadas por duas famílias de juntas ortogonais entre si. O artigo é escrito na seguinte seqüência: primeiro, uma formulação geral tridimensional é fornecida. As relações constitutivas médias são formuladas utilizando-se a hipótese de que as juntas verticais representam um conjunto alinhado de inclusão de planos de fraqueza e as juntas horizontais formam planos contínuos de fraqueza. A formulação é, então, aplicada para estabelecer as propriedades elásticas médias do sistema. Depois, o fenômeno de ruptura progressiva da parede de alvenaria é investigado. O mecanismo de ruptura consiste na formação de macro-fissuras nas unidades ou uma ruptura dúctil/frágil nas juntas horizontais. O modo de ruptura efetivo é função da história do carregamento imposto. As propriedades das juntas verticais têm um efeito muito limitado na ruptura macroscópica. Assim, para propósitos práticos, as juntas verticais podem ser admitidas como lineares elásticas isotrópicas. O artigo mostra que em análise elástica a alvenaria pode ser considerada como um meio ortotrópico. Os valores das constantes elásticas são muito influenciadas pelas propriedades e espessura das juntas de argamassa. 
PAPA \& NAPPI (1993) apresentaram um modelo de material baseado num procedimento de homogeneização para a análise de estruturas de alvenaria. A alvenaria é considerada como um material composto e suas propriedades mecânicas globais são determinadas em função das propriedades dos seus componentes: as unidades (admitidas como elásticas) e a argamassa (admitida como sujeita ao dano). O método adotado consiste de duas etapas. Numa primeira etapa uma homogeneização vertical é realizada, incluindo as unidades e as juntas horizontais. Numa segunda etapa, a homogeneização horizontal é realizada, com os materiais previamente obtidos. Para avaliar a capacidade e as limitações do modelo, ensaios experimentais em painéis reduzidos de alvenaria foram executados, impondo-se diferentes combinações de carregamento para estado plano de tensão. Considerando-se a usual dispersão dos resultados experimentais encontrados com os painéis de alvenaria, a ruptura predita pela aproximação teórica parece estar em boa concordância com as evidências experimentais.

Em 1995, ANTHOINE apresentou um trabalho onde aplica a teoria da homogeneização para meios periódicos de uma forma mais rigorosa, com o intuito de determinar as características da alvenaria no estado plano. De acordo com o autor, procedimentos semelhantes têm sido utilizados por muitos pesquisadores, mas, em geral, com técnicas aproximadas. Em particular, os processos de homogeneização vêm sendo aplicados através de passos sucessivos de homogeneização, as juntas horizontais e verticais sendo introduzidas de forma sucessiva. Além disso, usualmente a alvenaria é considerada como um meio bidimensional sujeito a um estado plano de tensões, ou como um meio tridimensional muito espesso, assim sua espessura finita nunca é levada em consideração. No artigo a teoria da homogeneização para meios periódicos é implementada em uma só etapa e considera-se a geometria real da alvenaria (o padrão da argamassa e espessura da parede). Os resultados obtidos foram comparados com análises baseadas em métodos simplificados existentes e constituem uma base de referência para avaliar a relevância de algumas aproximações geralmente utilizadas na literatura. Como resultado importante, as aplicações numéricas realizadas demonstraram que variando-se o padrão das juntas, ignorando-se as juntas verticais ou assumindo-se estado plano 
de tensão, resultam em estimativas razoáveis do comportamento elástico global da alvenaria. No entanto, um minucioso estudo das tensões elásticas desenvolvidas nos diferentes materiais constituintes (unidade e argamassa) antecipa que a situação pode resultar completamente diferente na análise não-linear. Em particular, o estado plano de tensões assumido causa controvérsias, por ser uma aproximação do modelo real, que é tridimensional.

LEE et al., em 1996, introduziram uma técnica de homogeneização para investigar o comportamento elastofrágil de painéis de alvenaria sujeitos a carregamento lateral horizontal. Para modelar o comportamento da alvenaria, são utilizados dois passos sucessivos de homogeneização para obter as propriedades elásticas médias. $\mathrm{Na}$ primeira etapa, as unidades são homogeneizadas com as juntas verticais, obtendo-se as propriedades elásticas equivalentes de um sistema em camadas. Numa segunda etapa o sistema em camadas é então homogeneizado com as juntas horizontais para obter as propriedades equivalentes do material alvenaria. A única nãolinearidade considerada está associada à fissuração. O modelo constitutivo é incorporado em um programa de elementos finitos, utilizando-se elementos tridimensionais. Dos exemplos analisados, os autores concluem que a homogeneização proposta, em duas etapas, é conveniente, prática e pode ser utilizada para minimizar o custo computacional da análise de painéis de alvenaria sujeitos a carregamento lateral. A previsão numérica da carga última e o padrão de fissuração está em boa concordância com os ensaios. Parâmetros mais precisos dos materiais, assim como a resistência à tração e a resistência à tração da junta entre a unidade e a argamassa, podem fornecer um modelo mais preciso. Foram realizadas também análises numéricas de painéis de alvenaria com diferentes condições de contorno e aberturas que apresentaram uma boa concordância com resultados experimentais.

Em 1997 PAPA \& NAPPI propuseram um modelo para análise da alvenaria estrutural baseado em noções de plasticidade e dano. É considerado apenas o estado plano de tensões e uma superfície de ruptura no plano é introduzida. Incrementos de deformação inelástica são supostos apenas quando o estado de tensão ultrapassa os limites do critério de 
escoamento. Os incrementos são considerados parcialmente irreversiveis e são relacionados a um decréscimo gradual de rigidez. Seguindo conceitos básicos da teoria da plasticidade, incrementos de deformação plástica são assumidos como normais à superfície de ruptura. Depois de implementar o modelo em um programa de elementos finitos, um procedimento adequado é utilizado com o intuito de limitar o efeito de dependência de malha. Com o objetivo de verificar os resultados numéricos, foram considerados modelos experimentais reduzidos realizados pelos autores em 1993 em painéis de alvenaria. Levando-se em consideração a grande dispersão dos pontos de ruptura experimentais, foi encontrada uma boa concordância entre esses pontos de ruptura obtidos e os resultados numéricos. Verificou-se que as respostas numéricas, em termos de deslocamentos, apresentaram uma rigidez levemente maior que a experimental. Apesar disso o modelo permite que se determine a força de ruptura e a distribuição do dano com boa precisão.

Em 1997, LOURENÇO, DE BORST \& ROTS desenvolveram um modelo para estado plano de tensão de materiais ortotrópicos frágeis. A teoria da plasticidade, que é adotada para descrever o comportamento nãolinear, utiliza algoritmos modernos, incluindo uma técnica implícita de integração das tensões, o método de Newton-Raphson e uma matriz de rigidez tangente consistente. O modelo é capaz de predizer respostas independentes ao longo dos eixos do material. Ele possui características de energia de fratura à tração e à compressão, que são diferentes ao longo de cada eixo do material. O critério de resistência proposto no trabalho combina as vantagens dos conceitos da plasticidade moderna com uma poderosa representação anisotrópica do comportamento do material, que inclui diferentes características de encruamento/amolecimento ao longo de cada eixo do material. O critério de resistência composto é adequado para modelar materiais anisotrópicos sob estado plano de tensão e consiste de uma extensão das formulações tradicionais para materiais frágeis isotrópicos para descrever o comportamento ortotrópico. Critérios de resistência individuais são considerados para tração e compressão, descrevendo diferentes mecanismos de ruptura. O primeiro critério é associado com um processo de fratura localizada, denominado fissura do material, e o segundo critério é associado com um processo de fratura mais 
distribuído, que usualmente é denominado esmagamento do material. O critério de resistência apresentado representa um passo mais adiante do trabalho de FEENSTRA \& DE BORST (1996), que utilizaram esta aproximação para o concreto com o critério de Rankine associado ao critério de Drucker-Prager. Com o intuito de modelar o comportamento do material ortotrópico, os autores propõem um critério tipo Hill para a compressão e um critério tipo Rankine para a tração, conforme a figura 2.5. O dano interno devido aos mecanismos de ruptura pode ser representado por dois parâmetros internos, $\mathrm{K}_{\mathrm{t}}$ e $\mathrm{K}_{\mathrm{c}}$, um para o dano em tração e outro para o dano em compressão. O modelo é formulado de forma que cada parâmetro interno é relacionado com duas energias de fraturamento independentes ao longo de cada eixo do material. Por essa razão, é possível reproduzir diferentes comportamentos não-lineares ao longo de duas direções ortogonais.

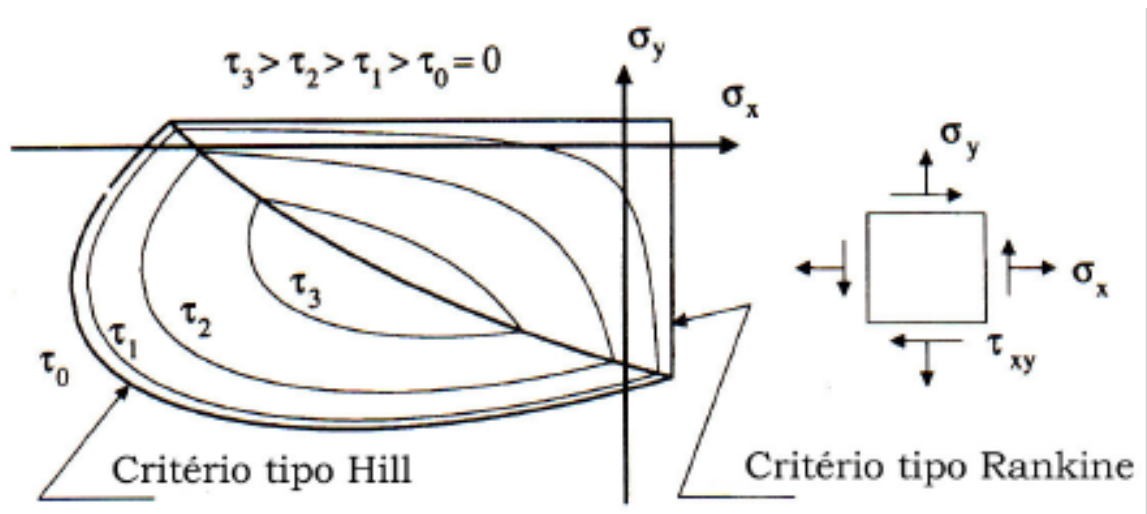

Figura 2.5 - Critério de resistência proposto. Diferentes valores de resistência à tração e compressão são adotados em cada um dos eixos dos materiais. Adaptada de LOURENÇO et al. (1997)

Boa concordância foi encontrada comparando-se resultados numéricos com dados experimentais para paredes de alvenaria de tijolos cerâmicos submetidas ao cisalhamento, onde ambos os modos de ruptura (tração e compressão) estão presentes. Outra grande vantagem apresentada pelo modelo foi a sua capacidade de acompanhar a curva tensãodeformação até a total degradação da resistência. 
LOURENÇO \& ROTS (1997b) elaboraram um estudo minucioso avaliando o desempenho do processo de homogeneização em duas etapas, que é baseado na hipótese de materiais em duas camadas. Foram feitas análises dos respectivos processos adotados por PANDE et al. (1989) e PAPA (1990). A eficiência das técnicas de homogeneização para a análise de estruturas de alvenaria foi discutida. A maior vantagem apresentada pela homogeneização é que, uma vez completamente determinadas as propriedades dos materiais constituintes, o comportamento do material composto pode ser estimado sem a necessidade de ensaios adicionais. Isto significa que alterações na geometria, por exemplo: dimensão das unidades e espessura das juntas ou arranjos geométricos, podem ser manipulados exclusivamente de forma numérica. Foi demonstrado que a homogeneização em duas etapas pode ser utilizada para a determinação das características lineares da alvenaria. Apesar disso, notou-se que resultados diferentes foram obtidos com os processos analisados, o que significa que o procedimento não é objetivo, mesmo em uma análise elástica linear. Portanto, na presença do comportamento não-linear, a técnica provavelmente iria gerar grandes erros, pelo menos para análises localizadas, e na presente forma, não é recomendada.

LUCIANO \& SACCO (1997) apresentaram um modelo de dano para alvenarias antigas, baseado numa formulação variacional para o problema periódico. É desenvolvido um procedimento numérico para a determinação das propriedades elásticas do material íntegro e danificado. Assim, a evolução do dano da alvenaria, considerando a geometria exata e as propriedades mecânicas dos constituintes do compósito é obtida. Assumese que o dano é devido a fusão e crescimento da fratura apenas na argamassa. Um volume elementar representativo é escolhido, sendo identificados oito estados possíveis de dano e material intacto para a alvenaria. A teoria da homogeneização, para materiais com micro-estrutura periódica, é utilizada para definir o módulo de elasticidade global da alvenaria fissurada e não fissurada. Um modelo de dano discreto foi obtido para o material alvenaria, resolvendo-se o problema micro/macro, isto é, o modelo de dano macromecânico foi determinado utilizando-se as características micromecânicas e a teoria da homogeneização. O modelo de dano obtido parece simples e capaz de identificar o comportamento de 
alvenarias regulares. Dois critérios de resistência para a argamassa foram adotados: um considerando a energia da fratura, e outro considerando o modelo de Coulomb. Como o procedimento proposto permite a determinação do estado elástico global no volume elementar representativo, pode-se enfatizar que qualquer outro tipo de critério de resistência local pode ser adotado no modelo. A eficácia do modelo de dano proposto foi analisada para o desenvolvimento de uma aplicação estrutural simples.

DE BUHAN \& DE FELICE (1997) apresentaram um modelo contínuo para estimar a ruptura da alvenaria, considerada como um material homogêneo. Em particular é demonstrado como a técnica de homogeneização permite construir um critério de resistência macroscópico para a alvenaria, descrita como um conjunto de unidades regulares separadas por juntas de argamassa em suas interfaces. Os autores alertam que a validade do modelo proposto, da forma como foi aplicado no artigo, é completamente dependente da dimensão do volume elementar representativo. É necessário que esta dimensão permaneça suficientemente pequena em relação às outras dimensões da estrutura, como por exemplo, o comprimento da parede.

Em 1997, PEGON \& ANTHOINE utilizaram a teoria da homogeneização para meios periódicos para deduzir o comportamento nãolinear da alvenaria no estado plano. Duas hipóteses diferentes são consideradas: o estado p lano de tensões e o estado plano de deformações. O estudo demonstrou que é possível determinar o comportamento nãolinear macroscópico da alvenaria, conhecendo-se o comportamento dos seus materiais constituintes, utilizando-se a teoria da homogeneização para meios periódicos. As dificuldades numéricas relacionadas com as características de amolecimento da lei constitutiva adotada podem ser contornadas através da utilização de estratégias de solução avançada. Apesar disso, duas propriedades importantes precisam ser consideradas:

a) Se uma análise bidimensional for realizada, o estado plano de deformações deve ser utilizado, porque a utilização do estado plano de tensões pode acarretar resultados errados, qualitativa e quantitativamente;

b) As juntas verticais não podem ser desprezadas, pois estas influem de forma significativa no comportamento global da alvenaria. Em particular, a aproximação simplificada de materiais em camadas não é 
confiável. Isto acontece apenas nos casos de comportamento não-linear. No caso de comportamento linear, uma estimativa bastante razoável das características elásticas macroscópicas podem ser obtidas admitindo-se estado plano de tensões e/ou aproximação de materiais em camadas.

LOURENÇO, ROTS \& BLAAUWENDRAAD (1998) apresentaram um novo critério de ruptura que inclui diferentes resistências ao longo de cada eixo do material. A capacidade do modelo de representar o comportamento não-linear de materiais ortotrópicos é demonstrado, e um conjunto de ensaios para caracterizar o comportamento constitutivo da alvenaria é proposto. A capacidade do modelo em reproduzir o comportamento de diferentes tipos de alvenaria é demonstrado através da comparação com dados experimentais avaliados em painéis de alvenaria submetidas ao cisalhamento e uma boa concordância foi encontrada. Um claro entendimento do comportamento de paredes de alvenaria submetidas ao cisalhamento, e o fenômeno não-linear envolvido em seu colapso é apresentado com a ajuda de uma comparação detalhada entre resultados numéricos e experimentais. No modelo adotaram-se dois mecanismos de ruptura distintos: um associado com o processo de fratura localizada e um associado com o processo de fratura dispersa, que pode ser definida como "esmagamento do material". Comparações entre os resultados experimentais e numéricos são apresentadas. Foi demonstrado que o modelo anisotrópico proposto é capaz de predizer efetivamente o comportamento das estruturas de alvenaria, tanto com modo de ruptura dúctil quanto frágil, assim como valores de carga de colapso suficientemente precisas.

LOPEZ et al. (1998) apresentaram um modelo de homogeneização que intrinsecamente inclui as propriedades mecânicas e geométricas dos diferentes componentes. O modelo apresentado é baseado em um estudo de equilíbrio e compatibilidade de uma célula básica da alvenaria sobre diferentes condições de carregamento. As principais hipóteses adotadas são:

a) O comprimento e a altura do elemento estrutural são grandes se comparados com sua espessura, o que permite que se adote o estado plano de tensões desde que o carregamento esteja atuando no plano; 
b) Dado o arranjo das unidades e das juntas de argamassa, o material composto pode ser tratado como ortotrópico.

O modelo constitutivo é baseado na formulação das equações de equilíbrio e compatibilidade para cada um dos modos de deformação da célula básica. Os autores concluíram que o processo de homogeneização simplifica significativamente o custo computacional da análise de painéis de alvenaria, tanto na geração das redes como no tempo de processamento. Verificou-se que, para análises localizadas, o processo de micromodelagem (unidade e argamassa separadas) é mais eficiente do que a macromodelagem. O modelo de homogeneização proposto não é capaz de identificar o mecanismo de fratura, mas identifica a zona de dano, que pode ser associado com o tipo de fissuração através da análise do estado de tensões dos elementos. O modelo permite ainda a utilização de juntas de argamassa orientadas em direções diferentes com respeito ao sistema de referência global.

LEE et al. (1998) apresentaram investigações numéricas de paredes de alvenaria estrutural de unidades cerâmicas submetidas a estados planos uniformes de tensão/deformação empregando-se várias técnicas de homogeneização. A alvenaria estrutural foi considerada como um material composto por unidades, juntas horizontais e juntas verticais. Assumiu-se uma ligação perfeita entre os materiais constituintes. Duas técnicas de homogeneização baseadas na energia de deformação são aplicadas para se determinar o módulo de elasticidade equivalente da alvenaria. Relações constitutivas são deduzidas para relacionar tensões e deformações dos materiais constituintes com as tensões e deformações médias da alvenaria. A resistência à tração da alvenaria é encontrada baseando-se na ruptura de um dos materiais constituintes. Demonstrou-se que a tensão de resistência à tração é função dos parâmetros elásticos da unidade e da argamassa, assim como da resistência à tração da argamassa. O estudo demonstrou que, apesar das fissuras iniciais ocorrerem sob forças de tração horizontais, a resistência última do painel de alvenaria é maior nesta direção do que na direção vertical.

BATI et al. (1999a,1999b) apresentaram um modelo micromecânico para determinar as propriedades médias elástico-lineares das estruturas em 
alvenaria. O modelo proposto descreve a alvenaria como uma matriz de argamassa com inserção das unidades de forma cilíndrica elíptica. No processo de homogeneização, constantes elásticas macroscópicas são determinadas a partir das propriedades mecânicas dos materiais constituintes e da proporção dos mesmos no volume da alvenaria. Comparações entre os resultados teóricos com valores obtidos experimentalmente e com resultados de outros processos de homogeneização demonstraram que o procedimento é adequado, apresentando resultados muito bons. Mesmo considerando-se diferentes padrões da alvenaria, inclusive utilizando-se espessuras grandes de argamassa, os resultados obtidos foram satisfatórios.

\subsection{Fechamento}

Analisando as informações obtidas nos diversos trabalhos apresentados, verifica-se que os modelos disponíveis para a análise do material alvenaria são inúmeros. A escolha do modelo a ser adotado em cada estudo depende do objetivo da análise e do grau de precisão necessária.

No presente trabalho será feita uma análise sobre o processo de homogeneização. Serão apresentados, também, modelos não-lineares, disponíveis em softwares comerciais, e será feita uma análise da sua representatividade em relação a alguns modelos experimentais.

A seguir apresenta-se um quadro resumo com os diferentes modelos agrupados, incluindo suas vantagens e desvantagens. 


\section{Quadro Resumo}

\begin{tabular}{|c|c|c|}
\hline Modelo & Vantagens & Desvantagens \\
\hline $\begin{array}{l}\text { Modelo discreto com } \\
\text { comportamento linear } \\
\text { isotrópico }\end{array}$ & $\begin{array}{l}\text { Bons resultados em } \\
\text { estruturas submetidas a } \\
\text { níveis baixos de tensão }\end{array}$ & $\begin{array}{l}\text { Não adequado para casos } \\
\text { em que as tensões } \\
\text { aplicadas são altas e onde } \\
\text { é necessária uma análise } \\
\text { de redistribuição de } \\
\text { tensões. }\end{array}$ \\
\hline $\begin{array}{l}\text { Modelo homogeneizado } \\
\text { com comportamento } \\
\text { linear ortotrópico }\end{array}$ & $\begin{array}{l}\text { Adequado para estudo do } \\
\text { comportamento global da } \\
\text { estrutura. Com a } \\
\text { vantagem de uma } \\
\text { modelagem mais simples e } \\
\text { um tempo de } \\
\text { processamento menor que } \\
\text { o modelo discreto. }\end{array}$ & $\begin{array}{l}\text { Em termos locais, grandes } \\
\text { diferenças podem ser } \\
\text { encontradas, mesmo numa } \\
\text { análise linear. O modelo } \\
\text { não é capaz de identificar } \\
\text { picos de tensões em } \\
\text { regiões localizadas, que o } \\
\text { modelo discreto consegue } \\
\text { determinar. }\end{array}$ \\
\hline $\begin{array}{l}\text { Modelo homogeneizado } \\
\text { com comportamento não- } \\
\text { linear do material }\end{array}$ & $\begin{array}{l}\text { Apresenta bons resultados } \\
\text { em termos de } \\
\text { comportamento global e } \\
\text { determinação da carga de } \\
\text { ruptura. }\end{array}$ & $\begin{array}{l}\text { O modelo não é capaz de } \\
\text { representar alguns } \\
\text { mecanismos básicos de } \\
\text { ruptura da alvenaria, como } \\
\text { por exemplo, a fissuração } \\
\text { nas juntas e unidades e o } \\
\text { escorregamento das } \\
\text { juntas. }\end{array}$ \\
\hline $\begin{array}{l}\text { Modelo discreto com } \\
\text { comportamento elástico } \\
\text { linear para as unidades e } \\
\text { elemento de ligação não- } \\
\text { linear nas juntas }\end{array}$ & $\begin{array}{l}\text { Modelagem apropriada } \\
\text { com a vantagem de } \\
\text { determinação das } \\
\text { características do material } \\
\text { através de ensaios } \\
\text { uniaxiais. }\end{array}$ & $\begin{array}{l}\text { Não considera a fissuração } \\
\text { e a não-linearidade da } \\
\text { unidade. Não é capaz de } \\
\text { determinar a ruptura da } \\
\text { estrutura, quando } \\
\text { fortemente influenciada } \\
\text { pelas rupturas nas } \\
\text { unidades. }\end{array}$ \\
\hline $\begin{array}{l}\text { Modelo discreto com } \\
\text { características de } \\
\text { deformação não-linear } \\
\text { para a unidade e a } \\
\text { argamassa, critério para a } \\
\text { ruptura da unidade, da } \\
\text { argamassa e da junta. }\end{array}$ & $\begin{array}{l}\text { A idealização proposta é } \\
\text { capaz de representar o } \\
\text { comportamento nas } \\
\text { estruturas em alvenaria, } \\
\text { determinando a carga } \\
\text { inicial de fissuração, a } \\
\text { carga última e o padrão de } \\
\text { ruptura com boa precisão. }\end{array}$ & $\begin{array}{l}\text { São necessários ensaios } \\
\text { complexos de } \\
\text { caracterização das } \\
\text { unidades, da argamassa e } \\
\text { de amostras de paredes. }\end{array}$ \\
\hline $\begin{array}{l}\text { Modelo de fissuras } \\
\text { discretas considerando-se } \\
\text { as propriedades não- } \\
\text { lineares dos materiais. }\end{array}$ & $\begin{array}{l}\text { Mais apropriado para a } \\
\text { análise de painéis } \\
\text { submetidos a forças } \\
\text { concentradas. }\end{array}$ & $\begin{array}{l}\text { Apresenta um custo } \\
\text { computacional elevado. }\end{array}$ \\
\hline $\begin{array}{l}\text { Modelo de fissuras } \\
\text { espalhadas com a } \\
\text { consideração do } \\
\text { comportamento não-linear } \\
\text { dos componentes. }\end{array}$ & $\begin{array}{l}\text { Bons resultados na } \\
\text { determinação da força } \\
\text { última de ruptura e no } \\
\text { padrão de ruptura dos } \\
\text { painéis. Tempo de } \\
\text { processamento mais baixo. }\end{array}$ & $\begin{array}{l}\text { Podem aparecer tensões de } \\
\text { travamento e os resultados } \\
\text { devem ser analisados com } \\
\text { cuidado devido à } \\
\text { dependência da dimensão } \\
\text { da rede. }\end{array}$ \\
\hline
\end{tabular}


MODELOS

\subsection{Introdução}

Apresenta-se aqui um resumo dos modelos utilizados na realização deste trabalho. Os modelos empregados se restringiram àqueles encontrados nos softwares ANSYS e ABAQUS e que se apresentavam mais adequados à análise numérica de alvenaria estrutural.

\subsubsection{Modelos para materiais frágeis (ANSYS)}

De acordo com o manual do programa, o modelo para materiais frágeis do ANSYS inclui a ruptura por fissuração ou esmagamento. É possivel a consideração de fissuração, em zonas tracionadas, e esmagamento, em zonas comprimidas. Esse modelo é aplicável ao concreto, rocha, e outros materiais que apresentem uma baixa resistência à tração e uma alta resistência à compressão. O modelo considera que o material rompe completamente assim que atinge a carga máxima. É considerado um comportamento elástico linear até o ponto de ruptura. Graficamente o comportamento, para o caso uniaxial, é representado na figura 3.1. Esse critério pode ser utilizado exclusivamente com o elemento SOLID65. O elemento é utilizado para modelagens tridimensionais de estruturas com ou sem barras de aço (reforços). Aplicando-se ao concreto, por exemplo, o 
elemento pode ser utilizado para modelar o concreto e as armaduras. O elemento é definido por oito nós, possuindo três graus de liberdade por nó: translações segundo as direções $\mathrm{x}, \mathrm{y}$ e $\mathrm{z}$. O modelo permite a inclusão de armaduras dispersas, compostas de até três materiais diferentes e independentes, orientadas segundo três direções quaisquer.

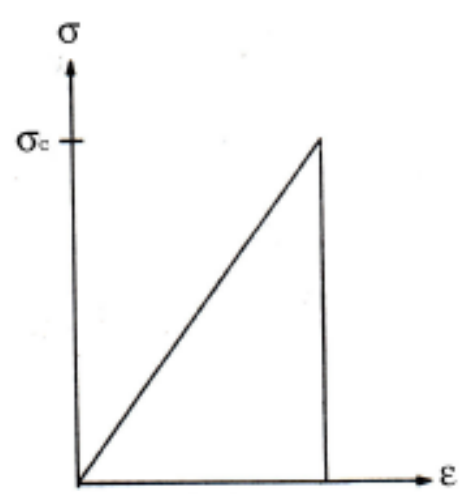

(a) Comportamento uniaxial à compressão

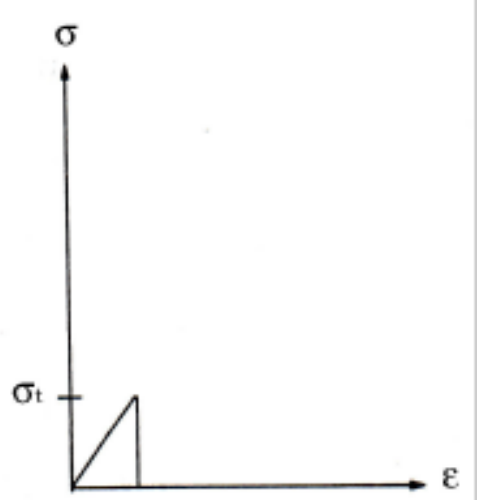

(b) Comportamento uniaxial à tração

Figura 3.1 - Comportamento uniaxial do modelo

Adaptada do Manual do ANSYS

A fissuração é representada no ANSYS por um modelo de fissuras dispersas. Atingida a superfície de ruptura por tensões de tração em um ponto de integração do elemento, introduz-se, por meio de modificações nas relações entre tensões e deformações, na direção normal à face da fissura, um plano de menor resistência. A fissuração pode acontecer em até três direções ortogonais, de forma que uma fissura pode se desenvolver em um plano e se uma subseqüente tensão, tangencial à face da fissura, for grande o bastante, uma segunda (ou terceira) fissura vai se desenvolver. A fissura é tratada como uma faixa dispersa de fissuras e não como uma fissura discreta.

Segundo os manuais, o critério de ruptura do material devido a um estado multiaxial de tensões pode ser expresso da seguinte forma:

$$
\frac{\mathrm{F}}{\mathrm{f}_{\mathrm{c}}}-\mathrm{S} \geq 0
$$

Onde:

$\mathrm{F}$ é função do estado de tensões principais $\left(\sigma_{\mathrm{xp}}, \sigma_{\mathrm{yp}}, \sigma_{\mathrm{zp}}\right)$ 
S é a superfície de ruptura

$\mathrm{f}_{\mathrm{c}}$ é a resistência uniaxial ao esmagamento

$\sigma_{\mathrm{xp}}, \sigma_{\mathrm{yp}}, \sigma_{\mathrm{zp}}$ são as tensões principais nas direções principais.

Satisfeita essa equação, ocorrerá fissuração, se alguma das tensões principais for de tração, ou esmagamento, se todas as tensões principais forem de compressão.

Tanto a função $\mathrm{F}$, quanto a superfície de ruptura $\mathrm{S}$, é expressa em termos das tensões principais $\sigma_{1}, \sigma_{2}, \sigma_{3}$, onde:

$$
\begin{aligned}
& \sigma_{1}=\max \left(\sigma_{x p}, \sigma_{y p}, \sigma_{z p}\right) \\
& \sigma_{3}=\min \left(\sigma_{x p}, \sigma_{y p}, \sigma_{z p}\right)
\end{aligned}
$$

$\mathrm{E} \sigma_{1} \geq \sigma_{2} \geq \sigma_{3}$. A ruptura do material é definida por quatro domínios:

$$
\begin{array}{ll}
0 \geq \sigma_{1} \geq \sigma_{2} \geq \sigma_{3} & (\text { comp/comp /comp) } \\
\sigma_{1} \geq 0 \geq \sigma_{2} \geq \sigma_{3} & (\text { tração/comp/comp) } \\
\sigma_{1} \geq \sigma_{2} \geq 0 \geq \sigma_{3} & (\text { tração/tração/comp) } \\
\sigma_{1} \geq \sigma_{2} \geq \sigma_{3} \geq 0 & \text { (tração/tração/tração) }
\end{array}
$$

Em cada um dos domínios, funções independentes descrevem $\mathrm{F}$ e a superfície de ruptura S. A superfície S é apresentada nas figuras 3.2 e 3.3.

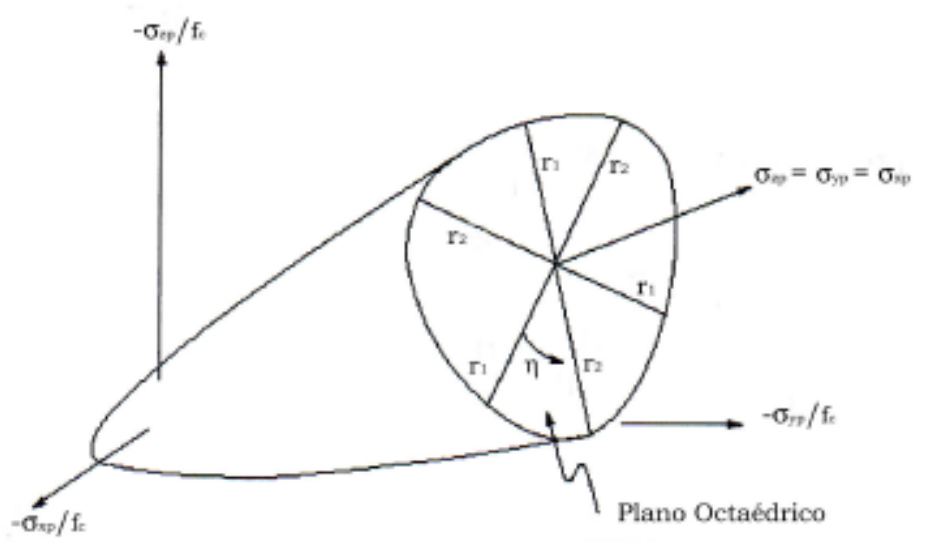

Figura 3.2 - Superfície de ruptura em três dimensões Adaptada do Manual do ANSYS 


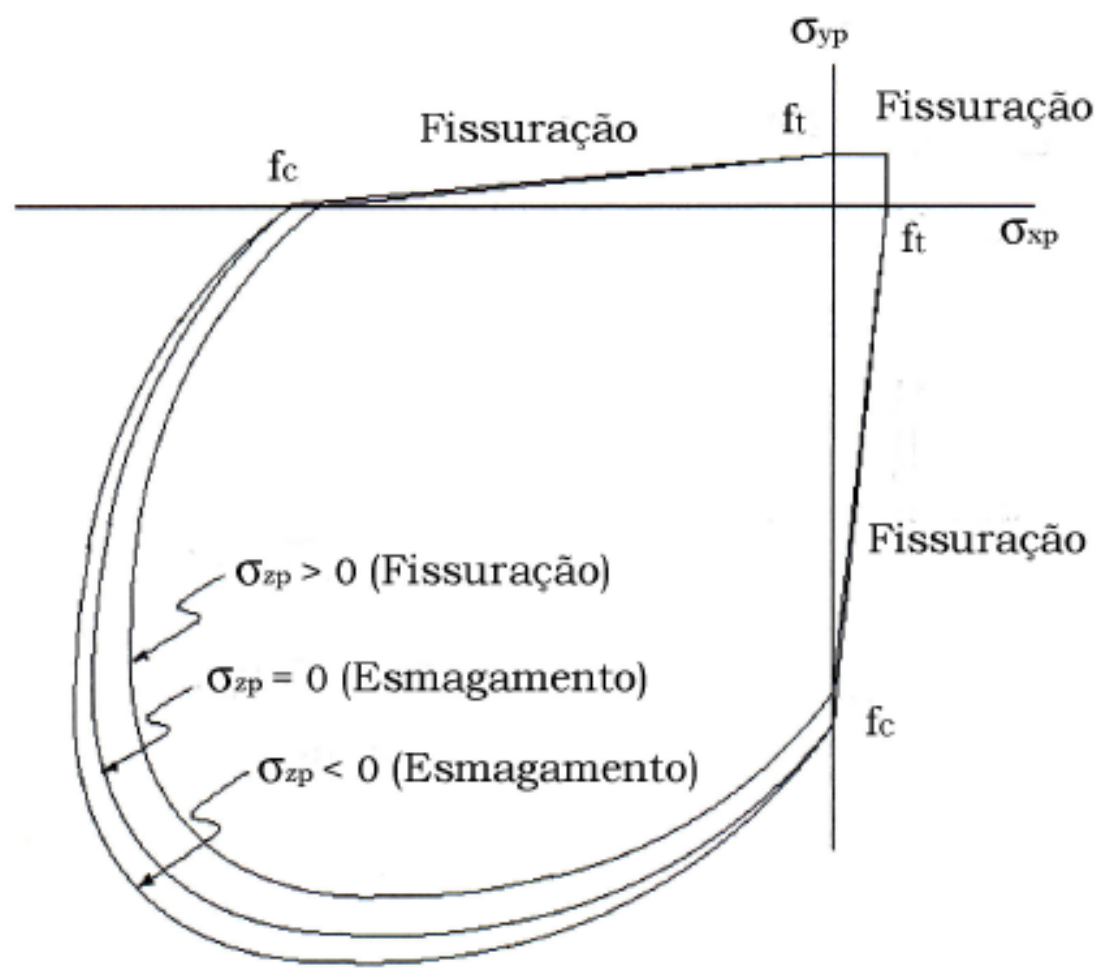

Figura 3.3 - Superfície de ruptura em duas dimensões

Adaptada do Manual do ANSYS

O modelo adotado de fissuras dispersas não considera a energia de fraturamento associada ao critério de ruptura, tornando os modelos que o utilizam sujeitos a problemas de dependência das redes utilizadas nas modelagens. Assim, os resultados das análises realizadas com esse modelo devem ser avaliados cuidadosamente, sendo recomendável cautela no seu emprego, observando-se o comportamento de diferentes malhas.

Quanto ao esmagamento, uma vez atingida a superfície de ruptura em um ponto de integração, considera-se que há uma completa deterioração da integridade do material e ocorre uma imediata perda da capacidade do modelo absorver tensões, as quais se anulam bruscamente.

Nenhum dos modelos de que o ANSYS dispõe para a representação de comportamentos não lineares de materiais, específico para materiais frágeis ou não, é capaz de caracterizar o fenômeno do amolecimento. 


\subsubsection{Modelo elastoplástico clássico (ABAGUS/Standard)}

A maioria dos modelos de plasticidade do ABAQUS utiliza a técnica de incrementos, na qual a taxa de deformação é decomposta em uma parte elástica e uma parte plástica (inelástica). Modelos de plasticidade incremental são usualmente definidos em termos de:

a) Uma superfície de ruptura - generaliza o conceito de carga de ruptura numa "função teste", que pode ser utilizada para determinar se o material responde elasticamente em um estado particular de tensões;

b) Uma regra de fluxo - que define a deformação plástica que ocorre se o ponto do material não está mais respondendo de forma puramente elástica;

c) Lei de evolução - que define o encruamento, a forma ou caminho, com que a definição de ruptura ou do fluxo muda conforme as deformações plásticas ocorrem.

Este modelo de material, denominado de PLASTIC pelo ABAQUS, é usualmente adotado para a análise não linear de metais. No ABAQUS este modelo adota as superfícies clássicas de von Mises ou Hill, com fluxo associativo, o que significa que não há deformação plástica volumétrica. Este modelo apresenta-se bastante simples e adequado, fornecendo bons resultados para aplicações corriqueiras, incluindo análise de ruptura, perfilamento de metais e estudos gerais de colapso.

Devido à sua simplicidade, as equações algébricas são facilmente desenvolvidas em termos de variáveis simples e a matriz de rigidez do material pode se escrita explicitamente. Os dados de entrada no programa para este modelo são os pontos que definem a curva tensão x deformação plástica do material. Nos casos em que a não linearidade da alvenaria for essencialmente devida ao comportamento plástico dos seus componentes, e não devida à fissuração, esse modelo pode simular de forma mais adequada o seu comportamento. 


\subsubsection{Modelo elastoplástico para o concreto (ABAQUS/Standard)}

Segundo o manual, o modelo elastoplástico para o concreto do ABAGUS/Standard é direcionado para o comportamento do material submetido à ação de carregamentos monotônicos sob pressões de confinamento pequenas (menores que quatro ou cinco vezes a maior tensão de compressão que pode ser admitida para o concreto na compressão uniaxial). Ele foi concebido para fornecer uma ferramenta capaz de modelar o concreto simples e o concreto armado em todos os tipos de estruturas: vigas, pórticos, cascas e sólidos. Assim como acontece nas paredes de alvenaria, o modelo considera a fissuração como o aspecto mais importante do comportamento do material. O modelo considera que a fissuração ocorre na estrutura quando a tensão atuante atinge a superfície de ruptura definida e considera também a anisotropia introduzida no material pelo aparecimento das fissuras. O modelo adotado é de fissuras dispersas, já que as fissuras não são definidas individualmente e sim consideradas nos pontos de integração do elemento. Mudanças independentes nas relações constitutivas são realizadas em cada ponto de integração do modelo em elementos finitos, e a presença de fissuras é considerada nesses cálculos à medida que elas afetam as tensões e a rigidez do material associada com o ponto de integração.

A fissuração é admitida como sendo o aspecto mais importante do comportamento do material, e a sua representação, bem como o comportamento pós-fissura, predomina na definição do modelo. A hipótese adotada é de que a fissuração ocorre quando a tensão atinge a superfície de ruptura denominada superfície de fissuração. Esta superfície é uma relação linear entre a tensão média, $p$, e a tensão equivalente de von Mises, $q$, e está ilustrada na figura 3.4. Quando uma fissura é detectada, sua orientação é armazenada para ser utilizada em cálculos subseqüentes. Fissuras posteriores que ocorram no mesmo ponto são restritas a serem ortogonais a essa direção, já que as componentes de tensão associadas com a fissura aberta não são incluídas na definição da superfície de ruptura utilizada para verificar o aparecimento de fissuras adicionais. Verificado o aparecimento de uma fissura, um critério de dano elástico é então utilizado 
para descrever o comportamento pós-ruptura do concreto com fissuras abertas.

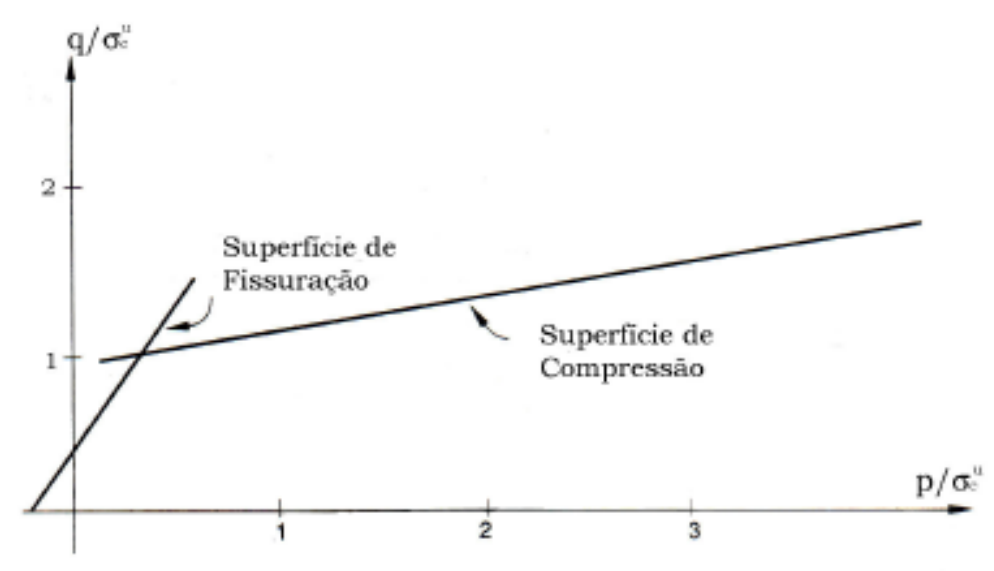

Figura 3.4 - Superficie de ruptura no plano $p$ - $q$

Adaptada do Manual do ABAGUS

Quando o material é carregado à tração, responde elasticamente até uma carga de 7-10\% da tensão última de compressão; a partir desse nível as fissuras começam a se formar. Na prática as fissuras se formam tão rapidamente que é muito difícil observar o seu comportamento, mesmo nos ensaios experimentais com deformação controlada. Com o propósito de desenvolver o modelo, o programa assume que o material perde resistência através do mecanismo de amolecimento, e que este é predominantemente um efeito de dano, no sentido de que as fissuras abertas podem ser representadas pela perda da rigidez elástica. O modelo despreza qualquer deformação permanente associada com a fissuração; isto é, ele assume que as fissuras podem se fechar quando a tensão através delas se torna de compressão.

Guando as componentes de tensão principal são predominantemente de compressão, a resposta do concreto é modelada por uma teoria elastoplástica, utilizando uma forma simples para a superfície de ruptura escrita em termos da tensão média, $p$, e da tensão equivalente de von Mises, q. Esta superfície está ilustrada na figura 3.4. São adotados fluxo associativo e encruamento isótropo. Este modelo simplifica significativamente o comportamento real: o fluxo associativo geralmente superestima o volume de deformação plástica. A superfície de ruptura 
utilizada não representa de forma precisa os estados triaxiais de tensão e compressão, por não levar em consideração o terceiro invariante das tensões. As respostas uniaxiais do material à fissuração e à compressão estão ilustradas na figura 3.5.

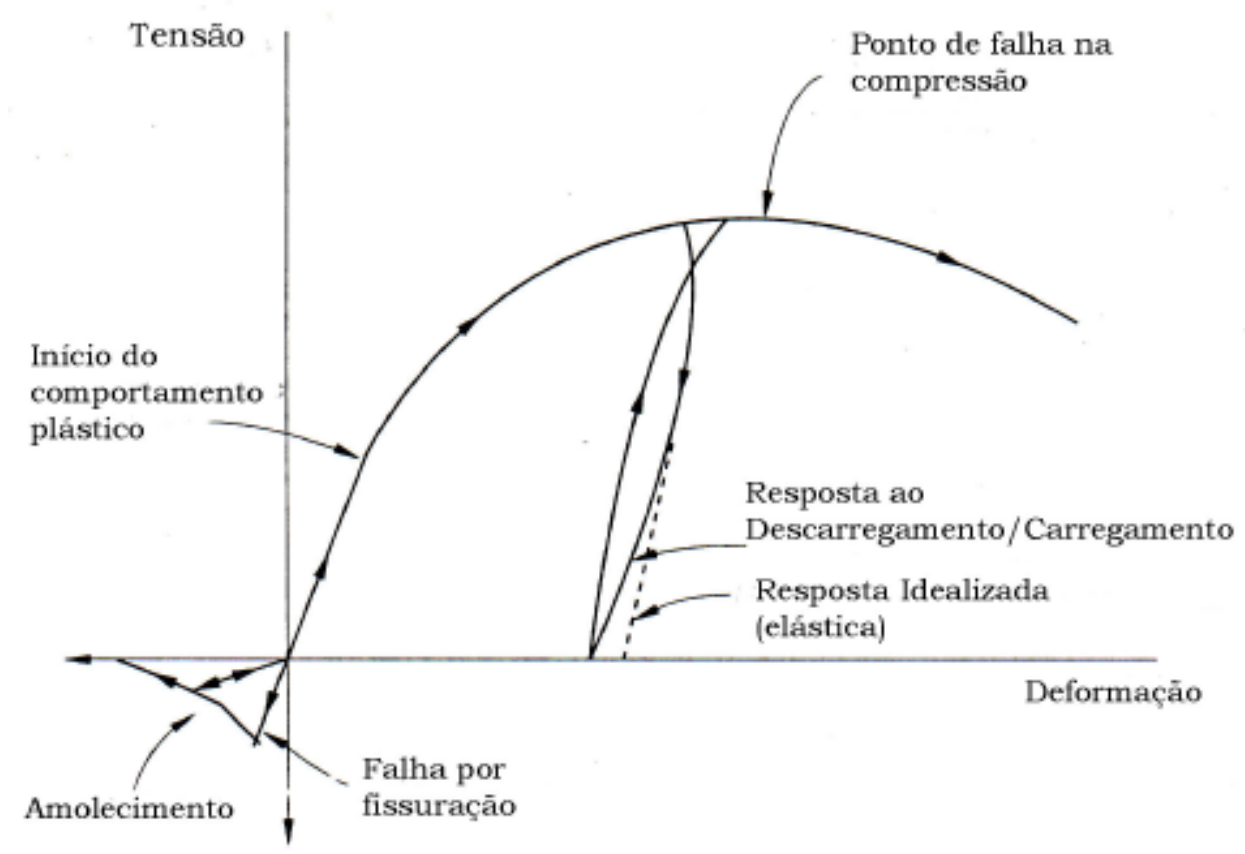

Figura 3.5 - Comportamento uniaxial do modelo

Adaptada do Manual do ABAQUS

Quando o material é carregado em compressão, no início exibe uma resposta elástica. À medida que a tensão aumenta, aparecem deformações plásticas, e a resposta do material sofre um "amolecimento". Guando a tensão última do material é atingida, sua rigidez vai diminuindo até que não suporte mais nenhum acréscimo de tensão. No comportamento real, se a carga aplicada for removida em algum ponto depois que a deformação plástica ocorrer, a resposta ao descarregamento é menos rígida que a resposta elástica inicial: este efeito é ignorado no modelo. 


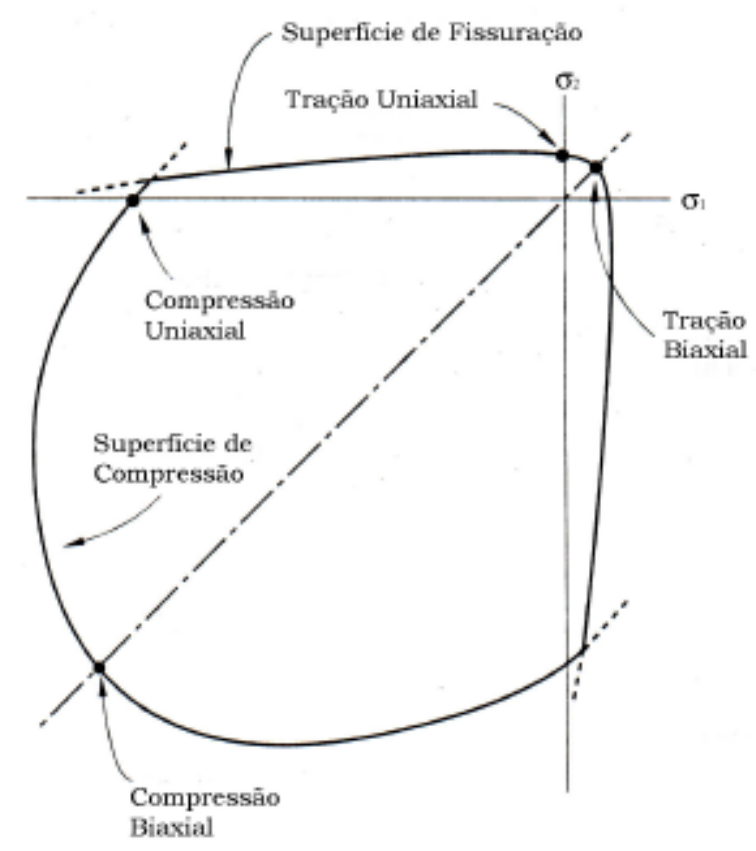

Figura 3.6 - Superfície de ruptura no estado plano de tensões Adaptada do Manual do ABAQUS

Considerando-se o estado multiaxial de tensões, estas observações podem ser generalizadas utilizando-se os conceitos de superfícies de ruptura e da resistência última no espaço das tensões principais. Estas superfícies são ajustadas com dados experimentais. Superfícies típicas são apresentadas nas figuras 3.4 e 3.6.

\subsubsection{Modelo para materiais frágeis (ABAQUS/Explicit)}

O modelo de fissuras para materiais frágeis do ABAQUS/Explicit pretende modelar o concreto simples, mas pode ser usado para outros materiais como rocha, materiais cerâmicos e alvenaria. Apresentam-se aqui as características básicas do modelo e as diferenças entre esse modelo e o modelo elastoplástico apresentado no item 3.1.3.

Em geral aceita-se que o concreto exibe dois modos de ruptura básicos: um modo frágil, no qual microfissuras existentes fundem-se formando macrofissuras que representam regiões de grandes deformações localizadas; e um modo dúctil onde as microfissuras se desenvolvem mais 
ou menos uniformemente através do material, produzindo deformações não localizadas. O comportamento frágil é associado com mecanismos que são observados sob estados de tensão de tração ou tração/compressão, como clivagem, cisalhamento e modos mistos de fratura. Esses mecanismos quase sempre envolvem um amolecimento do material. O comportamento dúctil é associado com o mecanismo de distribuição de microfissuras que é observado principalmente sob estados de tensão em compressão. $\mathrm{Na}$ maioria das vezes envolve encruamento do material, mas um amolecimento subseqüente é possivel quando tem-se baixas pressões de confinamento. $\mathrm{O}$ modelo de fissura existente no programa modela apenas os aspectos frágeis do comportamento do material. Apesar de se tratar de uma simplificação, existem aplicações onde apenas o comportamento frágil do material é significante e, assim, a hipótese de que o material é elástico linear na compressão é justificável.

Um modelo de fissuras espalhadas é adotado para representar o comportamento frágil das macrofissuras descontínuas. Nesta aproximação as fissuras não são consideradas individualmente, mas a sua presença influencia os cálculos, considerando-se que as fissuras afetam as tensões e a rigidez do material em cada um dos pontos calculados.

Por simplicidade considera-se apenas a direção na qual a fissura foi detectada no ponto do material em questão. O conceito físico mais próximo é que existe um conjunto contínuo de fissuras no ponto, orientadas como determinado pelo modelo. A anisotropia introduzida pela fissuração é incluída no modelo considerando-se que ela é importante nas simulações para as quais o modelo foi realizado.

Várias objeções foram levantadas a respeito do modelo de fissuras espalhadas. A preocupação principal é que este modelo aproximado introduz sensibilidade da rede nas soluções, no sentido de que os resultados em elementos finitos não convergem para uma solução única. Por exemplo, uma vez que a fissuração é associada com a deformação de amolecimento, um refinamento da rede vai levar a um estreitamento da faixa de fissuração.

Vários pesquisadores têm proposto modelos com três direções básicas: fissuras fixas ortogonais; o modelo de fissuras rotacionadas; e as fissuras fixas multirotacionais (não ortogonais). No modelo fixo de fissuras 
ortogonais, a direção normal à primeira fissura é alinhada com a direção da tensão principal máxima de tração no momento em que se inicia a fissura. O modelo armazena essa direção, e as fissuras subseqüentes formadas no ponto considerado só podem se formar em direções ortogonais à da primeira fissura. No conceito de fissuras rotacionadas, apenas uma única fissura pode se formar em um determinado ponto (alinhada com a direção da tensão principal máxima de tração). Então a direção da fissura simples rotaciona com a direção do eixo de tensões principais. Este modelo não armazena as direções da fissura. O modelo de fissuras multidirecionais permite a formação de qualquer número de fissuras num ponto, desde que as direções das tensões mudem com o carregamento aplicado. O modelo armazena todas as direções de fissuras formadas.

O modelo de fissuras multidirecionais é o menos popular, principalmente porque o critério utilizado para decidir quando as fissuras subseqüentes vão se formar (para limitar o número de fissuras em um ponto) é arbitrário: o conceito de "ângulo limite" é introduzido para prevenir que novas fissuras se formem com ângulos menores que este valor limite em relação às fissuras existentes. O modelo de fissuras fixas e de fissuras rotacionadas tem sido bastante utilizados, embora possam ser levantadas objeções contra ambos. No modelo de fissuras rotacionadas, o conceito de fechamento e reabertura de fissuras não é bem definido, porque a orientação da fissura pode variar continuamente. O modelo de fissuras fixas tem sido criticado principalmente porque o tratamento tradicional de "retenção de cisalhamento", empregado no modelo, tende a fazer com que a resposta seja muito rígida. Este problema pode ser resolvido formulando-se a retenção por cisalhamento de forma que se assegure que a tensão de cisalhamento se aproxime de zero à medida que a deformação na interface acontece (isto é feito no modelo do ABAGUS). Finalmente, apesar do modelo de fissuras ortogonais fixas possuir a limitação da ortogonalidade, é considerado superior ao modelo de fissuras rotacionadas nos casos onde o efeito de múltiplas fissuras é importante (o modelo de fissuras rotacionadas é limitado a uma única fissura em cada ponto).

O modelo de fissuras ortogonais fixas é utilizado no ABAQUS, de forma que o número máximo de fissuras em um ponto do material é limitado pelo número de direções das componentes de tensão presentes no 
ponto do material no modelo de elementos finitos (por exemplo: um máximo de três fissuras em modelos tridimensionais, axissimétricos, e problemas de estado plano de deformação; ou um máximo de duas fissuras nos casos de problemas em estado plano de tensão). Uma vez que aconteça uma fissura em um ponto do material, as formas das componentes de todos os valores e quantidades de vetores e tensores são ortogonais, assim esse sistema local é cartesiano retangular. Aberturas e fechamentos de fissuras podem acontecer ao longo das direções das normais às superfícies da fissura. $\mathrm{O}$ modelo despreza qualquer deformação permanente associada com a fissuração, isto é, assume-se que as fissuras podem se fechar completamente quando a tensão através delas se tornar de compressão.

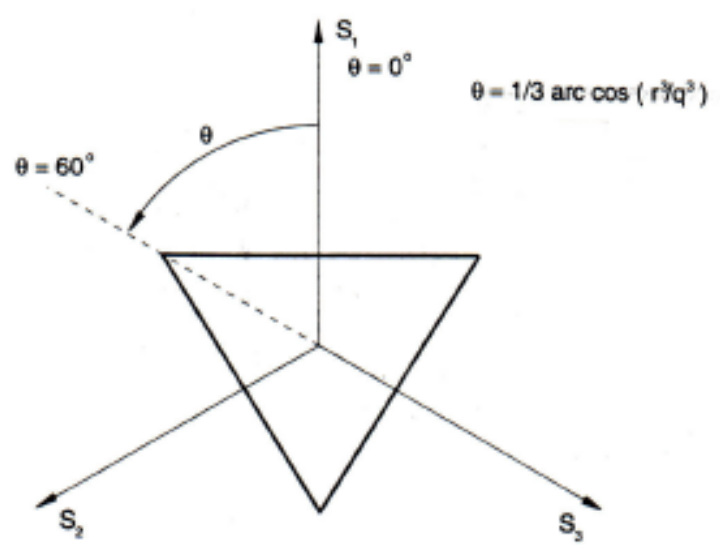

\section{Figura 3.7 - Critério de Rankine no plano desviador}

Adaptada do Manual do ABAQUS

O critério de Rankine é utilizado para verificar a ocorrência da fissura. De acordo com esse critério, a fissura se forma quando a tensão principal máxima de tração excede a resistência à tração do material frágil. Assim que o critério de Rankine para formação de fissura é atingido, assume-se que uma primeira fissura se formou. A superfície de detecção de fissuras de Rankine é apresentada na figura 3.7 no plano desviador de tensões, na figura 3.8 no plano meridiano e na figura 3.9 no estado plano de tensões. A superfície de fissuração é adotada como normal à tensão principal máxima de tração. As fissuras subseqüentes são consideradas sempre ortogonais à direção da primeira fissura, no mesmo ponto. 


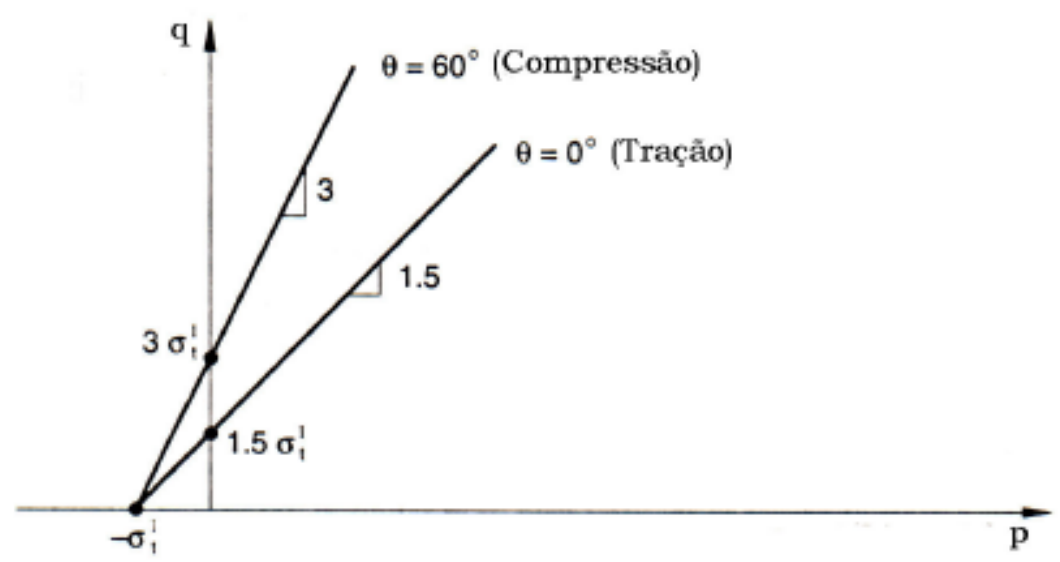

Figura 3.8 - Critério de Rankine no plano $p$ - $q$ Adaptada do Manual do ABAQUS

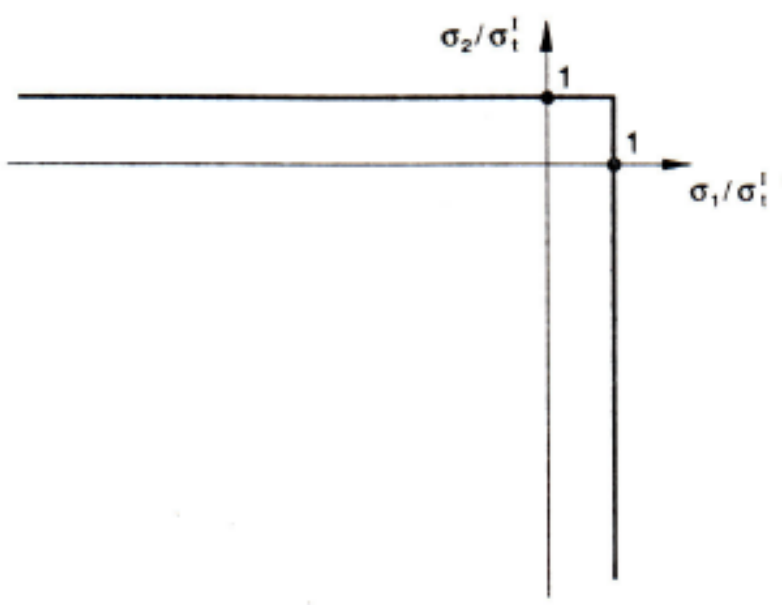

Figura 3.9 - Critério de Rankine no estado plano de tensões

Adaptada do Manual do ABAQUS

A orientação das fissuras é armazenada para cálculos posteriores, e são sempre adotadas, por conveniência, num sistema local de coordenadas na direção das fissuras. A fissuração é irreversivel, no sentido de que uma vez que ocorra num determinado ponto, ela permanece ao longo de todo o processo. Mas, a fissura pode se fechar e tornar a abrir posteriormente. 


\subsection{Fechamento}

Os modelos apresentados serão utilizados para analisar o comportamento de painéis de alvenaria submetidos à compressão. Os resultados numéricos obtidos serão confrontados com resultados experimentais. Serão comparadas principalmente as forças de ruptura, o mecanismo de ruptura e as relações tensão x deformação. 


\subsection{Generalidades}

A alvenaria pode ser considerada como um meio contínuo, não homogêneo e que apresenta características mecânicas ortotrópicas. Trata-se ainda de um meio composto por dois materiais diferentes, a unidade (bloco ou tijolo) e a argamassa arranjadas de forma periódica. De acordo com ANTHOINE (1995) é possível utilizar-se da teoria da homogeneização para meios periódicos e determinar o comportamento da alvenaria a partir do comportamento dos seus materiais constituintes. $O$ processo de homogeneização consiste em se definir um material fictício cujas propriedades mecânicas são equivalentes às características médias de um dado material não-homogêneo.

Admitindo-se que as dimensões das não homogeneidades sejam pequenas quando comparadas com a dimensão da estrutura e tratando-se de um material composto, formado de blocos unidos pela argamassa, é possivel considerar a alvenaria como um material homogêneo.

Segundo LOURENÇO \& ROTS (1997b) o problema de descrever o comportamento da alvenaria em termos de tensões e deformações médias tem sido aproximado, basicamente, de duas maneiras. Uma delas é coletar, confrontar e interpretar extensivos dados experimentais e procurar expressões analíticas para uma lei constitutiva ortotrópica que pareça ajustar esses dados. Esta aproximação é necessária porque o conhecimento 
do comportamento composto da alvenaria é escasso, entretanto os resultados são limitados pelas condições em que os dados são obtidos.

Outra maneira é utilizar técnicas aproximadas de homogeneização. Neste caso, uma lei macroconstitutiva é obtida a partir da lei microconstitutiva e da geometria do material composto, de maneira que a lei macroconstitutiva não é efetivamente implementada, ou exatamente conhecida. Conhecendo-se essa relação, o comportamento da alvenaria é determinado, sendo que alterações na sua geometria podem ser manipuladas numericamente, sem a necessidade de um número excessivo de ensaios.

A última aproximação é interessante porque é comum utilizarem-se blocos de diferentes geometrias e argamassa de diferentes espessuras. Por esse motivo, a pesquisa das possibilidades de utilizar técnicas de homogeneização para a análise de estruturas de alvenaria tem se intensificado na última década.

\subsection{Determinação das características elásticas da alvenaria}

Apresenta-se aqui uma comparação entre as propriedades elásticas obtidas numericamente $\mathrm{e}$ as propriedades obtidas analiticamente, utilizando-se o método proposto por PANDE et al. (1989) para uma célula de alvenaria (figura 4.1).

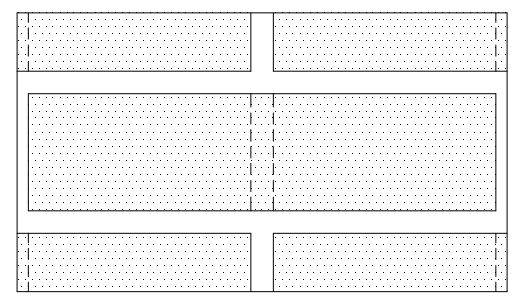

Figura 4.1 - Célula típica da alvenaria

Adaptada de LOURENÇO(1996)

O processo utilizado apresentado por PANDE et al. consiste de duas etapas: num primeiro passo é realizada uma homogeneização horizontal, unindo-se os blocos e as juntas verticais; numa segunda etapa a 
homogeneização vertical é efetuada, unindo-se o material já homogeneizado e as juntas horizontais. Para a determinação numérica, a célula é modelada utilizando-se o software ANSYS. A discretização da célula é apresentada na figura 4.2. Ressalta-se que foram analisadas outras discretizações com dimensões menores, mas os resultados não apresentaram diferenças significativas. Adotou-se um elemento quadrilateral para estado plano de tensões, o PLANE42, que possui quatro nós e dois graus de liberdade por nó (translações segundo as direções x e y).

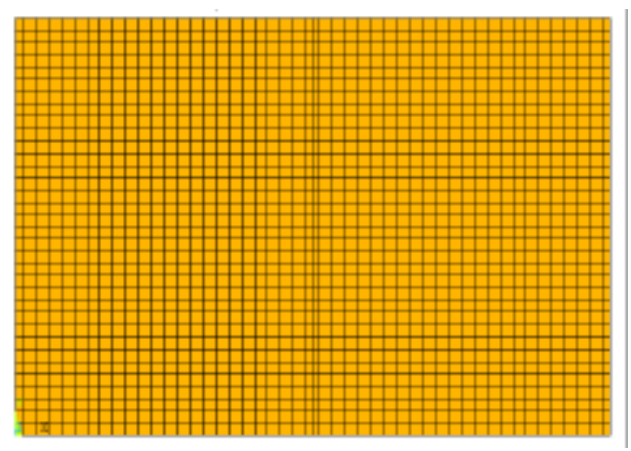

Figura 4.2 - Discretização da Célula

No presente estudo o bloco e a argamassa são considerados com comportamento linear isotrópico. As propriedades adotadas para o bloco são constantes e a razão entre o módulo de elasticidade do bloco e da argamassa variam de 1,1 até 11 . As propriedades dos materiais adotadas para as modelagens são:

Módulo de elasticidade do bloco

Coeficiente de Poisson do bloco

Coeficiente de Poisson da argamassa

Largura do bloco

Altura do bloco

Espessura do bloco
- $\quad E_{b}=1,1 \times 10^{4} \mathrm{~N} / \mathrm{mm}^{2}$

$-v_{b}=0,25$

$-v_{\mathrm{a}}=0,20$

$-\quad \mathrm{L}_{\mathrm{b}}=225 \mathrm{~mm}$

- $\quad \mathrm{H}_{\mathrm{b}}=225 \mathrm{~mm}$

- $\quad$ Esp $=100 \mathrm{~mm}$

Para se determinar numericamente o módulo de elasticidade do material equivalente, a alvenaria é discretizada com as propriedades do bloco e da argamassa separadamente. Para se determinar o módulo de 
elasticidade em uma determinada direção, por exemplo, para o eixo x, aplica-se na célula de alvenaria um carregamento uniformemente distribuído nessa direção. Determina-se a deformação média das faces da célula na direção $x$ e admitindo-se que a deformação do material equivalente é a mesma, já que os dois sistemas devem possuir a mesma energia de deformação, calcula-se o módulo de elasticidade longitudinal da célula na direção $\mathrm{x}$. Com a média das deformações das faces da célula na direção y, obtém-se o coeficiente de Poisson $v_{x y}$. Um procedimento similar é utilizado para a direção y.

Para efeito de comparação as relações entre as constantes elásticas ortotrópicas, $\mathrm{E}_{\mathrm{x}}$ e $\mathrm{E}_{\mathrm{y}}$, obtidas por PANDE e obtidas numericamente para estado plano de tensões, são apresentadas nas figuras 4.3 e 4.4 .

Observando-se as figuras 4.3 e 4.4 , verifica-se que o valor dos módulos de elasticidade na direção x e y obtidos pelo método de PANDE et al. foi praticamente o mesmo que o obtido numericamente. Mesmo com a variação da espessura da argamassa e da relação $\mathrm{E}_{\mathrm{b}} / \mathrm{E}_{\mathrm{a}}$ os dois resultados apresentam-se bem próximos. Nota-se, também, que um acréscimo na espessura da argamassa provoca um decréscimo no valor do módulo de elasticidade nas duas direções. Verifica-se também que à medida que se aumenta o valor do módulo de elasticidade da argamassa o valor do E da alvenaria aumenta.

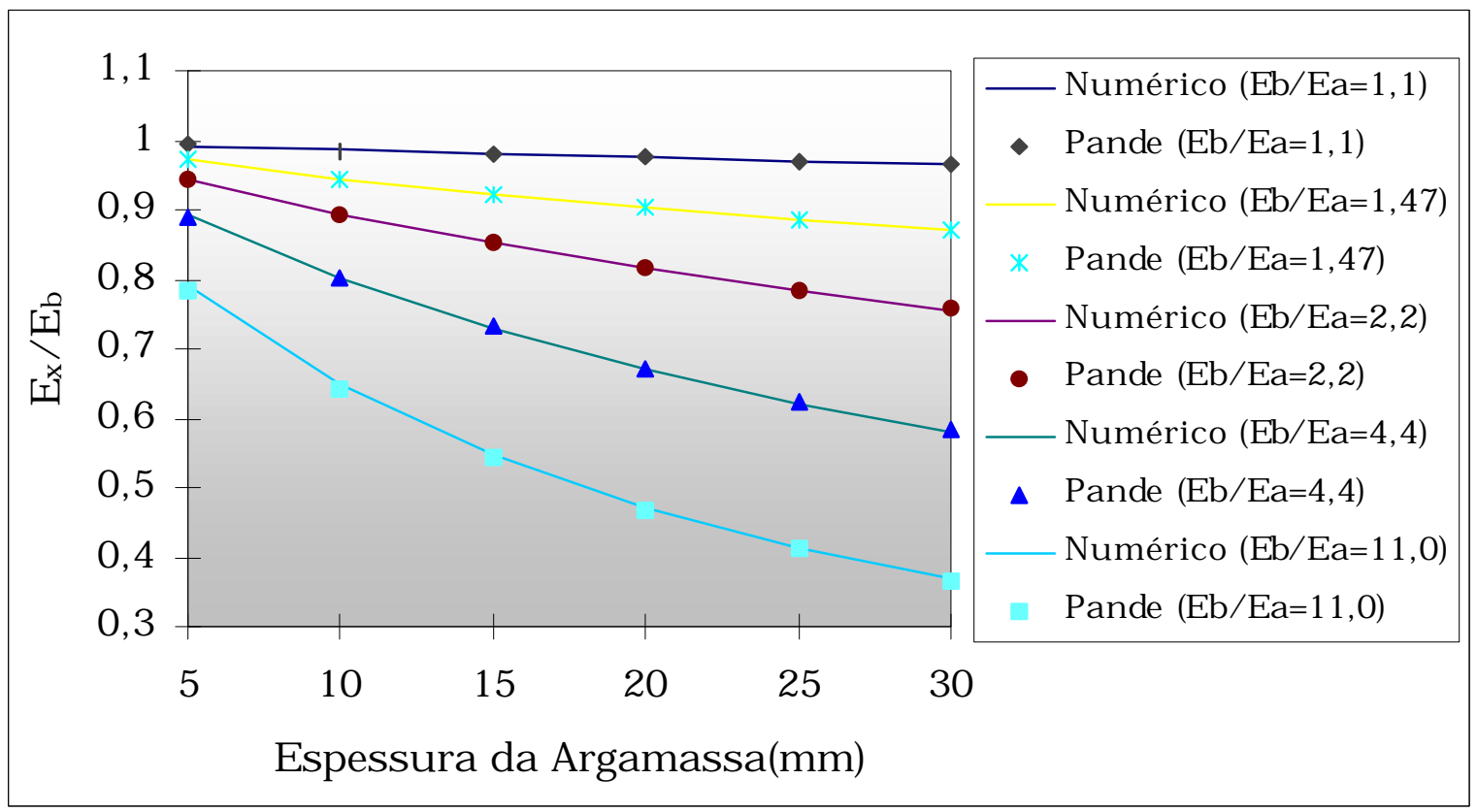

Figura 4.3 - Gráfico da relação $E_{x} / E_{b} x$ Espessura da Argamassa 


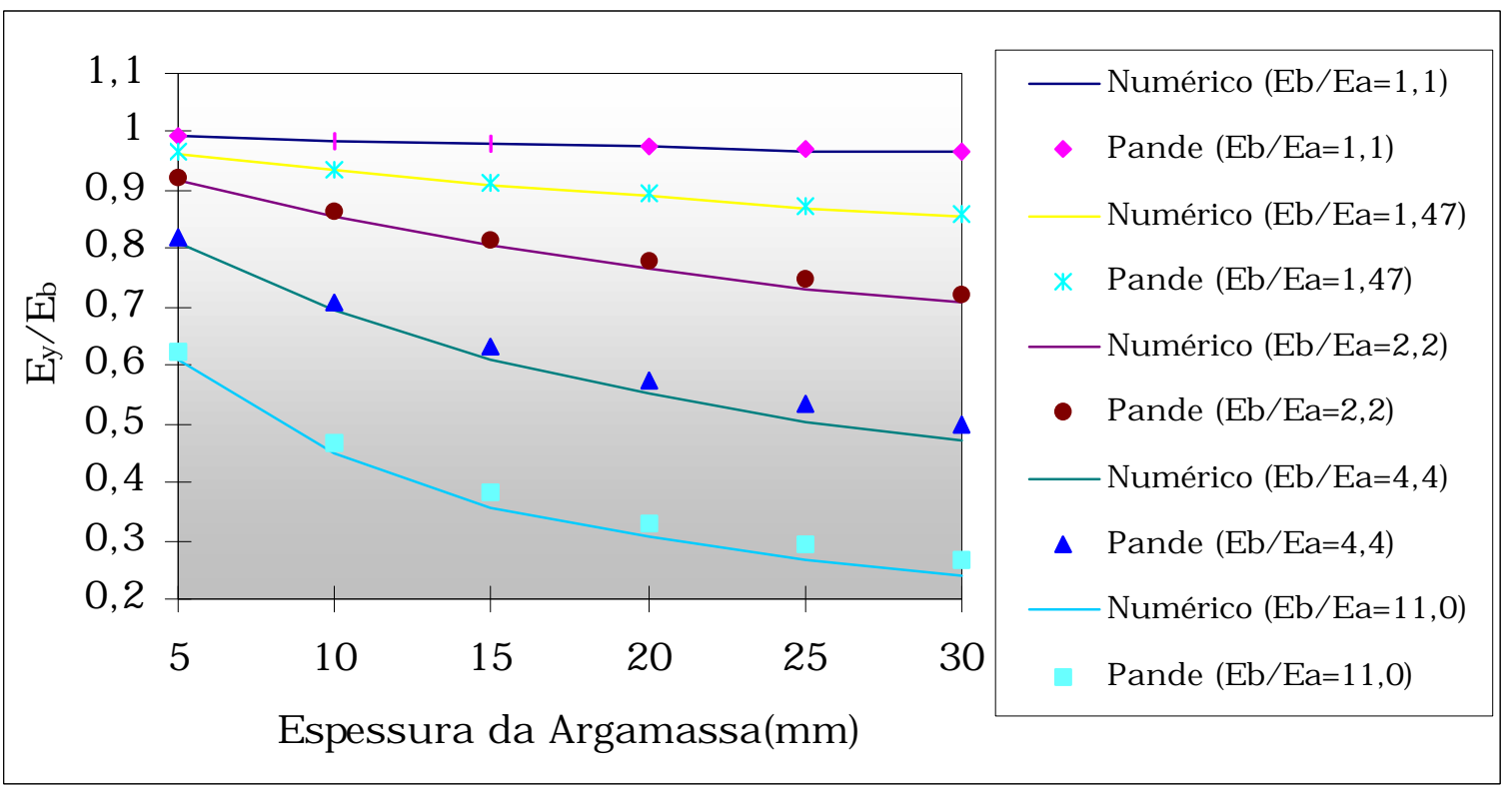

Figura 4.4 - Gráfico da relação $E_{y} / E_{b} x$ Espessura da Argamassa

Na figura 4.5 apresenta-se a variação da relação $E_{x} / E_{y}$ com a espessura da argamassa. Analisando-se o gráfico nota-se que, à medida que o valor do módulo de elasticidade da argamassa se aproxima do valor do módulo de elasticidade do bloco, os valores dos módulos de elasticidade na direção x e y vão se aproximando. Verifica-se, também, que quanto mais próximos forem esses valores mais os resultados obtidos com os dois métodos se aproximam, como já era esperado.

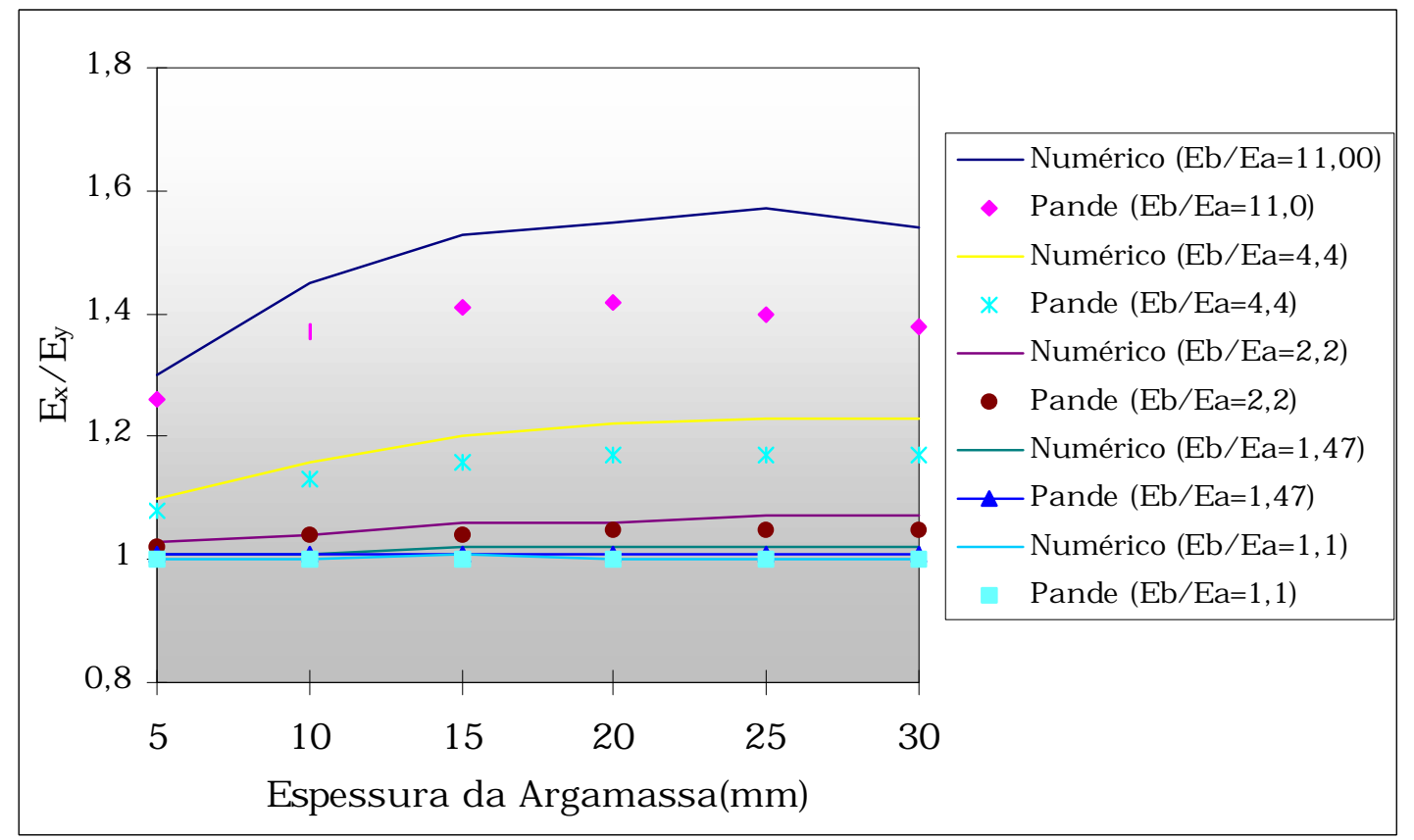

Figura 4.5 - Gráfico da relação $\mathrm{E}_{\mathrm{x}} / \mathrm{E}_{\mathrm{y}} \mathrm{x}$ Espessura da Argamassa 
A partir dos resultados apresentados nos gráficos, pode-se notar que um acréscimo na espessura da argamassa resulta em um decréscimo no módulo de elasticidade nas duas direções. Por outro lado, um acréscimo do módulo de elasticidade da argamassa provoca um acréscimo nos valores dos módulos de elasticidade.

Pode-se concluir que o módulo de elasticidade do material equivalente, na direção normal às juntas horizontais, é menor que na direção paralela às mesmas. Ressalta-se que essa conclusão é válida apenas para as dimensões apresentadas.

\subsection{Estudo linear do material ortotrópico equivalente}

Com a análise da célula básica de alvenaria descrita concluiu-se que a homogeneização por dois passos sucessivos apresenta resultados satisfatórios, quando o material está sujeito a um comportamento elástico linear. O desempenho do método na análise de grandes estruturas pode ser avaliado através de dois exemplos, comparando-se o modelo definido como natural (ou micromodelo), onde a alvenaria é modelada com as propriedades de seus componentes separadamente e os modelos homogeneizados apresentados no item anterior. O micromodelo está sendo considerado como o mais representativo do comportamento real da estrutura, sendo os seus resultados admitidos como os corretos para efeito de comparação.

\subsubsection{EXEMPLO 1 - Força horizontal uniformemente distribuída}

Neste exemplo analisa-se uma parede de alvenaria de $1970 \mathrm{~mm}$ de comprimento por $1106 \mathrm{~mm}$ de altura (nove unidades no seu comprimento e dezoito na sua altura) e submetida a uma força horizontal uniformemente distribuída ao longo do topo da parede, conforme ilustrado na figura 4.6. O carregamento é aplicado na direção do eixo $x$ utilizando-se uma viga de grande rigidez para garantir que a força seja distribuída de maneira uniforme ao longo da parede. É aplicada uma força $\mathrm{F}=1,0 \mathrm{MN}$. 


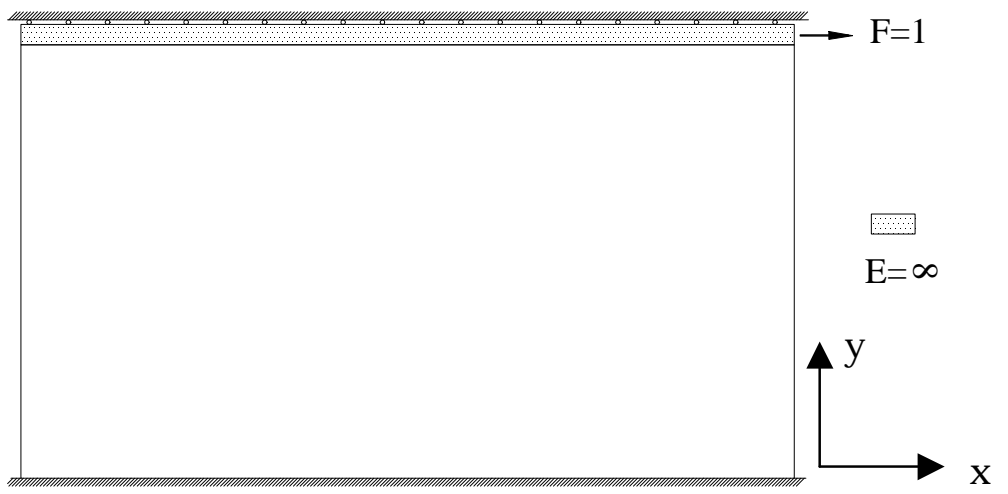

Figura 4.6 - Caso de Carregamento 1

Adotou-se um bloco com dimensões em milímetros de 210x52×100 e utilizaram-se juntas de argamassa de $10 \mathrm{~mm}$ de espessura. Para efeito de comparação três modelos são considerados: um modelo natural (ou micromodelo), onde o bloco e a argamassa são discretizados separadamente utilizando-se um elemento quadrilateral de quatro nós (PLANE42); e dois modelos homogeneizados, no qual a parede é discretizada como um material único e ortotrópico, utilizando-se o mesmo elemento. As propriedades dos modelos homogeneizados são determinadas utilizando-se as equações de PANDE et al. (1989) para um modelo e para o outro as propriedades são determinadas numericamente. O bloco possui módulo de elasticidade longitudinal $\left(\mathrm{E}_{\mathrm{b}}\right)$ de $20000 \mathrm{~N} / \mathrm{mm}^{2}$ e coeficiente de Poisson $\left(v_{\mathrm{b}}\right)$ de 0 ,15. A argamassa possui módulo de elasticidade longitudinal $\left(E_{a}\right)$ de $2000 \mathrm{~N} / \mathrm{mm}^{2}$ e coeficiente de Poisson $\left(v_{\mathrm{a}}\right)$ de 0,125. As propriedades ortotrópicas calculadas estão ilustradas na tabela 4.1 .

Tabela 4.1 - Propriedades Ortotrópicas

\begin{tabular}{|l|l|l||}
\hline \hline Propriedades & PANDE et al. & Numérico \\
\hline \hline $\mathrm{E}_{\mathrm{x}}$ & $12320,0 \mathrm{~N} / \mathrm{mm}^{2}$ & $12691,7 \mathrm{~N} / \mathrm{mm}^{2}$ \\
\hline $\mathrm{E}_{\mathrm{y}}$ & $8164,1 \mathrm{~N} / \mathrm{mm}^{2}$ & $7893,7 \mathrm{~N} / \mathrm{mm}^{2}$ \\
\hline $\mathrm{v}_{\mathrm{xy}}$ & 0,113 & 0,128 \\
\hline $\mathrm{G}_{\mathrm{xy}}$ & $3160,5 \mathrm{~N} / \mathrm{mm}^{2}$ & $3356,3 \mathrm{~N} / \mathrm{mm}^{2}$ \\
\hline
\end{tabular}


Na figura 4.7 apresenta-se o resultado obtido para o deslocamento na direção x com os três modelos adotados. Verifica-se que os dois modelos homogeneizados apresentam uma boa concordância com o micromodelo. Os valores obtidos para o deslocamento são bem próximos. Considerando-se o valor obtido com o micromodelo como sendo o resultado correto, o erro obtido com o modelo homogeneizado numericamente foi de $0,43 \%$ e o erro do modelo do PANDE foi de 5,39\%. Dessa forma conclui-se que para análise dos deslocamentos o processo de homogeneização numérica apresentou um resultado melhor.
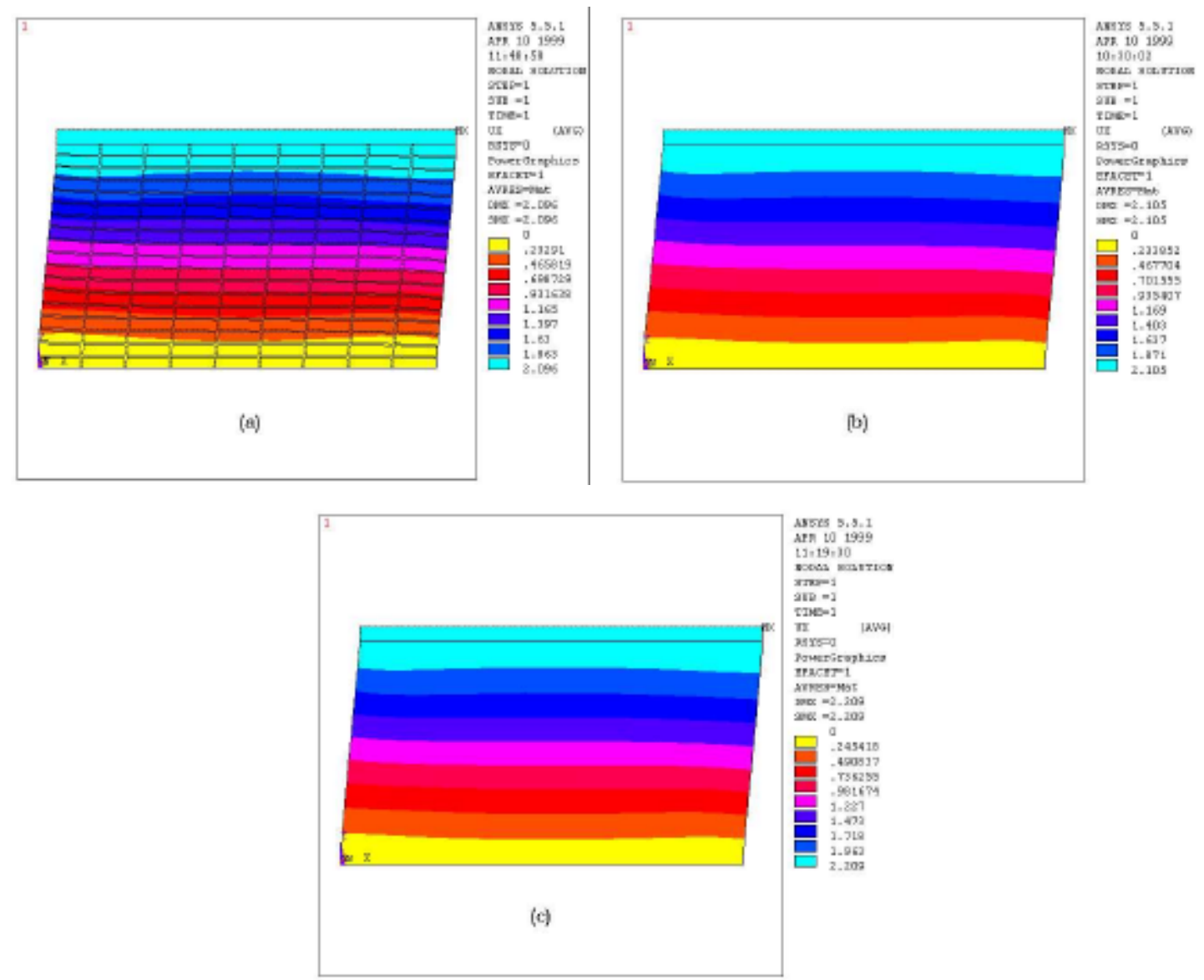

Figura 4.7 - Deslocamentos: (a) micromodelo; (b) homogeneização numérica; (c) homogeneização PANDE et al. 

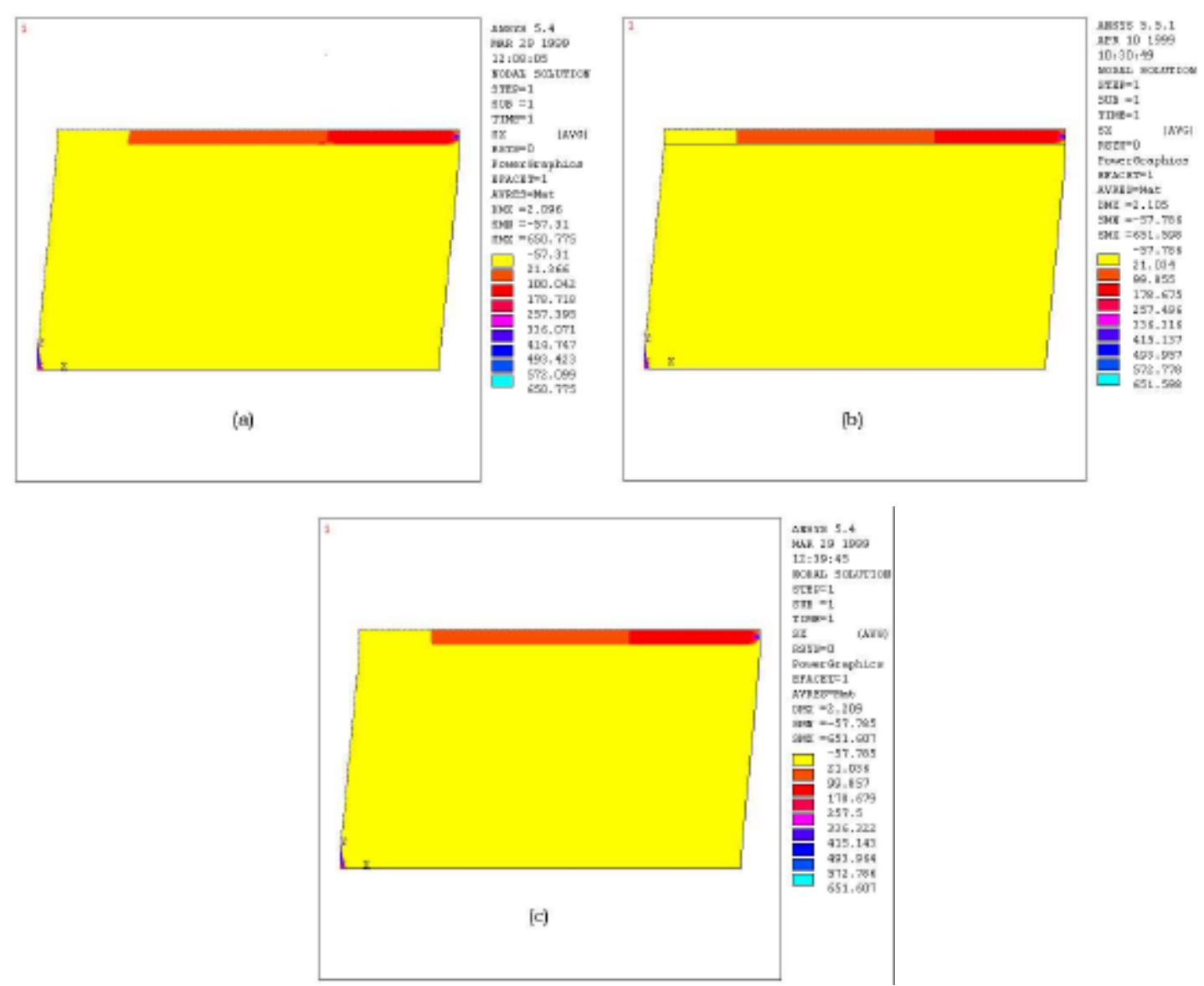

Figura 4.8 - Tensões $\sigma_{x}$ : (a) micromodelo; (b) homogeneização numérica; (c) homogeneização PANDE et al.

Os resultados obtidos para tensões $\left(\sigma_{\mathrm{x}}, \sigma_{\mathrm{y}}\right.$ e $\left.\tau_{\mathrm{xy}}\right)$ são apresentados nas figuras $4.8,4.9$ e 4.10. Verifica-se que o comportamento global da estrutura homogeneizada está em boa concordância com o micromodelo. Analisando-se os resultados, verifica-se que a distribuição de tensões nas paredes são similares e para uma análise geral o modelo homogeneizado apresenta um comportamento bem próximo do real, com a vantagem de uma modelagem mais rápida e um tempo de processamento menor. 

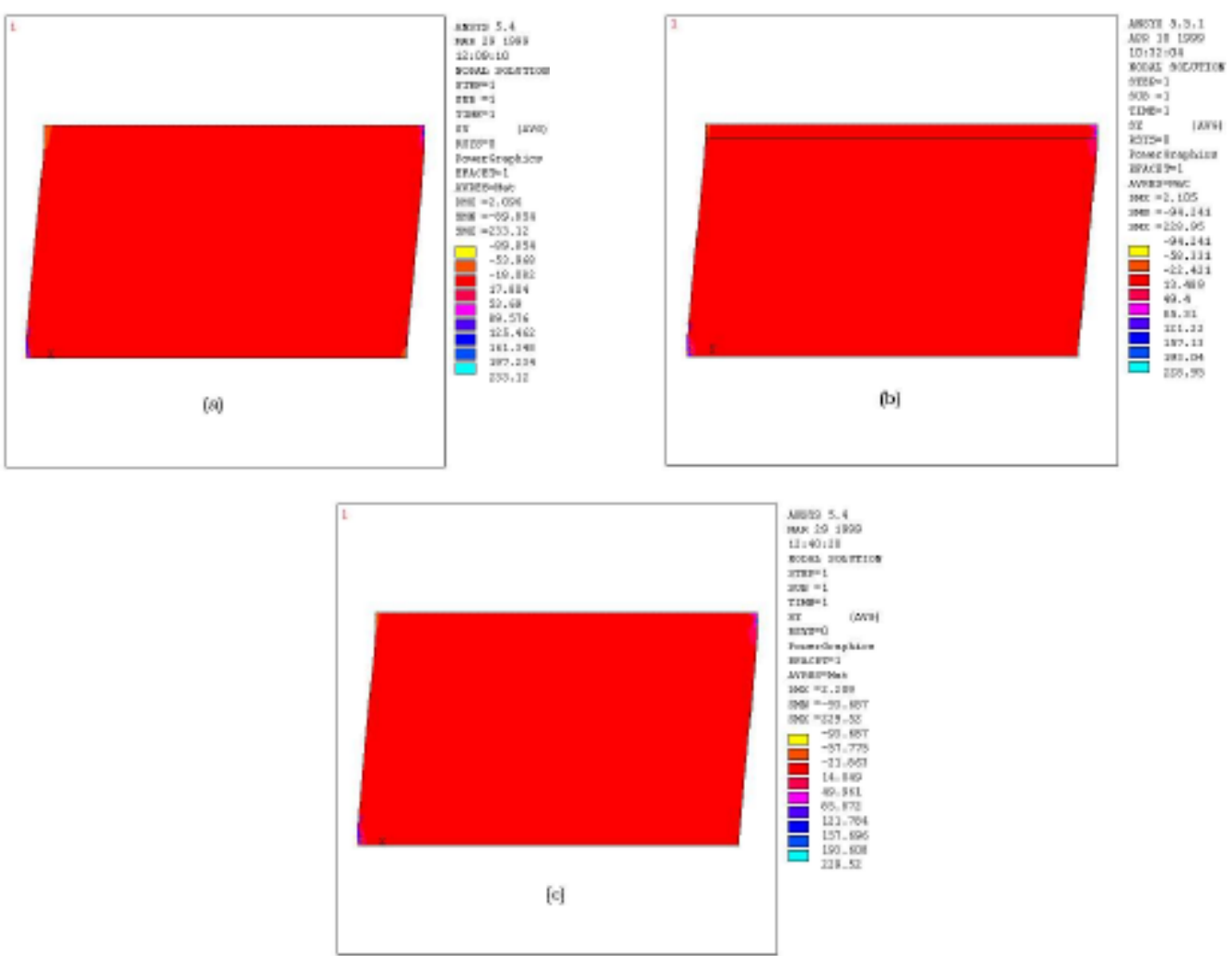

Figura 4.9 - Tensões $\sigma_{\mathrm{y}}$ : (a) micromodelo; (b) homogeneização numérica;

(c) homogeneização PANDE et al.
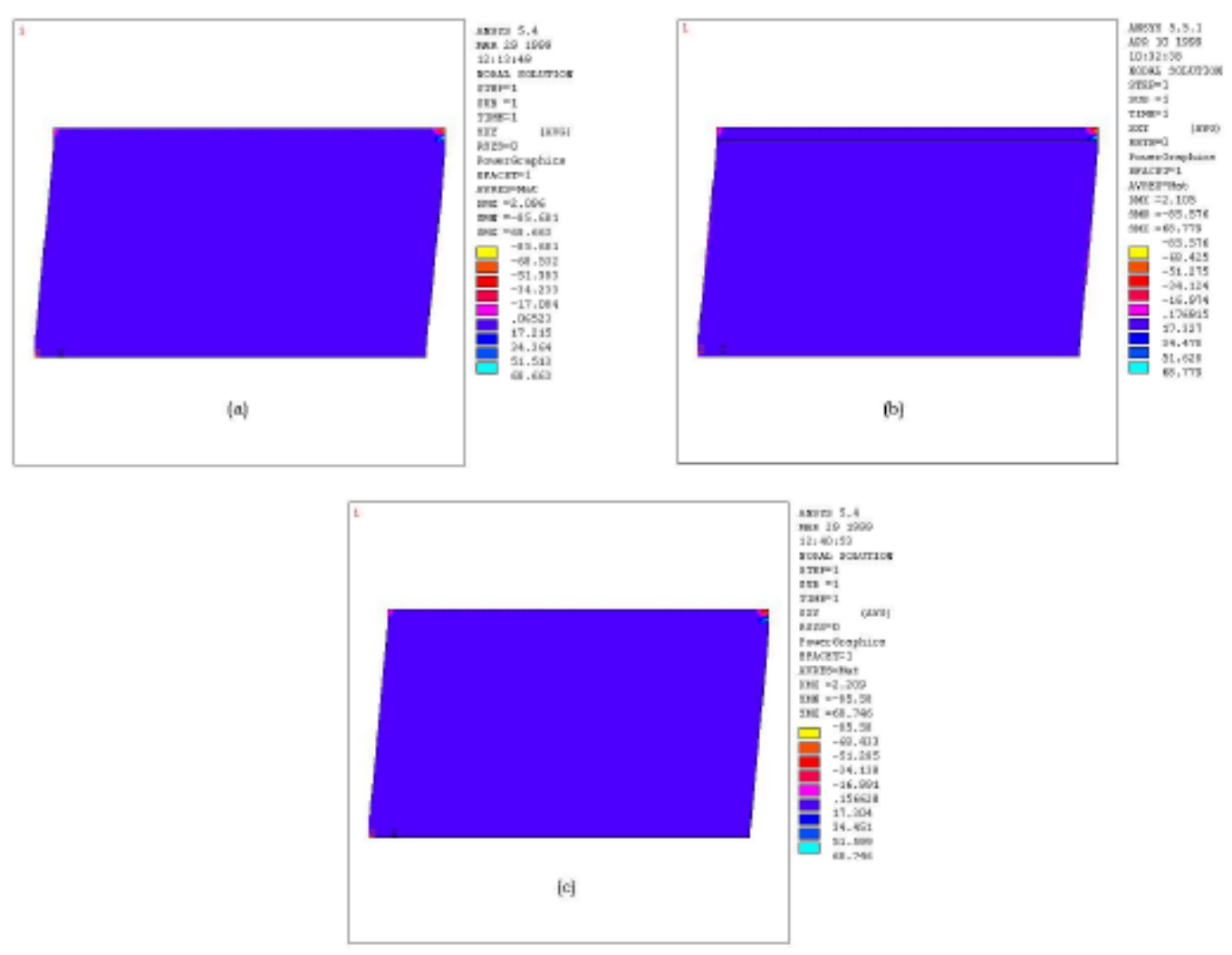

Figura 4.10 - Tensões $\tau_{x y}$ : (a) micromodelo; (b) homogeneização numérica;

(c) homogeneização PANDE et al. 
Na figura 4.11 apresenta-se uma analise localizada da distribuição da tensão $\sigma_{\mathrm{y}}$ na parede. Verifica-se que existe uma concentração de tensões no ponto de aplicação da força, como a variação da tensão ao longo da parede é pequena nas figuras 4.9 e 4.10 a tensão fica praticamente constante. Esse padrão se repete nos outros modelos.

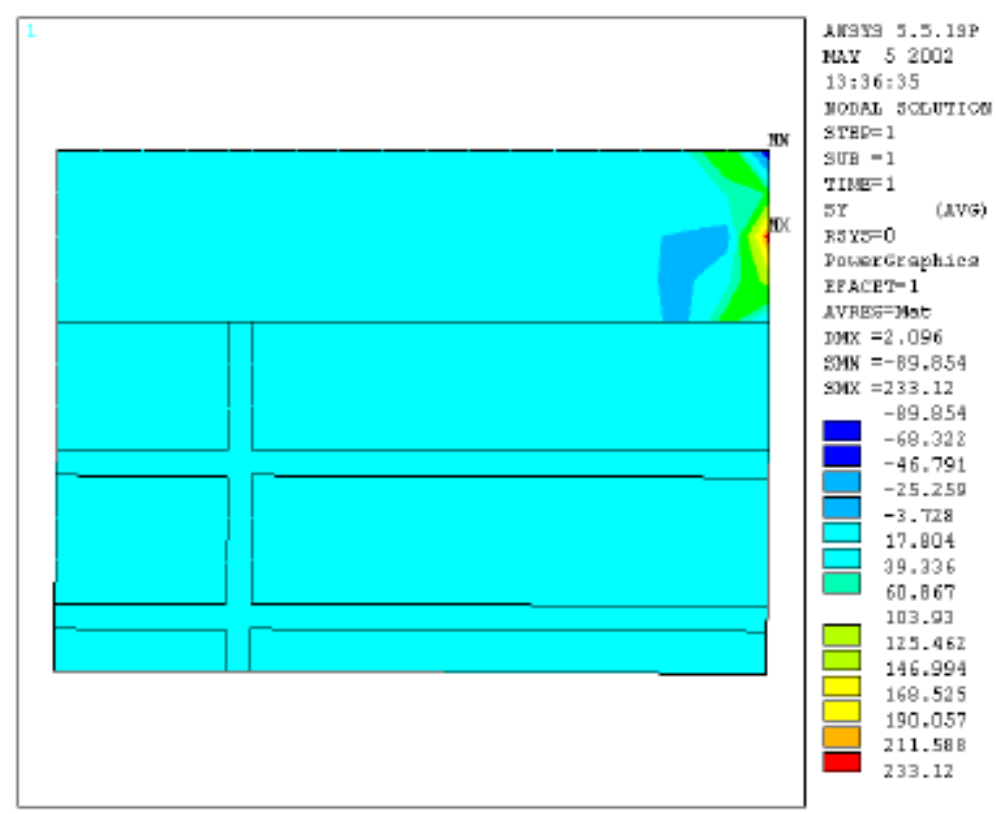

Figura 4.11 - Tensão $\sigma_{y}$ próxima ao ponto de aplicação da força (micromodelo)

$\mathrm{Na}$ tabela 4.2 apresentam-se as porcentagens dos erros obtidos para as tensões máximas, utilizando-se cada um dos modelos de homogeneização propostos. Pelos valores obtidos verifica-se que os dois modelos apresentam resultados bastante coerentes, e, para uma análise macroscópica do comportamento global da estrutura, podem ser adotados com boa precisão.

Tabela 4.2 - Porcentagem de erro em relação ao micromodelo

\begin{tabular}{|c|c|c|c|}
\hline Modelo & $\sigma_{\mathrm{X}}($ máx.) & $\sigma_{\mathrm{Y}}($ máx.) & $\tau_{\mathrm{XY}}($ máx.) \\
\hline \hline Numérico & $-0,12 \%$ & $1,78 \%$ & $-0,17 \%$ \\
\hline PANDE & $-0,12 \%$ & $1,54 \%$ & $-0,12 \%$ \\
\hline
\end{tabular}


$\mathrm{Na}$ figura 4.12 apresenta-se a variação das tensões normais verticais em uma linha situada a $274 \mathrm{~mm}$ da base da parede, onde tem-se uma camada de bloco e argamassa alternadas. A figura 4.13 apresenta a variação das mesmas tensões em uma linha situada a $305 \mathrm{~mm}$ da base da parede, onde se tem uma junta horizontal de argamassa. Verifica-se que, apesar dos modelos homogeneizados apresentarem uma boa concordância com o micromodelo em termos de comportamento global, em termos locais algumas diferenças podem ser encontradas, mesmo numa análise linear. No micromodelo aparecem picos de tensões em pontos localizados, principalmente na argamassa, o que não ocorre no modelo homogeneizado. Portanto, quando se pretende fazer uma análise mais precisa do comportamento das estruturas em alvenaria, uma análise não linear, por exemplo, o mais seguro é a consideração do micromodelo. Nesse modelo é possível observar os picos de tensão localizados, o que não é possivel nos modelos homogeneizados.

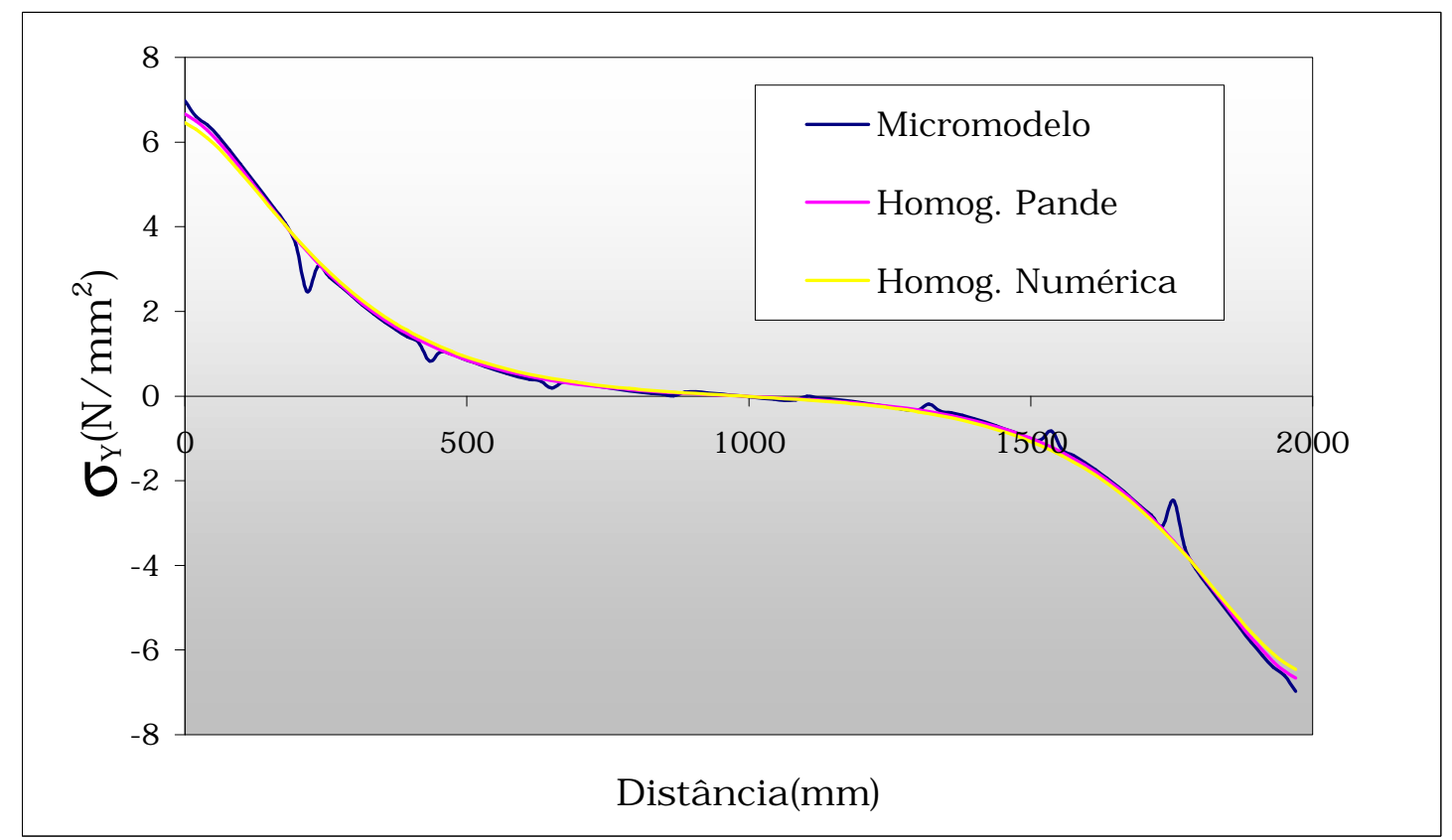

Figura 4.12 - Tensão Vertical na Parede $(y=274)$ 


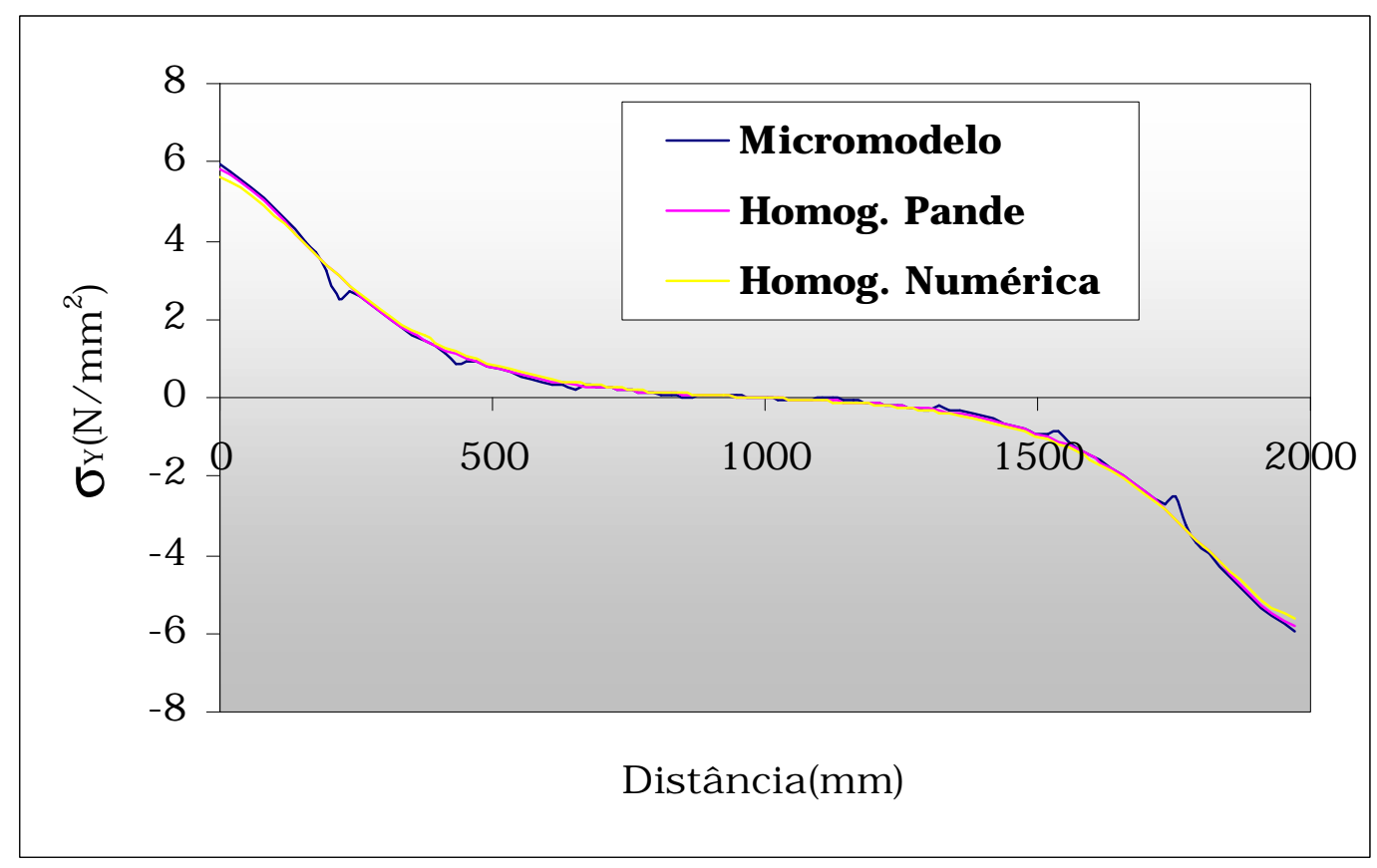

Figura 4.13 - Tensão Vertical na Parede $(y=305)$

\subsubsection{EXEMPLO 2 - Força vertical uniformemente distribuída}

Neste exemplo analisa-se a mesma parede descrita no item 4.3.1, aplicando-se uma força vertical uniformemente distribuída ao longo do comprimento. Conforme ilustrado na figura 4.14, aplica-se uma força de $10 \mathrm{~N} / \mathrm{mm}$.

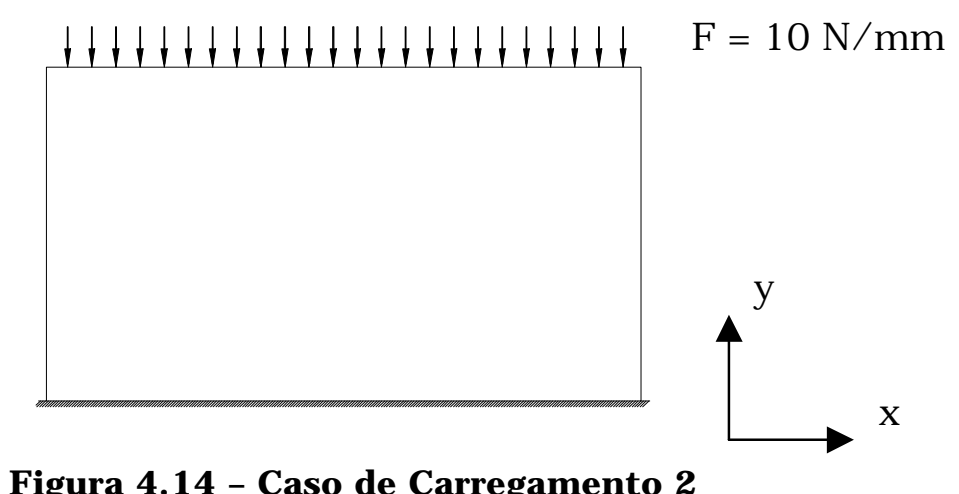

Para efeito de comparação quatro modelos são considerados: dois micromodelos, ou naturais, onde o bloco e argamassa são discretizados separadamente. No primeiro utiliza-se um elemento quadrilateral de quatro 
nós para estado plano de tensão (PLANE42); no segundo utiliza-se um elemento sólido de oito nós (SOLID45). Consideram-se, também, dois modelos homogeneizados, nos quais a parede é modelada como um material único e ortotrópico, utilizando-se o elemento plano PLANE42. As propriedades dos materiais e dos modelos homogeneizados são as mesmas apresentadas no item 4.3.1.

Analisando-se os resultados obtidos com os diferentes modelos para o deslocamento na direção y, figura 4.15, verifica-se que os valores estão bastante próximos. Adotando-se o valor calculado com o micromodelo plano como referência, o erro obtido com o micromodelo sólido foi de - 1,35\%. Com o modelo de homogeneização numérica, o erro foi de 5,17\%, e com o modelo de homogeneização do Pande, de 1,63\%. Neste exemplo nota-se que o processo de homogeneização do Pande apresentou melhores resultados que a homogeneização numérica, ao contrário do exemplo anterior.
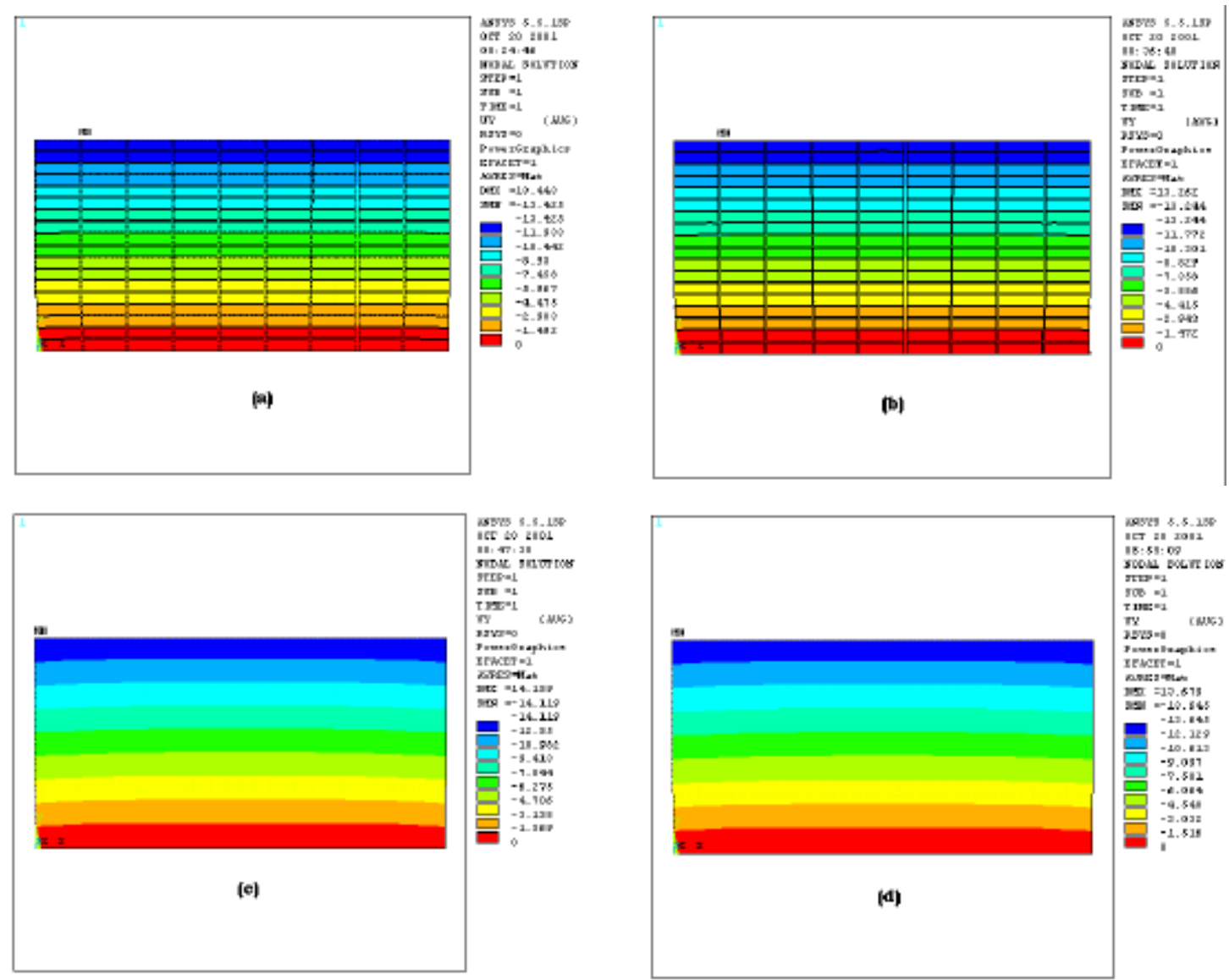

Figura 4.15 - Deslocamentos: (a) micromodelo plano; (b) micromodelo sólido; (c) homogeneização numérica; (d) homogeneização PANDE et al. 
O processo numérico apresenta a grande vantagem de ser mais genérico, não dependendo de nenhuma teoria adicional ou de hipóteses adotadas. Este processo pode ser utilizado para a determinação das características médias de qualquer estrutura em alvenaria, independente da sua geometria e características dos materiais. Conclui-se, portanto, que é o melhor processo de homogeneização.

Os micromodelos plano e sólido apresentaram resultados bastante próximos, sendo que o modelo plano apresenta uma modelagem mais simples e um tempo de processamento menor.

$\mathrm{Na}$ figura 4.16 apresenta-se a variação das tensões normais verticais em uma linha situada a $274 \mathrm{~mm}$ da base da parede, onde se tem uma camada de bloco e argamassa alternados. A figura 4.17 apresenta a variação das mesmas tensões em uma linha situada a $305 \mathrm{~mm}$ da base da parede, onde se tem uma junta horizontal de argamassa.

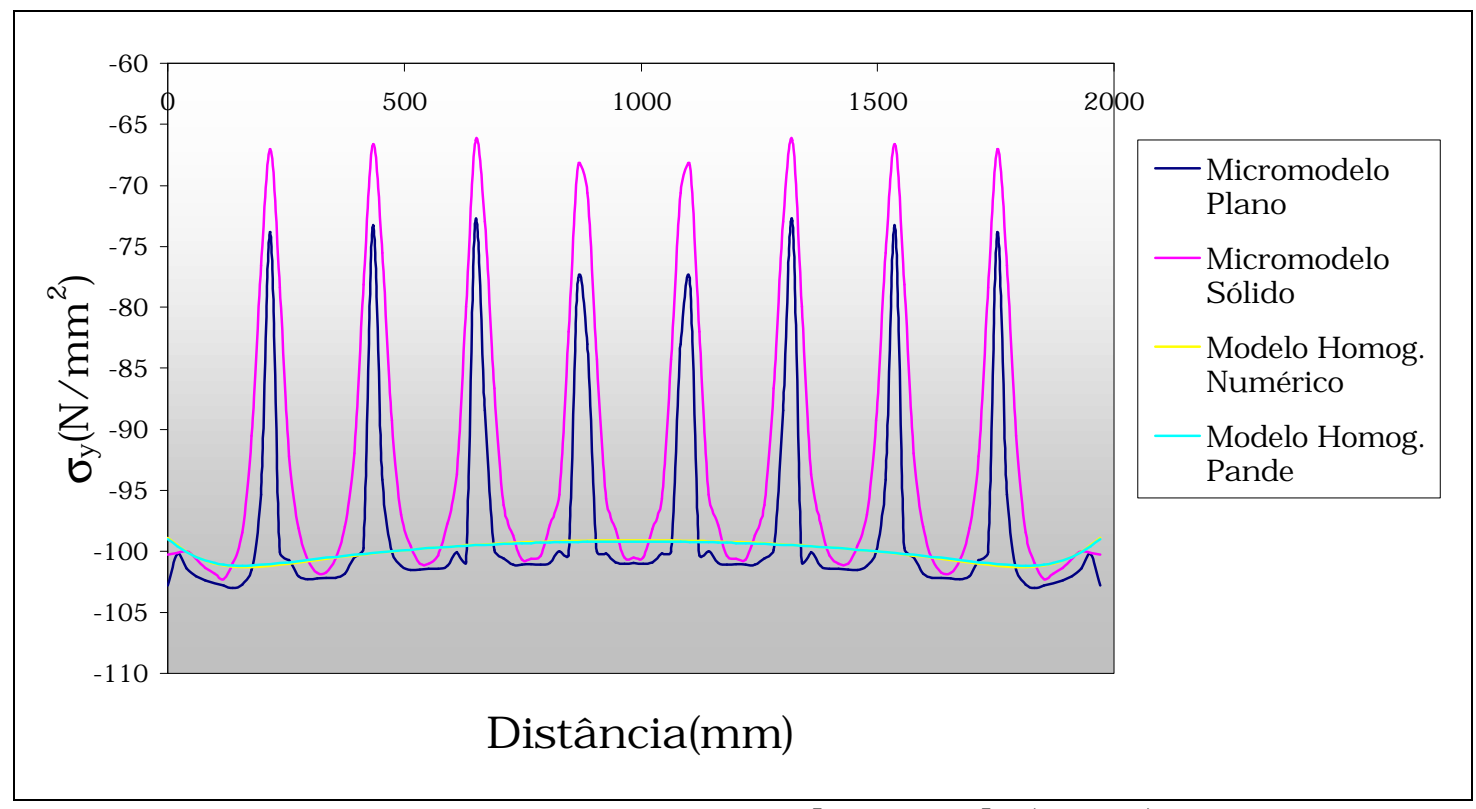

Figura 4.16 - Tensão Vertical na Parede (y=274) 


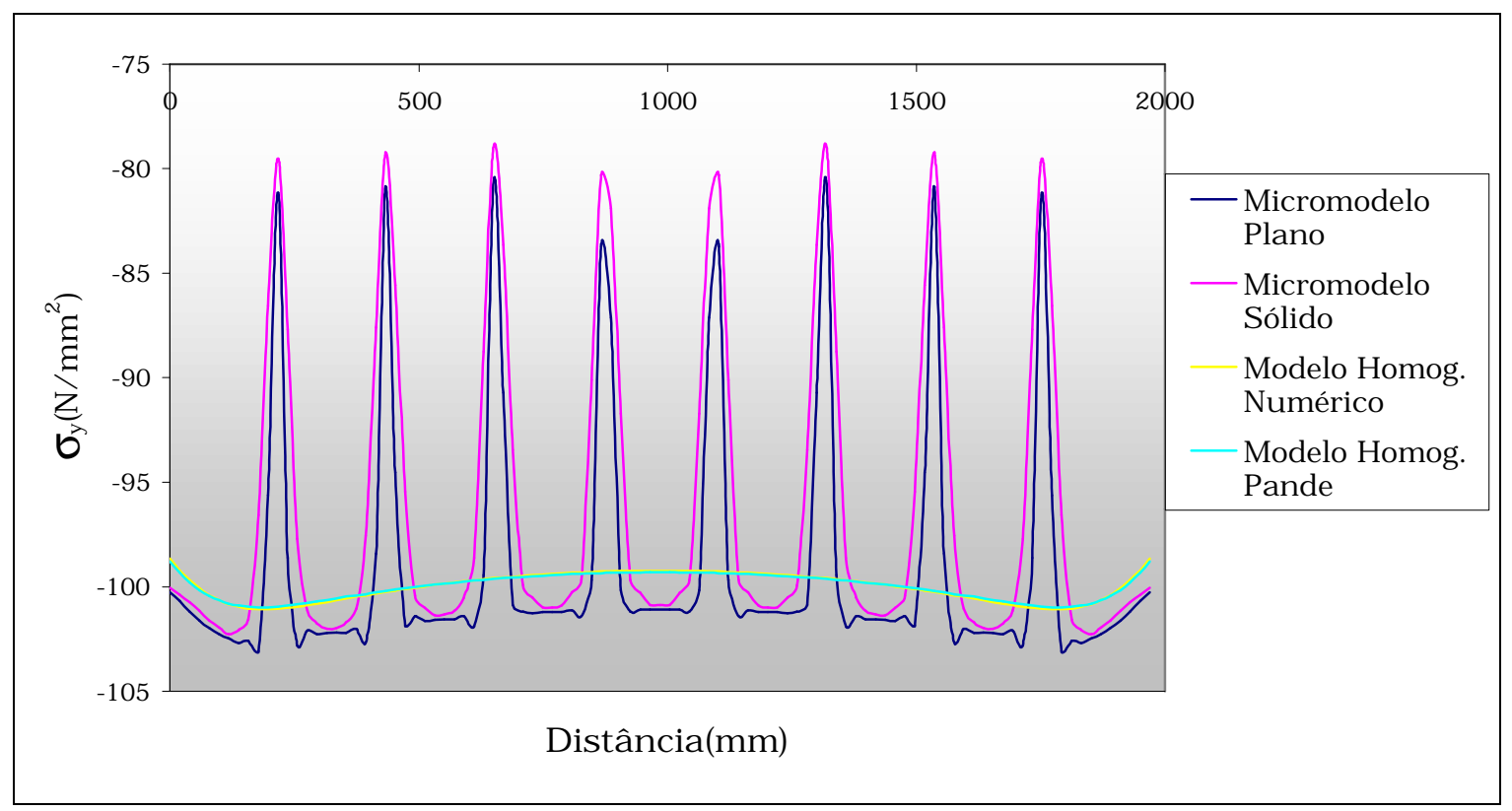

Figura 4.17 - Tensão Vertical na Parede $(y=305)$

Analisando-se os resultados, verifica-se que, apesar do modelo homogeneizado representar de forma satisfatória o comportamento global da estrutura, em termos locais os resultados apresentam diferenças significativas, principalmente as concentrações de tensões nas juntas de argamassa, que não são detectadas pelo modelo homogeneizado.

As figuras 4.18 e 4.19 apresentam a variação das tensão de cisalhamento $\left(\tau_{\mathrm{xy}}\right)$ a $274 \mathrm{~mm}$ e $305 \mathrm{~mm}$ da base da parede, respectivamente.

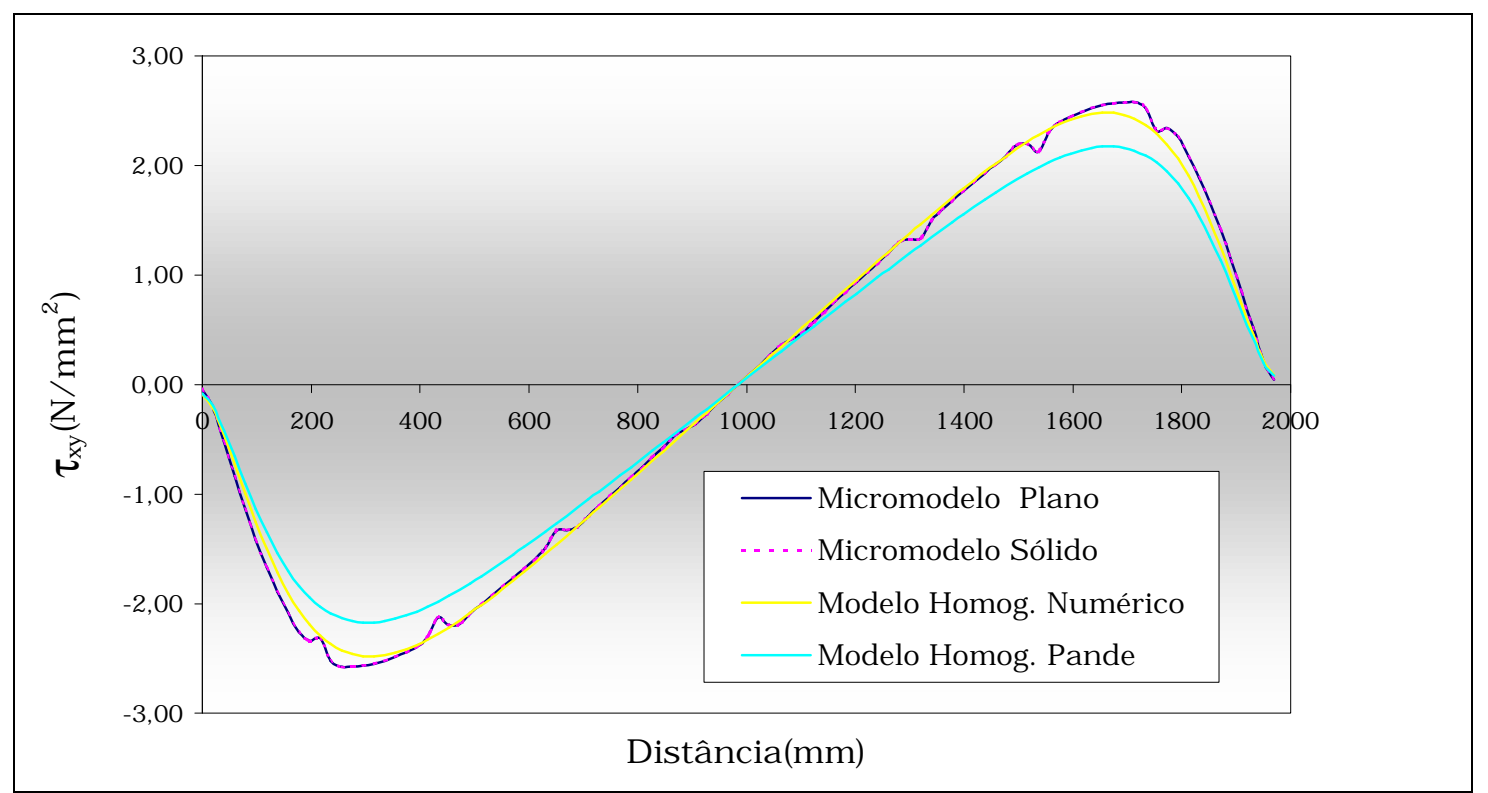

Figura 4.18 - Tensão de Cisalhamento na Parede $(y=274)$ 


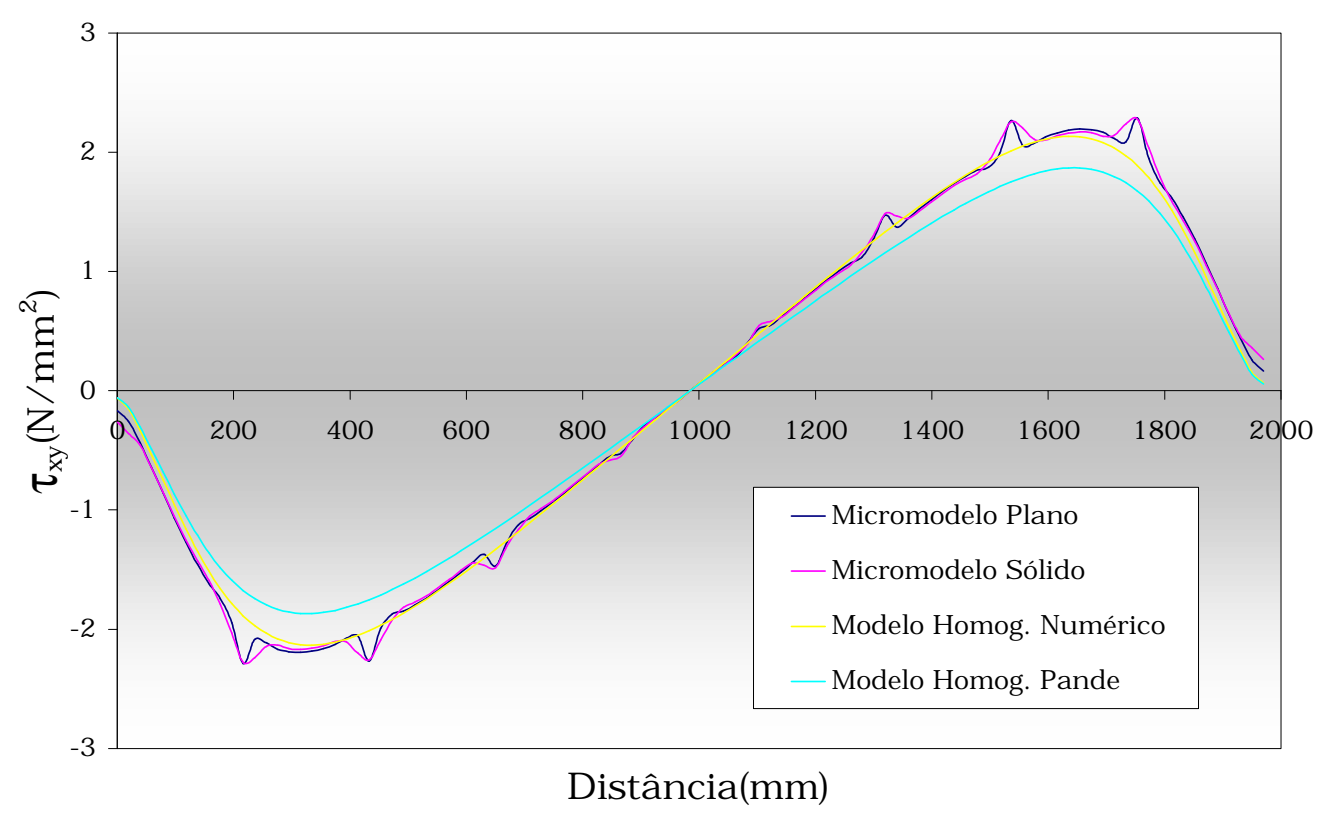

Figura 4.19 - Tensão de Cisalhamento na Parede ( $y=305)$

Nestes gráficos nota-se que, apesar dos modelos também apresentarem diferenças em termos locais, a representação dos modelos homogeneizados se mostra bastante coerente com os micromodelos.

\subsection{Fechamento}

Conclui-se que os modelos homogeneizados devem ser utilizados com critério e os seus resultados devem ser cuidadosamente analisados em termos locais. Principalmente com utilização de propriedades não lineares dos materiais, esses modelos podem apresentar resultados incoerentes.

Nos próximos capítulos serão apresentados resultados de simulações numéricas, onde serão utilizados modelos não-lineares. Em virtude dos resultados obtidos neste capítulo e os apresentados na revisão bibliográfica, optou-se por fazer as análises utilizando-se a micromodelagem. 


\section{AFERIÇÃO DOS MODELOS NÃO LINEARES PARA ALVENARIA SUBMETIDA À COMPRESSÃO}

\subsection{CONSIDERAÇÕES PRELIMINARES}

Com o objetivo de avaliar e calibrar os modelos não lineares descritos apresentam-se neste item alguns exemplos de estruturas em alvenaria analisadas com estes modelos. Comparando-se os resultados entre os diferentes modelos e confrontando-os com resultados experimentais, pretende-se avaliar até que ponto eles são capazes de representar com precisão o comportamento da alvenaria. Nos exemplos analisados a alvenaria é constituída por unidades maciças de concreto.

\subsection{EXEMPLO}

Este exemplo foi modelado e ensaiado por ALI \& PAGE (1988a). No estudo realizado a alvenaria é considerada em estado plano de tensões, segundo o autor uma hipótese razoável para a maioria dos casos de carregamento no plano. A tabela 5.1 apresenta as propriedades dos materiais obtidas em laboratório. A unidade e a argamassa são consideradas separadamente no modelo, por isso são necessárias as propriedades individuais dos componentes ao invés das propriedades médias da alvenaria. 
Tabela 5.1 - Propriedades dos componentes dos materiais

\begin{tabular}{|c|c|}
\hline \multicolumn{2}{|c|}{ Propriedades da Unidade } \\
\hline Resistência à compressão & $15,3 \mathrm{MPa}$ \\
\hline Resistência à tração & $1,2 \mathrm{MPa}$ \\
\hline Módulo de elasticidade & $14.700 \mathrm{MPa}$ \\
\hline Coeficiente de Poisson & 0,16 \\
\hline Deformação última à compressão( $\left.\varepsilon_{\mathrm{cu}}\right)$ & $270 \times 10^{-5}$ \\
\hline \multicolumn{2}{|c|}{ Propriedades da Argamassa } \\
\hline Resistência à compressão & $7,3 \mathrm{MPa}$ \\
\hline Resistēncia à tração & $0,78 \mathrm{MPa}$ \\
\hline Módulo de elasticidade & $7.400 \mathrm{MPa}$ \\
\hline Coeficiênte de Poisson & 0,21 \\
\hline Deformação úlțima à compressão $\left(\varepsilon_{\mathrm{cu}}\right)$ & $680 \times 10^{-5}$ \\
\hline \hline
\end{tabular}

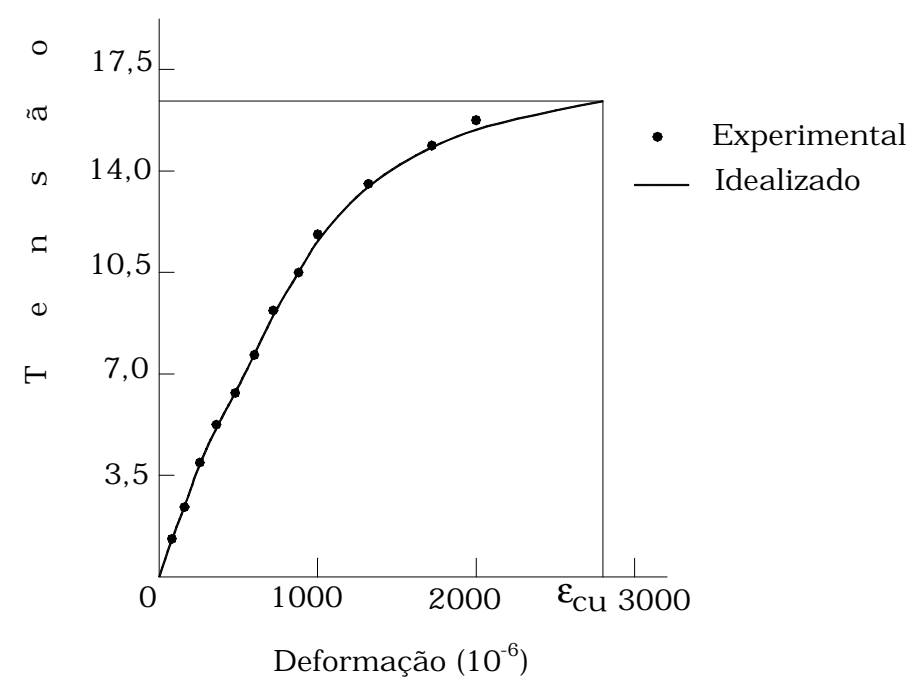

Figura 5.1 - Tensão x Deformação do artefato bloco

Adaptada de ALI \& PAGE (1988)

As características de deformação da unidade foram obtidas de testes de compressão uniaxial. As unidades são consideradas isotrópicas e exibem características de deformação não lineares, como apresentado na figura 5.1. A alvenaria utilizada nessa pesquisa foi construída com unidades de concreto maciças. A curva tensão-deformação da argamassa foi obtida indiretamente através de ensaios de compressão de prismas, e está 
apresentada na figura 5.2. A resistência à compressão da argamassa foi obtida através de ensaios com corpos-de-prova cilíndricos. Por este motivo existe uma diferença entre os valores da tabela 5.1 e da figura 5.2.

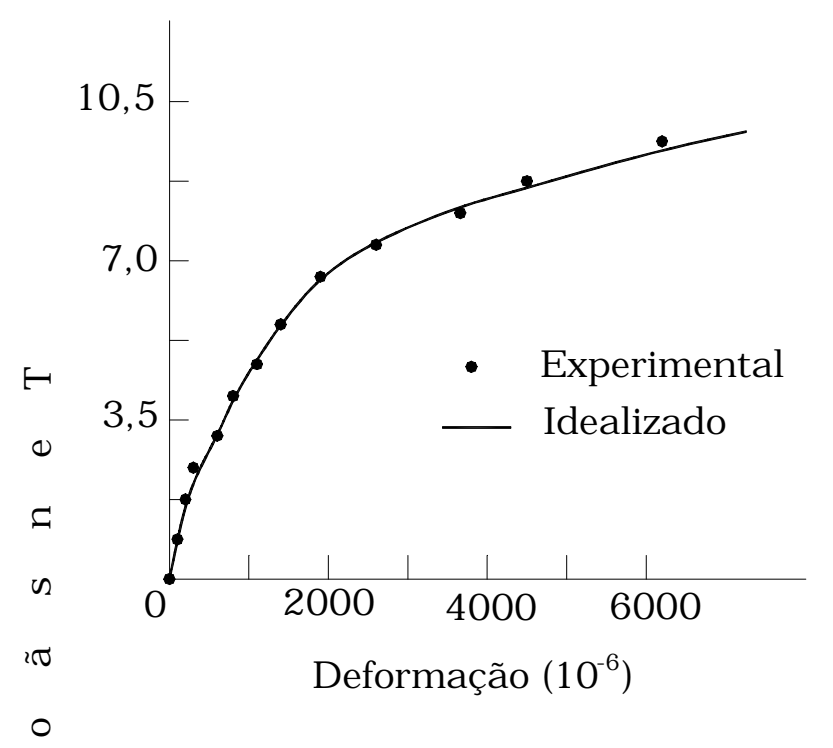

Figura 5.2 - Tensão x Deformação da argamassa

Adaptada de ALI \& PAGE (1988)

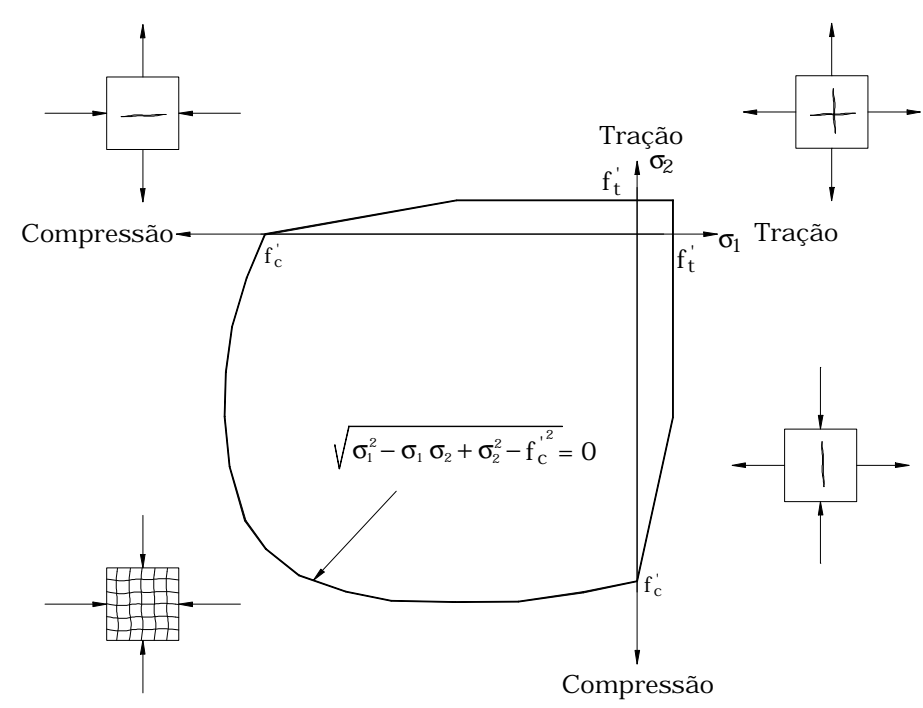

Figura 5.3 - Superficie de ruptura

Adaptada de ALI \& PAGE (1988)

De acordo com PAGE, tanto a unidade quanto a argamassa são materiais frágeis com propriedades similares às do concreto. Assim, critérios de ruptura convencionais do concreto são adotados para modelar a 
ruptura da alvenaria. Para determinar a ruptura por fissuração ou esmagamento, o critério de von Mises foi adotado com uma interrupção (“cutoff”) na tração (fig. 5.3). Apesar do uso desse tipo de superfície ser conservadora no caso de altas compressões, seu uso foi justificado, já que uma ruptura local por esmagamento na alvenaria submetida a forças concentradas é incomum.

O modelo utilizado na pesquisa usa o critério de resistência para verificar a iniciação e a propagação da fissura, e o modelo de fissuras dispersas para reproduzir os efeitos da fissuração.

Dois modelos diferentes de análise foram feitos. Um admitindo-se uma imediata dissipação de tensões na região de fissuração (modelo de colapso frágil), enquanto o outro permite uma dissipação mais gradual de tensões (um modelo de amolecimento). No trabalho original foi adotada a representação do modelo de amolecimento à tração apresentada na figura 5.4. A inclinação do ramo descendente da curva tensão-deformação foi definida pelo parâmetro $n$, que foi calibrado no modelo com o comportamento do prisma de alvenaria apresentado na figura 5.5. Adotouse o amolecimento apenas à tração, considerando-se que a maioria das rupturas com análises de forças concentradas em alvenaria são relacionadas à tração.

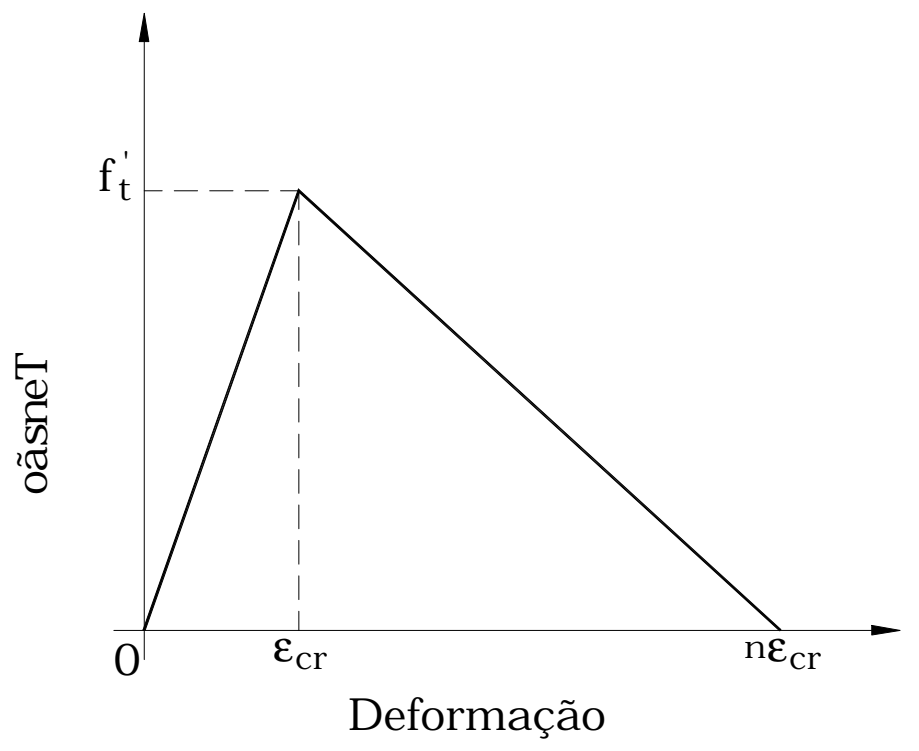

Figura 5.4 - Representação do amolecimento à tração

Adaptada de ALI \& PAGE (1988) 


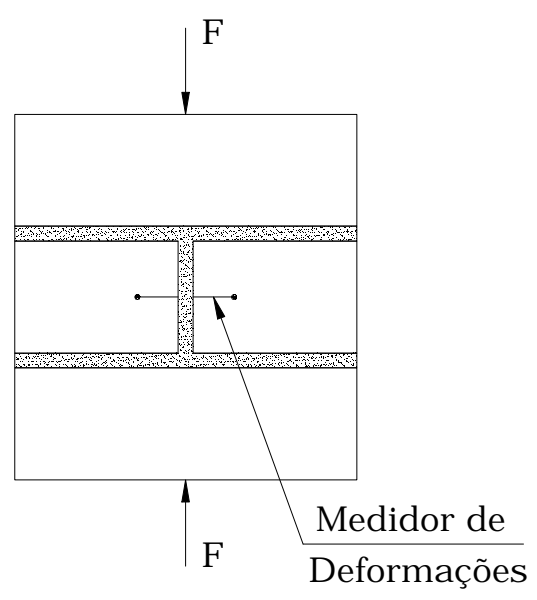

Figura 5.5 - Prisma ensaiado

Adaptada de ALI \& PAGE (1988)

Com o objetivo de aferir os modelos dos programas ANSYS e ABAQUS, apresentados anteriormente, foi feita a análise do prisma utilizando-se os modelos não lineares do concreto desses dois programas.

Com o programa ANSYS utilizou-se o modelo denominado CONCRETE65, com um elemento sólido com três graus de liberdade por nó (translações segundo as direções $\mathrm{x}, \mathrm{y}$ e $\mathrm{z}$ ), pois esse software só possui o modelo específico para o concreto com esse elemento. Esse modelo inclui a ruptura por fissuração, em zonas tracionadas, e o esmagamento, em zonas comprimidas. O modelo considera que o material rompe completamente assim que atinge a tensão de resistência máxima.

Com o ABAQUS foram feitas modelagens com um elemento plano denominado CPS4, com dois graus de liberdade por nó (translações segundo as direções x e y); e com um elemento sólido denominado C3D8, com três graus de liberdade por nó (translações segundo as direções $\mathrm{x}, \mathrm{y}$ e z). No modelo para o concreto do ABAQUS a fissuração é definida como a aspecto mais importante do comportamento do material. Uma superfície de ruptura é definida, adotando-se a hipótese de que a fissuração acontece quando a tensão principal atinge essa superfície. Verificado o aparecimento de uma fissura, um critério de dano elástico é utilizado para descrever o comportamento pós-ruptura do material. 
O carregamento foi aplicado em incrementos de carga, sendo que ambos os programas apresentam uma estrutura interna que vai avaliando o passo de carga anterior e, com base nisso, definindo qual o valor do próximo passo de carga a ser aplicado. O usuário sugere o valor inicial do incremento e o número máximo de passos de carga que o programa deve utilizar; dentro dessa variação o próprio programa vai definindo os valores dos passos de carga a serem utilizados. Adotou-se um passo de carga inicial de $1 \%$ do valor da carga total e definiu-se que o programa utilizasse um máximo de quinhentos passos de carga.

Nas figuras 5.6 e 5.7 apresenta-se a curva força x deformação para o prisma utilizando-se os programas descritos. A deformação foi medida ao longo dos incrementos de carga através da junta vertical, considerando os dois pontos marcados na figura 5.5. Observa-se que o valor da deformação máxima apresentada na figura 5.6 é bem menor que os valores de deformação última à compressão apresentados para o bloco e a argamassa na tabela 5.1. Essa diferença pode ser explicada pelo fato da deformação apresentada na figura 5.6 ser devido à tração do prisma, apresentando assim um valor menor que a deformação dos componentes à compressão.

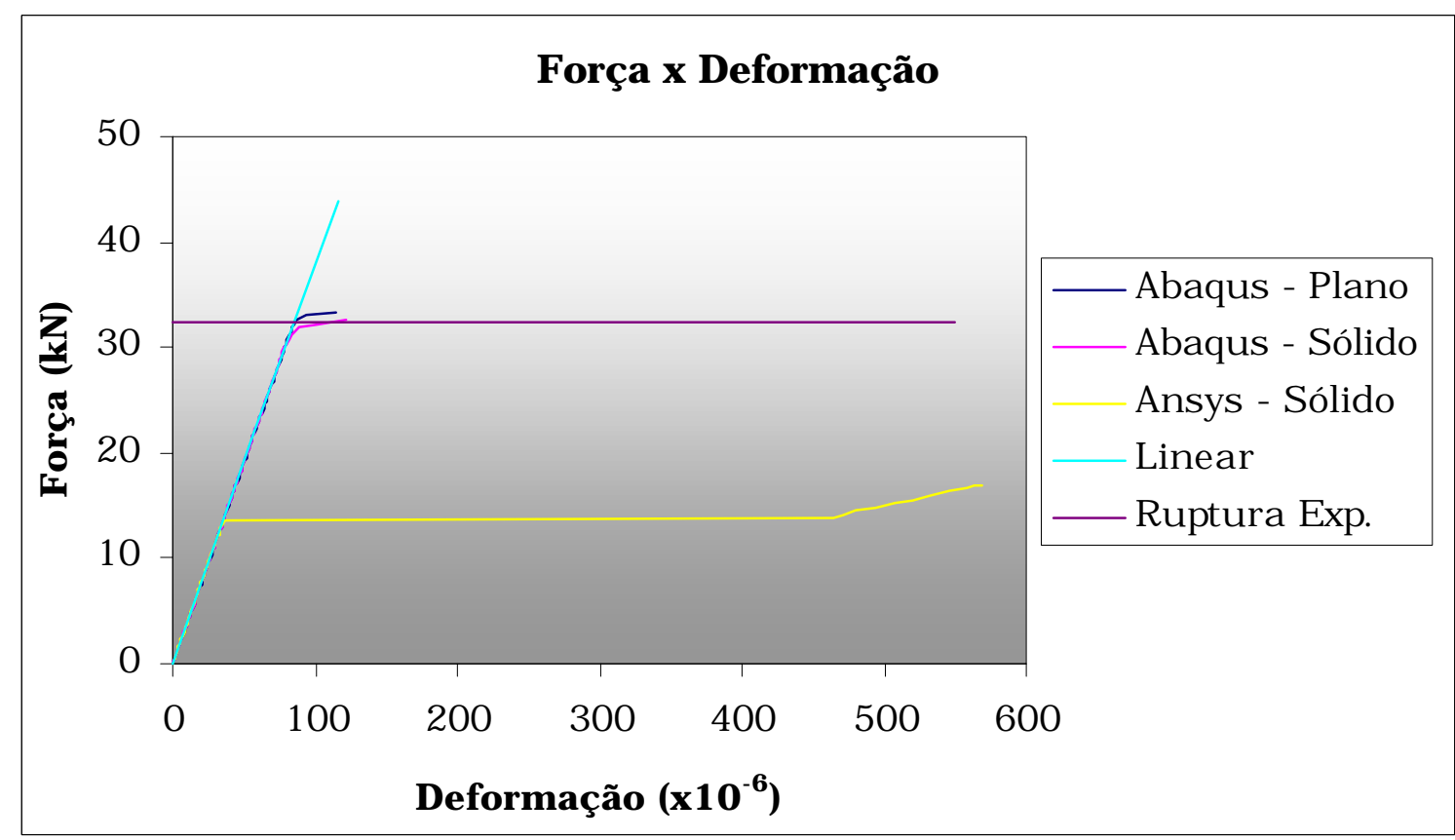

Figura 5.6 - Gráfico Força x Deformação 


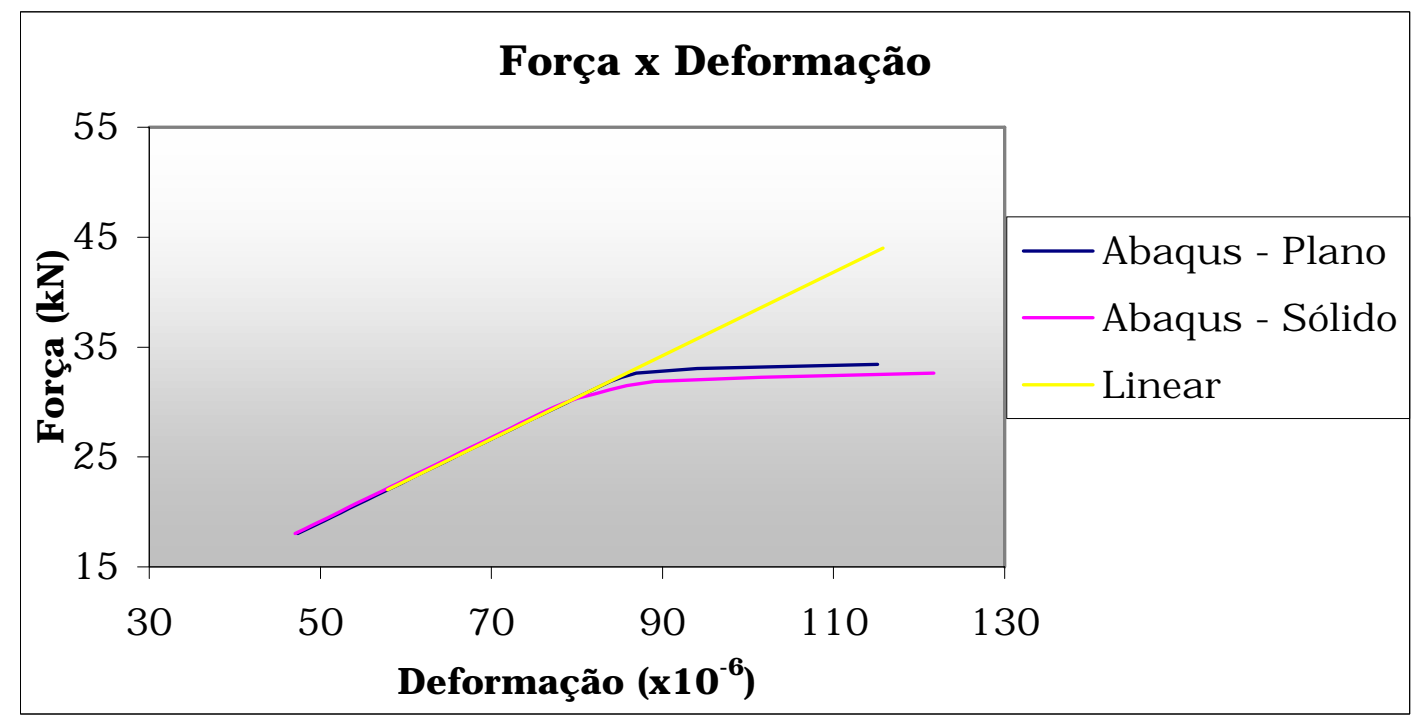

Figura 5.7 - Detalhe do gráfico Força x Deformação

Nota-se que o programa ABAQUS conseguiu estimar a força de ruptura bem próxima da carga experimental, tanto para o elemento plano quanto para o elemento sólido. O elemento plano superestimou em $3 \%$ a carga de ruptura; com o elemento sólido a carga foi praticamente a mesma, apresentando uma diferença de apenas 0,3\%. Já o programa ANSYS, além de não atingir a carga última de ruptura experimental, apresentou um gráfico bastante incoerente para o comportamento do material, fornecendo deformações excessivas e irreais para a alvenaria em um nível de carregamento muito baixo.

Nesse mesmo trabalho Ali \& Page fizeram a análise e o ensaio de algumas paredes de alvenaria, com unidades e argamassa com as mesmas propriedades dos materiais do prisma. As paredes tinham dimensões de $102,5 \mathrm{~cm}$ de altura, $71 \mathrm{~cm}$ de comprimento e $11 \mathrm{~cm}$ de espessura (figura 5.8). Nesse modelo foi feita uma variação do carregamento, aumentando-se gradativamente a área de aplicação desse carregamento na parede. Partindo-se de uma força distribuída numa área equivalente a 10\% da área da seção transversal da parede até chegar a uma área de 50\%. Na figura 5.9 apresentam-se as cargas de ruptura obtidas por PAGE com seus dois modelos, o frágil e o com amolecimento, e as obtidas com os programas ABAQUS e ANSYS. No gráfico, $\beta$ é a razão entre a área de aplicação da força e a área transversal total da parede. 


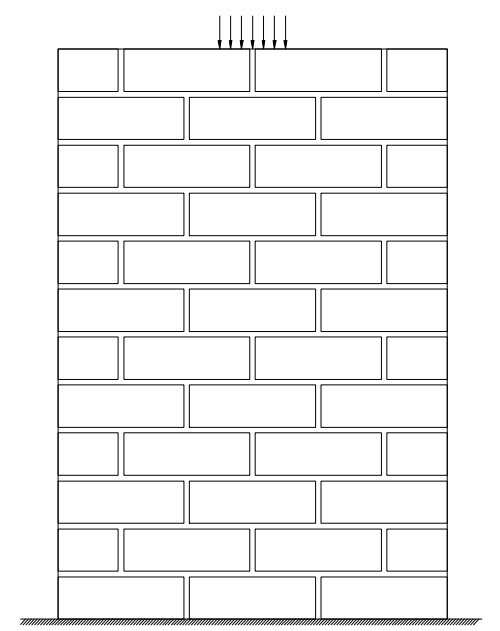

Figura 5.8 - Parede ensaiada

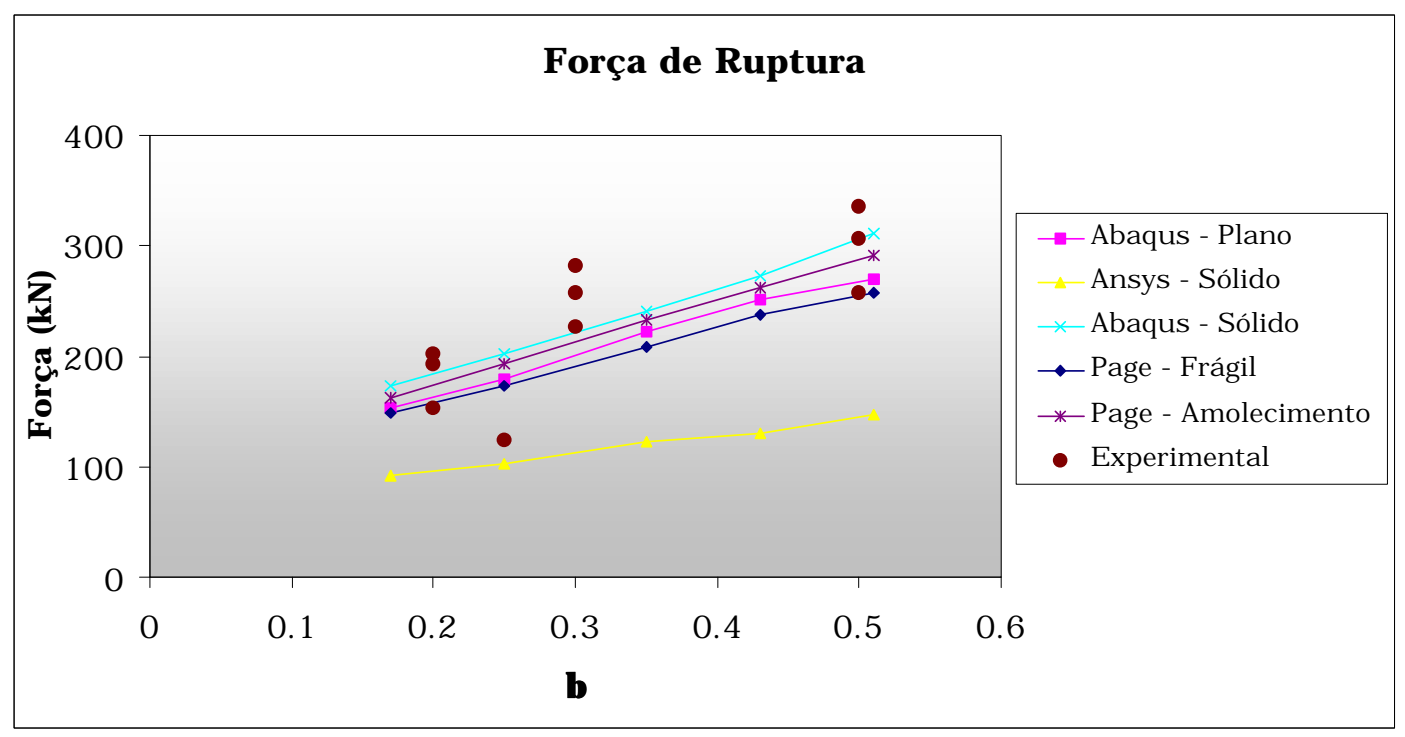

Figura 5.9 - Gráfico Força de ruptura x Área carregada

Analisando-se o gráfico da figura 5.9 percebe-se que os valores obtidos com o elemento plano do ABAQUS são um pouco maiores que os obtidos com o modelo frágil de PAGE. Já o modelo do ABAQUS utilizando elementos sólidos ficou mais próximo dos resultados obtidos com o modelo com amolecimento de PAGE. Conclui-se que o modelo do ABAQUS apresenta resultados satisfatórios tanto quando se utiliza o elemento plano quanto o sólido. A principal vantagem de se utilizar elementos planos, ao invés de sólidos, é a redução do número de graus de liberdade do modelo, obtendo-se, assim, um tempo de processamento bem menor. Já o programa 
ANSYS, como pode ser observado, fornece cargas de ruptura com valores bem menores que os outros programas, não representando bem o comportamento da alvenaria. O modelo é muito frágil, já que não considera nenhum tipo de amolecimento ou perda gradativa de rigidez depois de atingida a superfície de ruptura, fornecendo resultados insatisfatórios para a análise de estruturas em alvenaria. Comparando-se com os resultados experimentais verifica-se que todos os modelos ficaram, de um modo geral, a favor da segurança. Destaca-se que o modelo sólido do ABAQUS e o modelo com amolecimento do PAGE forneceram resultados mais próximos dos experimentais.

De acordo com PAGE \& SHRIVE (1990), quando uma força concentrada é aplicada a uma parede de alvenaria, altas tensões locais se desenvolvem, logo abaixo do ponto de aplicação da força. Na região imediatamente abaixo do ponto de aplicação do carregamento surge um estado de compressão biaxial. Um pouco mais abaixo o estado de tensão muda para uma compressão vertical e tração biaxial. Na figura 5.10 apresenta-se a distribuição da tensão transversal (normal horizontal) na parede como uma função da distância abaixo do ponto de aplicação da força.

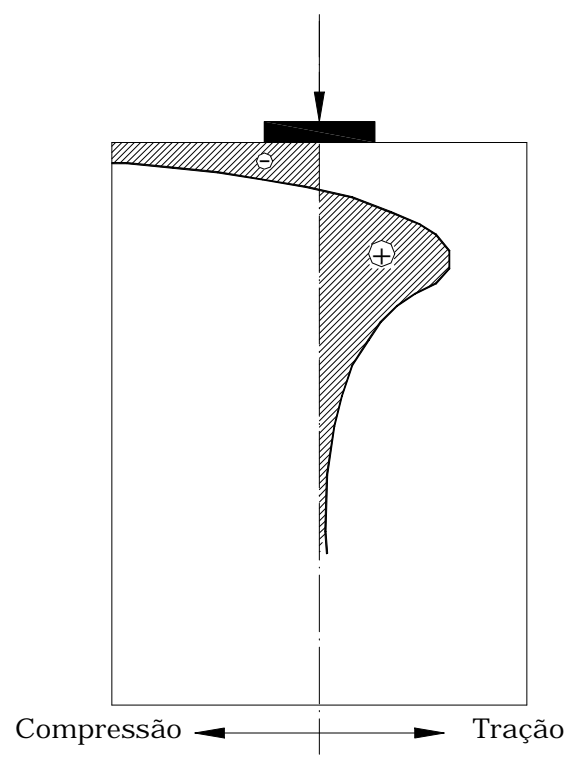

Figura 5.10 - Tensões transversais em uma parede sólida submetida a uma força concentrada

Adaptada de PAGE \& SHRIVE (1990) 
Na figura 5.11 apresenta-se o padrão de ruptura para a parede 3, onde $\beta=0,35$. Nota-se que as fissuras começam a aparecer numa região um pouco abaixo da aplicação da força, e não imediatamente abaixo. Isso confirma o comportamento coerente com o esperado. A vinculação adotada no modelo numérico, engastamento da base da parede, é a mesma utilizada no artigo.

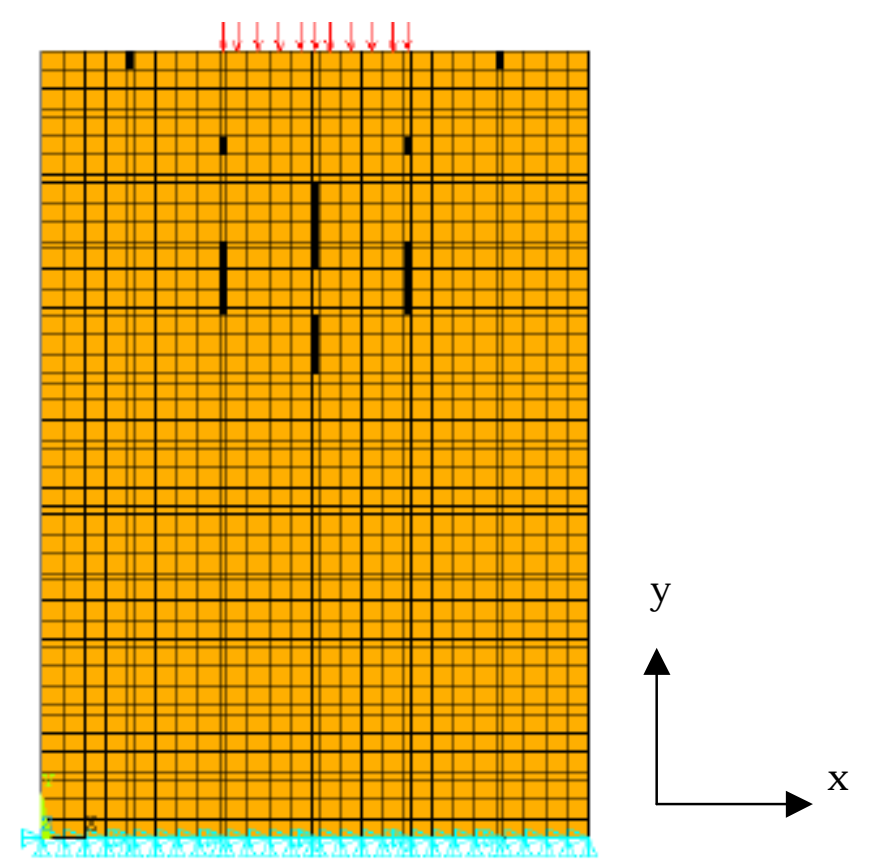

Figura 5.11 - Padrão de ruptura

As figuras 5.12 e 5.13 apresentam a variação das tensões $\sigma_{\mathrm{x}}$ e $\sigma_{\mathrm{y}}$ ao longo da altura da parede, comparando-se os valores da análise linear e da análise não linear, utilizando-se o modelo para estado plano do ABAQUS. As linhas amarelas indicam as juntas horizontais de argamassa. Ressaltase que o nível de solicitação para esses gráficos corresponde ao nível máximo que foi possível atingir com o programa. A partir desse valor não é mais possível aumentar a força aplicada na parede, devido à falta de convergência. Adotou-se esse valor como sendo a força de ruptura da estrutura. Nota-se que as tensões na base da parede permanecem em comportamento linear, apresentando os mesmos valores em ambas as análises. O comportamento não linear só acontece no trecho superior da parede, pois nessa posição os elementos rompem antes que as fissuras possam se propagar até a base da parede. As tensões $\sigma_{\mathrm{y}}$ são de compressão 
ao longo de toda a altura da parede, enquanto as tensões $\sigma_{\mathrm{x}}$ começam de compressão e depois há uma inversão para tração, o que explica o aparecimento de fissuras nesse trecho. Pode-se observar que a ruptura da parede acontece entre a $8^{\mathrm{a}}$ e a $11^{\text {a }}$ fiada, exatamente na região em que as tensões transversais são de tração.

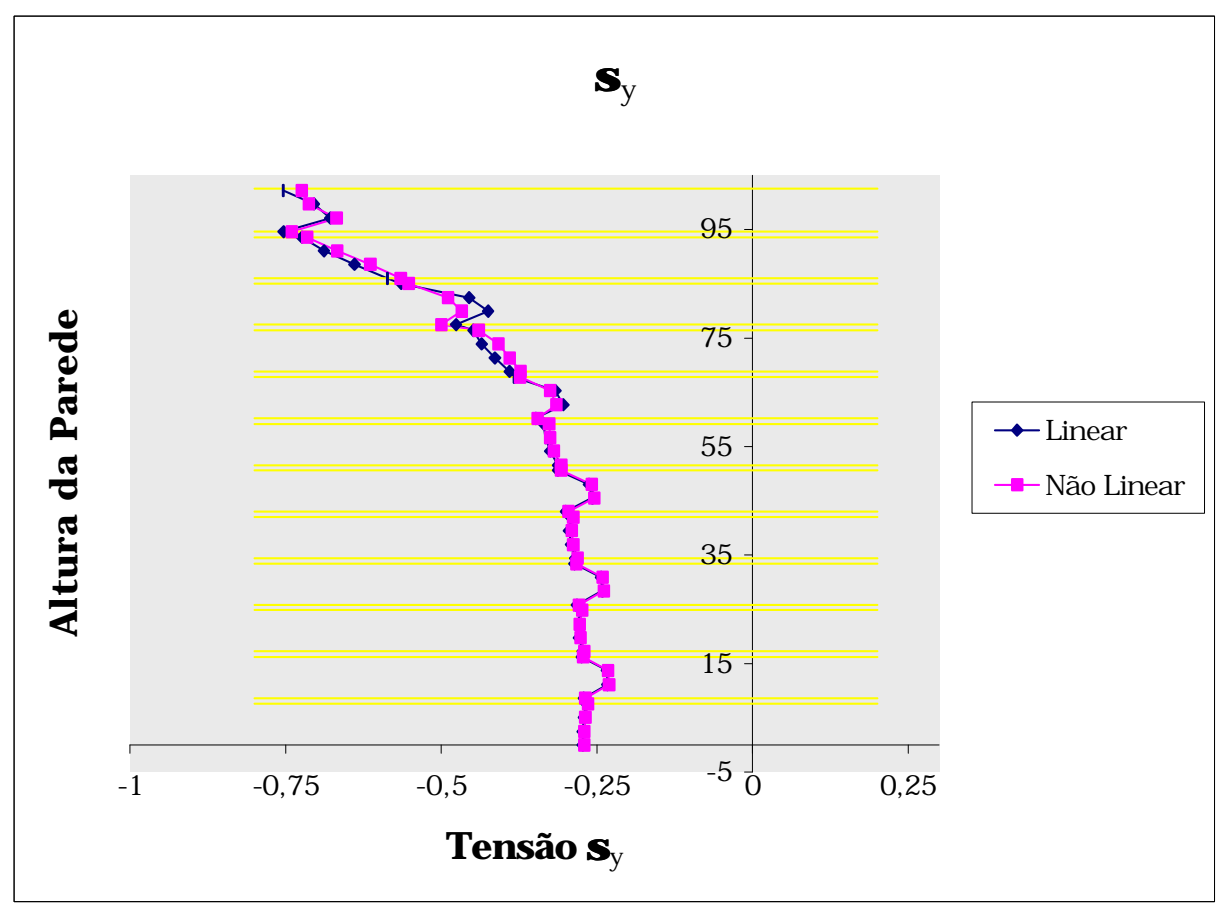

Figura 5.12 - Gráfico da tensão vertical $\left(\sigma_{y}\right)$ ao longo da altura da parede

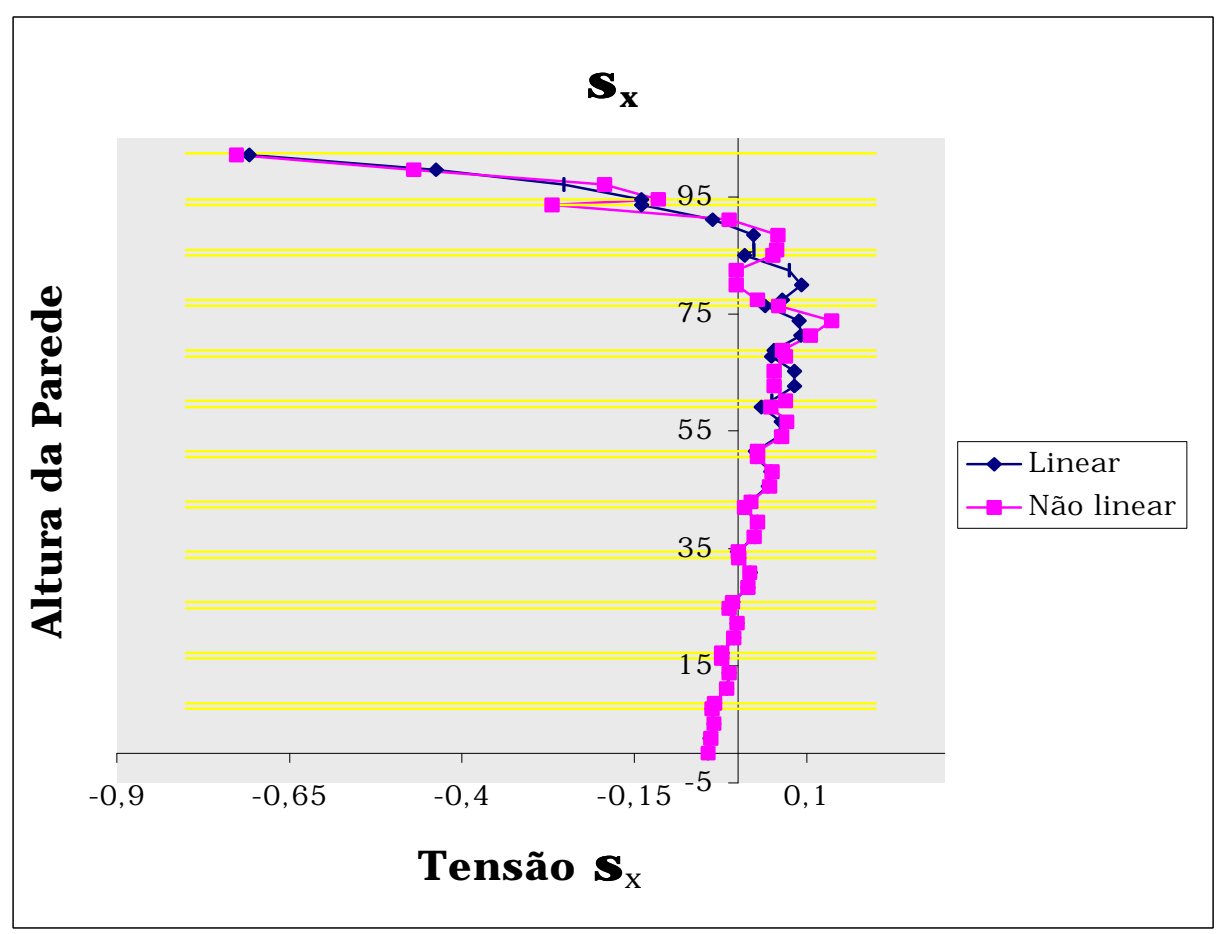

Figura 5.13 - Gráfico tensão transversal $\left(\sigma_{\mathrm{x}}\right)$ ao longo da altura da parede 


\subsection{FECHAMENTO}

Conclui-se que o modelo do ABAQUS representa bem o comportamento não-linear da alvenaria de unidades sólidas de concreto. Apesar de ser um modelo específico para o concreto, é possível utilizá-lo para fazer uma análise satisfatória das estruturas em alvenaria. A fissuração é um aspecto muito importante na análise dessas estruturas e o modelo representa de forma bastante coerente esse fenômeno. 


\subsection{INTRODUÇÃO}

Neste capítulo apresenta-se a análise de um painel de alvenaria em forma de "H", ensaiado por CAPUZZO NETO (2000) no laboratório do Departamento de Engenharia de Estruturas da EESC. Esse painel foi construído utilizando-se blocos cerâmicos vazados. A análise numérica foi realizada utilizando-se o software ABAQUS e considerou-se o comportamento linear e não linear dos materiais.

\subsection{ANÁLISE DE INTERAÇÃO DE PAREDES}

\subsubsection{Análise experimental e análise numérica}

Foram ensaiados três painéis com uma cinta de amarração na última fiada. O esquema de amarração é apresentado na figura $6.1 \mathrm{e}$ as dimensões dos painéis são apresentadas na figura 6.2. Os painéis possuem juntas verticais e horizontais de $1 \mathrm{~cm}$. 


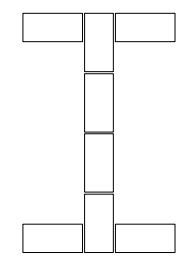

Fiada impar

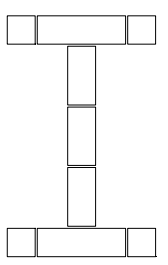

Fiada par

Figura 6.1 - Esquema de amarração das paredes Adaptada de CAPUZZO NETO (2000)

O esquema de instrumentação utilizado por CAPUZZO NETO (2000) está apresentado na figura 6.3; os pontos que estão em faces opostas possuem a mesma disposição. Foram utilizados transdutores com curso de $10 \mathrm{~mm}$ e base de $57 \mathrm{~cm}$, com a finalidade de medir os encurtamentos dos trechos superiores e inferiores das paredes. O carregamento foi aplicado na alma, na região entre os flanges. Utilizou-se uma viga metálica para que a força aplicada fosse distribuída uniformemente ao longo da parede.

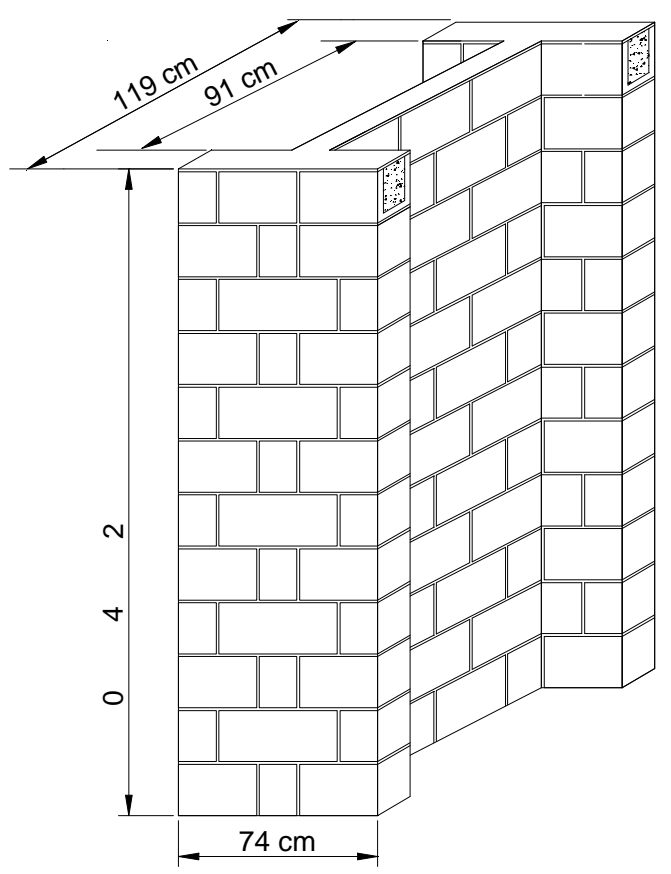

Figura 6.2 - Painel de alvenaria Adaptada de CAPUZZO NETO (2000) 

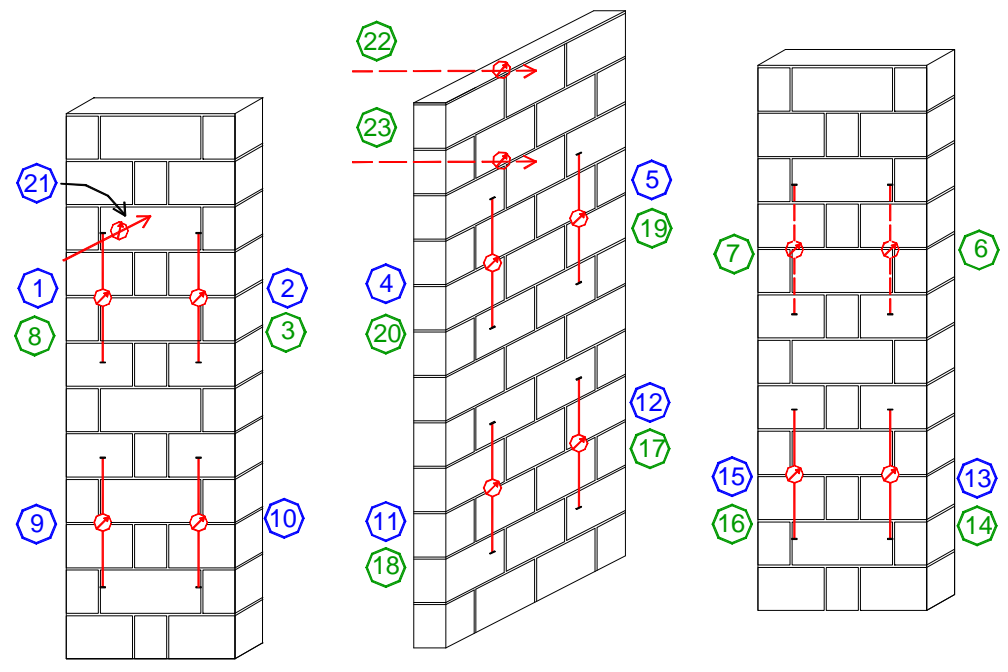

Face visível

Face oposta

Figura 6.3 - Instrumentação dos Painéis

Adaptada de CAPUZZO NETO (2000)

A análise numérica linear e não-linear foi feita utilizando-se o software ABAQUS, já que foi mostrado no capítulo anterior que o modelo do ANSYS não representa de forma satisfatória o comportamento da alvenaria. As paredes foram discretizadas com um elemento de casca denominado S4, que possui seis graus de liberdade por nó. $\mathrm{Na}$ base dos painéis foram restringidas as translações dos nós.

A modelagem foi feita discretizando-se os blocos e a argamassa separadamente. A rede utilizada encontra-se na figura 6.4. Foi aplicado um carregamento, uniformemente distribuído, apenas na região entre os flanges. As propriedades dos componentes foram obtidas experimentalmente e encontram-se na tabela 6.1.

Em relação ao bloco utilizou-se o módulo de elasticidade em relação à área líquida (cerca de $50 \%$ da área bruta). Adotou-se este procedimento em razão do módulo de elasticidade referente à área bruta ser um valor aparente, não representando as características do material. As dimensões nominais do bloco em centímetros são de 14x19x29 (largura x altura x

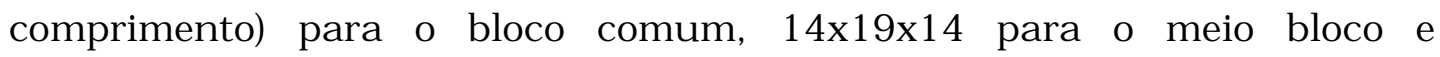
14x19x44 para o bloco de amarração. Na modelagem numérica foi utilizada uma espessura de $7 \mathrm{~cm}$, referente a $50 \%$ da largura bruta do bloco, para ajustar a área líquida. 


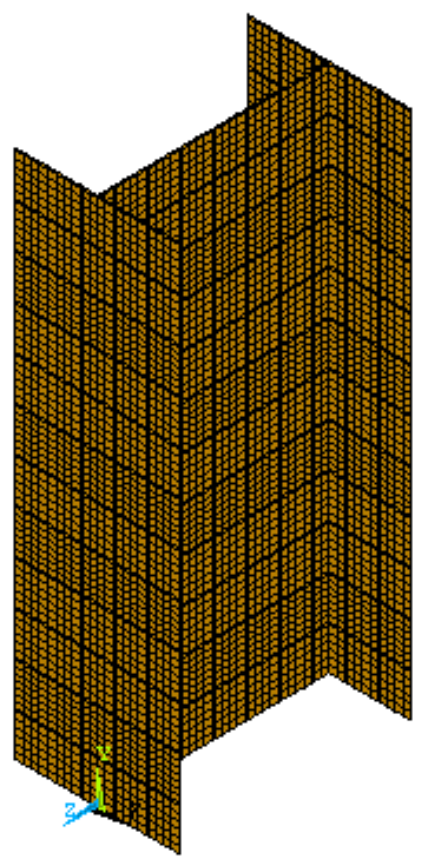

Figura 6.4 - Discretização do painel

As resistências à tração da unidade e da argamassa foram consideradas como sendo de $10 \%$ da resistência à compressão. O graute colocado na última fiada foi considerado apenas em comportamento elástico linear. Tal elemento tem a função apenas de amarrar o topo das paredes e redistribuir as forças aplicadas de maneira mais uniforme.

Tabela 6.1 - Propriedades dos componentes

\begin{tabular}{|c|c||}
\hline \multicolumn{2}{|c||}{ Propriedades da Unidade } \\
\hline Resistência à compressão & $25,8 \mathrm{MPa}$ \\
\hline Módulo de elasticidade & $8026 \mathrm{MPa}$ \\
\hline Coeficiente de Poisson & 0,25 \\
\hline \multicolumn{2}{|c||}{ Propriedades da Argamassa } \\
\hline Resistência à compressão & $9,4 \mathrm{MPa}$ \\
\hline Módulo de elasticidade & $10.900 \mathrm{MPa}$ \\
\hline Coeficiente de Poisson & 0,20 \\
\hline \multicolumn{2}{|c||}{ Propriedades do Graute } \\
\hline Módulo de elasticidade & $30.000,0 \mathrm{MPa}$ \\
\hline Coeficiente de Poisson & 0,20 \\
\hline
\end{tabular}


A força de ruptura média obtida para os três painéis ensaiados foi de $510 \mathrm{kN}$, enquanto a força de ruptura da análise numérica foi de $425 \mathrm{kN}$, ou seja $83,3 \%$ da força real. Ressalta-se que a força admitida como de ruptura na análise numérica é o valor máximo para o qual é possível atingir a convergência com o programa. A partir desse valor não é possível aumentar o nível de solicitação do modelo pois o programa não consegue convergir para uma solução.

A força média correspondente ao aparecimento da primeira fissura no ensaio foi de $387 \mathrm{kN}$. É importante ressaltar que a marcação das fissuras nos ensaios era realizada nos intervalos dos estágios de carregamento, tratando-se portanto de um valor aproximado. $\mathrm{Na}$ análise numérica esse valor foi $310 \mathrm{kN}$, o que corresponde a $80 \%$ da força do ensaio. Apesar da dificuldade na obtenção de dados precisos das propriedades dos materiais, o fato da resistência máxima à tração dos materiais ter sido estimada e a imprecisão na obtenção do valor exato da força de aparecimento da primeira fissura no ensaio, os resultados numéricos apresentam-se consistentes coerentes com o trabalho experimental.

\subsubsection{Deslocamentos verticais}

A principal medida realizada no ensaio foi o deslocamento relativo vertical, sendo esse portanto um parâmetro importante de comparação. Nas tabelas 6.2, 6.3 e 6.4 apresentam-se os resultados obtidos numericamente, considerando-se a análise linear e não linear, e comparando-os com os respectivos valores médios obtidos experimentalmente.

A força de ruptura esperada foi estimada considerando a relação entre a resistência da parede $\left(\mathrm{f}_{\mathrm{cpa}}\right)$ e a resistência do bloco $\left(\mathrm{f}_{\mathrm{b}}\right)$ igual a $\mathrm{f}_{\mathrm{cpa}} / \mathrm{f}_{\mathrm{b}}=0,33$, conforme MACHADO Jr. et al. (1999).

$\mathrm{Na}$ tabela 6.2 apresentam-se os resultados numéricos e experimentais obtidos para uma força de $280 \mathrm{kN}$. Esse valor corresponde a $60 \%$ da força de ruptura esperada. Adotou-se esse valor baseado no trabalho de CAPUZZO NETO (2000), por se tratar de um estágio de carregamento do ensaio e por se considerar que até essa fase a alvenaria se encontra em comportamento linear. Segundo HENDRY et al. (1981) a 
alvenaria cerâmica pode ser considerada em comportamento linear até $75 \%$ da força de ruptura.

Analisando-se os resultados obtidos conclui-se que existe uma boa correlação entre os resultados numéricos e experimentais. Verifica-se que no trecho inferior o deslocamento na alma e no flange apresentam valores bem próximos um do outro, o que indica que existe uma distribuição dos esforços bastante homogênea nessa região, concluindo-se que há uma transferência de esforços bastante efetiva entre a alma e o flange. Na tabela 6.2 apresentam-se, também, os valores dos deslocamentos para a análise não linear, que são iguais aos valores da análise linear, confirmando a hipótese de que nesse nível de carregamento o comportamento da alvenaria ainda se encontra no regime linear. Comparando-se os valores numéricos com os experimentais verifica-se que os resultados estão próximos, sendo que no trecho superior as diferenças são maiores.

Tabela 6.2 - Deslocamentos relativos verticais numéricos e experimentais $(\mathrm{F}=280 \mathrm{kN})$

\begin{tabular}{|c|c|c|c|c|c|c|}
\cline { 2 - 7 } & \multicolumn{3}{c|}{ Trecho inferior } & \multicolumn{3}{c|}{ Trecho superior } \\
\cline { 2 - 7 } & $\begin{array}{c}\text { Flange } \\
\text { (mm) }\end{array}$ & $\begin{array}{c}\text { Alma } \\
\text { (mm) }\end{array}$ & $\begin{array}{c}\text { Flange } \\
\text { Alma }\end{array}$ & $\begin{array}{c}\text { Flange } \\
\text { (mm) }\end{array}$ & $\begin{array}{c}\text { Alma } \\
\text { (mm) }\end{array}$ & $\begin{array}{c}\text { Flange/ } \\
\text { Alma }\end{array}$ \\
\hline Ensaio 1-1 & $-0,090$ & $-0,099$ & 0,91 & $-0,065$ & $-0,135$ & 0,48 \\
\hline Ensaio 1-2 & $-0,089$ & $-0,101$ & 0,88 & $-0,057$ & $-0,140$ & 0,41 \\
\hline Ensaio 1-3 & $-0,089$ & $-0,071$ & 1,25 & $-0,070$ & $-0,126$ & 0,56 \\
\hline Média & $-0,089$ & $-0,090$ & 0,99 & $-0,064$ & $-0,134$ & 0,48 \\
\hline Abaqus Linear & $-0,108$ & $-0,113$ & 0,96 & $-0,089$ & $-0,142$ & 0,63 \\
\hline Abaqus Não-Linear & $-0,108$ & $-0,113$ & 0,96 & $-0,089$ & $-0,142$ & 0,63 \\
\hline Média/Abaqus & $82,4 \%$ & $79,6 \%$ & & $71,9 \%$ & $94,4 \%$ & \\
\hline $\begin{array}{c}\text { Média/Abaqus Não- } \\
\text { Linear }\end{array}$ & $82,4 \%$ & $79,6 \%$ & & $71,9 \%$ & $94,4 \%$ & \\
\hline
\end{tabular}

$\mathrm{Na}$ tabela 6.3 apresentam-se os resultados numéricos e experimentais para uma força aplicada de $400 \mathrm{kN}$, que corresponde a $87 \%$ da força de ruptura teórica. Nesse nível de carregamento a alvenaria já se encontra fissurada. Analisando-se os resultados da tabela 6.3, percebe-se que os valores de deslocamento para análise linear e não linear continuam sendo idênticos, o que indica que mesmo fissurada a alvenaria não apresenta um comportamento não linear evidente no que se refere ao 
deslocamento vertical relativo entre seus pontos. Comparando-se os valores de deslocamento no trecho inferior do flange e da alma verifica-se que se confirma a tendência de homogeneização dos deslocamentos no trecho inferior. Pode-se, então, concluir que, mesmo depois de iniciada a fissuração da parede, a transferência de tensões entre a alma e o flange continua acontecendo.

Tabela 6.3 - Deslocamentos relativos verticais numéricos e experimentais $(\mathrm{F}=400 \mathrm{kN})$

\begin{tabular}{|c|c|c|c|c|c|c|}
\cline { 2 - 7 } & \multicolumn{3}{c|}{ Trecho inferior } & \multicolumn{3}{c|}{ Trecho superior } \\
\cline { 2 - 7 } & $\begin{array}{c}\text { Flange } \\
\text { (mm) }\end{array}$ & $\begin{array}{c}\text { Alma } \\
\text { (mm) }\end{array}$ & $\begin{array}{c}\text { Flange/ } \\
\text { Alma }\end{array}$ & $\begin{array}{c}\text { Flange } \\
\text { (mm) }\end{array}$ & $\begin{array}{c}\text { Alma } \\
\text { (mm) }\end{array}$ & $\begin{array}{c}\text { Flange/ } \\
\text { Alma }\end{array}$ \\
\hline Ensaio 1-1 & $-0,121$ & $-0,163$ & 0,74 & $-0,049$ & $-0,239$ & 0,21 \\
\hline Ensaio 1-2 & $-0,134$ & $-0,152$ & 0,88 & $-0,081$ & $-0,229$ & 0,35 \\
\hline Ensaio 1-3 & $-0,123$ & $-0,129$ & 0,95 & $-0,055$ & $-0,227$ & 0,24 \\
\hline Média & $-0,126$ & $-0,148$ & 0,85 & $-0,062$ & $-0,232$ & 0,27 \\
\hline Abaqus Linear & $-0,155$ & $-0,162$ & 0,96 & $-0,128$ & $-0,204$ & 0,63 \\
\hline Abaqus Não-Linear & $-0,155$ & $-0,162$ & 0,96 & $-0,128$ & $-0,204$ & 0,63 \\
\hline Média/Abaqus & $81,3 \%$ & $91,4 \%$ & & $48,4 \%$ & $113,7 \%$ & \\
\hline Média/Abaqus Não- & $81,3 \%$ & $91,4 \%$ & & $48,4 \%$ & $113,7 \%$ & \\
Linear & & & & & & \\
\hline
\end{tabular}

Tabela 6.4 - Deslocamentos relativos verticais numéricos e experimentais $(F=425 \mathrm{kN})$

\begin{tabular}{|c|c|c|c|c|c|c|}
\cline { 2 - 7 } & \multicolumn{3}{c}{ Trecho inferior } & \multicolumn{3}{c|}{ Trecho superior } \\
\cline { 2 - 7 } & $\begin{array}{c}\text { Flange } \\
\text { (mm) }\end{array}$ & $\begin{array}{c}\text { Alma } \\
\text { (mm) }\end{array}$ & $\begin{array}{c}\text { Flange/ } \\
\text { Alma }\end{array}$ & $\begin{array}{c}\text { Flange } \\
\text { (mm) }\end{array}$ & $\begin{array}{c}\text { Alma } \\
\text { (mm) }\end{array}$ & $\begin{array}{c}\text { Flange/ } \\
\text { Alma }\end{array}$ \\
\hline Ensaio 1-1 & $-0,124$ & $-0,173$ & 0,72 & $-0,048$ & $-0,251$ & 0,19 \\
\hline Ensaio 1-2 & $-0,126$ & - & - & $-0,056$ & - & - \\
\hline Ensaio 1-3 & $-0,110$ & $-0,166$ & 0,66 & $-0,082$ & $-0,261$ & 0,31 \\
\hline Média & $-0,120$ & $-0,170$ & 0,71 & $-0,062$ & $-0,256$ & 0,24 \\
\hline Abaqus Linear & $-0,164$ & $-0,172$ & 0,97 & $-0,135$ & $-0,216$ & 0,63 \\
\hline Abaqus Não-Linear & $-0,163$ & $-0,172$ & 0,95 & $-0,135$ & $-0,216$ & 0,63 \\
\hline Média/Abaqus & $73,2 \%$ & $98,9 \%$ & & $45,9 \%$ & $118,5 \%$ & \\
\hline Média/Abaqus Não- & $73,6 \%$ & $98,9 \%$ & & $45,9 \%$ & $118,5 \%$ & \\
\hline Linear & & & & & & \\
\hline
\end{tabular}

$\mathrm{Na}$ tabela 6.4 apresentam-se os resultados numéricos e experimentais para uma força aplicada de $425 \mathrm{kN}$, que é a força de ruptura 
teórica obtida com a análise numérica. Verifica-se que nesse estágio de carregamento tem-se uma pequena diferença entre o deslocamento da análise linear e da não linear. Apesar da diferença ser muito pequena, podese concluir que, à medida que o carregamento aplicado vai se aproximando da força de ruptura do painel, a transferência de tensões entre o flange e a alma vai se tornando menor. O que se explica pelo fato da forma de ruína corresponder exatamente à separação entre essas duas partes da estrutura. Nesse estágio de carregamento alguns transdutores precisaram ser retirados no ensaio, por isso alguns valores na tabela estão em branco. Com isso, não é possível fazer uma comparação mais ampla entre os valores numéricos e experimentais. Um dos fatos que pode ter prejudicado a comparação foi a dificuldade de obtenção das propriedades dos materiais de maneira precisa, o que causou uma resposta numérica um pouco diferente da real.

A figura 6.5 apresenta os resultados obtidos na modelagem numérica para os deslocamentos na direção vertical, para uma força de $425 \mathrm{kN}$. Observando-se a figura, nota-se que os deslocamentos dos pontos da parede central (próximo à aplicação do carregamento) são bem maiores que os deslocamentos nos flanges, no trecho superior da parede. Já no trecho inferior os deslocamentos na alma e nos flanges tendem a se uniformizar.
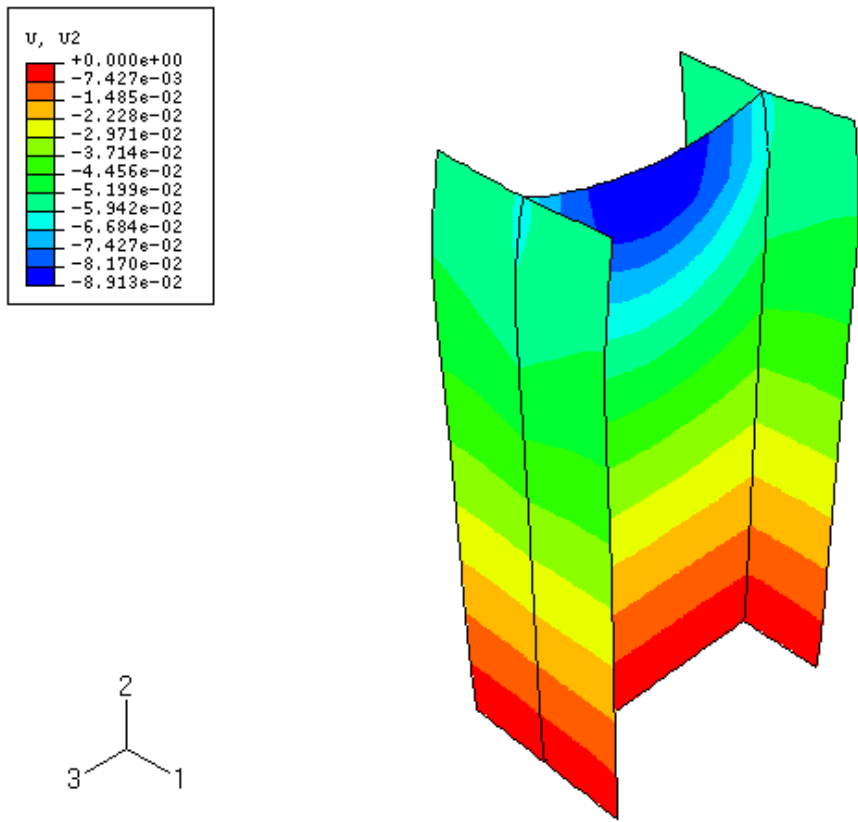

Figura 6.5 - Deslocamentos verticais na direção $2(\mathrm{~cm})$ 
Para melhor visualização dos resultados obtidos na análise numérica, nas figuras 6.6, 6.7 e 6.8 apresentam-se os deslocamentos verticais ao longo da altura da parede para as forças aplicadas de $280 \mathrm{kN}$, $400 \mathrm{kN}$ e $425 \mathrm{kN}$, respectivamente. Estes deslocamentos referem-se a mesma linha vertical onde se localizam os pontos instrumentados nos ensaios (conforme figura 6.3).

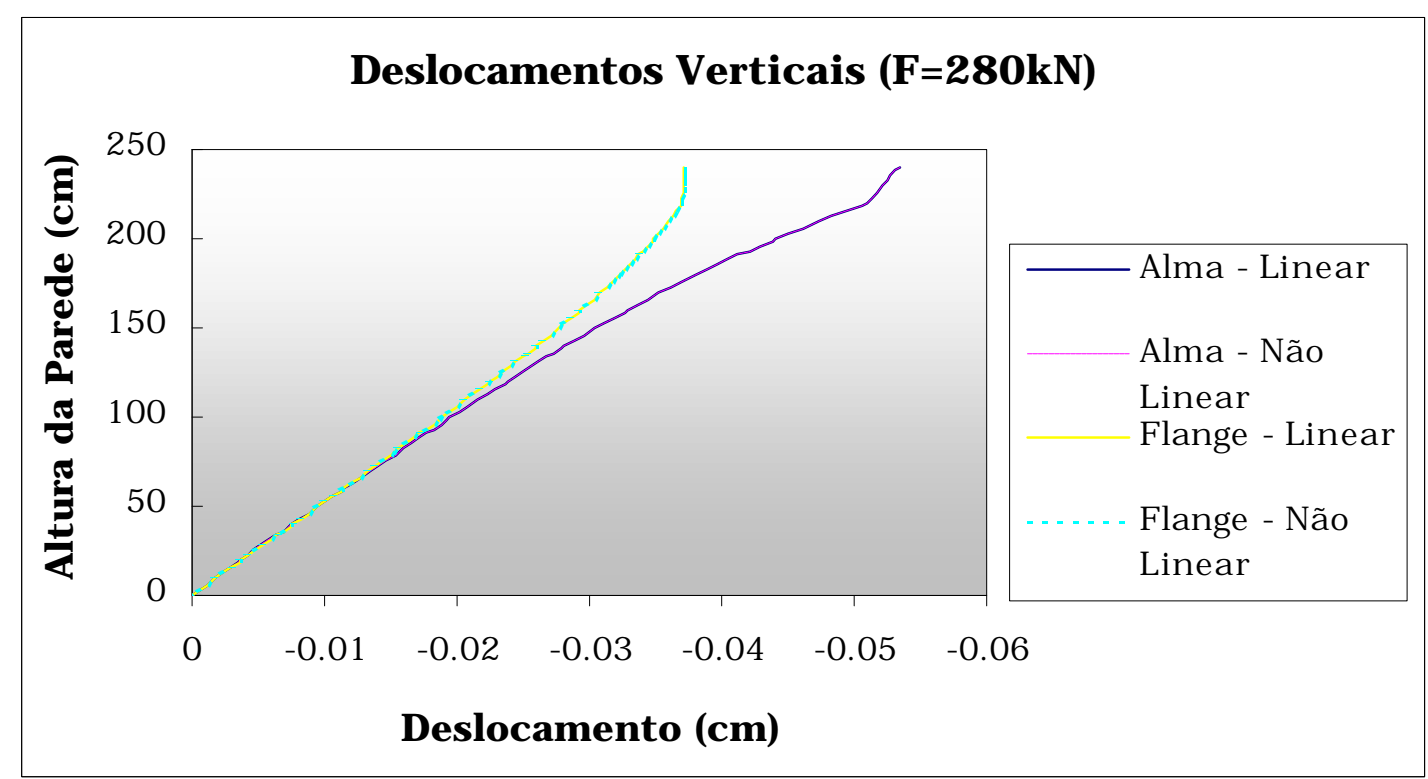

Figura 6.6 - Deslocamentos verticais ao longo da altura da parede $(\mathrm{F}=\mathbf{2 8 0 \mathrm { kN }})$

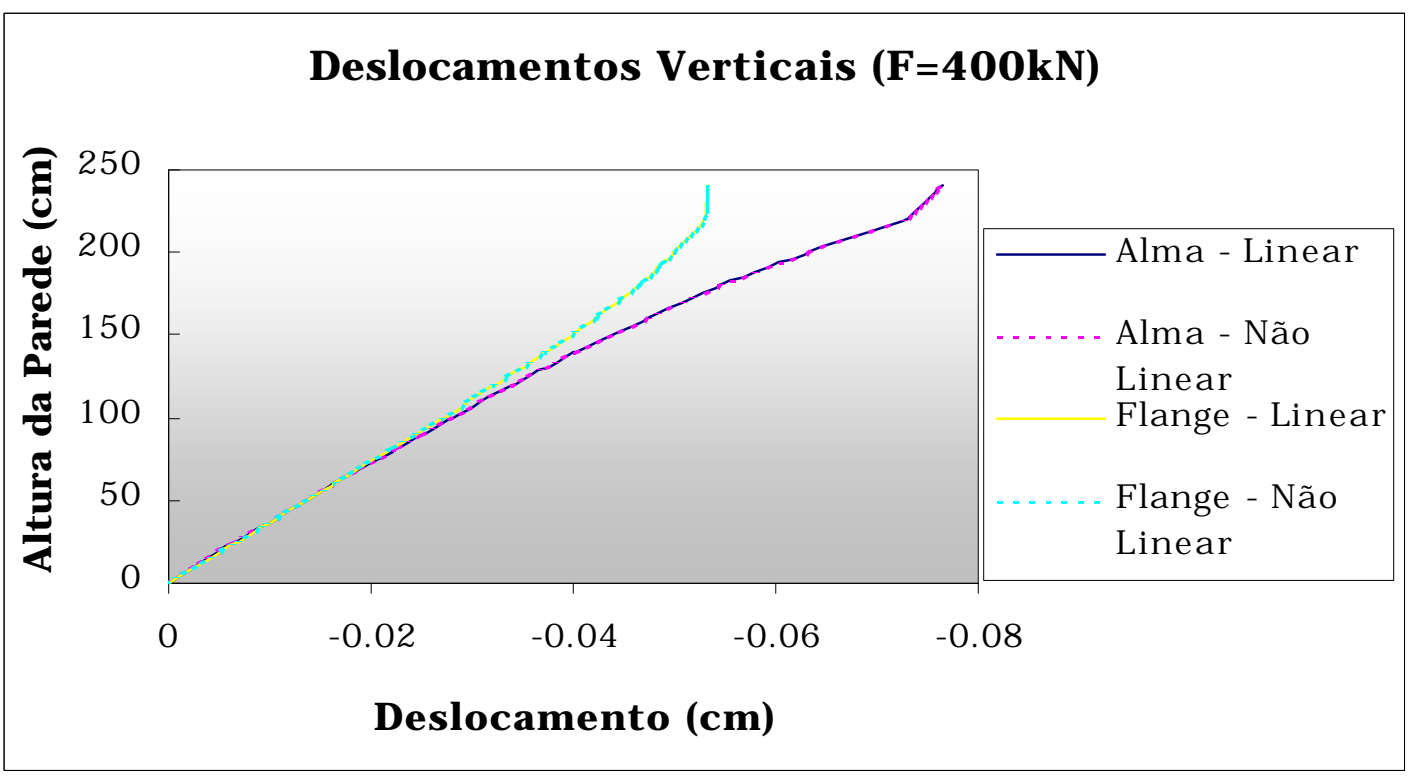

Figura 6.7 - Deslocamentos verticais ao longo da altura da parede $(\mathrm{F}=400 \mathrm{kN})$ 
Conforme pode ser observado, no topo da parede os deslocamentos na alma apresentam-se maiores que os deslocamentos no flange. À medida que se caminha para a base da parede a tendência de uniformização dos mesmos é muito grande. Nos três gráficos pode-se verificar essa uniformização, comprovando-se que o painel $\mathrm{H}$ realmente trabalha como um conjunto intertravado, podendo-se considerar que a tensão é distribuída pelo painel, não ficando concentrada na alma, onde é aplicado o carregamento. Analisando-se os gráficos percebe-se, também, que não existe diferença entre a análise linear e a não linear.

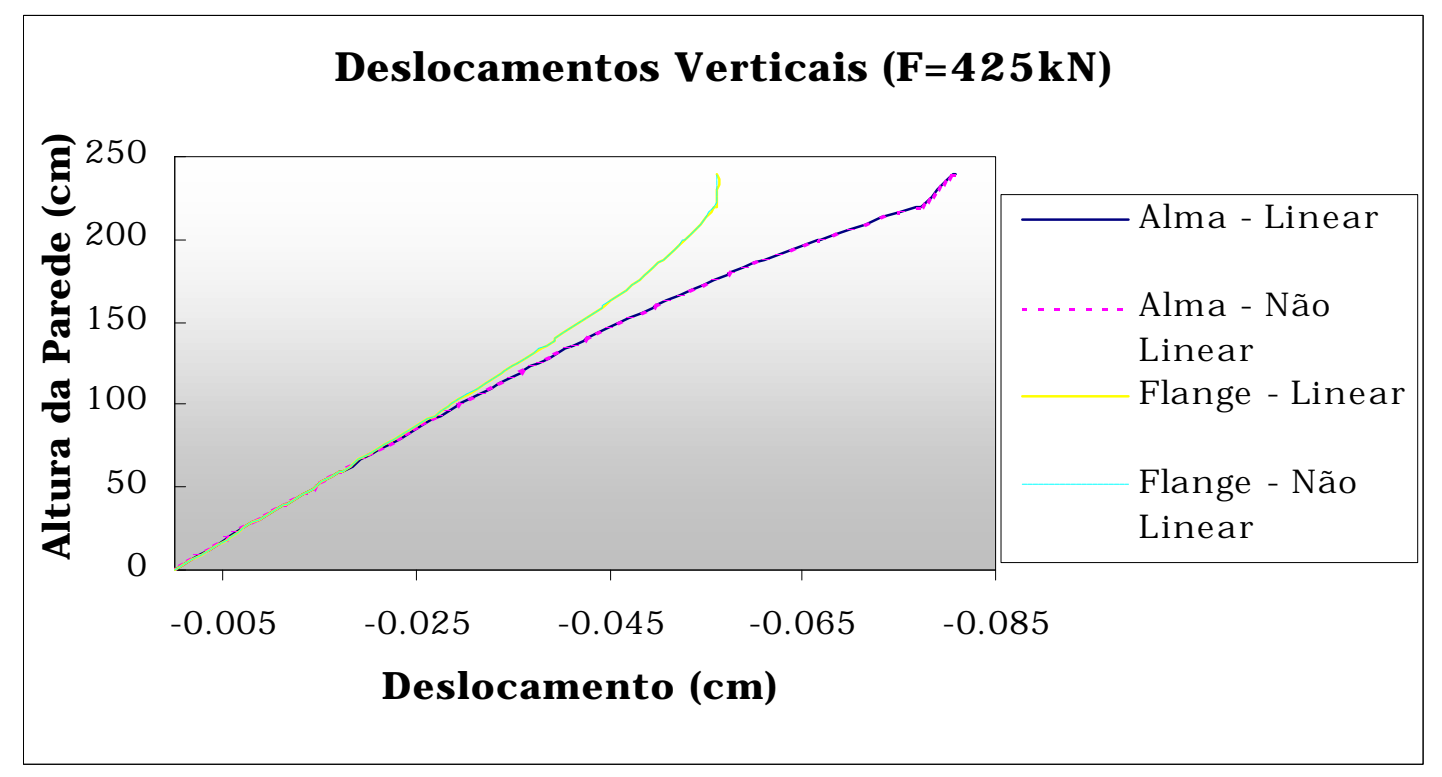

Figura 6.8 - Deslocamentos verticais ao longo da altura da parede $(\mathrm{F}=425 \mathrm{kN})$

\subsubsection{Tensões normais verticais}

A figura 6.9 apresenta a distribuição das tensões normais verticais $\left(\sigma_{22}\right)$ no painel. Os valores referem-se a uma força de $425 \mathrm{kN}$, sendo as tensões em relação à área líquida.

Nota-se na figura 6.9 que o flange sofre flexão, estando a face interna mais comprimida que a interna. Observa-se que na parede central, na região de aplicação do carregamento, existe uma concentração de tensões. Nota-se, também, que nas juntas verticais de argamassa, 
principalmente no trecho superior, existe uma concentração de tensões localizadas. No trecho inferior as tensões já se apresentam uniformizadas.

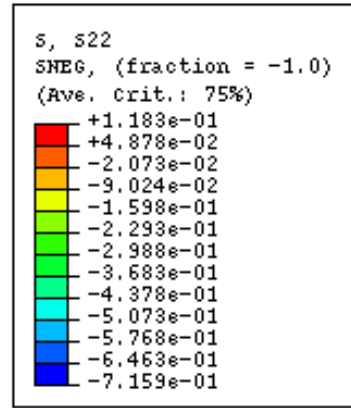<smiles>[2H]C(I)I</smiles>

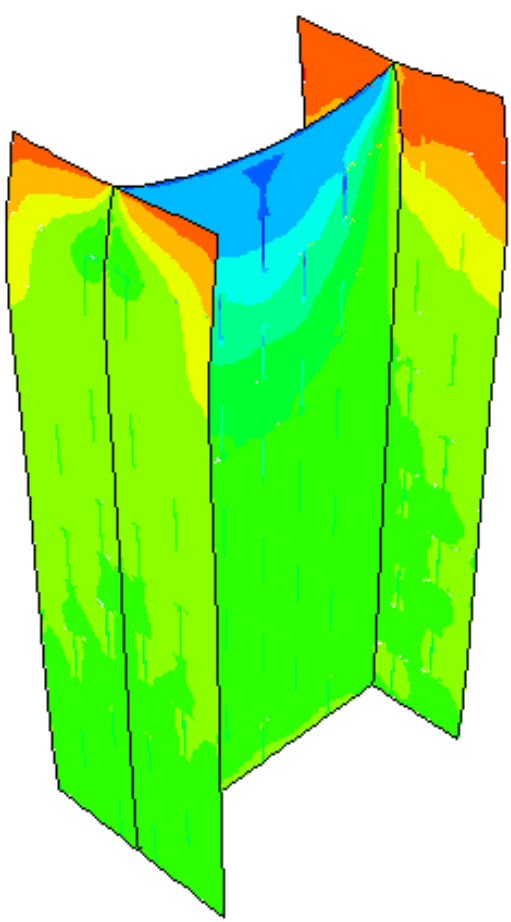

Figura 6.9 - Tensões normais verticais $-\sigma_{22}\left(\mathrm{kN} / \mathrm{cm}^{2}\right)$

Nas figuras 6.10, 6.11 e 6.12 apresentam-se as tensões normais verticais ao longo da altura da parede para uma força aplicada de $280 \mathrm{kN}$, $400 \mathrm{kN}$ e $425 \mathrm{kN}$. Verifica-se nos três gráficos que as tensões na base da parede convergem para um mesmo valor, na alma e no flange. Comprovando-se dessa forma a homogeneização das tensões ao longo da altura da parede e confirmando que a força aplicada é transferida da alma para o flange através dos blocos intertravados de forma bastante eficiente. 


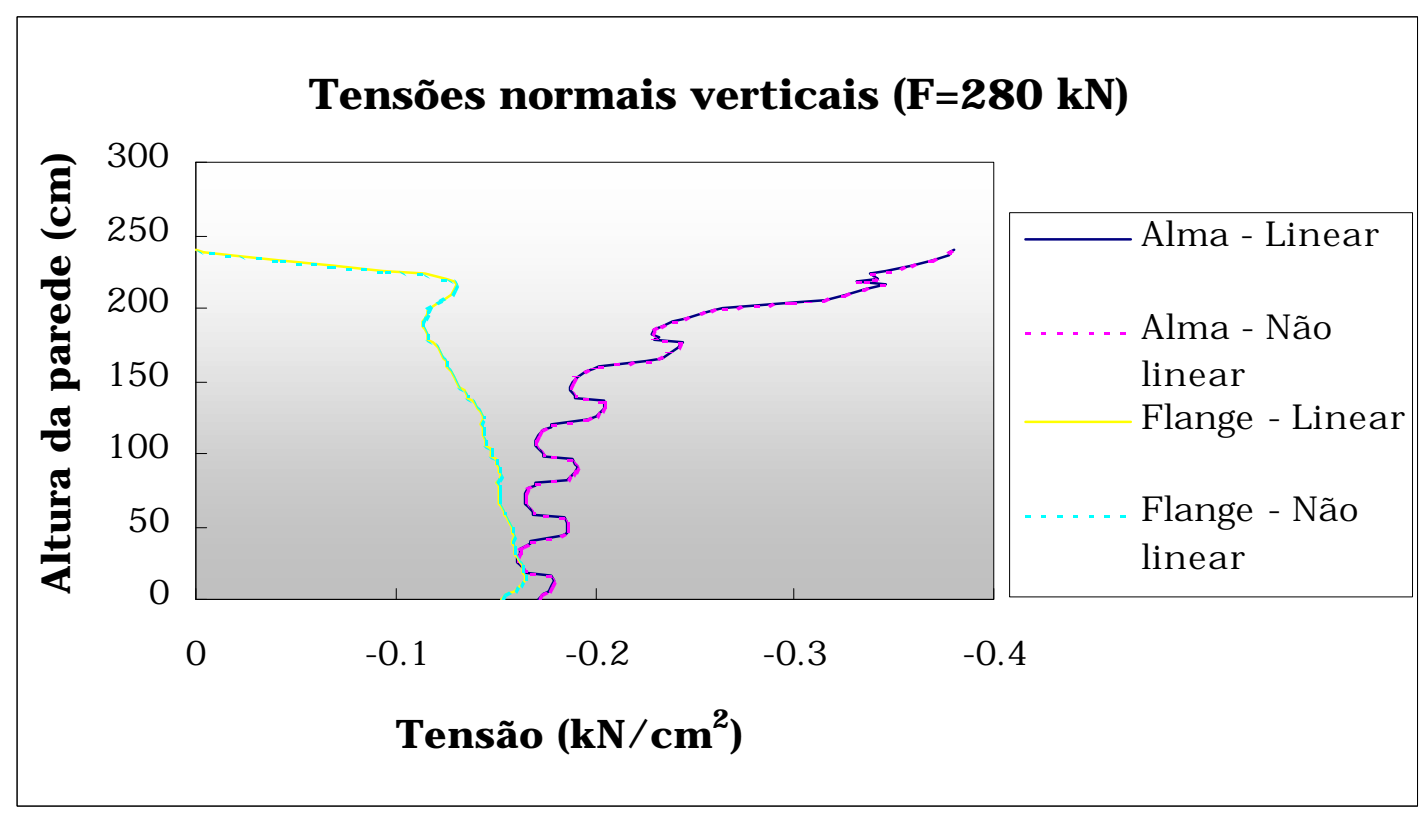

Figura 6.10 - Tensões normais verticais ao longo da altura da parede $(\mathrm{F}=280 \mathrm{kN})$

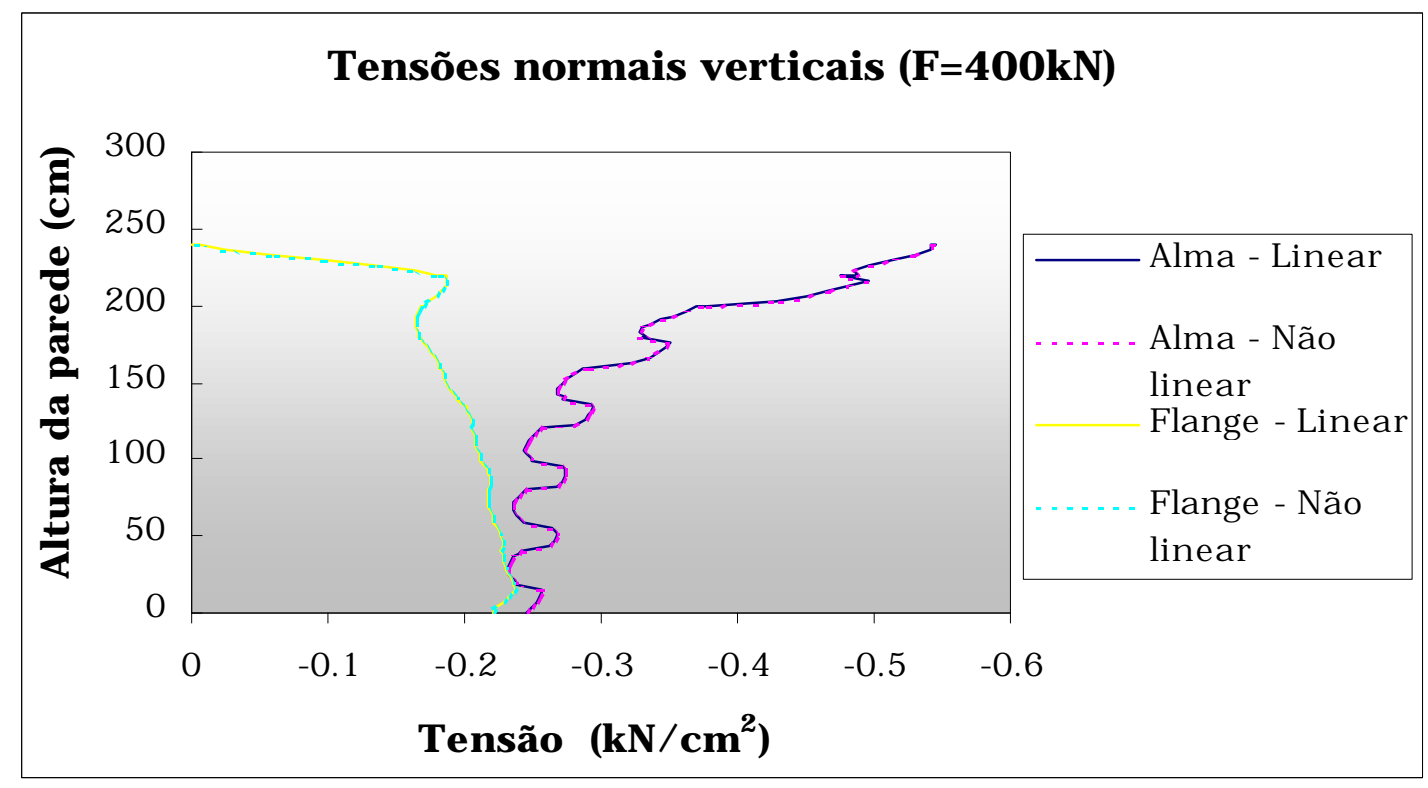

Figura 6.11 - Tensões normais verticais ao longo da altura da parede $(\mathrm{F}=400 \mathrm{kN})$ 


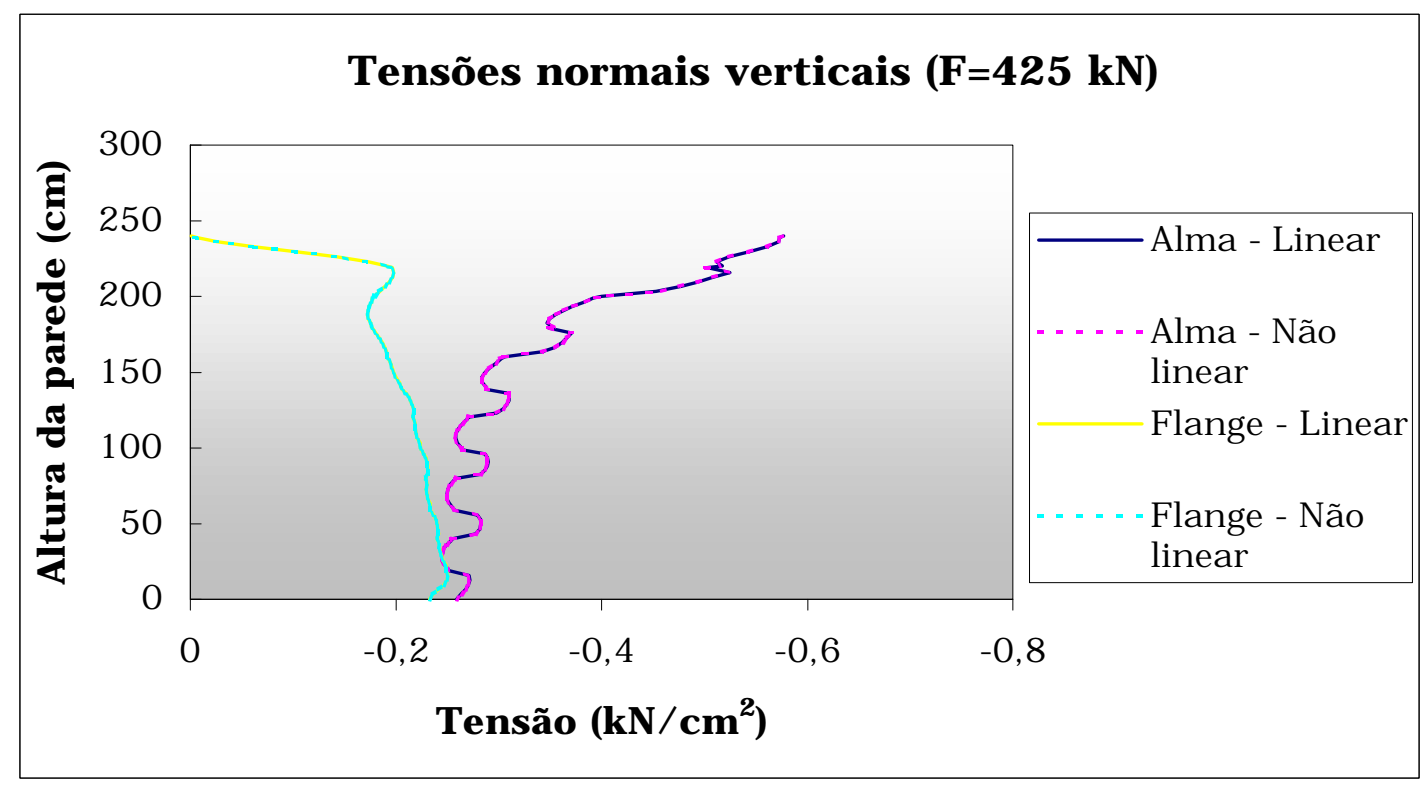

Figura 6.12 - Tensões normais verticais ao longo da altura da parede $(F=425 k N)$

\subsubsection{Deformação}

Nas figuras $6.13,6.14,6.15$ e 6.16 apresentam-se os valores de tensão no grupo $\mathrm{x}$ deformação para os resultados numéricos $\mathrm{e}$ experimentais nos pontos instrumentados da figura 6.3. Analisando-se os gráficos, verifica-se que os resultados da análise numérica apresentam-se praticamente lineares até a ruptura. Comparando-se com os resultados experimentais conclui-se que os resultados numéricos apresentam uma média dos resultados experimentais. Na análise numérica a estrutura é perfeitamente simétrica tanto em termos de geometria como de condições de contorno. Na análise experimental essa simetria não pode ser totalmente garantida. Conclui-se, portanto, que a análise numérica fornece uma aproximação razoável para a análise experimental.

Analisando-se as figuras 6.13 e 6.14, referentes ao trecho inferior da parede, percebe-se que nessa região o gráfico da análise numérica pode ser considerado como uma média dos resultados experimentais. Nesse trecho a distribuição de tensões é bastante uniforme, e as deformações obtidas no flange e na alma são bastante próximas. Dessa forma está garantida a transferência de tensões da alma para o flange através dos 
blocos intertravados. Este fato também justifica a importância da realização de instrumentações simétricas durante a realização dos ensaios experimentais, porque só dessa forma se pode verificar de forma adequada esta transferência de tensões.

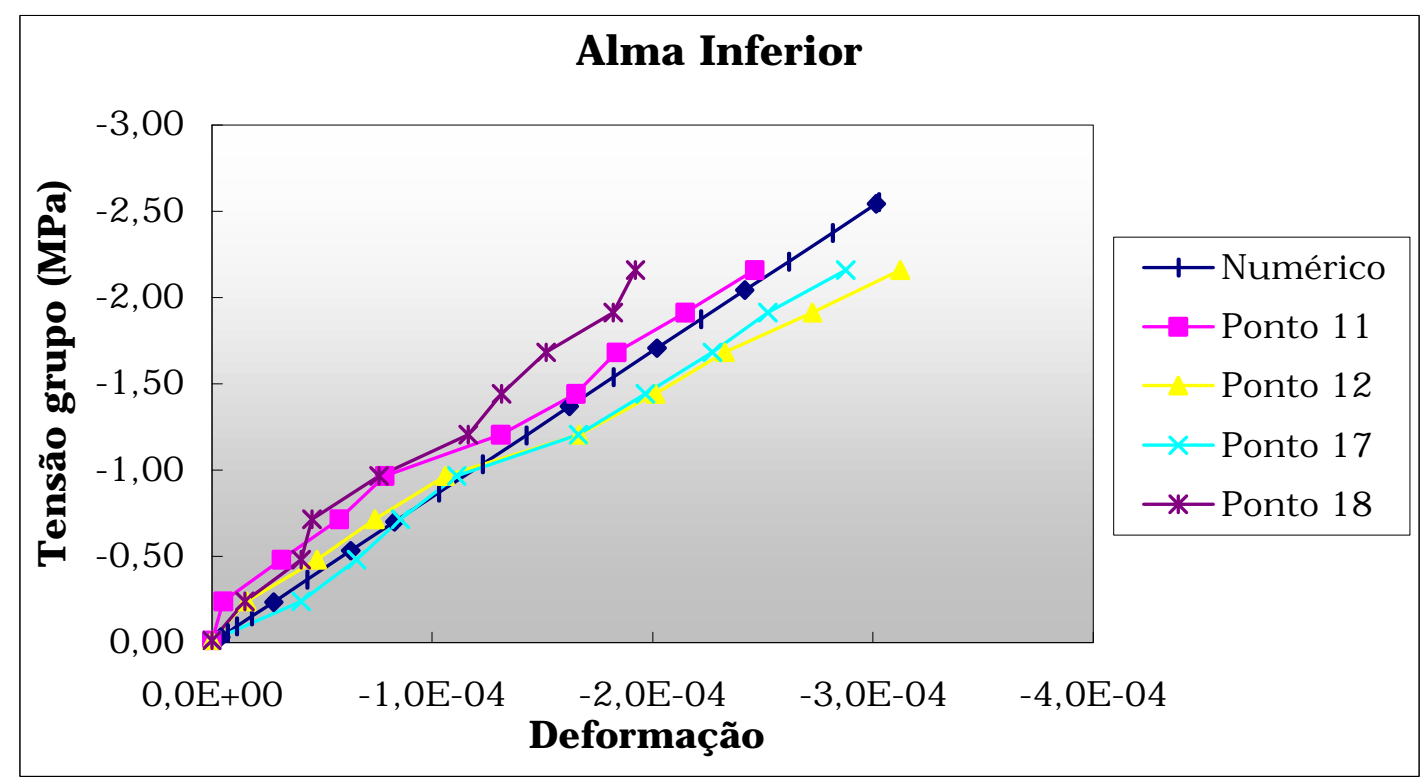

Figura 6.13 - Comportamento típico do trecho inferior da alma

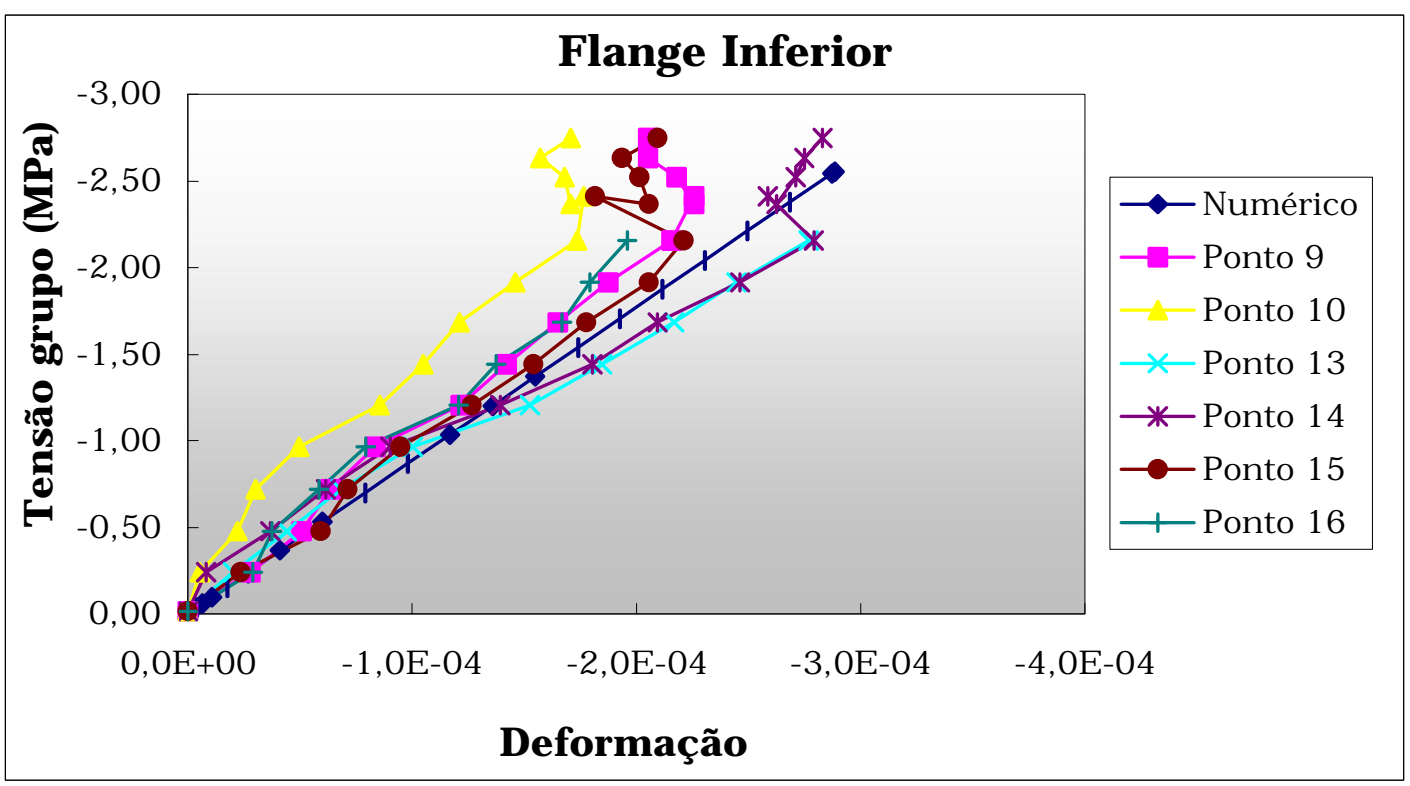

Figura 6.14 - Comportamento típico do trecho inferior do flange 
Analisando-se a figura 6.15 verifica-se que nesse caso as deformações obtidas experimentalmente estão bem próximas dos resultados numéricos, principalmente para níveis mais baixos de tensão. À medida que os níveis de tensão vão aumentado, nota-se uma tendência dos valores de deformação obtidos numericamente irem se tornando menores que os valores experimentais.

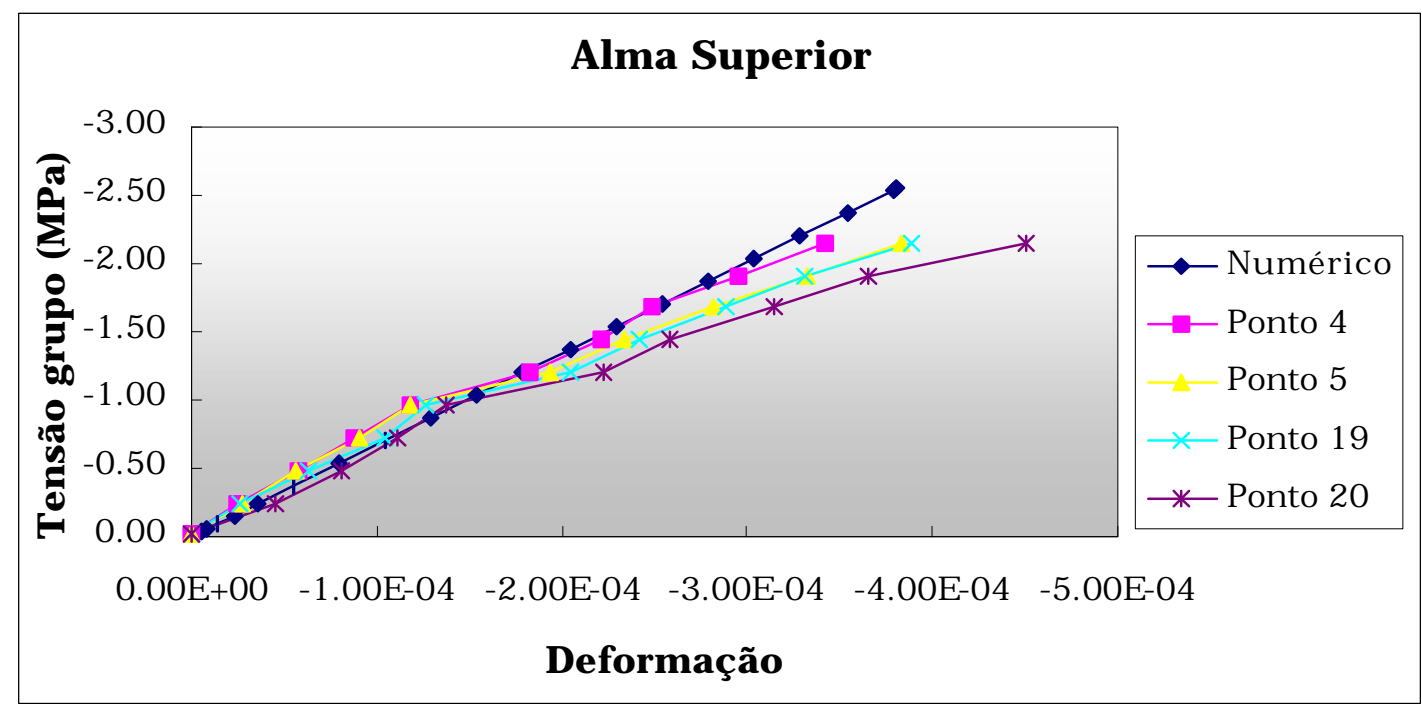

Figura 6.15 - Comportamento típico do trecho superior da alma

Na figura 6.16, ao contrário, as deformações numéricas vão se tornando maiores que as experimentais à medida que os níveis de solicitação vão crescendo. Isso pode ser explicado, em parte, pelo fato de que experimentalmente não existe uma garantia da simetria (forças e geometria) da estrutura tão precisa como numericamente. No modelo numérico a estrutura se deforma de maneira perfeitamente simétrica. Não existe excentricidade de força nem problemas de condições de contorno, como acontece no caso experimental. Outro fato importante é a forma de ruptura do painel nos ensaios, que aconteceu por compressão na região superior da parede central, geralmente nos blocos da cinta de amarração ou logo abaixo. As fissuras iniciaram na parede central em regiões próximas à interseção e abaixo da cinta de amarração da última fiada. Na modelagem numérica a interface entre a alma e o flange foi simulada com comunhão de nós, não havendo a possibilidade de descolamento ou deslizamento entre 
eles. Dessa forma o modelo numérico não é capaz de representar a ruptura da parede na interface.

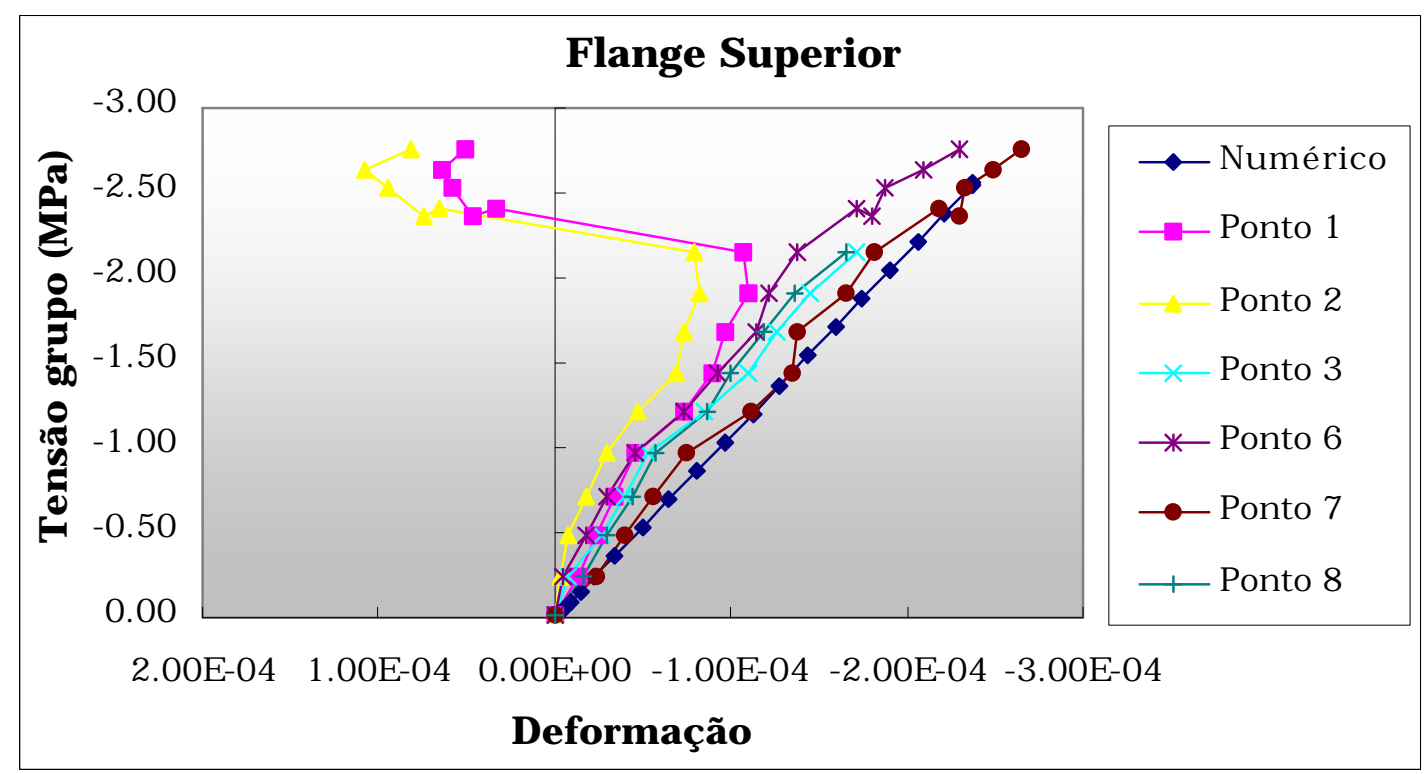

Figura 6.16 - Comportamento típico do trecho superior do flange

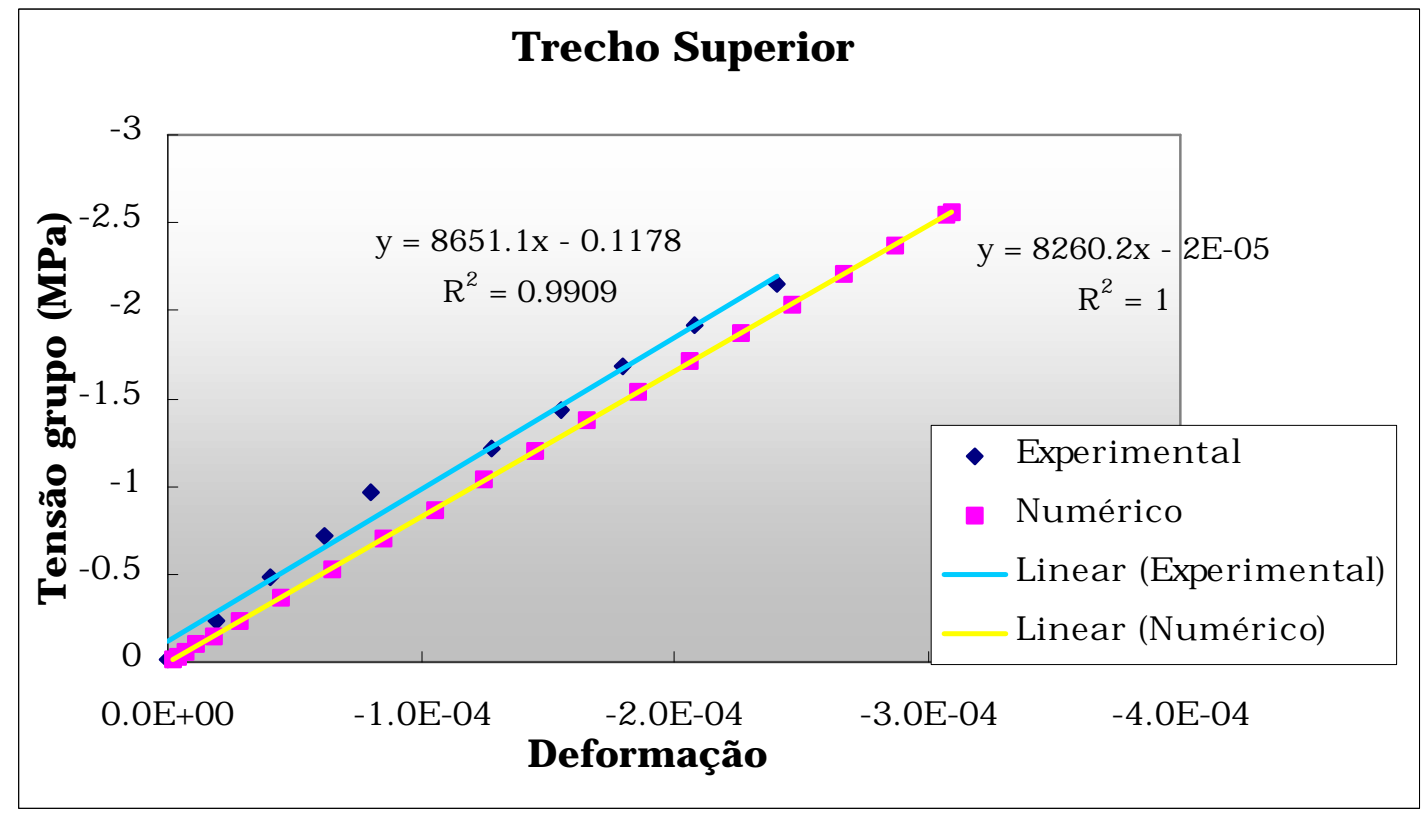

Figura 6.17 - Diagrama tensão x deformação típico do trecho superior

Nas figuras 6.17 e 6.18 apresentam-se a curva tensão x deformação típica para a região superior e inferior da parede. São mostrados os 
resultados experimentais e numéricos. Nota-se que os valores dos módulos de elasticidade médio, numérico e experimental encontram-se muito próximos. Verifica-se que em ambos os casos o módulo de elasticidade experimental médio da alvenaria é maior que o numérico. Isso pode ser explicado pelo fato do módulo de elasticidade do bloco, obtido experimentalmente, ser um dado difícil de ser medido com precisão. Esperava-se um valor maior do que o obtido. Supondo-se que o valor real desse módulo seja maior que o utilizado no modelo, os resultados numéricos se aproximariam mais dos experimentais.

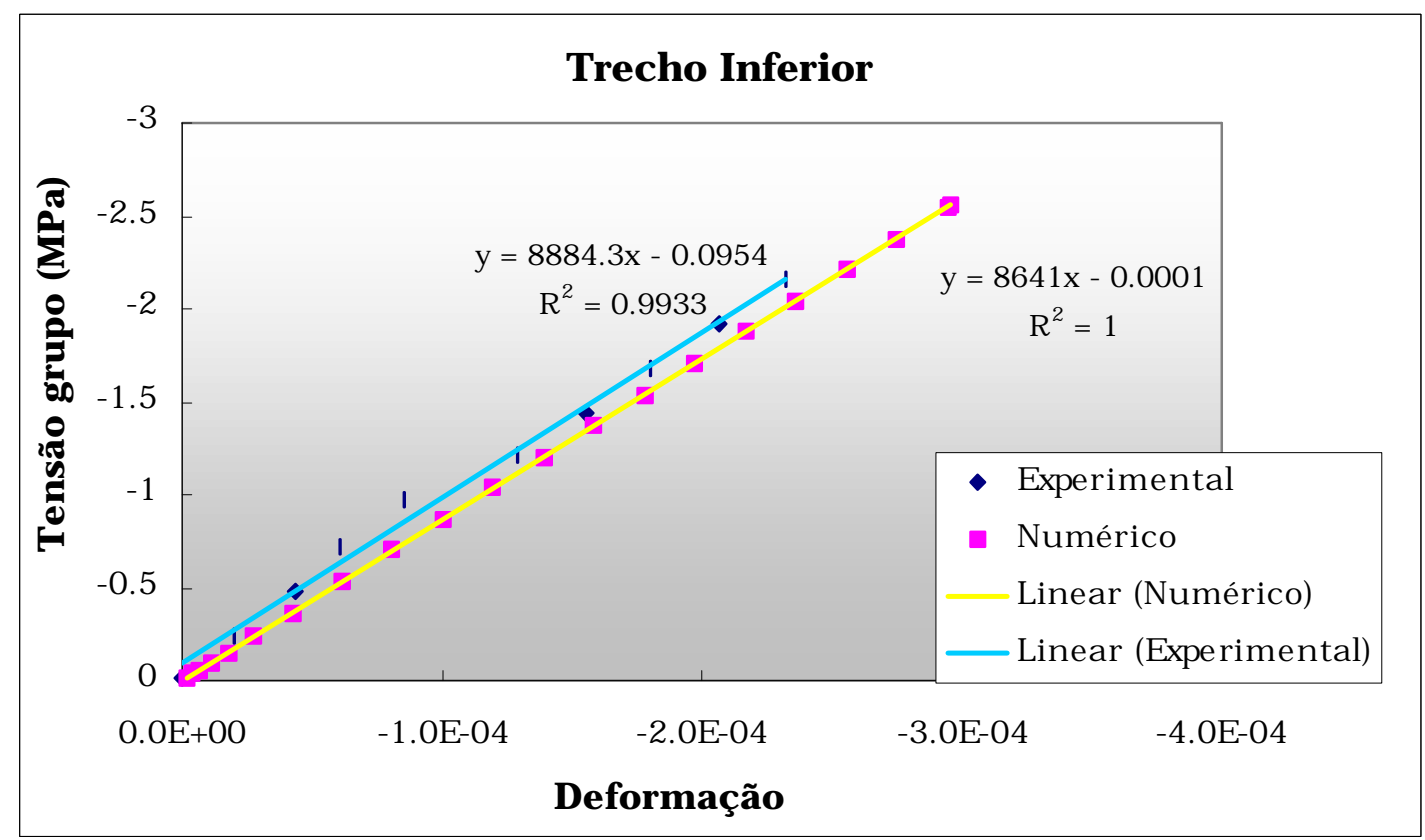

Figura 6.18 - Diagrama tensão x deformação típico do trecho inferior

Na figura 6.19 apresentam-se as deformações plásticas verticais do painel. Nota-se que existe uma concentração das deformações no trecho superior do painel, e principalmente nas juntas de argamassa. 


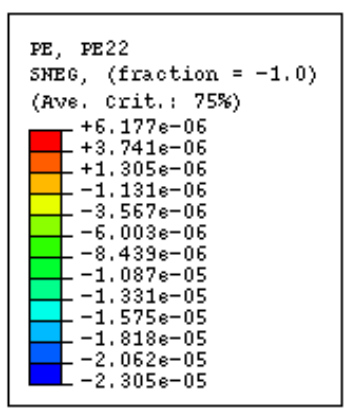<smiles>[2H]C(I)I</smiles>

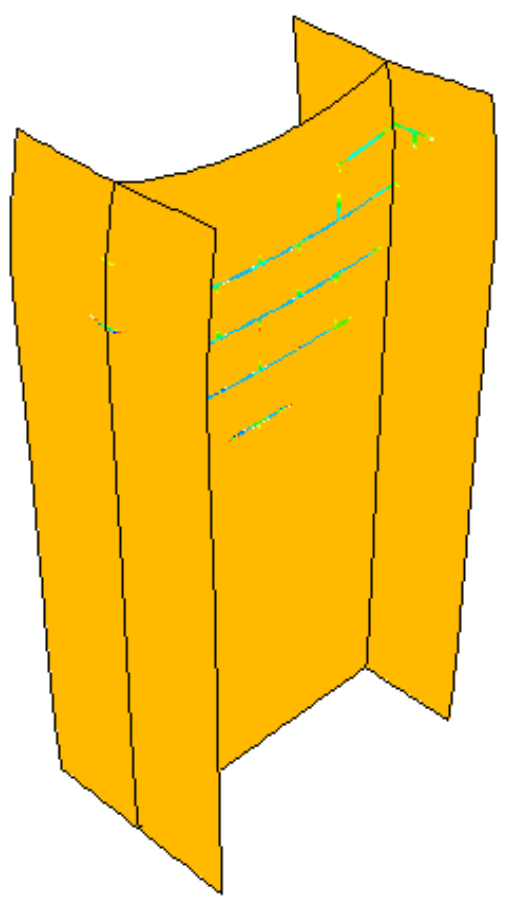

Figura 6.19 - Deformações plásticas verticais $\left(\varepsilon_{\mathrm{p} 22}\right)$

\subsection{Fechamento}

Conclui-se que o modelo CONCRETE do ABAQUS apresenta-se adequado para análise de estruturas em alvenaria de blocos cerâmicos. Os resultados obtidos para deslocamentos, deformações, tensões e força de ruptura apresentaram-se coerentes com os resultados experimentais. 


\section{MODELAGEM DE PAREDINHAS COMPRIMIDAS}

\section{T.1 INTRODUÇÃO}

Neste capítulo apresenta-se a análise de corpos-de-prova em alvenaria de blocos vazados de concreto, com dimensões de $80 \mathrm{~cm}$ x $80 \mathrm{~cm}$ x $14 \mathrm{~cm}$, ensaiados à compressão por JUSTE (2001) no laboratório do Departamento de Engenharia de Estruturas da EESC-USP. A análise numérica foi realizada com o software ABAQUS, considerando-se o comportamento não linear dos materiais.

Os corpos de prova utilizados (vide figura 7.1) são aqui denominados "paredinhas". Esse termo foi escolhido com o objetivo de diferenciá-los dos tradicionais prismas de dois e três blocos superpostos e das paredes, que possuem dimensões bem maiores, tendo a altura comparável à de um pédireito usual, ou seja, no mínimo 2,40 m.

Os componentes utilizados para a execução das paredinhas tiveram as seguintes características básicas:

a) Resistência à compressão dos blocos - Foram considerados blocos com resistências nominais de 4,5 $\mathrm{MPa}$ e 12,0 $\mathrm{MPa}$.

b) Argamassa - Foram utilizados dois traços de argamassa recomendados pela BS 5628 (1978): 


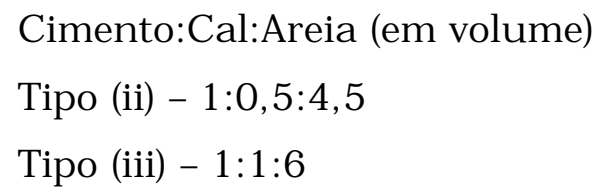

\section{T.2 TRABALHO EXPERIMENTAL}

Conforme JUSTE (2001) a empresa TATU PRÉMOLDADOS LTDA foi fornecedora dos blocos utilizados nos ensaios. As dimensões reais dos blocos empregados foram de 14x19x39 cm (largura x altura x comprimento) para o bloco inteiro e $14 \times 19 \times 19 \mathrm{~cm}$ para o meio bloco. A relação obtida entre a área líquida e a área bruta foi de 0,53.

Os valores das resistências médias à compressão dos blocos são apresentados na tabela 7.1. Observe-se que a resistência medida em laboratório foi muito maior que o especificado pelo fabricante.

Tabela 7.1 - Valores médios de resistência à compressão dos blocos

\begin{tabular}{|c|c|c|c|}
\hline $\begin{array}{c}\text { Tipo de } \\
\text { Bloco }\end{array}$ & $\begin{array}{c}\text { Classe de } \\
\text { Resistência }(\mathrm{MPa})\end{array}$ & $\begin{array}{c}\text { Área bruta } \\
\left(546 \mathrm{~cm}^{2}\right)\end{array}$ & $\begin{array}{c}\text { Área líquida } \\
\left(300 \mathrm{~cm}^{2}\right)\end{array}$ \\
\cline { 3 - 4 } & $\mathrm{f}$ & $\mathrm{f}_{\mathrm{bm}}(\mathrm{MPa})$ & $\mathrm{f}_{\mathrm{bm}}(\mathrm{MPa})$ \\
\hline \hline $\mathrm{B} 1$ & 4,5 & 10,80 & 20,38 \\
\hline $\mathrm{B} 2$ & 12,0 & 22,92 & 43,24 \\
\hline
\end{tabular}

O módulo de elasticidade dos blocos foi obtido a partir da equação de uma parábola quadrática ajustada à curva obtida experimentalmente no gráfico tensão-deformação. O ajuste desta curva foi feito até níveis de tensão da ordem de $60 \%$ do valor da carga de ruptura. Segundo JUSTE (2001) este valor foi estipulado por permitir o cálculo do módulo de elasticidade secante entre níveis de tensões no intervalo de 5 e 33\% da carga de ruptura e por apresentar ótimos coeficientes de ajustes para as parábolas obtidas.

Os valores dos módulos de elasticidade para os blocos são apresentados na tabela 7.2. 
Tabela 7.2 - Valores médios dos módulos de elasticidade dos blocos

\begin{tabular}{|c|c|c|}
\hline \multirow{2}{*}{$\begin{array}{c}\text { Tipo de } \\
\text { Bloco }\end{array}$} & $\begin{array}{c}\text { Área bruta } \\
\left(546 \mathrm{~cm}^{2}\right)\end{array}$ & $\begin{array}{c}\text { Área líquida } \\
\left(300 \mathrm{~cm}^{2}\right)\end{array}$ \\
\cline { 2 - 3 } & $\mathrm{E}_{\mathrm{bm}}(\mathrm{MPa})$ & $\mathrm{E}_{\mathrm{bm}}(\mathrm{MPa})$ \\
\hline \hline $\mathrm{B} 1$ & 6228,0 & 11750,9 \\
\hline $\mathrm{B} 2$ & 7554,0 & 14252,8 \\
\hline
\end{tabular}

Para os blocos $\mathrm{B} 1$ a relação $\mathrm{E}_{\mathrm{b}} / \mathrm{f}_{\mathrm{bm}}$ obtida experimentalmente atendeu aos limites especificados por DRYSDALE et al. (1994), entre 500 e 1000, e SAHLIN (1971), entre 500 e 1500. Porém, para os blocos B2 este valor ficou abaixo do esperado.

Os valores da resistência média à compressão das argamassas são apresentados na tabela 7.3.

\begin{tabular}{|c|c|}
\hline $\begin{array}{c}\text { Tipo de } \\
\text { Argamassa }\end{array}$ & $\mathrm{f}_{\mathrm{am}}(\mathrm{MPa})$ \\
\hline $\mathrm{A} 1$ & 10,24 \\
\hline $\mathrm{A} 2$ & 5,05 \\
\hline
\end{tabular}

Os ensaios finais dos corpos de prova de argamassa foram feitos com o objetivo de realizar o controle da resistência à compressão. Não foram determinados, para estes ensaios, os valores dos módulos de elasticidade das argamassas. Utilizou-se então a relação entre o módulo de elasticidade e resistência à compressão das argamassas do ensaio preliminar realizado por Juste, para determinar o módulo de elasticidade das argamassas do ensaio final. Conforme tabela 7.4. 
Tabela 7.4 - Valores dos módulos de elasticidade das argamassas

\begin{tabular}{|c|c|c|}
\hline $\begin{array}{c}\text { Tipo de } \\
\text { Argamassa }\end{array}$ & $\begin{array}{c}\text { Relação } \mathrm{E}_{\mathrm{am}} / \mathrm{f}_{\mathrm{am}} \\
\text { Ensaio Preliminar }\end{array}$ & $\begin{array}{c}\mathrm{E}_{\mathrm{am}}(\mathrm{MPa}) \\
\text { Estimado }\end{array}$ \\
\hline \hline A1 & 1517 & 15534,0 \\
\hline A2 & 1809 & 9113,5 \\
\hline
\end{tabular}

O esquema de instrumentação utilizado durante os ensaios para as paredinhas analisadas é apresentado na figura 7.1.

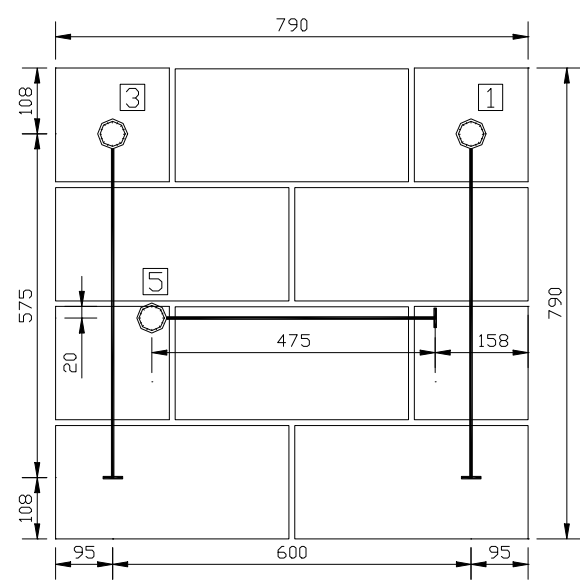

(a)

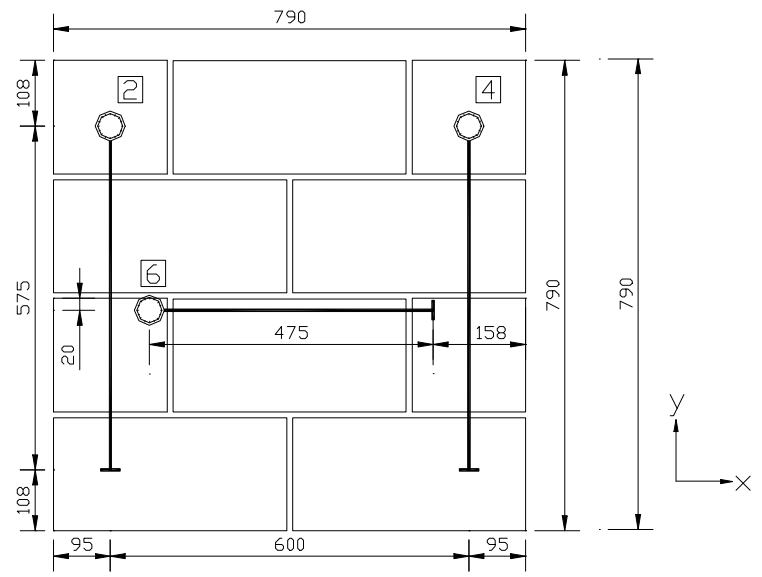

(b)

Figura 7.1 - (a) Vista frontal (b) Vista oposta.

Posição de transdutores na paredinha (medidas em mm).

Adaptada de JUSTE (2001)

$\mathrm{Na}$ tabela 7.5 apresentam-se os valores médios de força de compressão de ruptura obtidos nos ensaios, e a resistência média à compressão referida à área bruta das paredinhas. São apresentados os valores para as paredinhas ensaiadas com carregamento na direção y, ou seja, compressão perpendicular à junta de assentamento. Foram utilizadas três paredinhas de cada tipo. 
Tabela 7.5 - Resistência à compressão das paredinhas

\begin{tabular}{|c|c|c|}
\hline $\begin{array}{c}\text { Série } \\
\text { Correspondente }\end{array}$ & $\begin{array}{c}\text { F rup, ensaio } \\
(\mathrm{kN})\end{array}$ & $\begin{array}{c}\text { Resistência média à } \\
\text { compressão (área bruta) } \\
\mathrm{f}_{\mathrm{pam}}(\mathrm{MPa}) \\
\end{array}$ \\
\hline $\begin{array}{c}\mathrm{PAB} \mathrm{A}_{\mathrm{A}} \mathrm{E}_{\mathrm{Y}}(\mathrm{Bloco} 1 \mathrm{e} \\
\text { Argamassa } 1)\end{array}$ & 550 & 4,97 \\
\hline $\begin{array}{c}\text { PAB2A1E }_{Y}(\text { Bloco } 2 \text { e } \\
\text { Argamassa 1) }\end{array}$ & 978 & 8,84 \\
\hline $\begin{array}{c}\mathrm{PAB} 1 \mathrm{~A} 2 \mathrm{E}_{\mathrm{Y}}(\mathrm{Bloco} 1 \mathrm{e} \\
\text { Argamassa 2) }\end{array}$ & 456 & 4,12 \\
\hline $\begin{array}{c}\mathrm{PAB}^{2 A 2 E_{Y}}(\text { Bloco } 2 \mathrm{e} \\
\text { Argamassa 2) }\end{array}$ & $625^{*}$ & 5,65 \\
\hline
\end{tabular}

De acordo com JUSTE (2001), de um modo geral, as paredinhas ensaiadas na direção Y apresentaram propagação de fissuras verticais, predominantemente através das juntas verticais na região central das paredes, sendo algumas desviadas pelas regiões dos blocos. Observou-se também a presença de fissuras verticais ao longo dos septos laterais das paredinhas. A ruptura ocorreu, na maioria das vezes, por tração transversal dos blocos.

Porém, para as paredinhas que utilizaram blocos B2, as fissurações descritas acima ocorreram de maneira bem menos pronunciada, prevalecendo a ruptura por esmagamento da argamassa.

\subsection{ANÁLISE NUMÉRICA}

A análise numérica não-linear foi feita utilizando-se o software ABAQUS. As paredes foram discretizadas com um elemento sólido denominado C3D8, que possui oito nós e três graus de liberdade por nó 
(translações segundo os eixos $\mathrm{x}, \mathrm{y}$ e $\mathrm{z}$ ). Na base das paredes foram restringidas as translações dos nós. Foi aplicado um carregamento uniformemente distribuído no topo da parede. A rede utilizada encontra-se na figura 7.2.

É importante ressaltar que foram realizadas modelagens numéricas utilizando-se o elemento plano denominado S4, de quatro nós, com três graus de liberdade por nó. Este elemento não apresentou um resultado satisfatório. Explica-se este resultado analisando-se o tipo de ruptura apresentado nas paredinhas, em que os septos laterais dos blocos se rompem. Com isso, o modelo tridimensional se torna mais representativo. Embora ele não consiga representar de forma exata o que ocorre, o comportamento melhora bastante quando comparado com o resultado obtido com o elemento plano. Foi modelada uma parede equivalente, com a espessura adotada referente à área líquida.

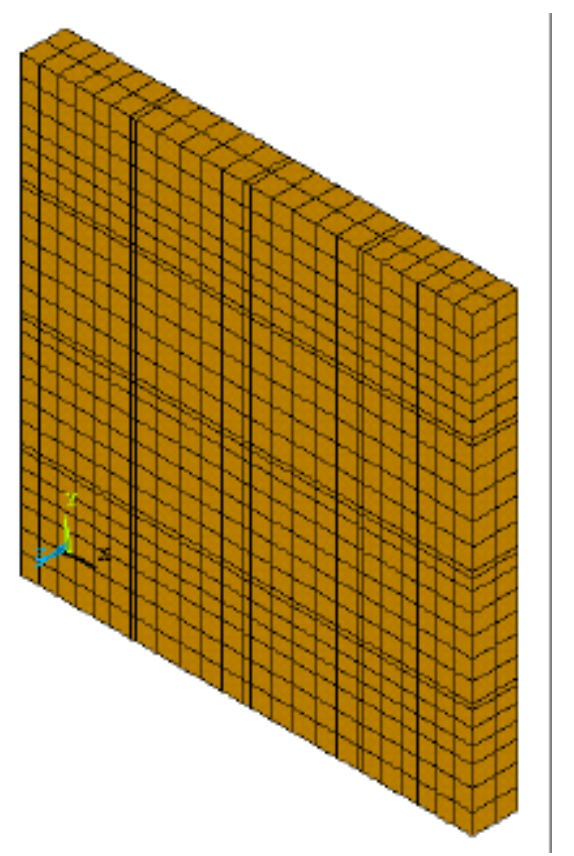

Figura 7.2 - Discretização da paredinha

Foram utilizados dois modelos não lineares: o modelo elastoplástico clássico (PLASTIC) e o elastoplástico para o concreto (CONCRETE), descritos 
no capítulo 3. Optou-se pela utilização dos dois modelos porque o modelo específico para o concreto (CONCRETE) não representou da forma esperada o comportamento das paredes. Ao contrário do exemplo apresentado no capítulo 6, onde foi utilizado bloco cerâmico, e os resultados numéricos obtidos com o modelo CONCRETE representaram de forma bastante coerente o comportamento do ensaio. Outro fator importante para a utilização do modelo PLASTIC foi a tentativa de modelar de forma mais precisa a variabilidade da relação tensão x deformação para os blocos de concreto.

A modelagem foi feita discretizando-se os blocos e a argamassa separadamente. As propriedades dos componentes (bloco e argamassa), utilizadas na simulação foram obtidas experimentalmente e encontram-se na tabela 7.6. É importante ressaltar que foi feita uma correção no módulo de elasticidade do bloco B2. Como foi apresentando no item anterior, a relação $\mathrm{E}_{\mathrm{b}} / \mathrm{f}_{\mathrm{bm}}$ deste bloco ficou abaixo dos limites especificados por DRYSDALE et al. (1994), entre 500 e 1000, e SAHLIN (1971), entre 500 e 1500. Nos primeiros modelos numéricos realizados verificou-se que a rigidez inicial das paredinhas construídas com esse bloco estava menor que a rigidez dos modelos experimentais. Optou-se, então, por utilizar um módulo de elasticidade igual a 500. $\mathrm{f}_{\mathrm{bm}}$, obtendo-se assim uma rigidez inicial mais próxima da experimental. Em relação ao bloco utilizou-se o módulo de elasticidade e a resistência à compressão em relação à área líquida (53\% da área bruta). Adotou-se este procedimento em razão do módulo de elasticidade referente à área bruta ser um valor aparente, não representando adequadamente as características do material quanto às necessidades de modelagem. As resistências à tração do bloco e da argamassa foram consideradas convencionalmente como sendo de $10 \%$ da resistência à compressão. Esse procedimento foi adotado devido à inexistência de testes para a determinação de tais parâmetros, no trabalho de JUSTE (2001). Cabe ressaltar que a percentagem adotada está dentro dos limites usuais para os materiais empregados. 
Tabela 7.6 - Propriedades dos componentes

\begin{tabular}{|c|c|}
\hline \multicolumn{2}{|c|}{ Propriedades do Bloco B1 } \\
\hline Resistência à compressão & $20,38 \mathrm{MPa}$ \\
\hline Módulo de elasticidade & $11.750,94 \mathrm{MPa}$ \\
\hline Coeficiente de Poisson & 0,20 \\
\hline \multicolumn{2}{|c|}{ Propriedades do Bloco B2 } \\
\hline Resistência à compressão & $43,24 \mathrm{MPa}$ \\
\hline Módulo de elasticidade & $21.620,0 \mathrm{MPa}$ \\
\hline Coeficiente de Poisson & 0,20 \\
\hline \multicolumn{2}{|c|}{ Propriedades da Argamassa A1 } \\
\hline Resistência à compressão & $10,24 \mathrm{MPa}$ \\
\hline Módulo de elasticidade & $15.534,0 \mathrm{MPa}$ \\
\hline Coeficiente de Poisson & 0,20 \\
\hline \multicolumn{2}{|c|}{ Propriedades da Argamassa A2 } \\
\hline Resistência à compressão & $5,05 \mathrm{MPa}$ \\
\hline Módulo de elasticidade & $9.135,5 \mathrm{MPa}$ \\
\hline Coeficiente de Poisson & 0,20 \\
\hline
\end{tabular}

Os valores da tabela 7.6 são os dados de entrada do modelo elastoplástico para o concreto (CONCRETE). Um outro parâmetro importante de entrada neste modelo é a razão entre a resistência à compressão biaxial e a uniaxial $\left(\mathrm{a}_{0}\right)$. Esse parâmetro foi ajustado de forma a representar de forma mais adequada o comportamento do modelo. Chegouse a um valor igual a 1,5; sendo o default do programa de 1,16 (valor típico para o concreto).

O parâmetro a aparece na equação da superfície de compressão do critério (eq. 7.1): 


$$
\mathrm{F}_{\mathrm{c}}=\mathrm{q}-\sqrt{3} \cdot \mathrm{a}_{0} \cdot \mathrm{p}-\sqrt{3} \cdot \tau_{\mathrm{c}}=0
$$

onde p é a tensão média definida por:

$$
\mathrm{p}=-\frac{1}{3}\left(\sigma_{1}+\sigma_{2}+\sigma_{3}\right)
$$

q é a tensão equivalente de von Mises:

$$
\mathrm{q}=\sqrt{\frac{2}{3} \cdot \mathrm{J}_{2}}
$$

$\mathrm{J}_{2}$ é o segundo invariante da parte deviatórica do tensor de tensões e $\tau_{\mathrm{c}}$ é a resistência num estado de cisalhamento puro.

Para o modelo elastoplástico clássico (PLASTIC), além do módulo de elasticidade e do coeficiente de Poisson, é preciso fornecer os pontos da curva tensão $\mathrm{x}$ deformação plástica para os dois componentes: bloco e argamassa. Para a obtenção dos dados de entrada, a partir da curva tensão $\mathrm{x}$ deformação total, obtida experimentalmente, subtraiu-se o valor da deformação elástica $\left(\varepsilon_{\mathrm{e}}=\sigma / \mathrm{E}\right)$, para cada um dos materiais.

\subsection{COMPARAÇÃO ENTRE AS ANÁLISES NUMÉRICAS E EXPERIMENTAIS}

\subsubsection{Parede PAB1A2}

Na tabela 7.7 apresentam-se os valores médios de resistência à compressão alcançada nos ensaios para a paredinha PAB1A2, bem como os obtidos com os dois modelos utilizados e as diferenças relativas aos resultados experimentais. 
Tabela 7.7 - Resistência à compressão parede PAB1A2

\begin{tabular}{|c|c|c|c|c|c|}
\hline \multirow{2}{*}{$\begin{array}{c}\text { Série } \\
\text { Correspondente }\end{array}$} & $\mathrm{f}_{\mathrm{pam}}(\mathrm{MPa})$ & \multicolumn{2}{|c|}{ PLASTIC } & \multicolumn{2}{c|}{ CONCRETE } \\
\cline { 3 - 6 } & Ensaio & $\mathrm{f}_{\mathrm{pa}}(\mathrm{MPa})$ & Diferença(\%) & $\mathrm{f}_{\mathrm{pa}}(\mathrm{MPa})$ & Diferença(\%) \\
\hline PAB1A2E & 4,12 & 4,85 & +18 & 3,49 & -15 \\
\hline
\end{tabular}

Analisando-se os valores obtidos nota-se que os dois modelos apresentam bons resultados, sendo que o modelo PLASTIC superestima a tensão de ruptura, ao contrário do CONCRETE, que a subestima.

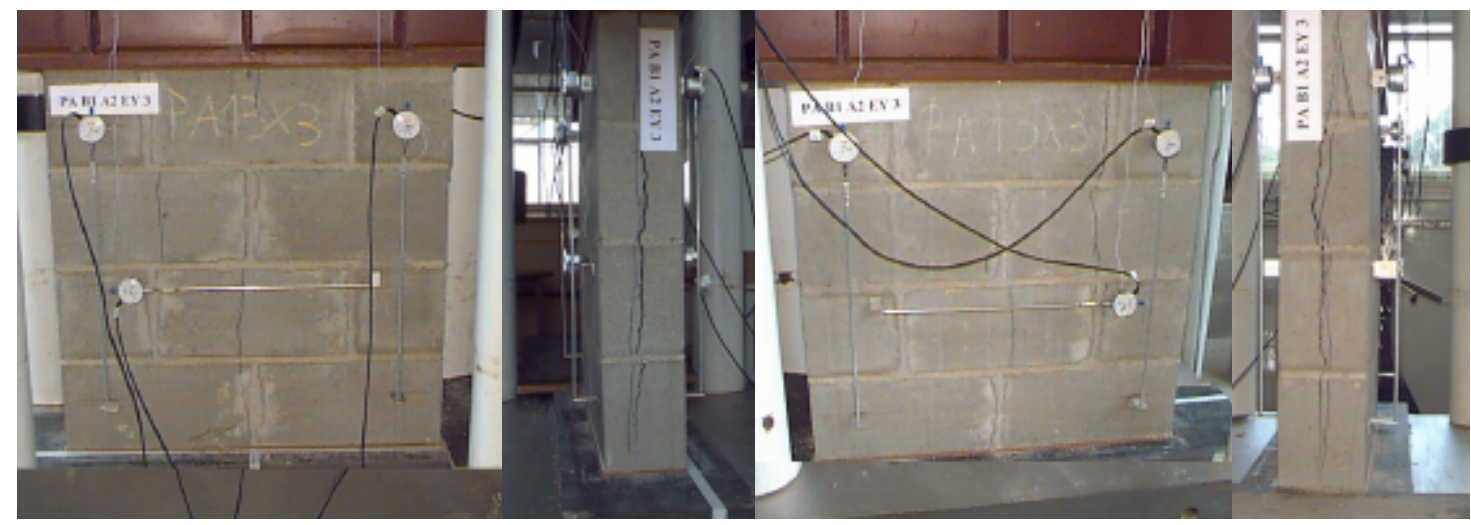

Figura 7.3 - Forma de ruptura típica (PAB1A2)

Analisando-se a figura 7.3 verifica-se que a ruptura aconteceu devido ao aparecimento de fissuras verticais, predominantemente através das juntas verticais, sendo que algumas atravessam os blocos. Nota-se também a ruptura dos septos laterais dos blocos. Nenhum dos modelos adotados é capaz de simular, de maneira precisa, essa forma de ruptura dos blocos, o que pode levar a imprecisões nos resultados obtidos numericamente quando comparados com os resultados dos ensaios, quando esta forma de ruptura for determinante. A característica tridimensional dos elementos empregados simula apenas aproximadamente essa forma de ruptura. Implementações no modelo exigiriam a representação do formato do bloco, o que seria inviável ao se trabalhar com elementos 3D.

As figuras $7.4,7.5,7.6$, e 7.7 apresentam, respectivamente, a tensão principal máxima, a tensão normal horizontal, a tensão normal vertical e a tensão de von Mises, para os dois modelos numéricos adotados. 

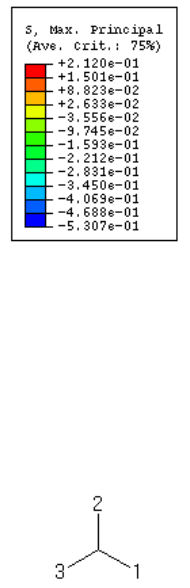

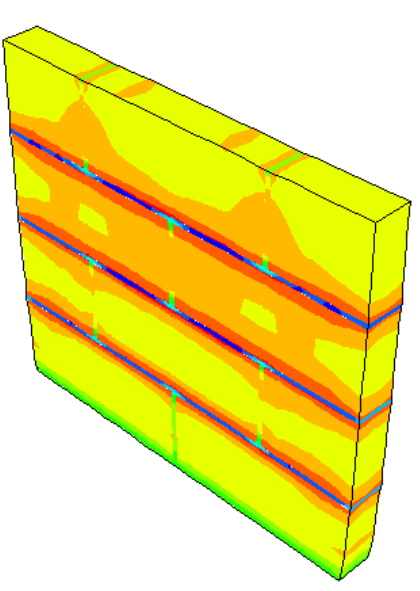

(a) PLASTIC

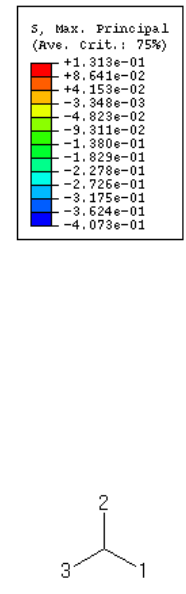

(b) CONCRETE

Figura 7.4 - Tensão principal máxima (PAB1A2)

Analisando-se a figura 7.4 verifica-se que as tensões máximas de tração ocorrem nas juntas verticais na região central das paredes e nos blocos, o que concorda com a forma de ruptura dos ensaios, por tração transversal dos blocos. É possível visualizar, também, que as juntas horizontais de argamassa estão submetidas a elevadas tensões de compressão, em ambos os modelos numéricos, o que indica que nesses pontos pode ocorrer o esmagamento da argamassa.
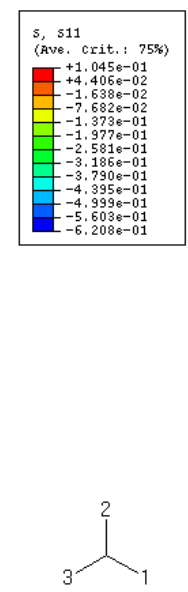

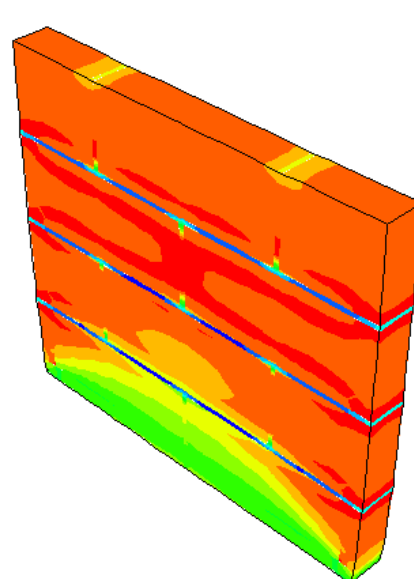

(a) PLASTIC
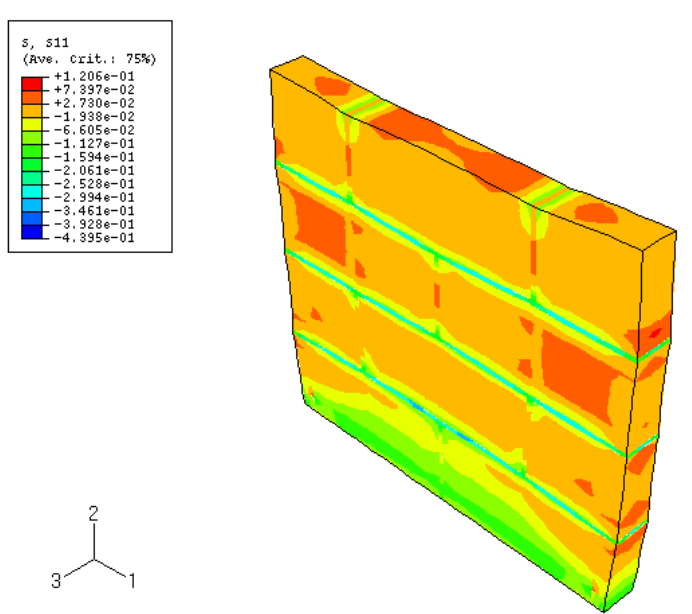

(b) CONCRETE

Figura 7.5 - Tensão normal horizontal $\sigma_{11}$ (PAB1A2) 
As tensões normais horizontais na parede encontram-se na figura 7.5. Nota-se, nos dois modelos, que as tensões de tração são maiores nas juntas verticais e se espalham em direção aos blocos, submetendo-os a uma tração transversal, que vai causar a sua fissuração. Nas juntas horizontais tem-se tensões de compressão.
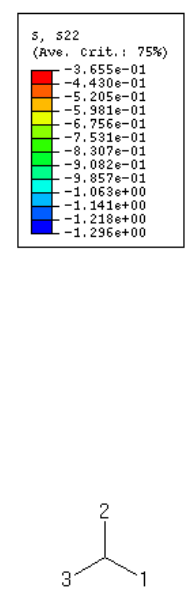

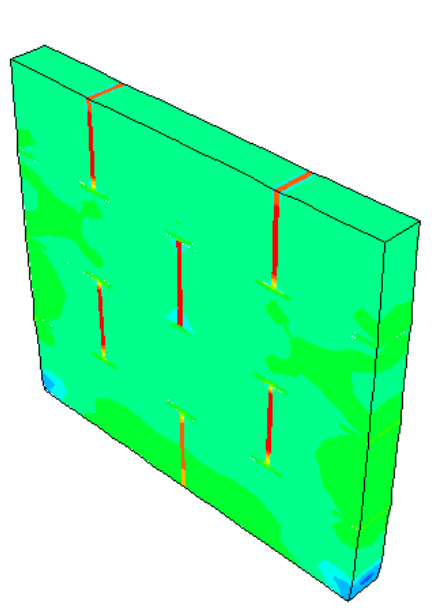

(a) PLASTIC

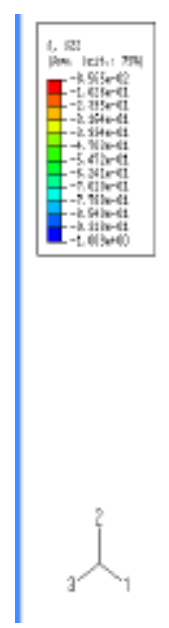

(b) CONCRETE

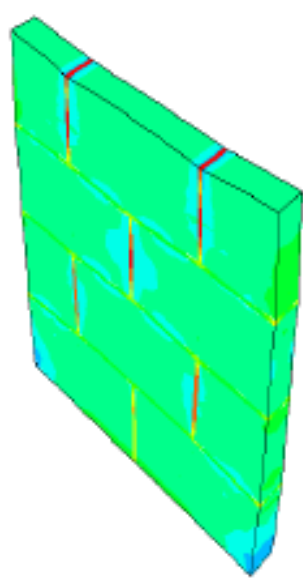

Figura 7.6 - Tensão normal vertical $\sigma_{22}$ (PAB1A2)

$\mathrm{Na}$ figura 7.6 apresenta-se a distribuição das tensões normais verticais na parede. Todas são de compressão, sendo que os valores mais altos encontram-se nos blocos.
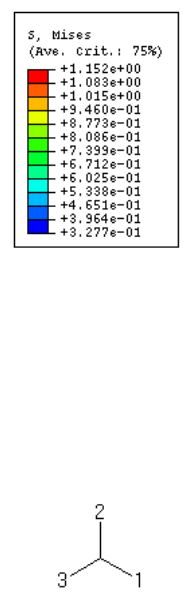

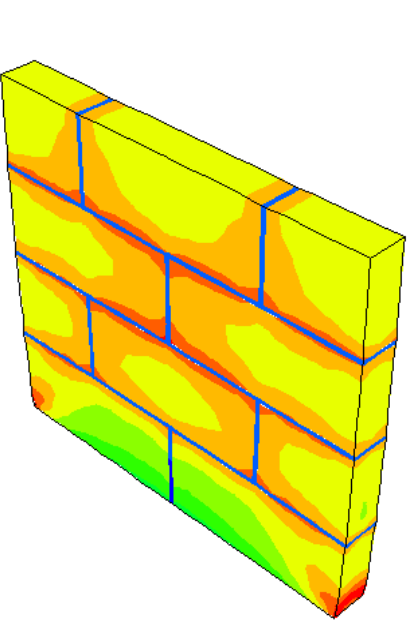

(a) PLASTIC

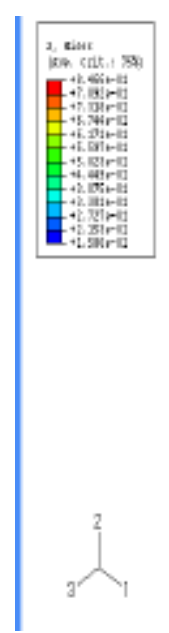

(b) CONCRETE

Figura 7.7- Tensão equivalente de von Mises (PAB1A2) 
Na figura 7.7 apresenta-se a tensão equivalente de von Mises para ambos os modelos. Verifica-se que a distribuição destas tensões nos dois modelos têm aspecto semelhante. Os maiores valores se encontram no centro da parede, onde aparecem as fissuras mais visiveis no ensaio.

Analisando-se, de maneira geral, as figuras 7.4 a 7.7 conclui-se que os modelos representam de forma bastante coerente o que acontece no ensaio. As tensões de tração mais altas encontram-se nas juntas verticais, onde aparecem as primeiras fissuras. $\mathrm{E}$ os blocos acabam sendo submetidos a tensões transversais de tração, o que provoca a sua ruptura.

Para essa parede específica onde tem-se a argamassa bem menos resistente que o bloco, portanto mais deformável, os dois modelos apresentaram bons resultados. Sendo que o modelo CONCRETE apresentou uma força de ruptura a favor da segurança e possui a vantagem de apresentar uma entrada de dados mais simples.

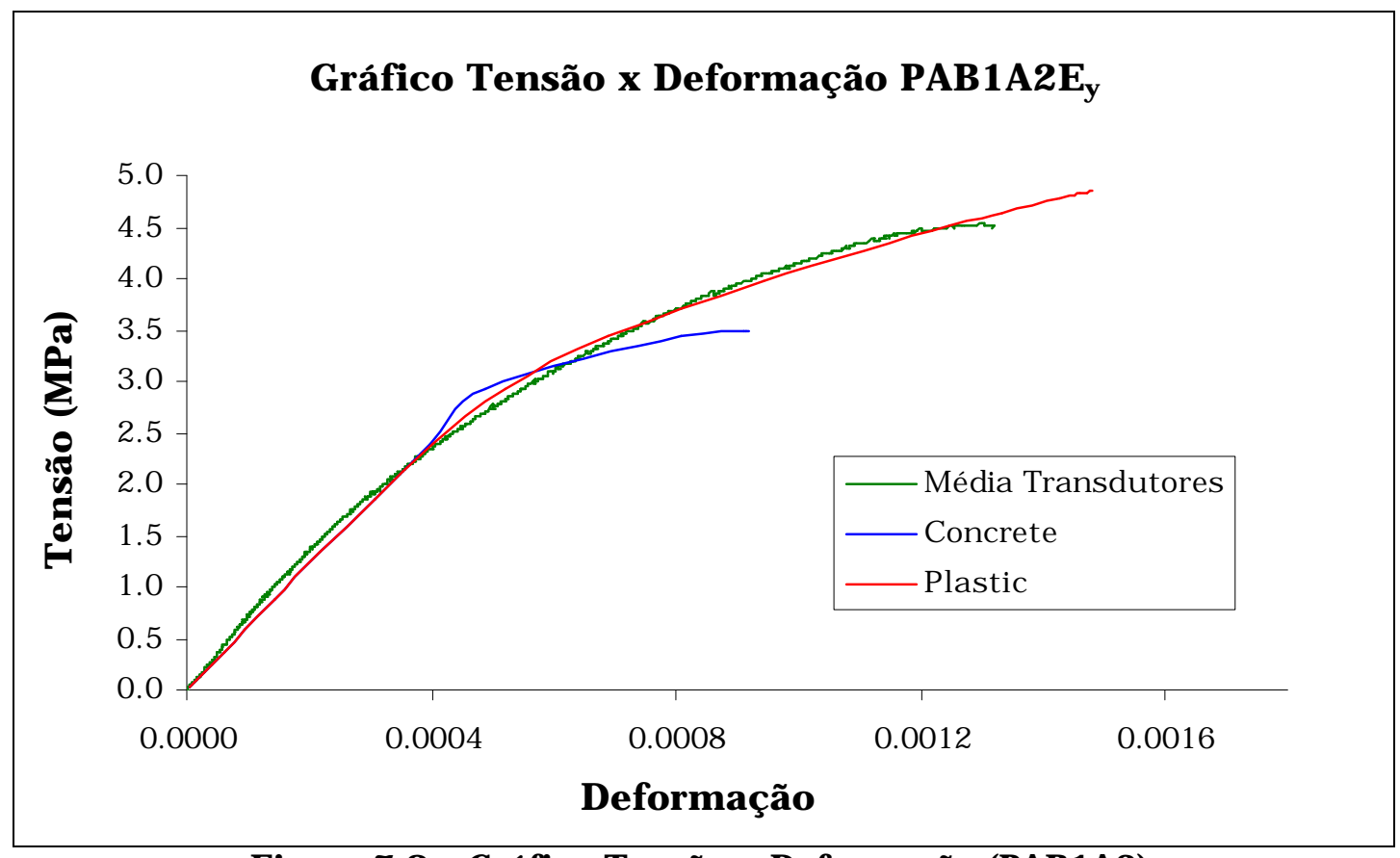

Figura 7.8 - Gráfico Tensão x Deformação (PAB1A2)

Na figura 7.8 apresenta-se a curva tensão $\mathrm{x}$ deformação para a parede PAB1A2, analisado-se as curvas conclui-se que os dois modelos representam de forma aproximada o comportamento da parede. No trecho linear o comportamento é basicamente o mesmo. No trecho não linear, o 
modelo PLASTIC representa de forma mais adequada o que ocorre no ensaio, analisando a relação tensão x deformação.

\subsubsection{Parede PAB1A1}

Na tabela 7.8 apresentam-se os valores médios de resistência à compressão alcançada nos ensaios para a paredinha PAB1A1, comparando com os obtidos com os dois modelos utilizados.

Tabela 7.8 - Resistência à compressão parede PAB1A1

\begin{tabular}{|c|c|c|c|c|c|}
\hline \multirow{2}{*}{$\begin{array}{c}\text { Série } \\
\text { Correspondente }\end{array}$} & \multirow{2}{*}{$\begin{array}{c}\mathrm{p}_{\mathrm{pam}}(\mathrm{MPa}) \\
\text { Ensaio }\end{array}$} & \multicolumn{2}{|c|}{ PLASTIC } & \multicolumn{2}{c|}{ CONCRETE } \\
\cline { 3 - 6 } & $\mathrm{f}_{\mathrm{pa}}(\mathrm{MPa})$ & Diferença(\%) & $\mathrm{f}_{\mathrm{pa}}(\mathrm{MPa})$ & Diferença(\%) \\
\hline \hline PAB1A1E & 4,97 & 4,91 & -1 & 4,32 & -13 \\
\hline
\end{tabular}

Nesta parede os dois modelos não lineares apresentaram resultados bem próximos do experimental, sendo que o modelo CONCRETE subestima a tensão de ruptura da parede.

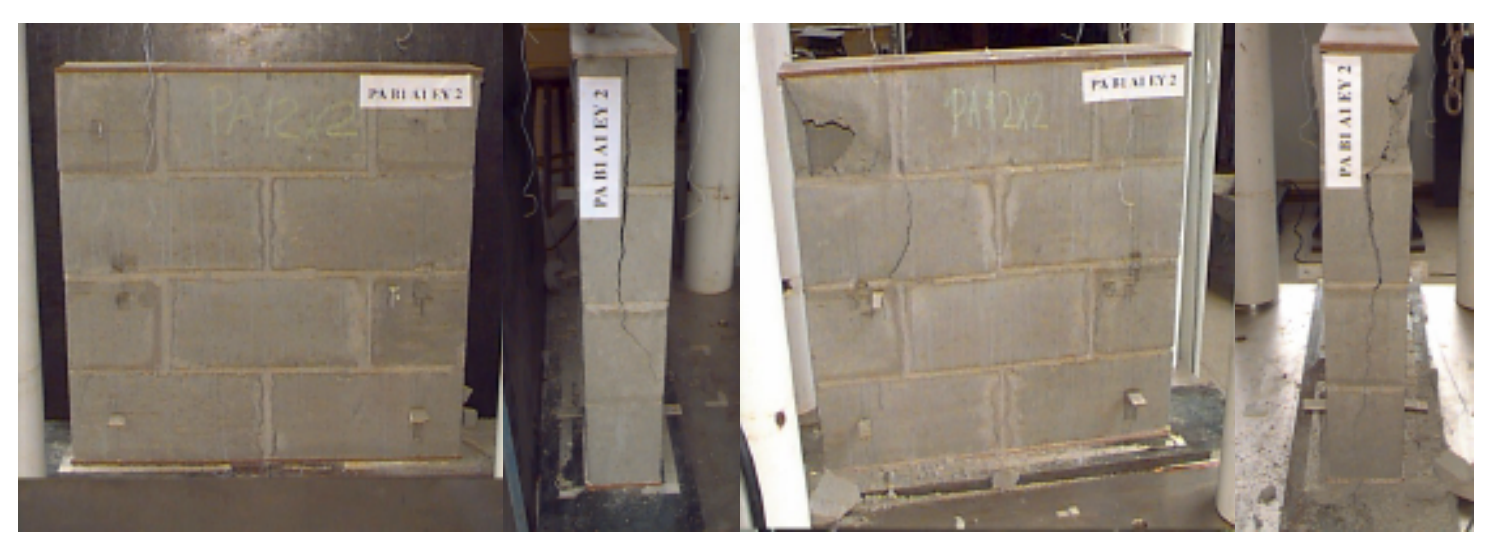

Figura 7.9 - Forma de ruptura típica (PAB1A1)

No ensaio verificou-se o aparecimento de fissuras verticais, predominantemente através das juntas verticais, sendo algumas desviadas pelas regiões dos blocos (figura 7.9). Nesta parede o modelo CONCRETE apresentou o aparecimento de fissuras tanto no bloco quanto na argamassa. Já o modelo PLASTIC apresentou deformações plásticas nos 
blocos e nas juntas da mesma ordem de grandeza. Neste ensaio a argamassa é mais resistente, e portanto menos deformável que no anterior. Com isso, além da paredinha apresentar uma resistência à compressão maior, a forma de ruptura se altera. Os blocos ficam sujeitos a tensões maiores de tração e apresentam mais fissuras, nas últimas fiadas e nos septos laterais.

A tensão principal máxima, a tensão normal horizontal, tensão normal vertical e a tensão de von Mises, são apresentadas nas figuras 7.10, $7.11,7.12$, e 7.13 para os modelos CONCRETE e PLASTIC.
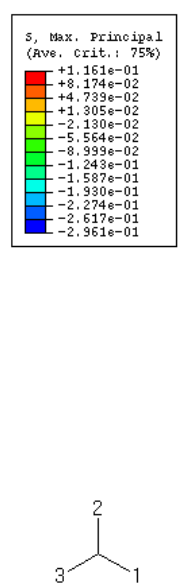

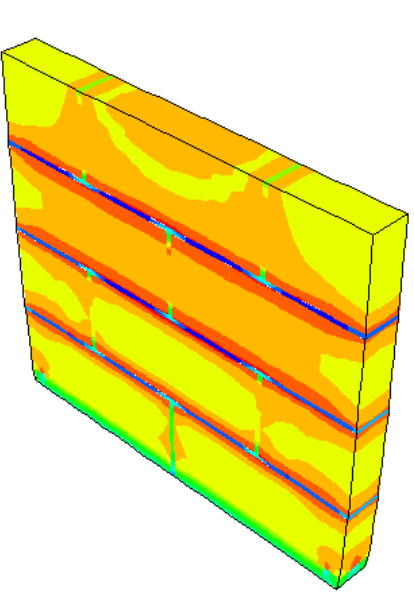

(a) PLASTIC
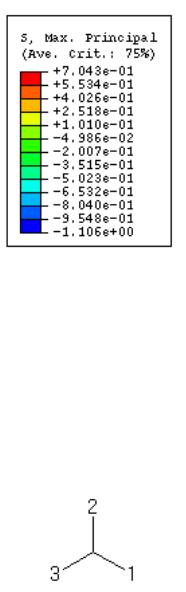

(b) CONCRETE

Figura 7.10 - Tensão principal máxima (PAB1A1)

Analisando-se a figura 7.10a verifica-se que as tensões máximas de tração do modelo PLASTIC ocorrem na região das juntas verticais e dos blocos, o que confirma a ruptura por tração transversal dos mesmos, conforme verificado nos ensaios. Verifica-se que nos dois modelos as tensões máximas na paredinha são basicamente de compressão, sendo os valores mais altos nas regiões das juntas, indicando que nesses pontos pode ocorrer o esmagamento da argamassa. 

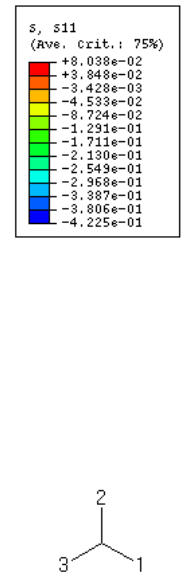

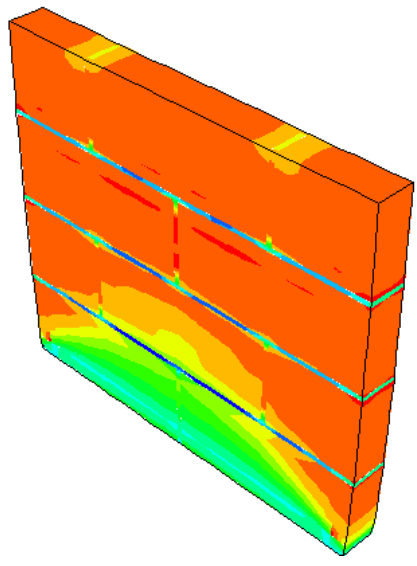

(a) PLASTIC

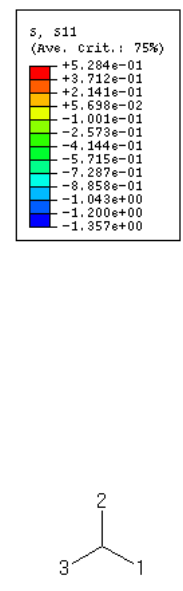

(b) CONCRETE

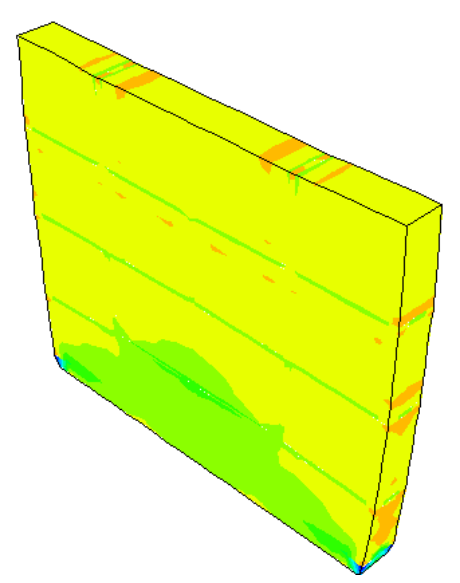

Figura 7.11- Tensão normal horizontal $\sigma_{11}$ (PAB1A1)

As tensões normais horizontais na parede são mostradas na figura 7.11. Nota-se, mais uma vez nos dois modelos, que as tensões de tração se concentram nas juntas verticais e se espalham pelos blocos. $\mathrm{E}$ as juntas estão submetidas a esforços de compressão, o que confirma o fato de trabalharem confinadas e estarem sujeitas ao esmagamento.
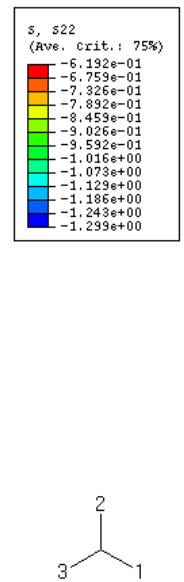

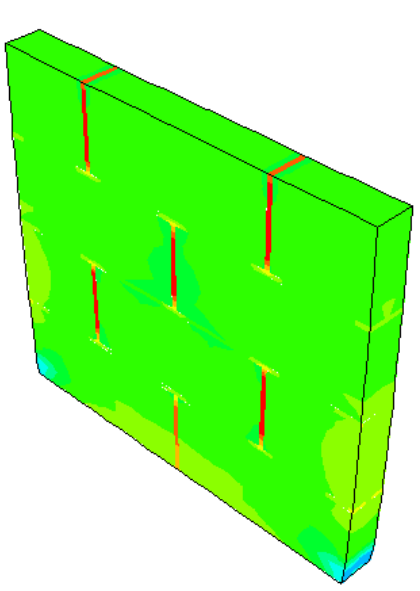

(a) PLASTIC

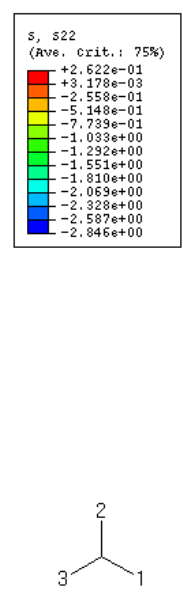

(b) CONCRETE

\section{Figura 7.12 - Tensão normal vertical $\sigma_{22}$ (PAB1A1)}

Na figura 7.12 apresenta-se a distribuição das tensões verticais na parede, que no modelo PLASTIC são todas de compressão. No modelo CONCRETE verifica-se o aparecimento de tensões de tração, o que provocou fissuras no bloco e na argamassa. Este fato pode ser explicado devido à 
maior resistência e menor deformabilidade da argamassa A1, quando comparada com a argamassa A2 da parede PAB1A2. As características da argamassa provocam um confinamento do bloco, e este acaba sendo submetido a tensões de tração que provocam a sua fissuração. Comparando-se as figuras 7.3 e 7.9 nota-se que a parede PAB1A1 apresenta fissuras bem visiveis nas faces das paredes, além da ruptura dos septos laterais, o que confirma os resultados numéricos.

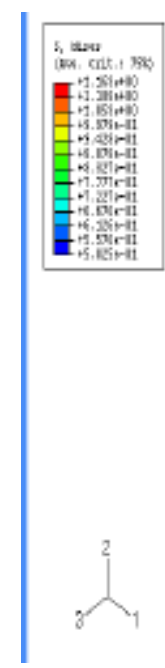

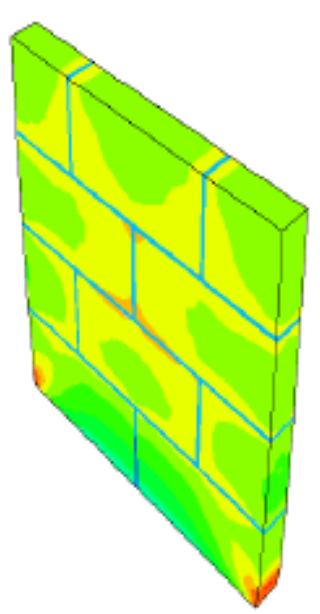

(a) PLASTIC

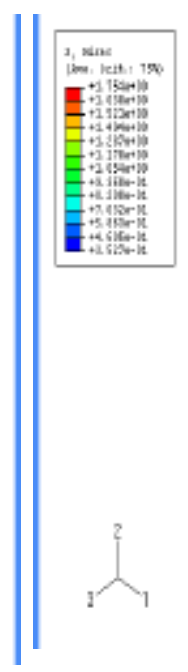

(b) CONCRETE

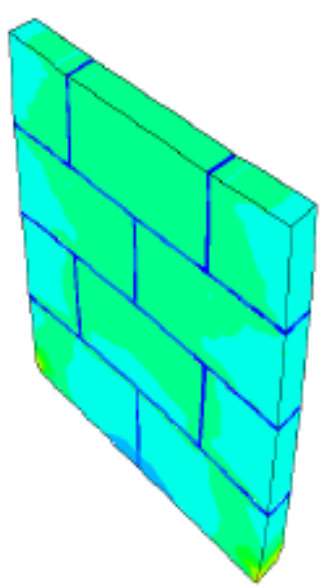

(PAB1A1)

Na figura 7.13 nota-se que os valores da tensão de von Mises para o modelo CONCRETE na região central da parede, particularmente nos blocos, é bem maior que as tensões apresentadas no modelo B1A2, o que provoca a sua fissuração. No presente corpo de prova, a argamassa utilizada é mais resistente que no anterior, o que modifica a forma de ruptura da paredinha. No modelo CONCRETE verifica-se o aparecimento de fissuras tanto no bloco quanto na argamassa. Apesar das maiores tensões de tração aparecerem nas juntas verticais, os blocos também sofrem uma tração significativa e também fissuram. 


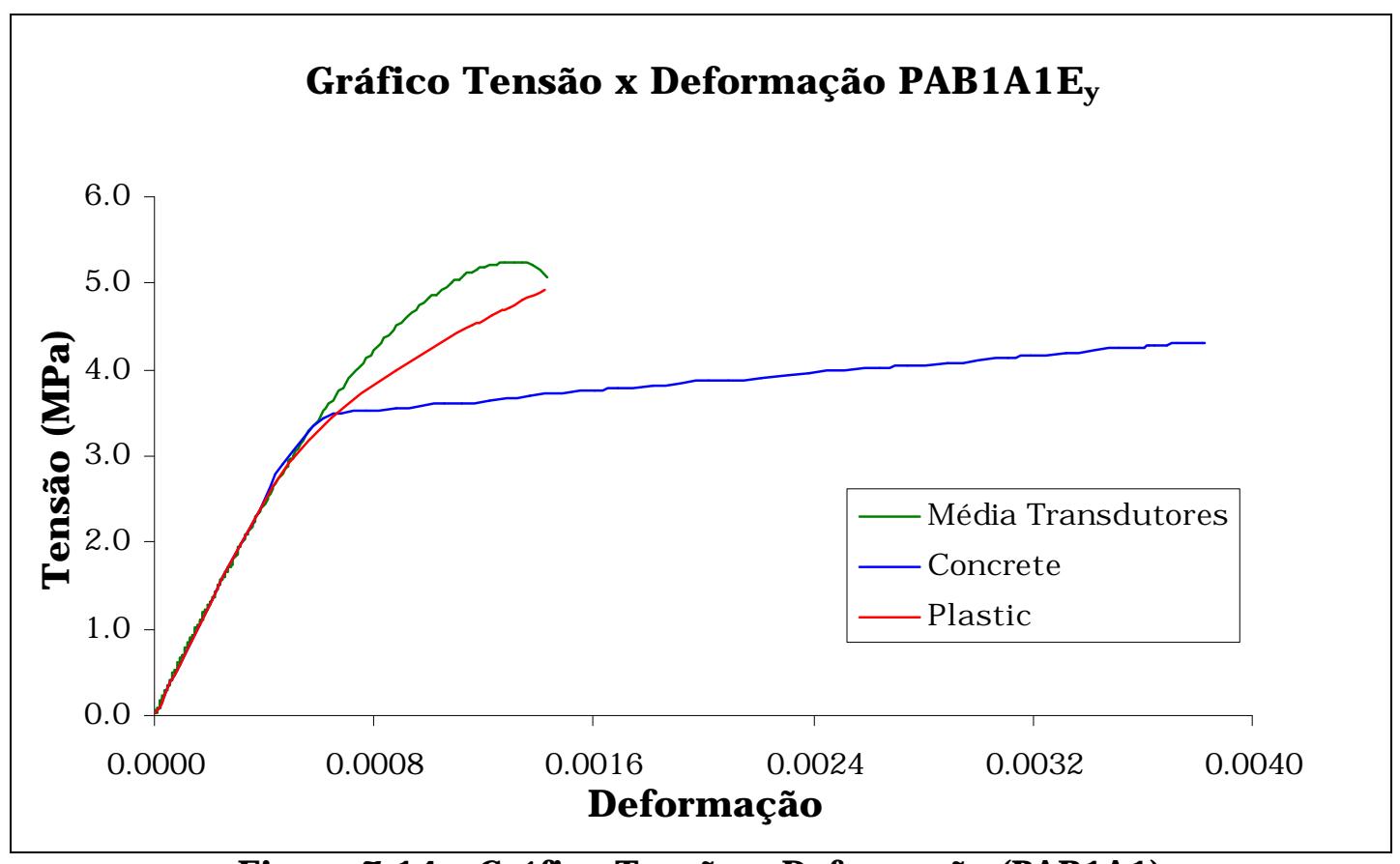

Figura 7.14 - Gráfico Tensão x Deformação (PAB1A1)

As curvas tensão-deformação experimentais e analíticas para a parede PAB1A1 são apresentadas na figura 7.14. Nota-se, neste caso, a superioridade da representação do modelo PLASTIC em relação ao CONCRETE. Não apenas o formato da curva é mais adequado, como a previsão da tensão de ruptura é mais próxima. Analisando-se o gráfico verifica-se a importância de se trabalhar com um módulo de elasticidade variável para os materiais. A utilização de uma expressão não linear para a relação tensão $\mathrm{x}$ deformação dos materiais no modelo CONCRETE melhoraria o comportamento deste modelo, obtendo-se resultados mais próximos dos experimentais.

\subsubsection{Parede PAB2A1}

Os resultados obtidos, com relação a resistência à compressão, nos ensaios e com os modelos utilizados para a paredinha PAB2A1, são apresentados na tabela 7.9 . 
Tabela 7.9 - Resistência à compressão parede PAB2A1

\begin{tabular}{|c|c|c|c|c|c|}
\hline \multirow{2}{*}{$\begin{array}{c}\text { Série } \\
\text { Correspondente }\end{array}$} & \multirow{2}{*}{$\begin{array}{c}\mathrm{p}_{\text {pam }}(\mathrm{MPa}) \\
\text { Ensaio }\end{array}$} & \multicolumn{2}{|c|}{ PLASTIC } & \multicolumn{2}{c|}{ CONCRETE } \\
\cline { 3 - 6 } & $\mathrm{f}_{\mathrm{pa}}(\mathrm{MPa})$ & Diferença(\%) & $\mathrm{f}_{\mathrm{pa}}(\mathrm{MPa})$ & Diferença(\%) \\
\hline \hline PAB2A1E & 8,84 & 5,68 & -36 & 7,31 & -17 \\
\hline
\end{tabular}

Neste caso o modelo CONCRETE apresentou um valor de ruptura mais próximo do experimental. Como pode ser observado na figura 7.15 neste ensaio não ocorreram fissuras muito pronunciadas no plano da parede, levando a uma forte compressão da argamassa e posterior ruptura dos septos. O modelo não representa de forma totalmente precisa esta forma de ruptura, apesar dos parâmetros de resistência de compressão do bloco incluírem esse tipo de ruptura, mas em condições diferentes de confinamento. Neste caso, o modelo PLASTIC também não conseguiu representar de forma muito eficiente a ruptura da parede, obtendo-se um valor previsto para a tensão de ruptura bem menor do que o experimental. No modelo PLASTIC a argamassa sofre uma forte compressão e atinge o valor de ruptura muito antes da fissuração dos septos laterais dos blocos.
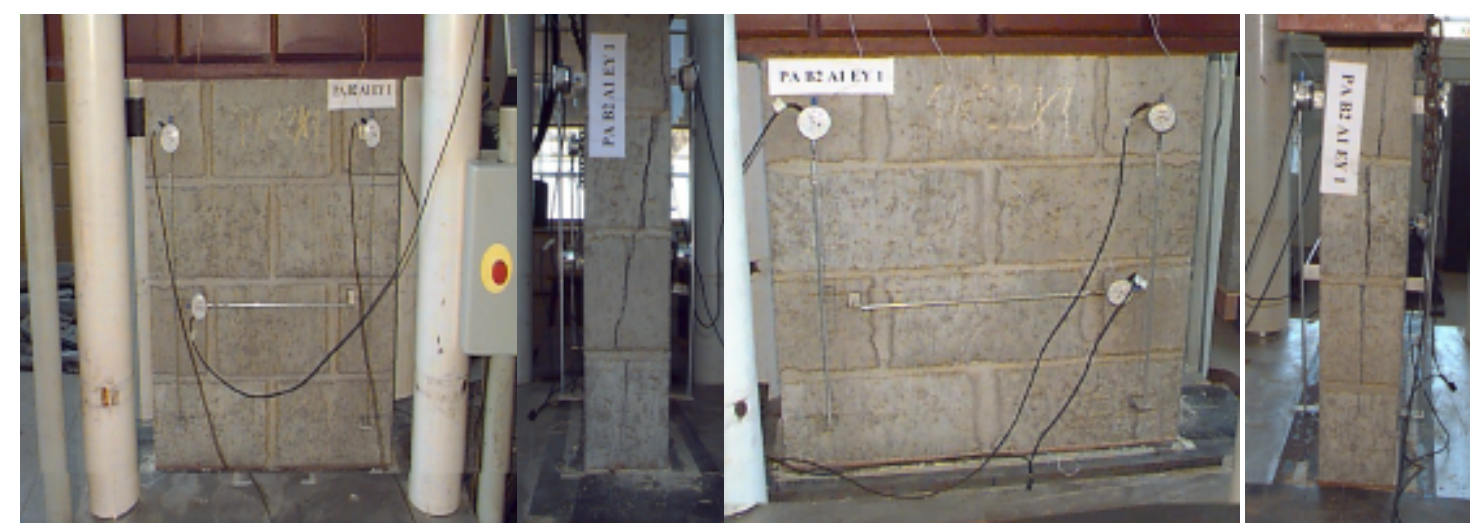

Figura 7.15 - Forma de ruptura típica (PAB2A1)

Na figura 7.16 apresentam-se as tensões principais máximas para a parede PAB2A1. Verifica-se que as máximas tensões de tração ocorrem na região das juntas verticais e dos blocos, sendo que na região das juntas horizontais ocorrem altas tensões de compressão, o que é consistente com o esmagamento da argamassa ocorrido nos ensaios. 

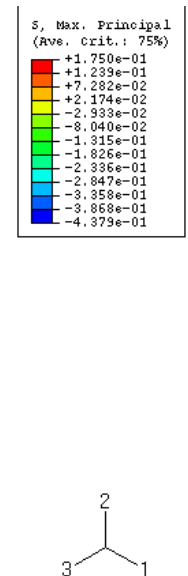

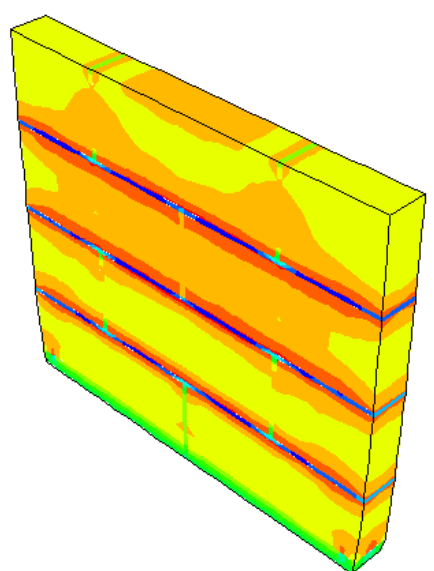

(a) PLASTIC
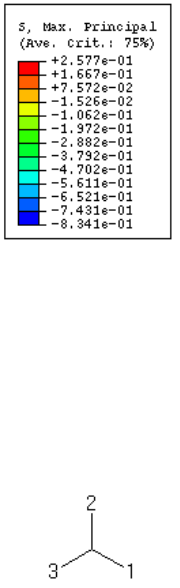

(b) CONCRETE

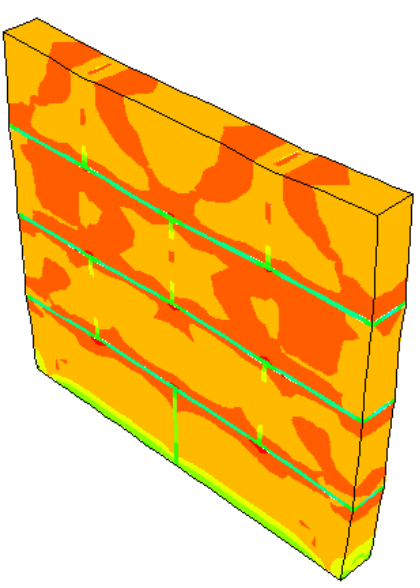

Figura 7.16 - Tensão principal máxima (PAB2A1)

A figura 7.17 apresenta as tensões normais horizontais $\sigma_{11}$, para os dois modelos. Pode-se perceber a concentração das tensões de tração nas juntas verticais, bem como nos blocos.
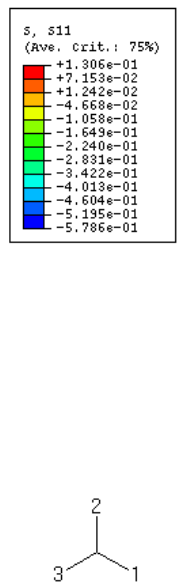

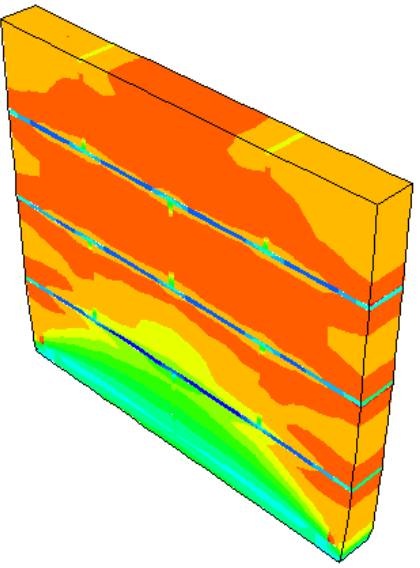

(a) PLASTIC
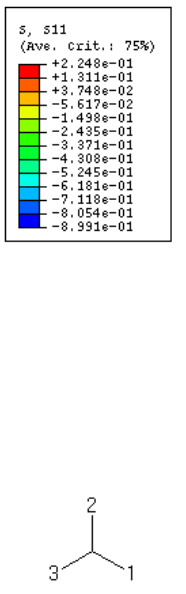

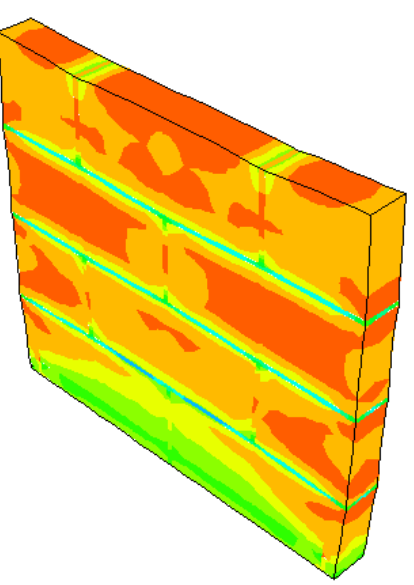

(b) CONCRETE

Figura 7.17 - Tensão normal horizontal $\sigma_{11}$ (PAB2A1) 


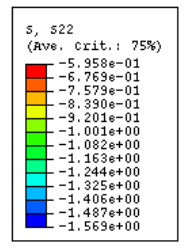

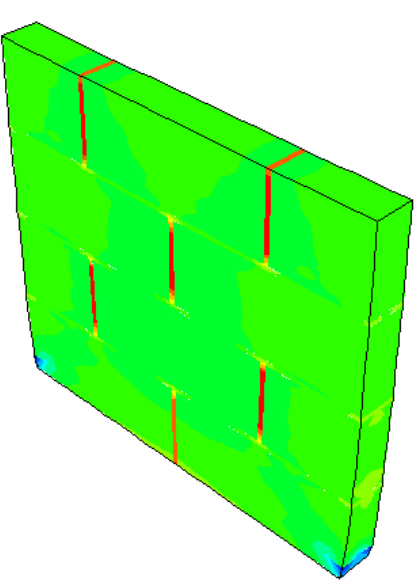

(a) PLASTIC
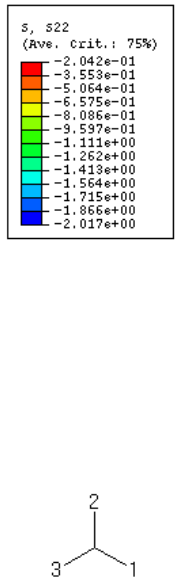

(b) CONCRETE

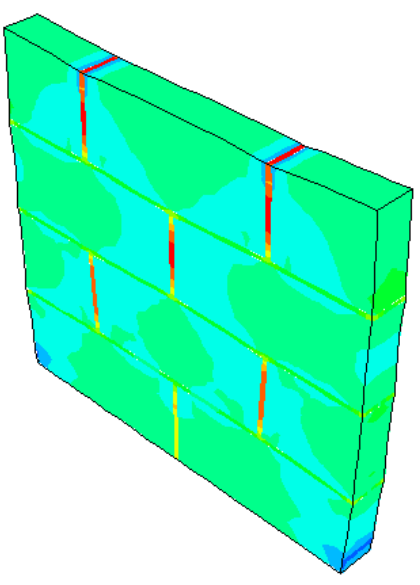

(PAB2A1)

Na figura 7.18 apresentam-se as distribuições das tensões normais verticais na parede, sendo todas de compressão. Deve-se ressaltar que os mais altos valores ocorrem nos blocos. Quanto às juntas, as horizontais são as mais solicitadas, o que é consistente com o carregamento aplicado e com o tipo de ruptura verificado no ensaio.

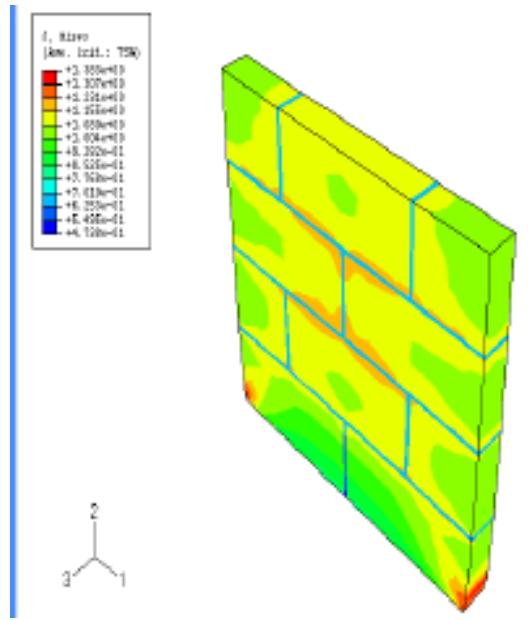

(a) PLASTIC
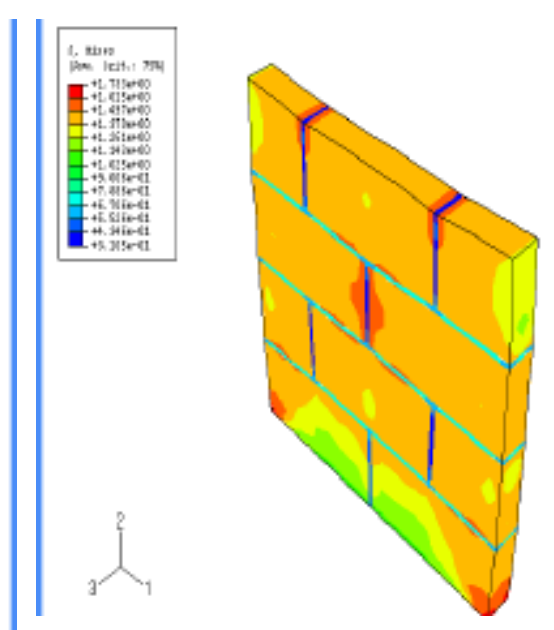

(b) CONCRETE

Figura 7.19 - Tensão equivalente de von Mises (PAB2A1)

Na figura 7.19 apresenta-se a tensão de von Mises para os dois modelos. Verifica-se que o modelo CONCRETE representa de maneira mais precisa a forma de ruptura da parede, apresentando concentração de tensões nos septos laterais. 
Analisando-se, de maneira geral, as figuras 7.16 a 7.19 conclui-se que os modelos representam de forma bastante coerente o que acontece no ensaio. As tensões de tração mais altas encontram-se nas juntas verticais, onde aparecem as primeiras fissuras nos ensaios. Nas regiões das juntas horizontais e dos blocos aparecem tensões de compressão, o que está de acordo com o ensaio, já que neste ensaio prevaleceu a ruptura por esmagamento da argamassa. Neste caso, em que o bloco e a argamassa possuem uma resistência alta à compressão, o modelo CONCRETE apresentou-se bem mais adequado para a análise da tensão de ruptura.

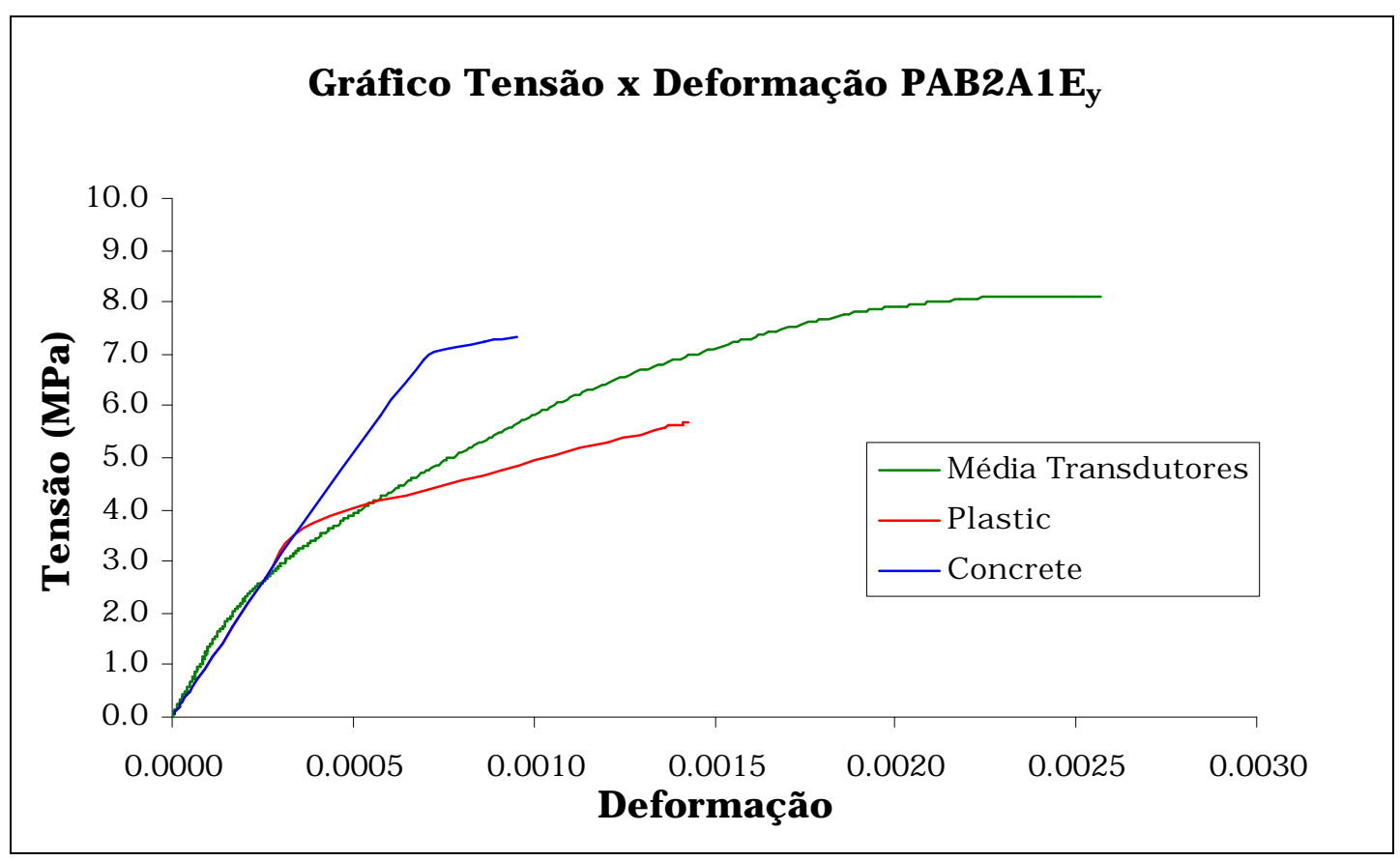

Figura 7.20 - Gráfico Tensão x Deformação (PAB2A1)

As curvas tensão $\mathrm{x}$ deformação para a parede PAB2Al são apresentadas na figura 7.20. Nota-se que nenhum dos dois modelos conseguiu representar adequadamente o comportamento não-linear da parede. No trecho linear o comportamento está bastante coerente com o ensaio e os dois modelos são basicamente iguais. No trecho não linear o modelo CONCRETE representa um pouco melhor o ensaio, produzindo uma força de ruptura mais próxima da encontrada experimentalmente. 


\subsubsection{Parede PAB2A2}

Na tabela 7.10 apresentam-se os valores médios de resistência à compressão obtidos nos ensaios para a paredinha PAB2A2, os previstos com o uso dos dois modelos utilizados e as diferenças relativas ao experimento.

Tabela 7.10 - Resistência à compressão parede PAB2A2

\begin{tabular}{|c|c|c|c|c|c||}
\hline \multirow{2}{*}{$\begin{array}{c}\text { Série } \\
\text { Correspondente }\end{array}$} & \multirow{2}{*}{$\begin{array}{c}\mathrm{p}_{\text {pam }}(\mathrm{MPa}) \\
\text { Ensaio }\end{array}$} & \multicolumn{2}{|c|}{ PLASTIC } & \multicolumn{2}{c|}{ CONCRETE } \\
\cline { 3 - 6 } & $\mathrm{f}_{\mathrm{pa}}(\mathrm{MPa})$ & Diferença(\%) & $\mathrm{f}_{\mathrm{pa}}(\mathrm{MPa})$ & Diferença(\%) \\
\hline \hline PAB2A2E $_{\mathrm{Y}}$ & 5,65 & 5,42 & -4 & 6,90 & +22 \\
\hline
\end{tabular}

Nesta parede a força de ruptura obtida experimentalmente pode não representar de forma coerente o comportamento real, já que não se trata de uma média e sim de um valor obtido em um único ensaio. Assim, julga-se difícil afirmar, com segurança, qual dos dois modelos numéricos representa de forma mais adequada a tensão de ruptura desta parede.

O modelo CONCRETE apresentou uma força de ruptura maior do que o valor obtido no ensaio, ao contrário dos exemplos anteriores, onde os valores fornecidos por ele eram menores que os dos ensaios. O modelo PLASTIC conseguiu representar de forma mais eficiente a força de ruptura, obtendo-se um valor mais próximo do experimental.

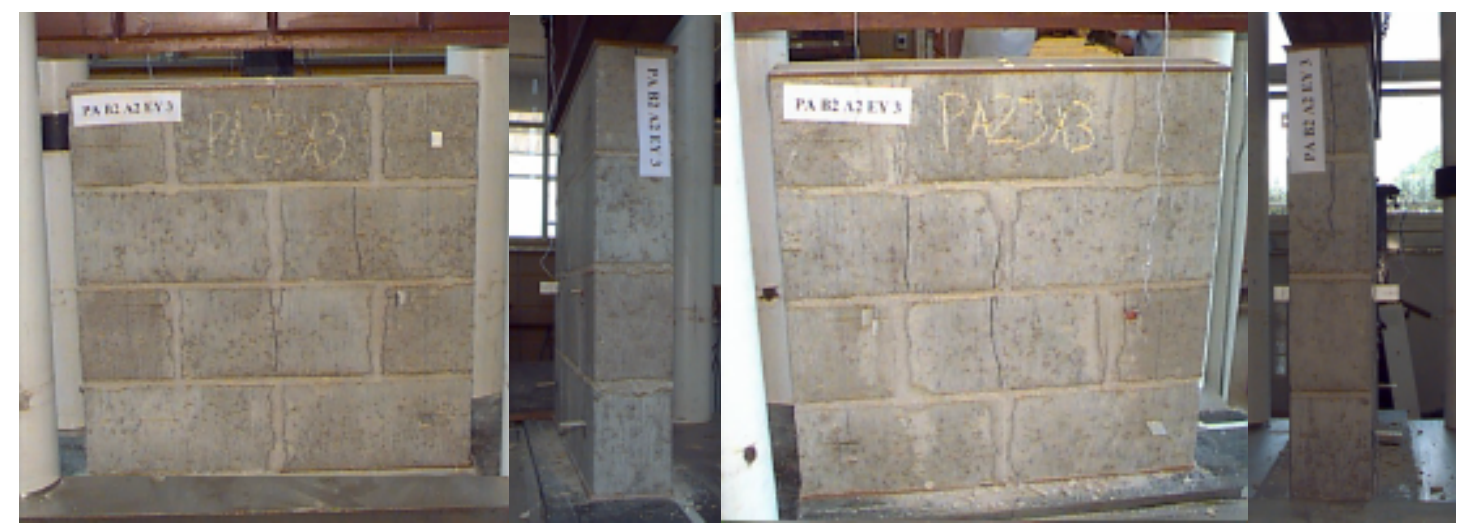

Figura 7.21 - Forma de ruptura típica (PAB2A2) 
Apresentam-se nas figuras 7.22, 7.23, 7.24, e 7.25 a tensão principal máxima, a tensão normal horizontal, tensão normal vertical e a tensão de von Mises, para os dois modelos numéricos adotados.

Analisando-se a figura 7.22 verifica-se que as tensões máximas de tração ocorrem na região das juntas verticais. Nota-se, também, a presença de tensões de tração na região dos blocos na $3^{a}$ fiada, região em que se tem fissuras nos blocos no ensaio (figura 7.21). As juntas horizontais estão submetidas a tensões de compressão em ambos os modelos, o que confirma o que aconteceu nos ensaios: fissuras nas regiões das juntas verticais e esmagamento da argamassa.
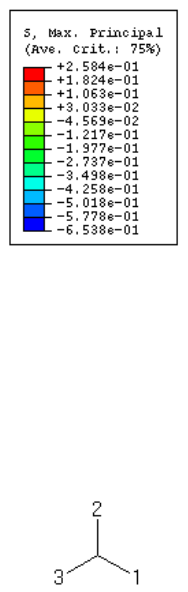

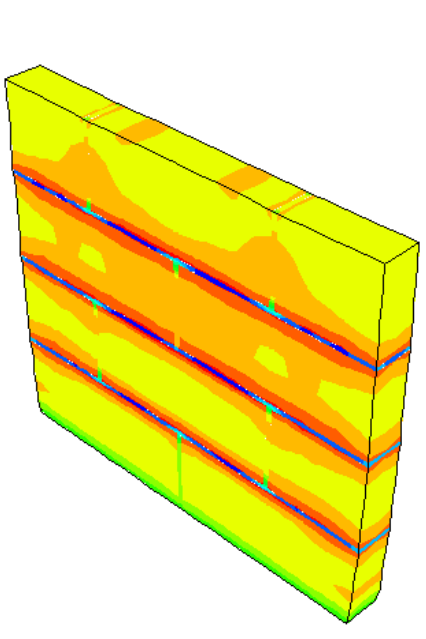

(a) PLASTIC

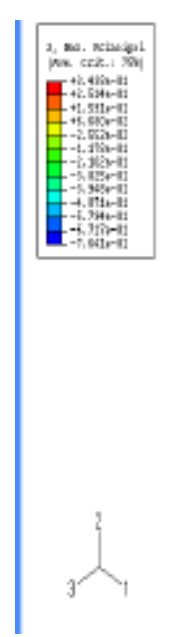

(b) CONCRETE

\section{Figura 7.22 - Tensão principal máxima (PAB2A2)}

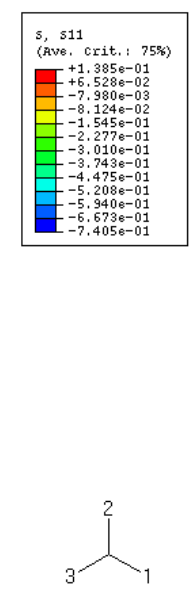

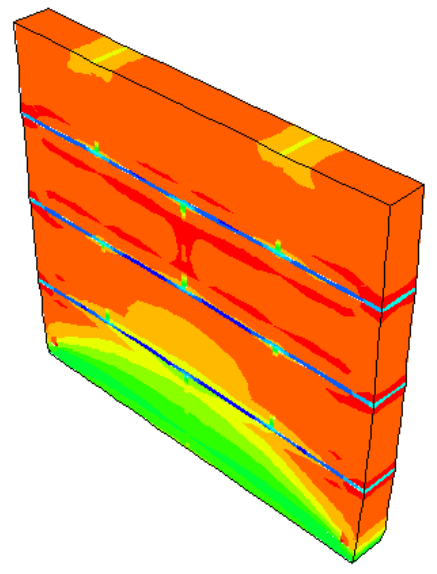

(a) PLASTIC

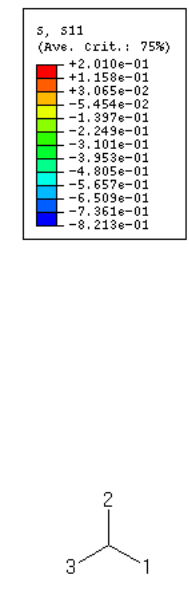

(b) CONCRETE

Figura 7.23 - Tensão normal horizontal $\sigma_{11}$ (PAB2A2) 
As tensões normais horizontais na parede encontram-se na figura 7.23. Nota-se, nos dois modelos, que as tensões de tração se concentram nas juntas verticais e espalham-se pelos blocos. Aqui, também, aparecem tensões de tração nos blocos, principalmente na região da $3^{\mathrm{a}}$ fiada.
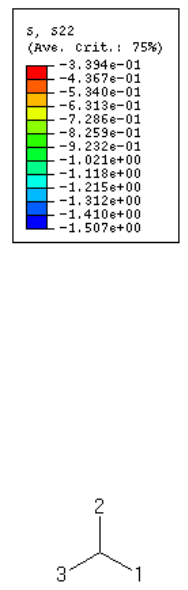

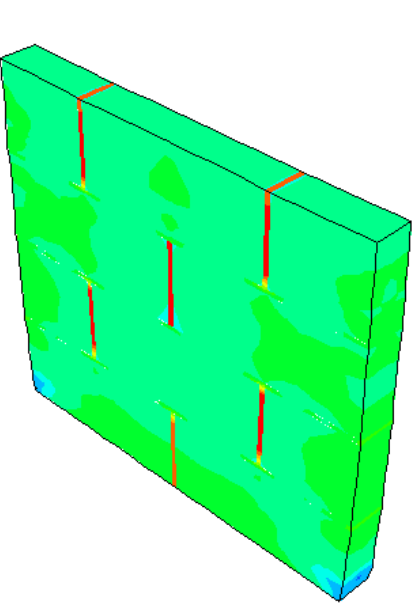

(a) PLASTIC
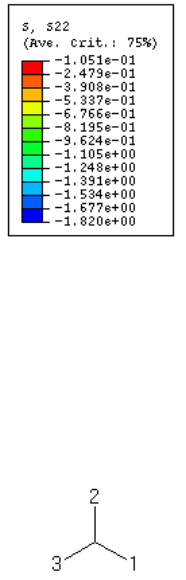

(b) CONCRETE

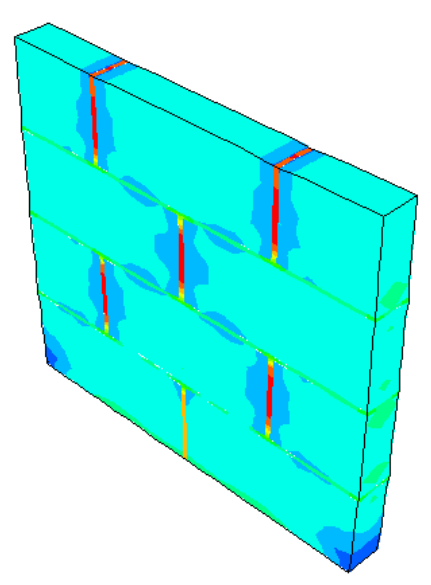

(PAB2A2)

Na figura 7.24 apresenta-se a distribuição das tensões normais verticais na parede, observando que todas são de compressão. Os valores mais altos encontram-se consistentemente nos blocos e nas juntas horizontais.
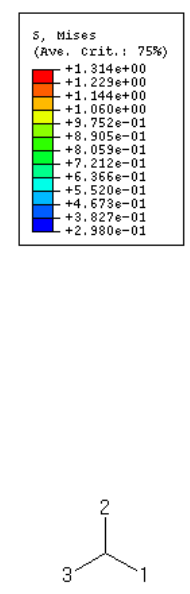

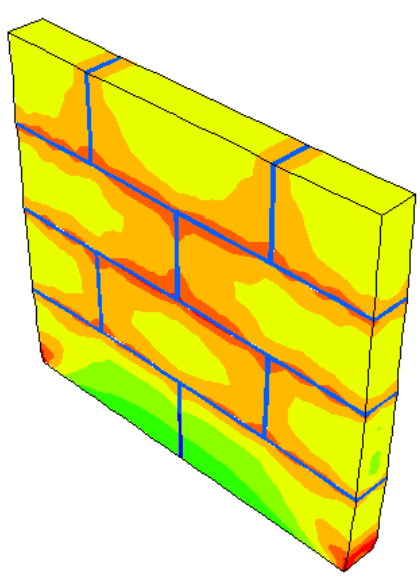

(a) PLASTIC
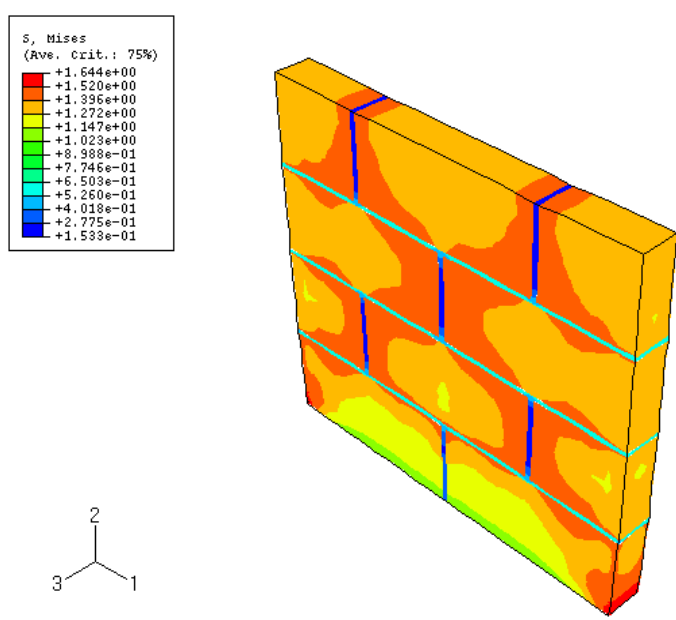

(b) CONCRETE

Figura 7.25 - Tensão equivalente de von Mises (PAB2A2) 
Na figura 7.25 apresenta-se a tensão de von Mises para os dois modelos. Ambos apresentam uma distribuição de tensões semelhante, com tensões maiores nas regiões próximas das juntas verticais.

Analisando-se, de maneira geral, as figuras 7.22 a 7.25 conclui-se que os modelos representam de forma bastante coerente o ensaio. As tensões de tração mais altas encontram-se nas juntas verticais, onde aparecem as primeiras fissuras nos experimentos. Nas juntas horizontais tem-se altas tensões de compressão, o que sugere o seu esmagamento. E nas regiões onde aparecem fissuras nos blocos no ensaio, as tensões nos modelos são predominantemente de tração. Em termos de distribuição de tensões, os dois modelos apresentam resultados similares.

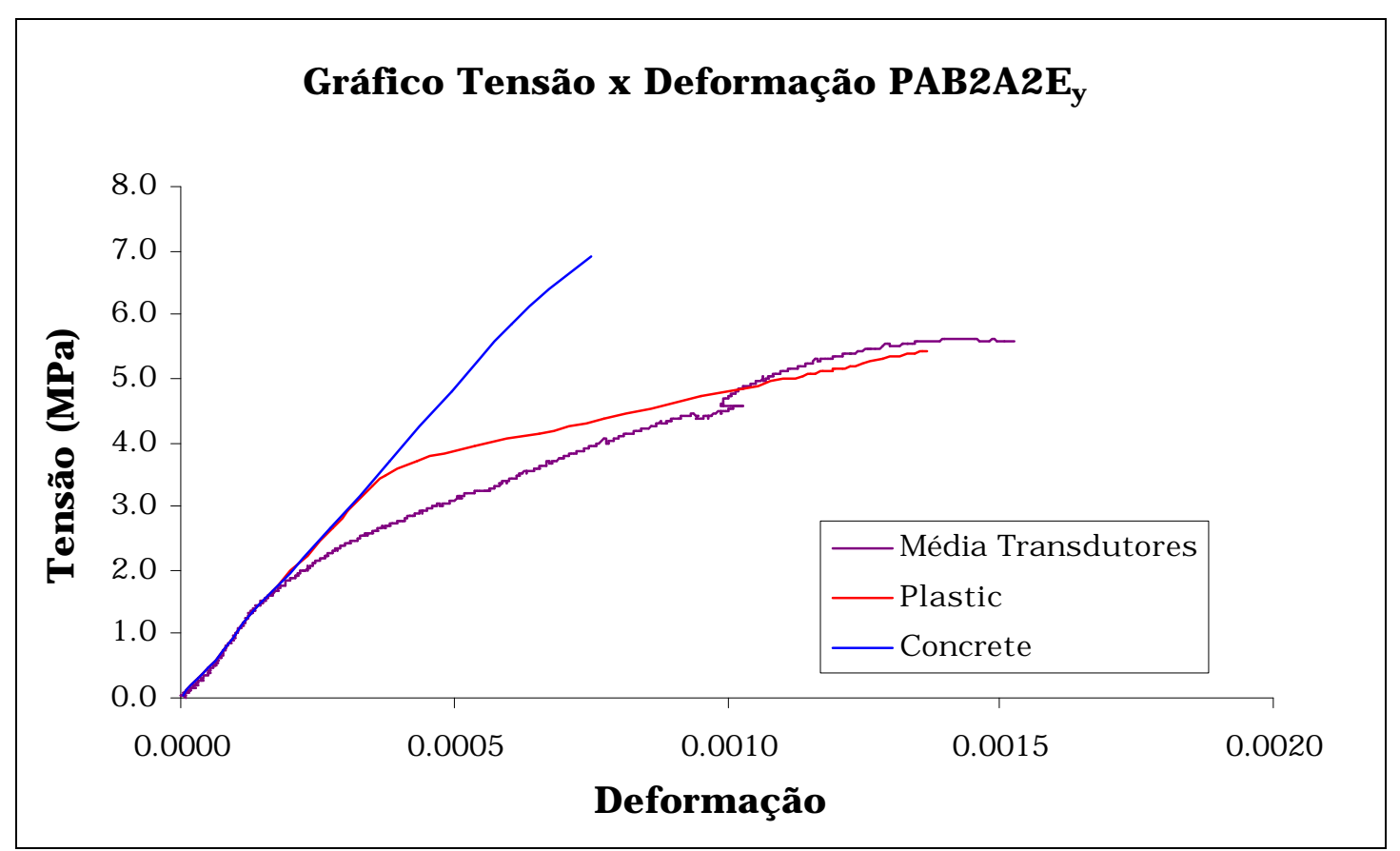

Figura 7.26 - Gráfico Tensão x Deformação (PAB2A2)

Na figura 7.26 apresenta-se a curva tensão $\mathrm{x}$ deformação para a parede PAB2A2. Analisando-se as curvas, conclui-se que o modelo PLASTIC representa de forma mais adequada o comportamento da parede, inclusive em relação à tensão de ruptura. No trecho linear o comportamento é o mesmo. 


\subsection{Fechamento}

Analisando-se os resultados numéricos obtidos conclui-se que de maneira geral os dois modelos apresentaram bons resultados em relação à força de ruptura. O modelo CONCRETE apresentou valores menores do que os obtidos experimentalmente, exceto para o modelo PAB2A2, mas como já foi explicado, a força de ruptura deste modelo não é uma média e sim o resultado de um único exemplar, o que pode justificar essa diferença. Para a determinação da força de ruptura, este modelo parece ser mais adequado, principalmente por apresentar resultados a favor da segurança.

Analisando-se as curvas tensão $\mathrm{x}$ deformação para os quatro modelos conclui-se que o modelo PLASTIC representa de forma mais adequada o comportamento dos exemplares ensaiados quanto à rigidez. Como neste modelo os dados de entrada são as curvas tensão x deformação dos materiais componentes da alvenaria, ele é capaz de descrever de forma mais precisa o comportamento da paredinha ensaiada. Portanto, para uma análise da relação tensão $\mathrm{x}$ deformação da estrutura, este modelo é mais indicado.

Uma observação importante é a importância de se trabalhar com um módulo de elasticidade variável para os materiais. A utilização de uma expressão não linear para a relação tensão x deformação dos materiais com certeza melhoraria o comportamento dos modelos numéricos, ficando mais próximos dos resultados experimentais.

Uma outra consideração importante é a inclusão da possibilidade de escorregamento entre as juntas de argamassa e os blocos. A consideração do escorregamento é fundamental para simulação de paredes submetidas a forças horizontais, onde o cisalhamento é importante. Nos presentes modelos, onde o carregamento é de compressão, essa consideração é de menor influência.

Como pode ser observado nas fotos dos ensaios, a ruptura dos septos laterais dos blocos acontece em todos os modelos. Essa ruptura foi tratada de forma aproximada e indireta no modelo CONCRETE, devido aos parâmetros do bloco terem sido afetados pelo estado de tensões presente nos septos laterais dos blocos e por se tratar de um elemento 3D, apesar dos efeitos de confinamento. 
O objetivo principal deste trabalho foi apresentar as ferramentas computacionais mais adequadas para a análise de alvenaria estrutural a serem utilizadas no suporte teórico a pesquisas experimentais desenvolvidas. Pretende-se, dessa forma, reduzir os custos e aumentar a eficiência nos ensaios. O trabalho foi desenvolvido elaborando-se um estudo sobre os vários recursos de modelagem numérica, linear e não linear, utilizando-se os softwares ABAQUS e ANSYS, disponiveis no Departamento de Engenharia de Estruturas da EESC-USP.

Durante a realização da pesquisa bibliográfica verificou-se que a fissuração é a causa mais freqüente e relevante da ruptura no comportamento das estruturas em alvenaria. A aplicação do método dos elementos finitos para a análise destas estruturas requer um modelo apropriado para o material, que inclua os seus mecanismos básicos de ruptura. Estes mecanismos são bastante complexos e podem ser dependentes dos blocos, da argamassa ou de uma combinação entre os dois. Na literatura técnica encontram-se vários modelos diferentes, sendo que cada um deles apresenta vantagens e desvantagens, o que torna a sua utilização dependente do tipo de estrutura analisada e da solicitação a que está sujeita. 
Uma das técnicas utilizadas por vários pesquisadores para análise de alvenaria estrutural é a da homogeneização. O processo consiste em se definir um material fictício cujas propriedades mecânicas são equivalentes às características médias de um dado material não homogêneo. Uma forma de se aplicar essa técnica consiste na obtenção de uma lei macroconstitutiva, a partir da lei microconstitutiva e da geometria do material composto. A grande vantagem dessa técnica é a possibilidade de incorporar alterações na sua geometria mediante manipulações numéricas, sem a necessidade de novos ensaios de caracterização do material.

No presente trabalho realizou-se uma homogeneização numérica, onde as propriedades médias da alvenaria foram obtidas partindo-se de simulações numéricas do volume elementar representativo da alvenaria. Obteve-se, dessa forma, as propriedades médias ortotrópicas do material.

Nas simulações realizadas verificou-se que um acréscimo na espessura da argamassa provoca um decréscimo no valor do módulo de elasticidade da alvenaria. Verificou-se, também, que à medida que se aumenta o valor do módulo de elasticidade (E) da argamassa, o valor do $\mathrm{E}$ da alvenaria aumenta, como era de se esperar. Com esses resultados ressalta-se a importância de um controle rigoroso ao se construir edificações em alvenaria estrutural. As resistências de seus componentes e as espessuras especificadas pelo projetista são de grande importância para a segurança da obra e para minimizar posteriores problemas com patologias.

Nas estruturas analisadas, utilizando-se a técnica de homogeneização numérica, verificou-se que os resultados de deslocamentos da estrutura homogeneizada ficaram muito próximos dos resultados obtidos com a micromodelagem. Em relação às tensões, obteve-se um comportamento global bastante coerente. A distribuição de tensões nas estruturas analisadas apresentou-se muito parecida com o micromodelo, apresentado a vantagem de uma modelagem mais rápida e um tempo de processamento menor.

Conclui-se que a técnica fornece resultados coerentes e uma boa precisão nos resultados para uma análise macroscópica do comportamento global da estrutura. 
Em termos locais algumas diferenças podem ser encontradas, mesmo numa análise linear. No micromodelo aparecem picos de tensão em regiões localizadas, principalmente na argamassa, o que não ocorre no modelo homogeneizado. Portanto, para uma análise mais precisa, em que efeitos locais tenham importância, como, por exemplo, ao se considerar a não-linearidade do material, o mais indicado é a utilização do micromodelo.

O processo numérico de homogeneização, quando comparado com o processo analítico, apresenta-se mais genérico, não dependendo de nenhuma formulação adicional. Pode ser utilizado para qualquer estrutura em alvenaria, independente de sua geometria e das características dos materiais. Considera-se, portanto, que é o melhor dentre os processos de homogeneização.

Comparando-se os modelos 2D e 3D, utilizando-se elementos planos e sólidos, verificou-se que ambos apresentaram resultados bem próximos para uma análise linear. A vantagem do modelo $2 \mathrm{D}$ é a modelagem, que se torna bem mais simples, apresentando tempo de processamento reduzido.

Conclui-se que os modelos homogeneizados devem ser utilizados com critério, sendo os seus resultados cuidadosamente analisados em termos locais, principalmente quando necessária uma análise não-linear da estrutura.

Os programas utilizados na análise não-linear do presente trabalho foram o ANSYS e o ABAQUS, disponiveis no Departamento de Engenharia de Estruturas da EESC-USP. Foram escolhidos os modelos que incluem características de comportamento típicas da alvenaria estrutural. O modelo do ANSYS inclui a ruptura por fissuração, em zonas tracionadas, e o esmagamento, em zonas comprimidas. O modelo considera que o material rompe completamente assim que atinge a tensão de resistência máxima. No ABAGUS a fissuração é definida como o aspecto mais importante do comportamento do material. Verificado o aparecimento de uma fissura (atingida a superfície de ruptura), um critério de dano elástico é utilizado para descrever o comportamento pós-ruptura do material.

Com o intuito de avaliar e calibrar esses dois modelos foi realizada a análise de um prisma construído com unidades sólidas de concreto. 
Verificou-se que com o ABAQUS foi possivel estimar, com suficiente precisão, a força de ruptura experimental tanto com elemento plano quanto com elemento sólido. Já com o software ANSYS não se conseguiu atingir a força de ruptura experimental, obtendo-se um comportamento global bastante incoerente, com deformações excessivas e irreais para a alvenaria, mesmo em um nível baixo de carregamento.

Os programas foram também avaliados analisando-se o comportamento de paredes de alvenaria em blocos sólidos de concreto. Da mesma forma que para o prisma, os resultados do ABAQUS para a força de ruptura das paredes foram muito bons, tanto na análise $2 \mathrm{D}$ como na 3D. A principal vantagem da utilização do elemento plano foi a redução do número de graus de liberdade do modelo, diminuindo, assim, o tempo de processamento. O modelo do ANSYS, apresentou forças de ruptura muito abaixo do esperado, gerando resultados insatisfatórios para a análise de estruturas em alvenaria.

Conclui-se que o modelo para o concreto do ABAQUS representa bem o comportamento não-linear de blocos sólidos de concreto. Apesar do modelo ser específico para o concreto, é possível utilizá-lo na análise de estruturas em alvenaria. A fissuração é um aspecto muito importante nessas estruturas e o modelo representa de forma bastante coerente esse fenômeno.

Com os resultados obtidos na avaliação dos softwares disponíveis para a pesquisa, optou-se por continuar as análises não-lineares apenas com o ABAQUS, em virtude dos modelos com o ANSYS não terem representado bem o comportamento da alvenaria.

O estudo da interação de paredes de alvenaria sujeitas a carregamentos verticais foi realizado através da análise numérica e comparação com os resultados experimentais de um painel $\mathrm{H}$, de blocos cerâmicos de alvenaria, ensaiado no SET-EESC-USP.

Considerando-se uma força aplicada de 60\% da de ruptura, nível de solicitação em que a alvenaria ainda não está fissurada e trabalha em regime linear, obteve-se uma boa correlação entre os valores numéricos e os experimentais, em termos de deformação. 
No trecho inferior do painel, as deformações na alma e no flange apresentaram valores bem próximos, indicando a existência de uma distribuição de esforços bastante homogênea nessa região. Conclui-se que há uma transferência de esforços bastante efetiva entre alma e flange.

Para um nível de solicitação de $87 \%$ da força de ruptura, estágio em que a alvenaria já se encontra fissurada, os resultados obtidos numericamente para as análises linear e não linear foram praticamente os mesmos. A alvenaria não apresentou nos modelos realizados um comportamento não-linear evidente, no que se refere ao deslocamento vertical relativo entre seus pontos, para esse nível de solicitação.

Considerando-se a força de ruptura numérica de $425 \mathrm{kN}$, estágio em que o programa não consegue atingir convergência, verificou-se uma pequena diferença entre os deslocamentos da análise linear e da não-linear. Ressalte-se que a força de ruptura teórica corresponde a 83\% da média dos valores obtidos nos ensaios dos painéis. Verificou-se, também, que à medida que se aproximou da ruptura do painel, a transferência de esforços entre flange e alma tornou-se menos efetiva. A explicação para esse fato está na forma de ruptura do painel que correspondeu exatamente à separação entre as duas partes da estrutura.

$\mathrm{Na}$ análise dos gráficos tensão do grupo x deformação, verificou-se que os resultados numéricos apresentaram-se praticamente lineares até a ruptura. Comparando-se com os resultados experimentais verificou-se que os resultados numéricos obtidos representam, aproximadamente, uma média dos resultados experimentais, confirmando a eficiência do modelo para representar o comportamento dessa estrutura.

Com a análise realizada observou-se a homogeneização das tensões ao longo da altura do painel, confirmando-se que a força aplicada na alma é transferida para o flange através dos blocos intertravados, de forma bastante eficiente.

Os valores de deformações obtidos numericamente ficaram bem próximos dos valores obtidos nos ensaios, principalmente para níveis mais baixos de solicitação.

É importante ressaltar a forma de ruptura do painel nos ensaios, que aconteceu por compressão da região superior da parede central e separação entre a alma e o flange que se inicia no trecho superior, devido ao 
aparecimento de fissuras na região de interseção. Na modelagem numérica essa interface foi simulada com comunhão de nós, não havendo possibilidade de descolamento ou deslizamento entre elas. Dessa forma o modelo numérico não foi capaz de representar a ruptura na interface das paredes. Apesar dessa limitação, o modelo CONCRETE do ABAQUS apresentou-se bastante eficiente para a análise de estruturas em alvenaria de blocos cerâmicos. Os resultados obtidos para deslocamentos, deformações, tensões e força de ruptura apresentaram-se bastante coerentes com os resultados experimentais. Pode-se, então, indicar a utilização desse modelo para a análise de estruturas em alvenaria cerâmica com segurança.

Para o estudo de casos específicos de paredes em alvenaria submetidas à compressão, foram analisadas as paredinhas ensaiadas por JUSTE (2001) no Laboratório do SET-EESC-USP. No presente trabalho, adota-se a nomenclatura de JUSTE em que entende-se por paredinhas corpos de prova em alvenaria de blocos de concreto com dimensões de $80 \mathrm{x}$ $80 \times 14 \mathrm{~cm}$.

Os componentes utilizados para a execução das paredinhas tiveram as seguintes características básicas:

- Blocos com resistência média à compressão de 10,80 MPa (B1) e 22,92 MPa (B2);

- Argamassas com resistência média à compressão de 10,24 $\mathrm{MPa}$ (A1) e 5,05 MPa (A2).

De acordo com JUSTE (2001), de um modo geral, as paredinhas ensaiadas apresentaram propagação de fissuras verticais, predominantemente através das juntas verticais na região central das paredes, sendo algumas desviadas pelas regiões dos blocos. Observou-se, também, a presença de fissuras verticais ao longo dos septos laterais das paredinhas. A ruptura ocorreu, na maioria das vezes, por tração transversal dos blocos.

Porém, para as paredinhas que utilizaram blocos B2, as fissurações descritas ocorreram de forma bem menos pronunciada, prevalecendo a ruptura por esmagamento da argamassa.

A análise numérica não-linear foi feita utilizando-se o software ABAQUS. Estudos preliminares demonstraram que o modelo elastoplástico 
para o concreto (CONCRETE), utilizado na análise de interação de paredes, não representou da forma esperada o comportamento das paredinhas, no aspecto tensão $\mathrm{x}$ deformação. Com isso, optou-se por adotar mais um modelo para a análise das paredinhas: o elastoplástico clássico (PLASTIC), obtendo-se, dessa forma, mais resultados para serem avaliados. Outro fator importante que influenciou nessa decisão foi a tentativa de modelar de forma mais precisa a variabilidade da relação tensão $\mathrm{x}$ deformação para os blocos de concreto.

Optou-se por um elemento tridimensional por ser mais representativo para o tipo de ruptura indicado pelas paredinhas, ou seja, fissuras dos septos laterais. Embora tal elemento não consiga representar de forma exata o que ocorre, fornece uma boa aproximação.

Em relação à força de ruptura, os dois modelos apresentaram-se bastante adequados. O modelo CONCRETE apresentou valores a favor da segurança, quando comparados com os valores de ruptura experimental. Exceto para o modelo PAB2A2, que não é uma média e sim o resultado de um único corpo-de-prova, o que pode explicar essa diferença. O modelo PLASTIC apresentou resultados bem próximos dos valores experimentais, para as paredinhas construídas com os blocos de menor resistência (B1). No caso da paredinha PAB2A1, bloco de maior resistência e argamassa de menor resistência, o resultado obtido foi bem abaixo do esperado. Neste corpo de prova a ruptura ocorre por esmagamento da argamassa e posterior fissuração dos septos laterais, sendo que as fissuras nas faces da parede não são evidentes. Conclui-se que o modelo PLASTIC não representa de forma satisfatória este tipo de comportamento, em se tratando da análise de força de ruptura.

Define-se, então, para o estudo da força de ruptura em paredes de alvenaria de blocos de concreto, o modelo CONCRETE como mais adequado, por ter apresentando resultados mais coerentes em todas as análises realizadas.

Analisando-se as curvas tensão $\mathrm{x}$ deformação para as paredinhas ensaidas verifica-se que o modelo PLASTIC é mais eficiente na representação do comportamento dos ensaios quanto à rigidez. Da mesma forma que para a força de ruptura, também no aspecto rigidez, o modelo só 
não conseguiu representar de forma muito eficiente o comportamento da paredinha PAB2A1.

Neste modelo os dados de entrada são as curvas tensão $\mathrm{x}$ deformação dos materiais componentes da paredinha ensaiada. É possível, então, simular de forma mais precisa a variabilidade da relação tensão $\mathrm{x}$ deformação para os blocos de concreto, quando comparado com o modelo CONCRETE.

Dessa forma conclui-se que para um estudo da relação tensão $\mathrm{x}$ deformação para as paredinhas de alvenaria submetidas à compressão o modelo PLASTIC é o mais indicado.

Considerando-se os resultados obtidos ressalta-se a importância de se trabalhar com um módulo de elasticidade variável para os materiais. A utilização de uma expressão não linear para a relação tensão x deformação dos materiais com certeza tornaria os modelos numéricos mais representativos, tornando os resultados mais próximos dos experimentais.

As distribuições de tensões apresentadas por ambos os modelos foram bastante coerentes com o comportamento dos ensaios. Apareceram tensões de tração nas regiões onde ocorreram fissuras durante os ensaios e tensões de compressão nas regiões sujeitas ao esmagamento, em geral nas juntas horizontais. Pode-se, dessa forma, admitir que ambos os modelos são adequados para a análise das distribuições de tensões.

Em resumo, para a análise de estruturas em alvenaria cerâmica, submetidas à compressão, indica-se a utilização do modelo CONCRETE do ABAQUS. Para a análise de estruturas em alvenaria de blocos de concreto, indicam-se os dois modelos: CONCRETE - quando o objetivo principal é analisar a força de ruptura e verificar a distribuição de tensões de uma forma geral e PLASTIC - quando o objetivo principal é fazer uma análise do comportamento tensão $\mathrm{x}$ deformação e verificar a distribuição de tensões.

Uma opção para análise de estruturas em alvenaria seria um modelo semelhante ao CONCRETE, mas com a inclusão de relações tensão $\mathrm{x}$ deformação não-lineares para os materiais.

Um aspecto relevante é a inclusão da possibilidade de escorregamento entre as juntas de argamassa e dos blocos. A consideração 
do escorregamento é fundamental para a simulação de paredes submetidas a forças horizontais, onde o cisalhamento é importante. Nos modelos apresentados neste trabalho, onde o carregamento é de compressão, essa consideração não influenciaria os resultados. 


\section{REFERÊNCIAS BIBLIOGRÁFICAS}

ALI, S.; PAGE, A.W. (1987). Non-linear finite element analysis of masonry subjected to concentrated load. Proc. Instn. Civil Engrs. v.83, p.815-832, Dec.

ALI, S.; PAGE, A.W. (1988a). Finite element model for masonry subjected to concentrated loads. Journal of Structural Engineering, v.114, n.8, p.1761-1784, Aug.

ALI, S.; PAGE, A.W. (1988b). Concentrated loads on solid masonry walls - a parametric study and design recommendations. Proc. Instn. Civil Engrs., v.85, part 2, p.271-289, Jun.

ALI, S.; PAGE, A.W. (1989). Cracking analysis of solid concrete masonry subjected to concentrated loads. ACI Structural Journal, v.86, n.4, p.367-375, Jul.

ANDREAUS, U. (1996). Failure criteria for masonry panels under in-plane loading. Journal of Structural Engineering, v.122, n.1, p.37-46, Jan.

AMRHEIN, J.E. (1978) Reinforced masonry engineering handbook. Masonry Institute of America. 
ANTHOINE, A. (1995). Derivation of the in-plane elastic characteristics of masonry through homogenization theory. International Journal of Solids and Structures, v.32, n.2, p.137-163.

BATI, S.B.; RANOCCHIAI, G.; ROVERO, L. (1999b). A micromechanical model for linear homogenization of brick masonry. Materials and Structures, v.32, p.22-30, Jan-Feb.

BATI, S.B.; RANOCCHIAI, G.; ROVERO, L. (1999a). Suitability of micromechanical model for elastic analysis of masonry. Journal of Engineering Mechanics, v.125, n.8, p.922-929, Aug.

BRITISH STANDARDS INSTITUTION (1978). BS 5628 - Code of practice for structural use of masonry. Part 1. Unreinforced masonry. Londres, Inglaterra.

CAPUZZO NETO, V. (2000). Estudo teórico e experimental da interação de paredes de alvenaria estrutural submetidas a ações verticais. São Carlos. 111 p. Dissertação (Mestrado) - Escola de Engenharia de São Carlos, Universidade de São Paulo.

CORREAA, M.R.S.; RAMALHO, M.A. (1994a). Efeitos de aberturas em painéis de alvenaria estrutural. In: INTERNATIONAL SEMINAR ON STRUCTURAL MASONRY FOR DEVELOPING CONTRIES, 5., Florianópolis, Brasil, 21-24 Agosto. Proceedings. Florianópolis, Universidade Federal Santa Catarina/University of Edinburgh/ ANTAC, p. $359-367$

CORREAA, M.R.S.; RAMALHO, M.A. (1994b). Procedimento para análise de edificios de alvenaria estrutural submetidos a ações verticais. In: INTERNATIONAL SEMINAR ON STRUCTURAL MASONRY FOR DEVELOPING CONTRIES, 5., Florianópolis, Brasil, 21-24 Agosto. Proceedings. Florianópolis, Universidade Federal Santa Catarina/University of Edinburgh/ ANTAC, p. 305-314 
DE BORST, R.; FEENSTRA, P.H. (1990). Studies in anisotropic plasticity with reference to the Hill criterion. International Journal of Numerical Methods in Engineering. v.29, p.315-336.

DE BUHAN, P.; DE FELICE, G. (1997). A homogenization approach to the ultimate strength of brick masonry. Journal Mech. Phys. Solids. v.45, n.7, p.1085-1104.

DHANASEKAR, M.; PAGE, A.W.; KLEEMAN, P.W. (1985). The failure of brick masonry under biaxial stresses. Proc. Instn. Civil Engrs, v.79, p.295-313, Jun.

DICKEY, W.L.; SCHNEIDER, R.R. (1994). Reinforced masonry design. Englewood Cliffs, Prentice Hall.

DRYSDALE, R.G.; HAMID, A.A.; BAKER, L.R. (1994). Masonry structures: behavior and design. Englewood Cliffs, New Jersey, Prentice Hall.

EL-METWALLY, S.E.E.; ASHOUR, A.F.; CHEN, W.F. (1991). Behavior and strength of concrete masonry walls. ACI Structural Journal, v.88, n.1, p.42-48, Jan-Feb.

FEENSTRA, P.H.; DE BORST, R. (1996). A composite plasticity model for concrete. International Journal of Numerical Methods in Engineering. v.33(5), p.707-730.

FUSCHI, P.; GIAMBANCO, G.; RIZZO, S. (1995). Nonlinear finite element analysis of no-tension masonry structures. Meccanica, v.30, p.233-249.

GAllegOS, H. (1991). Albañileria estructural. Peru, Fondo Editorial de la Pontificia Universidad Catolica del Perue. Segunda edición.

HENDRY, A.W. (1981). Structural Brickwork. London, The Macmillan Press Ltd. 
HENDRY, A.W.; SINHA, B.P.; DAVIES, S.R. (1981). An introduction to load bearing brickwork design. Chichester, England, Ellis Horwood Ltd.

HEYMAN, J. (1966). The stone skeleton. International Journal of Solids Structures, v.2, p.249-279.

HORDIJK, D.A. (1991). Local approach to fatigue of concrete. Dissertation, Delft University of Technology, Delft, The Netherlands.

JUSTE, A.E. (2001). Estudo da resistência e da deformabilidade de paredes comprimidas de alvenaria de blocos de concreto. São Carlos. 237 p. Dissertação (Mestrado) - Escola de Engenharia de São Carlos, Universidade de São Paulo.

LA ROVERE, H.L. (1994). Comparação entre métodos de análise de paredes estruturais com aberturas. In: INTERNATIONAL SEMINAR ON STRUCTURAL MASONRY FOR DEVELOPING CONTRIES, 5., Florianópolis, Brasil 21-24 Agosto. Proceedings. Florianópolis, Universidade. Federal. Santa Catarina / University of Edinburgh/ ANTAC.

LEE, J.S.; PANDE, G.N.; MIDDLETON, J.; KRALJ, B. (1996) Numerical modelling of brick masonry panels subject to lateral loadings. Computers and Structures, v.61, n.4, p.735-745.

LEE, J.S.; PANDE, G.N.; KRALJ, B. (1998) A comparative study on the approximate analysis of masonry structures. Materials and Structures, v.31, p.473-479, Aug-Sep.

LOFTI, H.R.; SHING, P.B. (1991) An appraisal of smeared crack models for masonry shear wall analysis. Computers and Structures, v.41, n.3, p.413-425. 
LOFTI, H.R.; SHING, P.B. (1994) Interface model applied to fracture of masonry structures. Journal of Structural Engineering, v.120, n.1, p.6380, Jan.

LOPEZ, J.; OLLER, S.; OÑATE, E.; LUBLINER, J. (1998). An homogeneous constitutive model for masonry. In: COMPUTACIONAL MECHANICS, Buenos Aires, 1998. Proceedings, Barcelona, 1998. p.1-19.

LOURENÇO, P.B. (1996). Computational strategies for masonry structures. Netherlands, Delft University Press.

LOURENÇO, P.B.; ROTS, J.G.; BLAAYWENDRAAD, J. (1997). Current possibilities of masonry modelling. In: SECOND INTERNATIONAL DIANA CONFERENCE, Amsterdam, 1997. Proceedings, p.285-295.

LOURENÇO, P.B.; DE BORST, R.; ROTS, J.G. (1997). A plane stress softening plasticity model for orthotropic materials. International Journal for Numerical Methods in Engineering, v.40, p.4033-4057.

LOURENÇO, P.B.; ROTS, J.G. (1997a). Multisurface interface model for analysis of masonry structures. Journal of Engineering Mechanics, v.123, n.7, p.660-668, Jul.

LOURENÇO, P.B.; ROTS, J.G. (1997b). On use of homogenisation techniques for the analysis of masonry structures. Masonry International, v.11, n.1, p.26-32.

LOURENÇO, P.B.; ROTS, J.G.; BLAAUWENDRAAD, J. (1998). Continuum model for masonry: parameter estimation and validation. Journal of Structural Engineering, v. 124, n.6, p.642-652, Jun.

LUCIANO, R.; SACCO, E. (1997). Homogenization technique and damage model for old masonry material. International Journal of Solids and Structures, v.34, n.24, p.3191-3208. 
LUCIANO, R.; SACCO, E. (1998). A damage model for masonry structures. European Journal of Mechanics - A/Solids, v.17, n.2, p.285-303.

MACHADO JR., E.F.; TAKEYA, T.; VAREDA, L.V. (1999). Ensaios de compressão simples em paredes de alvenaria de blocos cerâmicos. Relatório técnico: Cerâmica Selecta. São Carlos.

MIER, J.G.M. van (1984). Strain-softening of concrete under multiaxial loading conditions. Dissertation, Eindhoven University of Technology, Eindhoven, The Netherlands.

OLIVEIRA JÚNIOR, V. (1992). Recomendações para o projeto de edificios em alvenaria estrutural. 266 p. Dissertação (Mestrado) - Escola de Engenharia de São Carlos, Universidade de São Paulo.

PAGE, A.W. (1978). Finite element model for masonry. Journal of the Structural Division, v.104, n.ST8, p.1267-1285, Aug.

PAGE, A.W.; KLEEMAN, P.W.; DHANASEKAR, M. (1985). An in-plane finite element model for brick masonry. In: PROCEEDINGS OF A SESSION HELD IN CONJUNCTON WITH STRUCTURES CONGRESS '85, Chicago, Illinois, 1985. Proceedings. New York, p.1-18.

PAGE, A.W.; SHRIVE, N.G. (1990). Concentrated loads on masonry. British Masonry Society Proceedings, n.4, p.74-77.

PANDE, G.N.; LIANG, J.X.; MIDDLETTON, J. (1989). Equivalent elastic moduli for brick masonry. Computers and Geotechnics, v.8, p.243-265.

PAPA, E. (1990). Sulla meccanica del dannegiamento con particolare riferimento alle murature. Milano. 254p. Tese (Doutorado) - Politecnico de Milano. Facoltà di Ingegneria.

PAPA, E.; NAPPI, A. (1993). A numerical approach for the analysis of masonry structures. Masonry International, v.7, n.1, p.18-24 
PAPA, E.; NAPPI, A. (1997). Numerical modelling of masonry: a material model accounting for damage effects and plastic strain. Applied Math. Modelling, v.21, p.319-335, Jun.

PEGON, P.; ANTHOINE, A. (1997). Numerical strategies for solving continuum damage problems with softening: application to the homogenization of masonry. Computers and Structures, v.64, n.1-4, p.623-642.

PIETRUSZCZAK, S.; NIU, X. (1992). A mathematical description of macroscopic behaviour of brick masonry. International Journal of Solids and Structures. V.29, n.5, p.531-546.

RIDDINGTON, J.R.; NAOM, N.F. (1994). Finite element prediction of masonry compressive strength. Computers and Structures, v.52, n.1, p.113-119.

ROTS, J.G. (1991a). Numerical simulation of cracking in structural masonry. Heron, v.32, n.2, p.49-63.

ROTS, J.G. (1991b). Smeared and discrete representations of localized fracture. International Journal of Fracture, v.51, p.45-59.

SABBATINI, F.H. Considerações sobre a alvenaria estrutural. São Paulo, FDTE/EPUSP/IPT, s.d. 13p.

SAHLIN, S. (1971). Structural masonry. Englewood Cliffs, Prentice Hall.

SAYED-AHMED, E.; SHRIVE, N.G. (1996). Nonlinear finite-element model of hollow masonry. Journal of Structural Engineering. V.122, n.6, p.683690, Jun.

ULM, F.J.; PIAU, J.M. (1993). Fall of a temple theory: theory of contact applied to masonry joints. Journal of Structural Engineering, v.119, n.3, p.687-697, Mar. 
VONK, R.A. (1992). Softening of concrete loaded in compression. Dissertation, Eindhoven University of Technology, Eindhoven, The Netherlands. 